CONTRIBUTIONS TO ENGLISH AND AMERICAN LITERARY STUDIES 2

Antje Kley / Kai Merten (eds.)

\title{
What Literature Knows
}

Forays into Literary Knowledge Production

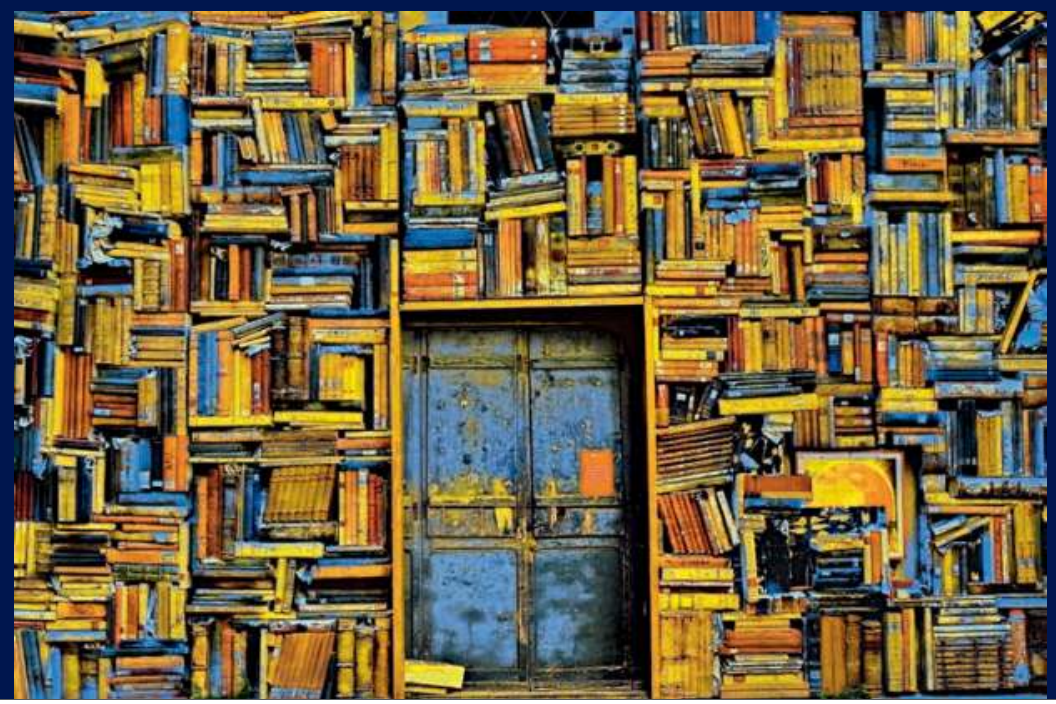


Antje Kley / Kai Merten (eds.)

\section{What Literature Knows}

This volume sheds light on the nexus between knowledge and literature. Arranged historically, contributions address both popular and canonical English and US-American writing from the early modern period to the present. They focus on how historically specific texts engage with epistemological questions in relation to material and social forms as well as representation. The authors discuss literature as a culturally embedded form of knowledge production in its own right, which deploys narrative and poetic means of exploration to establish an independent and sometimes dissident archive. The worlds that imaginary texts project are shown to open up alternative perspectives to be reckoned with in the academic articulation and public discussion of issues in economics and the sciences, identity formation and wellbeing, legal rationale and political decision-making.

\section{The Editors}

Antje Kley is professor of American Literary Studies at FAU Erlangen-Nürnberg, Germany. Her research interests focus on aesthetic forms and cultural functions of narrative, both autobiographical and fictional, in changing media environments between the eighteenth century and the present.

Kai Merten is professor of British Literature at the University of Erfurt, Germany. His research focuses on contemporary poetry in English, Romantic culture in Britain as well as on questions of mediality in British literature and Postcolonial Studies. He is also the founder of the Erfurt Network on New Materialism. 
What Literature Knows 


\section{CONTRIBUTIONS TO ENGLISH AND AMERICAN LITERARY STUDIES}

Edited by Ingo Berensmeyer, Christoph Ehland, Julika Griem, Andrew S. Gross and Antje Kley

\section{Editorial board:}

Martine W. Brownley (Emory University, Atlanta) Andrew Hadfield (University of Sussex, Brighton)

Heinz Ickstadt (Free University of Berlin) David James (Queen Mary University of London) Maurice S. Lee (Boston University) Laura Marcus (University of Oxford) Marek Paryż (University of Warsaw) Gill Plain (University of St. Andrews) Andrew Sanders (Durham University) Hans Ulrich Seeber (University of Stuttgart)

Vol. 2 
Antje Kley / Kai Merten (eds.)

\section{What Literature Knows}

Forays into Literary Knowledge Production 


\section{Bibliographic Information published by the Deutsche Nationalbibliothek}

The Deutsche Nationalbibliothek lists this publication in the Deutsche Nationalbibliografie; detailed bibliographic data is available in the internet at http://dnb.d-nb.de.

Die vorliegende Publikation wurde durch den Universitätsbund der Friedrich-Alexander-Universität Erlangen-Nürnberg gefördert.

Cover Image: @ AndrewSt/Shutterstock.com

$$
\begin{gathered}
\text { ISSN 2366-5068 } \\
\text { ISBN 978-3-631-75014-8 (Print) } \\
\text { E-ISBN 978-3-631-75786-4 (E-PDF) } \\
\text { E-ISBN 978-3-631-75787-1 (EPUB) } \\
\text { E-ISBN 978-3-631-75788-8 (MOBI) } \\
\text { DOI 10.3726/b14220 } \\
\text { @ Peter Lang GmbH } \\
\text { Internationaler Verlag der Wissenschaften } \\
\text { Berlin 2018 } \\
\text { All rights reserved. }
\end{gathered}
$$

Peter Lang - Berlin · Bern · Bruxelles · New York ·

Oxford $\cdot$ Warszawa $\cdot$ Wien

All parts of this publication are protected by copyright. Any utilisation outside the strict limits of the copyright law, without the permission of the publisher, is forbidden and liable to prosecution. This applies in particular to reproductions, translations, microfilming, and storage and processing in electronic retrieval systems.

This publication has been peer reviewed. www.peterlang.com 
Für Annegreth Horatschek anlässlich ihrer Emeritierung als Professorin für Englische Literatur an der Christian-Albrechts-Universität zu Kiel

Dedicated to Annegreth Horatschek on the occasion of her retirement as Professor of English Literature

at Christian-Albrechts-Universität zu Kiel

Juni / June 2018 



\section{Contents}

Antje Kley

What Literature Knows: An Introduction

Kai Merten

"His ignorance were wise": Gendered Knowledge in

Love's Labour's Lost (1594/95)

Richard Nate

"The pleasing visions I had formed": Natural Knowledge

and Self-Awareness in Jonathan Swift's Satires

Albert Meier

Access Denied: English Experiences in Karl Philipp Moritz's

Travel Report of 1782

Marcel Hartwig

Fothergill's Web: Transnational Quaker Networks and

the Pennsylvania Medical Library

Anthony John Harding

Wordsworth, The Excursion (1814), and the Crisis of Knowledge........

Justus Conrad Gronau

Romanticism and Anoetic Knowledge.

Philipp Erchinger

Curious to Know: John Clare’s “The Nightingale’s Nest” (1832)........135

Maria Kaspirek

Negotiating Authority: Literary and Medical Configurations

of Knowledge in $19^{\text {th }}$-Century America

Cord-Christian Casper

The Fourth Dimension and Impossible Knowledge in

Edwardian Speculative Fiction 
Aleksandra Boss and Martin Klepper

What Nancy Knew, What Carol Knew: Mass Literature and Knowledge

Matthias Bauer

Scientific Knowledge and the Display Function of Literature:

The White Hotel (1981) and Freud's Megalomania (2000)

Daniel Schäbler

The Art of Deception: Knowledge Distribution in English Literature

Ann Spangenberg

"We are only what we know": Knowledge in David

Mitchell's Cloud Atlas (2004)

\section{Jutta Zimmermann}

Eden Robinson's Monkey Beach (2000) as Multi-Narrative:

The Dialogic Relation of Indigenous and Western World Views

André Schwarck

"Useless, off-beat information!": Knowledge and Successiveness in Brian Friel's Molly Sweeney (1994)

Anja Pistor-Hatam

Historiography and the Production of Knowledge:

The Mongol Period

List of Contributors 


\section{Antje Kley \\ What Literature Knows: An Introduction}

The nexus of literature and knowledge is an underdetermined and capacious one. Both popular and culturally distinguished forms of literary writing exhibit a whole range of relations to knowledge landscapes, be they scientific, political, or administrative. Karl Richter, Jörg Schonert, and Michael Titzmann have distinguished four general types of relation between literature and knowledge: first, literature may integrate bodies of knowledge in order to confirm, modify, or criticize them. Second, literature may entertain fields of knowledge that scientific discourses have not taken up (yet). Third, literature may produce knowledge that is taken up and authorized later by academic discourses (e.g. psychoanalysis). And fourth, specialized bodies of knowledge might remain difficult to mediate or even inaccessible for literary writing (30). In all four types of relation literature functions as an 'interdiscourse' (Link, "Interdiscourse") which may participate in and selectively connect other more specialized discursive formations. ${ }^{1}$ The contributions to this volume address all four types of interconnection, and they all insist that literature's interdiscursive relation with specific areas of knowledge is fundamentally twofold, involving both the level of content and the level of discursive form, to selectively tap bodies of knowledge for representation and to produce knowledge in its own right. The essays collected here trace what the Münster research training group on "Literary Form: History and Culture of Aesthetic Modelling" conceives of as the characteristic cultural work literary writing performs in differentiated social contexts: literary writing explores debates

1 Interdiscourses build on general categories (like freedom, equality, or progress), collective symbols (like machine, organism, train, or computer), myths and elementary narratives (e.g. of rise and fall). They serve to accentuate, discuss, and subjectivize dominant knowledges from specialized discourses. The awareness created in interdiscursive communication and reception processes for the operative moment of various kinds of knowledge production feeds these processes' "generative intelligence," i.e. their drive for new interlinkings (Link, "Interdiscourse"). 
and articulates concrete perspectives and positions within complex knowledge cultures (Graduiertenkolleg Literarische Form 10).

Since literature's guiding epistemic value is not scientific truth or plausibility but a notion of truth that is built around historically shifting semantics from beauty to coherence and attraction, Jochen Hörisch describes literature as a 'dissident archive' which, as he explains, deserves to be taken seriously for providing a range of alternative perspectives to everyday and to disciplinary bodies of knowledge. Hörisch compares the cultural work literature performs to the playful switch of viewpoint required for the children's game of "I spy," which in German is more tellingly called "Ich sehe was, was Du nicht siehst [I can see something that you can't see],” building on the notion that different points of view may have access to a different range of perceptions and positions e.g. on illness, economics, legal rationale, individual or collective identities, political rhetorics, religious belief or the sciences (Hörisch 1-14). To those who value critique and processes of deliberation and understanding as much as accumulated stocks of facts and a metrics of social evaluation and control (Mau 1-22; Mack 1-18), words that "have savor" (M. Wood 9) may put into new perspective what we believe we know and return us, senses refreshed, to the conflictive plurality of human imaginations and cultural shapes that co-produce our own worlds (Bercovitch). The worlds that imaginary texts project thus entertain possibilities and alternative perspectives to be reckoned with in the academic articulation and public discussion of pertinent social issues. As Sheila Jasanoff shows in all her work on the co-production of scientific knowledge and political thought, the regulatory objectivity at work in the implementation of scientific knowledge, in the US in particular, deprives political and administrative action of a much-needed sensitivity to criticism (Jasanoff).

As Aleksandra Boss and Martin Klepper elaborate in their contribution to this volume on US-American mass cultural products of the 1930s, not only high-brow canonical writing, but also popular formats, which tend to reproduce cultural predilections and mores, enable audiences to understand what Jasanoff insists on considering: that (and how) knowledge is always embedded in both material and social forms.

With literary studies growing into cultural studies and with rising political encouragement of interdisciplinary projects, much work has been done in the past two decades on both the epistemological powers of literary 
textuality and on the poetics of knowledge production. Literature and science, literature and the law, and literature and economics have become important fields of research, dedicated to exploring the multifaceted 'coproduction of the social order' (Jasanoff). Equally hybrid transdisciplinary projects like narrative medicine and investigations into the power of literary discourses to reveal the relevance of implicit and affective dimensions in knowledge production thrive.

Historically, literature has often presented itself as a unique 'stage' (Merten, Text-Theater) for knowledge of the human being and has therefore also seen itself in competition with academic fields such as medicine, biology, or philosophy. The relationship of literature and institutionalized, official forms of knowledge is therefore a shifting and historically contingent one (Foucault): what has been academic knowledge in one age becomes relegated to a less official realm in the next. The belief in a God-given, beautiful order of nature, e.g., became an important topos of Romantic poetry at a time when emergent scientific fields shifted towards a much more secular understanding of the human environment (Merten, "Poetic Genres").

From a systematic perspective, literature cultivates a "provocatively relaxed" relation to notions of truth in an exact or scientific sense (Hörisch 15; see also M. Wood 56-59), while the "imagined yet referentially salient worlds" (Felski 104) which literary writing draws us into familiarize the unfamiliar and estrange what is too close to home to grasp. Literary writing stages plausible, interesting, and productive - rather than scientifically true - insights about the socially situated human being in all its paradoxical implications in (and anachronistic resistance against) the quietly pervasive powers of natural, material, and social environments (see Garber; Mack; Link "Flexible Normalism").

Let me mention two recent debates around educational policy in Germany to exemplify occasions calling for an intervention of literary and cultural studies voices of the kind this volume provides. When the German high school student Naina tweeted on Saturday January 10, 2015 that she was almost 18 and had no clue about taxes, rental or insurance contracts, but could easily interpret a poem in four languages, she received so many reactions that even the federal secretary of education, Johanna Wanka, felt the need to respond to the publicity stunt. The student's tweet hit a nerve of a culture unsure of its educational values. Wanka appreciated that 
the student had started the debate and expressed her support for teaching more practical skills in the country's schools. She added that it remained important to learn to interpret poems. Secretary Wanka did not elaborate on why reading and interpreting poems remained important, but from the perspective of this collection, the connection is easily made. Practices of close reading train modes of inquiry into language and its products, modes of paying attention to textual structures and historical contexts, ways of making sense, and strategies of interpretation that allow us to understand our own place in cultural traditions. These modes of inquiry might not come in 'handy' when we are confronted with tax laws or insurance contracts. They are likely to complicate things. While that might not be what we want when we seek to solve practical tasks at hand, there are countless daily scenarios - from traveling and participating in international tourism to the confrontation with disease and the hospital system, from the encounter with educational institutions and the banking system to casual encounters with people from backgrounds different from our own - which profit from such complication, as it helps us to understand how cultural discourses shape our everyday lives. From a historical perspective, an analysis of lyrical writing's relation to accounting, taxation, and contract law is also of interest as it fosters the articulation of the specificity of both as well as an illumination of their shared cultural context.

The long negotiations leading up to the position paper by the German Wissenschaftsrat (German Council of Science and Humanities) on "Grand Societal Challenges as a Topic for Science Policy" in April 2015 are another case in point for the fraught relation between socially generated expectations and academic modes of knowledge production in the sciences and in the humanities. In an attempt to avoid purely solutionist versions of innovation, transformative research, and usability, the paper calls on the heterogeneous plurality of all academic disciplines to contribute their specific forms of expertise to the long-term negotiations of "grand social challenges" in such areas as demographic change, energy supply and distribution, health, migration and security politics, mobility and communication. None of these problematics are purely natural phenomena; all of them have constitutive rather than ornamental - social, cultural, historical, medial, semantic, and ethical dimensions (see Rheinberger; Hörisch 10; M. Wood 61). The same is true for the paradigm of 'life' which currently generates a lot of mileage: even 
in the era of the life sciences, 'life' in all its social, historical, and semantic specificities is not least a humanist and a literary field of interest (Garber 15-43; Ette). This volume helps to map out how the humanities and literary studies in particular have illuminating things to say about grand social issues which do not yield trivial or optional solutions: e.g. about othering processes and how they structure intersectional cultural conflicts, about experiencing what seems strange and strange experiences, about the relation between religious belief and moral integrity, about the cultural relevance of remembering and forgetting, about how ideologies of victory and victimization interact, about how frequently diagnosed diseases like depression, anorexia, ADS, or Alzheimer might illuminate the pathologies of an era, and about many other questions the natural sciences or daily party politics raise but do not address themselves (Hörisch 10-14; Kley, "Literary Knowledge” 158-161).

This volume seeks to shed light on two interrelated dimensions of the nexus between knowledge and literature. Arranged historically, its contributions address various forms of literary production from the early modern period to the present and investigate how each period's historically specific literary mediality engages with concepts of knowledge and with questions concerning the interrelation of epistemology (both individual and collective), materiality, and representation (Horatschek, "Erfahrung”; "Inhabiting”). At the same time, the volume discusses literature as dissident archive and culturally embedded form of knowledge production in its own right, which deploys narrative, poetic, and discursive methods of exploration and experimentation that are clearly distinct from the quantifiable or empirical logics in such fields as the natural sciences, engineering, medicine, and economics. While empirical forms of knowledge production seek to produce a "view from nowhere" (Nagel; Daston) in order to achieve the ideal of objective verifiability, literary writing provides a decidedly interested, socially situated "view from somewhere" (Kley, "Literary Knowledge") in order to produce meaning and accrete credibility through imaginary acts of interrogation, claiming and confirmation (Mohanty).

The essays collected here address these questions in historically specific ways. They put particular emphasis on the Renaissance (Merten; Nate), the Enlightenment (Meier, Hartwig), the Romantic age in England (Harding; Gronau; Erchinger) and $19^{\text {th }}$-century US America (Kaspirek), Edwardian England (Casper) and early $20^{\text {th }}$-century US mass culture (Boss and Klepper) 
as well as more recent configurations of a "knowledge society" since the mid-20 ${ }^{\text {th }}$ century (Bauer; Schäbler; Spangenberg; Zimmermann; Schwarck). An essay concerned with the interconnections between historiography and knowledge formation during the Mongol period in Iran (1216-1335) forms the volume's coda (Pistor-Hatam).

What Literature Knows opens with two contributions concerned with traditional epistemological paradigms coming under strain in early modern England. Medieval cosmology and religious faith were still largely in place, but the onset of the Reformation, the impact of classical learning, and the dawn of the technology and culture of print begin to shift the contemporaneous worldview. The humanism of Montaigne and John Locke and the nascent practice of natural Philosophy in the wake of the Copernican Revolution, Baconian empiricism, Newtonian mechanics, as well as the founding of the Royal Society deeply unsettle time-honored notions of authority and the production of reliable knowledge (Cartwright and Baker 31-120; Kley, Ethik 71-111). Economic, political, and intellectual transitions of the modern age are intricately connected to these epistemological upheavals. In a cultural climate of merely nascent functional differentiation between social systems, writers both well known and unsung gained a strong voice in these transitions.

In his essay "'His ignorance were wise': Gendered knowledge in Love's Labour's Lost," Kai Merten chooses William Shakespeare's satirical romantic comedy (1594/95) as a characteristic dramatic staging of the contest between an institutionally stabilized factual or academic knowledge and social know-how ('wit'). His reading traces how gender relations shift significantly when seemingly fixed bodies of knowledge become temporarily unreliable. Against the historical background of 'mother nature' being cast in increasingly scientific terms and a general gendering of a) the practice of scientific observation as male and b) of the object of scientific observation as female, Merten's reading clarifies how "[w]omen in the play shake up the male, factual knowledge of a court academy, turning it into the procedural knowledge game of courtly love and thus turn themselves from objects into subjects of the knowledge discourse" (29). Merten reads the play's choreography of discrepant awareness as a specific formal device deployed to involve both the play and its contemporary recipients in the knowledge debates of their time. While awareness implies sovereignty and power, the 
play stages and finally suspends its inversion of a gendered episteme, postponing it, as Merten argues, to Shakespeare's The Winter's Tale.

Focusing on the relation between not yet entirely secularized scientific inquiry and the human inquirer, between scientific knowledge and selfknowledge, Richard Nate takes us to the early $18^{\text {th }}$ century in his "'The pleasing visions I had formed': Natural Knowledge and Self-Awareness in Jonathan Swift's Satires.” Reading Jonathan Swift's satire A Tale of a Tub (1704) and his novel Gulliver's Travels (1726), Nate explains how Swift's textual experiments chastise those scientific voices that do not only seek to improve the human lot, but do so with what seemed to Swift undue self-confidence and pride. "To study the outside world without taking into account human fallibility was," for a writer steeped in the humanist tradition and an adherent of the belief that literature had a moral agenda, "an indication that human pride was once again triumphant" (60). For Swift and his friend Pope, "[c]ritical self-inspection was regarded far more essential in developing a true personality than any attempt at discovering God's secrets through a scientific investigation of nature" (51). Swift's satirical portrayals of modern victims of their own curiosity bespeak this philosophical diagnosis.

Albert Meier's “Access Denied: English Experiences in Karl Philipp Moritz's Travel Report of 1782" provides an exemplary reading which argues that throughout the $17^{\text {th }}$ and into the enlightened $18^{\text {th }}$ century, national character as well as a people's social and cultural mores had to be derived first and foremost from fiction and travel narratives. Meier reminds us that both genres work with aesthetically and economically motivated stylizations rather than naively 'realistic' or pedantically precise depictions - designed to catch and entertain readers' interest. As Moritz's German wanderer's experiences are prefigured by the unreliable, heavily mediated, and consciously crafted guidance of literary writing and thus depend on his choice of literary intake, Meier concludes that "the authenticity of Moritz's narrative of England proves to be an ultimately literary construction, which - regardless of its basic soundness of detail - makes his generalizing characterization of the country and people factually questionable" (75). While Meier, too, asserts the specific, or even singular quality of literary epistemologies, affirming that one only sees what one knows, he remains suspicious of literature's status as a medium for knowledge production. 
Marcel Hartwig's “Fothergill's Web: Transnational Quaker Networks and the Pennsylvania Medical Library" is, next to Anja Pistor-Hatam's essay, one of two historiographic contributions which adopt a wide notion of the literary as written forms of mediation. Hartwig introduces the enlightenment scholar and London-based medical practitioner John Fothergill's efforts to negotiate the emergence and solidification of reliable medical knowledge in written exchanges with a host of pen pals. In our volume, Hartwig's essay constitutes the bridgehead for Kaspirek's and Schwarck's inquiries into the relations between medical and literary knowledge in the $19^{\text {th }}$ century and today. Hartwig reads Fothergill's epistolary exchanges in interconnection with the institutional practices of transnational collection and dissemination of the first Medical Library in Philadelphia. His microstudy aims "to show the intellectual work and the practices of knowledge production that are involved in institutionalizing a knowledge network of 'professional' medicine that by the end of the $18^{\text {th }}$ century paves the way for the success of rationalized pathological medicine in the Western hemispheres" (81). Reminding us of Albert Meier's similar observation about late $18^{\text {th }}$-century travel writing, Hartwig notes that the letters he investigates frequently borrow from established literary genres. 'Science' and the notion of the 'professional' remain, as Maria Kaspirek will confirm in her essay, anachronisms into the $19^{\text {th }}$ century.

The following set of essays is concerned with the epistemological crisis of the Romantic period in England, "a crisis of knowledge which was simultaneously a crisis of religious faith and of political stability" as Anthony Harding puts it (94). In this context, Romantic writers attempted "to forge a new kind of epistemology, a theory of knowledge that rejected the passive and mechanical role assigned to the mind by eighteenth century thinkers and asserted instead the essential creativity of the human imagination" (Cartwright and Baker 121; see also Kley, Ethik 177-212). They did so, of course, in manifold ways and on the basis of very different attitudes toward current changes in culture, society, literature, and the arts (Cartwright and Baker 120-70).

In "Wordsworth, The Excursion, and the Crisis of Knowledge," Anthony Harding reads Wordsworth's understudied poem (1814) as a response to John Locke's, David Hume's, and Immanuel Kant's thought. Their ideas helped to dethrone Cartesian Metaphysics and to unsettle Western culture's 
religiously based conception of what it means to know, while industrialization and profit-driven commercial values promoted profound social changes. In this context, the "poem is a response to a crisis of knowledge that is both personal to Wordsworth and part of a much broader $19^{\text {th }}$-century realignment of the relationship between philosophy and poetry" (95). From his close reading Harding concludes that The Excursion embraces as "a basis for a future ethics and politics" a limited kind of knowledge rooted not in religious belief but "in a secular, anthropological understanding of human experience" (110).

Picking up on Harding's concerns, Justus Conrad Gronau uses examples from Keats's and Shelley's poetic work to address a paradox frequently encountered in Romantic thought between a turn to subjective, non-propositional, and sense-based ways of encountering the world on the one hand and the need to express these in linguistically based reasoning on the other. In "Romanticism and Anoetic Knowledge," Gronau assumes that Romantic writing absorbs the epistemological uncertainty emerging from the simultaneous and frequently conflicting strengthening of adjacent epistemological fields like the literary, the scientific, and the economic. Poetry, Gronau asserts, transforms this uncertainty into a key component of its own aesthetics. His essay seeks to articulate the epistemic value of limits of knowledge, working toward a Romantic poetology of a particular form of non-propositional, not cognitively conceivable or 'anoetic' knowledge. A key characteristic of this poetology is a selfreflexive awareness of the paradoxical conditions and limitations of poetic mediality, an awareness nurtured by an explorative hovering between knowing and not knowing.

In "Curious to Know: John Clare's 'The Nightingale's Nest'," Philipp Erchinger programmatically explores the difference between a modern, strongly scientific notion of objective knowledge as 'justified true belief' and literary modes of knowledge production which deliberately replace systematic detachment from with involvement in the objects under consideration. In order to exemplify the difference between articulate and personal knowledge, between what Gilbert Ryle has distinguished as 'knowing that' and 'knowing how' (see also Ernst and Paul 12-22), Erchinger presents a contrastive case study of an $18^{\text {th }}$-century dictionary entry on the "Nightingale" and some of John Clare's Romantic bird poems. In contrast to the by then established 
textbook approach to natural history, Erchinger sees Clare's bird poems and natural history letters practicing poetic, process-based forms of investigation that "remain sensuously responsive to, and subject to be affected by, the matter they seek to know" (142). He shows how Clare's texts enable readers to read an observer's experience in the making and to entertain ecological modes of thinking that challenge the anthropocentric mind. Erchinger's essay is most explicit about heuristically differentiating modes of knowledge production tied to strict scientific protocols from those relying on more hermeneutic protocols of truth production. ${ }^{2}$ All essays collected in this volume rely at least implicitly on some version of this differentiation. Erchinger also elaborates what all contributors affirm quite explicitly, namely that literature knows that the notion of reliable knowledge is a contested one.

In "Negotiating Authority: Literary and Medical Configurations of Knowledge in Nineteenth-Century America," Maria Kaspirek confirms Hartwig's claim that only in the $19^{\text {th }}$ century do notions of 'science' and the 'professional' gain discursive currency. Presenting original evidence primarily from $19^{\text {th }}$-century medical journals, Kaspirek "reveals the hitherto neglected but substantial influence of literature on the consolidation of scientific knowledge on human nature" (156). Against the background of a gradual institutionalization of medical science - the nationwide American Medical Association was founded in 1847 -, Kaspirek studies literary engagements with medico-scientific discourse and its ethical concerns, medical professionals' reliance on literary observations in their diagnostics, the work of physician writers Oliver Wendell Holmes and Silas Weir Mitchell, and the medical case study as a literary genre. Subsequently she observes how the medical profession began to pathologize writers and their work to consolidate their own discursive authority in the field. Emphasizing that her observations are suggestive for the contemporary literature and science debates as well, she concludes that "[a]ll these examples paint the relationship between medicine and literature as a mutually beneficial one; two fields that were engaged in the struggle for epistemological authority, vitalized by

2 Since the turn of millennium, work in the field of New Materialism has picked up on this distinction between different modes of knowing, emphasizing its precariously unstable character (see Barad's onto-epistemology and Bennett's exploration of the lively powers of material formations). 
the public's interest in health and human nature, sharing common subjects, negotiating a field of tension between democratization and professionalism, and united not only in a quest for knowledge but also for national identity and independence from European paragons" (166).

In his essay "The Fourth Dimension and Impossible Knowledge in Edwardian Speculative Fiction," Cord-Christian Casper follows the Romantic interest in the limitations of knowledge into the early $20^{\text {th }}$ century. Casper investigates Early Modernist literary confrontations with the humanly unknowable. In Edwardian novels, short stories, or popular scientific tracts such limits of knowledge are associated with a realm of their own: the Fourth Dimension. Edwin Abbott's Flatland (1917), Charles Hinton's Scientific Romances (1886 /1896) as well as Joseph Conrad's and Ford Madox Ford's 1901 novel The Inheritors each stage attempts to represent this space beyond the limits of familiar perceptual and cognitive faculties. These narratives of hyperspace, however, deprive their readers of immediate paths towards dimensional transcendence. The journey to the Fourth Dimension stalls: interrupting the pursuit of impossible knowledge, each text selfreferentially marks the breakdown of its representational strategies. As a consequence, "analogies falter, the unlearning of conventions stagnates, and, ultimately, literature can only register impossible 4-D knowledge as a perpetual absence" (190). Far from elegiac, however, these marked impasses propel these speculative texts towards "a constant flight from generic constraint and cliché" (190). The article demonstrates that it is precisely by barring easy access to 'supra-sensible' knowledge that the texts inculcate ever-renewed narrative experiments and readerly speculation alike.

Based on the assumption that "mass literature matters" (193), Aleksandra Boss and Martin Klepper analyze - in connection with the then particularly popular culture of self-help - the American middle-class girl detective series Nancy Drew that appeared from the 1930s through the 1960s as well as the African American serial novel "Hell" that appeared in the Chicago Defender in 1929. Reviewing the series' content and formats, white and black literary mass markets of the time, and the tradition of American rituals of self-improvement, "What Nancy Knew, What Carol Knew: Mass Literature and Knowledge" suggests that "the discourse of self-improvement and mental mobility is so strong in the products of consumer culture and mass circulation because these products were on demand by virtue of this very 
discourse" (208). Throughout the series, the protagonists' knowledge proves to be ambivalent, "riddled [...] by the contradictions and silences of the discourses sustaining it," and fundamentally constrained "by the violence and prejudices of its times" (211). The series themselves thus develop a very specific cultural knowledge of self-help in terms of socially permissible behaviors, practices, and aspirations, and have much to say to their contemporaneous readers as well as readers and critics today.

In "Scientific Knowledge and the Display Function of Literature: The White Hotel (1981) and Freud's Megalomania (2000)," Matthias Bauer elaborates how literature may display, work through, and transfigure bodies of scientific knowledge, ideology, and rhetoric. In accordance with sociological accounts which distinguish between raw information and processed knowledge (Burke 1-17), Bauer argues that only the subjective mediation of bits and pieces of information may produce relevant meaning; modern literature as an instrument of subjective mediation therefore assumes significance in the production of the cultural achievements of subjectivity and responsivity. He turns to psychoanalysis as a scientific discourse strongly influenced by literary writing and explores two exemplary literary displays of the psychoanalytic processes to show how explicitly literary writing redresses psychoanalytic theory's weakness in terms of its disregard for self-reference. According to Bauer, self-referentiality makes "literature such a fascinating mode of experimental thinking" (228). This experimental thought reveals "contradictions in Freud's theory or between his findings and the findings in other disciplines" in Rosenfield's novel Freud's Megalomania; and it "confronts knowledge and history, academic discourse and real events" in D. M. Thomas' novel The White Hotel "both to stress the importance of psychoanalysis and to mark its boundaries" (233).

Daniel Schäbler addresses the formal textual realization of knowledge distribution and processes of deception, which he conceives of as a special case of discrepant awareness. His essay "The Art of Deception: Knowledge Distribution in English Literature" undertakes case studies of Shakespeare's play Hamlet and Ian McEwan's novel Sweet Tooth (2012) to conceptualize deceptive relations "as a three-way intrafictional communicative act [...] between the deceiver, the deceived, and the audience," (251) primarily designed to catch and entertain the reader's interest. Beyond that, Schäbler finds Hamlet mobilizing the supposedly stable deceptive triangle, so that 
the structural positions of deceiver and deceived displace each other, resulting in "a politically condemning and poetically just view of courtly tactics of the Elizabethan Age as well as of societal power-play on a larger scale" (246). Sweet Tooth is seen as employing modes of deception to show that contrary to official political discourse during the Cold War era - the relation between the epistemological category of truth and the ontological category of reality is an unstable one, governed by the authority which guides the respective formations of knowledge. Schäbler's analysis returns literary narrative quite literally to what Hörisch calls its staging of an epistemic version of "I spy."

In her essay "'We are only what we know': Knowledge in David Mitchell's Cloud Atlas," Ann Spangenberg is concerned with a postmodern version of the literary critique of timeless truths. She reads the novel's fictional presentation of six different socio-historical settings with different belief and media systems as an exploration of a cross-culturally pervasive human hunger for knowledge and domination. She traces the text's attempts to pry apart the perilous conjunction between the desire for power and that for knowledge in order to sound out possibilities for "the advancement of scientific and technological knowledge and a higher level of civilization, in the sense of longer, more peaceful and comfortable lives and more justice and equality" (254).

In her contribution "Eden Robinson's Monkey Beach as Multi-Narrative: The Dialogic Relation of Indigenous and Western World Views," Jutta Zimmermann addresses the need to decolonize regimes of knowledge which claim universal and timeless validity and to promote epistemic diversity. She reads the multinarrative structure of Monkey Beach, which interweaves Western trauma narrative and Indigenous survival narrative, as a "literary manifestation of an Indigenous worldview in which knowledge formation is seen as a dialogic process that puts in relation competing yet at the same time entangled views of the world" (278). The author argues that the text's structure "challenges the predominance of Western knowledge production by presenting Indigenous knowledge as more localized, yet at the same time more encompassing than Western scientific approaches” (278). The novel thus questions the culturally restrictive force of dominant, normative, medically, and psychologically defined notions of individual and collective well-being and launches its demand for decolonization processes that might 
help to ensure the survival of indigenous cultures and diverse humankind in general.

André Schwarck is interested in how literature may reveal and attend to the shortcomings of an advanced medical discourse and practice in his essay "'Useless, off-beat information!': Knowledge and Successiveness in Brian Friel's Molly Sweeney.” Reading Friel's play, based on Oliver Sack's medical case history of a blind man whose sight is successfully restored through a series of operations, Schwarck traces how the play intercepts the associative assimilation between seeing and knowing by undermining the idea that medical knowledge produces a life-transforming restoration of sight. Schwarck shows how expert medical knowledge becomes a source for the male characters in the play to establish and sustain authoritative narrative patterns. By imposing these patterns on Molly Sweeney, the female protagonist of Friel's play, knowledge becomes not only an indicator of male identity and authority but a catalyst for an inscrutable gender struggle. Schwarck's reading sheds light on how the play reveals the violence implied in medically successful protocols where they (necessarily?) fail to take into account how their patients' situatedness may cancel their own definition of success.

Anja Pistor-Hatam's essay "Historiography and the Production of Knowledge: The Mongol Period in Iran as a Case Study" participates in the postcolonial critique of hegemonic knowledge formations, focusing on the textuality and the narrative quality of historical accounts on the Mongol period in Iran (1216-1335). The author selects modern historical narratives by well-known but non-professional Iranian historians, all of which are regarded as state of the art in Iranian school and university education. The essay argues that large parts of these texts' content can only be accepted as plausible if one reads them as adopting not only Mongol history, but Mongol historiography. As constructions of historical meaning, they retrospectively employ fictions of coherence to forge a usable past that fits and supports an overall nationalist political paradigm.

All essays presented in this volume explore literary writing - in its popular and its canonical forms, in a narrow and in a wider sense - as ways of thinking about and as ways of experiencing the production, reception, evaluation, and reformulation of knowledge. They explore literary writing as a formally, rhetorically, and generically rich archive of re-descriptions of the world. They trace the dissident archive's attempts to surprise, seduce, 
enchant, or shock us into reading other people's minds, into accessing institutional environments, processes of knowledge formation, and social interactions in a different key, and into seeing individual self-understandings as socially mediated (see Felski). Interconnecting formalist and political protocols of reading, this volume thus articulates a more plastic sense of how philological expertise in imaginary and historiographical processes of meaning making, in conceptual clarification, in the negotiation of uncertainty, complexity, heterogeneity, and particularity (see Turner ix-xviii; Kelleter 167-173) may generate productively irritating forms of connectivity to other knowledge discourses.

The editors wish to thank all those who made the publication of this volume possible. Prominent among them are the two anonymous reviewers whose comments helped strengthen the volume's coherence; Michael Rücker, Sonja Peschutter and Sandra Grundmann, who saw the volume through the entire publication process at Lang from our first ideas to the printed book; and Katrin Horn, who kept us sane with her professional level-headedness in arranging the manuscript for print. Needless to say that all remaining errors are our own. We are grateful to the Universitätsbund of Friedrich-Alexander-Universität Erlangen-Nürnberg for generously funding all direct publication costs.

\section{Works Cited}

Barad, Karen. Meeting the Universe Halfway: Quantum Physics and the Entanglement of Matter and Meaning. Durham: Duke University Press, 2007.

Bennett, Jane. Vibrant Matter: A Political Ecology of Things. Durham: Duke University Press, 2010.

Bercovitch, Sacvan. "The Function of the Literary in a Time of Cultural Studies." "Culture" and the Problem of the Disciplines. Ed. John Carlos Rowe. NY: Columbia University Press, 1998. 69-86.

Burke, Peter. A Social History of Knowledge. Cambridge: Polity Press, 2000.

Cartwright, John, and Brian Baker. Literature and Science: Social Impact and Interaction. Santa Barbara: ABC-CLIO, 2005.

Ernst, Christoph, and Heike Paul. "Präsenz und implizites Wissen: Zur Interdependenz zweier Schlüsselbegriffe der Kultur- und Sozialwissenschaften.” 
Präsenz und implizites Wissen: Zur Interdependenz zweier Schlüsselbegriffe der Kultur- und Sozialwissenschaften. Ed. Christoph Ernst and Heike Paul. Bielefeld: transcript, 2013. 9-32.

Felski, Rita. Uses of Literature. Malden: Blackwell, 2008.

Foucault, Michel. The Archaeology of Knowledge and the Discourse on Language. Trans. A.M. Sheridan Smith and Rupert Swyer. New York: Pantheon, 1972.

Garber, Marjorie. A Manifesto for Literary Studies. Seattle: University of Washington Press, 2003.

Graduiertenkolleg Literarische Form. "Einleitung." Formen des Wissens: Epistemische Funktionen literarischer Verfahren. Ed. Graduiertenkolleg Literarische Form. Heidelberg: Winter, 2017. 9-27.

Horatschek, Annegreth. "Erfahrung, Repräsentation und Wissen: Wissenskonzepte in der englischen Literatur von Shakespeare bis zur Postmoderne.” LWU (forthcoming).

-. "'Inhabiting Landscapes of the Known and the Unknown Alike': Representation and Consciousness in British Literature." Consciousness: Integrating Eastern and Western Perspectives. Ed. Prem Saran Satsangi, Stuart Hameroff, and Vishal Sahni (forthcoming).

Hörisch, Jochen. Das Wissen der Literatur. München: Fink, 2007.

Jasanoff, Sheila. "The Idiom of Co-Production." States of Knowledge: The Co-Production of Science and the Social Order. Ed. Sheila Jasanoff. New York: Routledge, 2004. 1-12.

Kelleter, Frank. "A Tale of Two Natures: Worried Reflections on the Study of Literature and Culture in an Age of Neuroscience and Neo-Darwinism." JLT 1.1 (2007): 153-89.

Kley, Antje. Ethik medialer Repräsentation im englischen und US-amerikanischen Roman, 1741-2000. Heidelberg: Winter, 2009.

-. "Literary Knowledge Production and the Natural Sciences in the US." Knowledge Landscapes North America. Ed. Sabine Sielke. Heidelberg: Winter, 2016. 153-77.

Link, Jürgen. "From the 'Power of the Norm' to 'Flexible Normalism': Considerations after Foucault." Cultural Critique 57.1 (2004): 14-32.

Mack, Michael. Philosophy and Literature in Times of Crisis: Challenging our Infatuation with Numbers. London: Bloomsbury, 2014. 
Merten, Kai. Intermediales Text-Theater: Die Bühne des Politischen und des Wissens vom Menschen bei Wordsworth und Scott. Berlin: De Gruyter, 2014.

-. "Poetic Genres in the Romantic Age I: William Wordsworth's and Samuel Taylor Coleridge's 'Lyrical Ballads', Nature Poetry.” A History of British Poetry: Genres - Developments - Model Interpretations. Ed. Sibylle Baumbach, Birgit Neumann, and Ansgar Nünning. Trier: WVT, 2015. 217-28.

Mohanty, Satya P. “On Situating Objective Knowledge.” Literary Theory and the Claims of History: Postmodernism, Objectivity, Multicultural Politics. Ithaca: Cornell University Press, 1997. 149-97.

Nagel, Thomas. The View From Nowhere. Oxford: Oxford University Press, 1986.

Rheinberger, Hans-Jörg. Natur und Kultur im Spiegel des Wissens: Marsilius Vorlesung am 6. Februar 2014. Heidelberg: Winter, 2015.

Richter, Karl, Jörg Schönert, and Michael Titzmann. "Literatur - Wissen Wissenschaft. Überlegungen zu einer komplexen Relation.” Die Literatur und die Wissenschaften 1770-1930. Ed. Karl Richter, Jörg Schönert, and Michael Titzmann. Stuttgart: Metzler, 1997. 9-38.

Ryle, Gilbert. "Knowing How and Knowing That." Proceedings of the Aristotelian Society 46 (1945/46): 1-6.

Turner, James. Philology: The Forgotten Origins of the Modern Humanities. Princeton: Princeton University Press, 2014.

Wissenschaftsrat. "Grand Social Challenges as a Topic for Science Policy." wissenschaftsrat.de. Wissenschaftsrat I German Council of Science and Humanities. 10 April 2015. Web. http://www.wissenschaftsrat.de/download/archiv/4594-15 engl.pdf 29 September 2015.

Wood, Allen. “The Objectivity of Value.” New Literary History 32 (2001): 859-81.

Wood, Michael. Literature and the Taste of Knowledge. Cambridge: Cambridge University Press, 2005. 

Kai Merten

\title{
"His ignorance were wise": Gendered Knowledge in Love's Labour's Lost (1594/95)
}

\begin{abstract}
William Shakespeare's satirical romantic comedy presents a characteristic dramatic staging of the contest between an institutionally stabilized factual or academic knowledge and social know-how ('wit'). The essay traces how gender relations shift significantly when seemingly fixed bodies of knowledge become temporarily unreliable. Against the historical background of 'mother nature' being cast in increasingly scientific terms and a general gendering of a) the practice of scientific observation as male and b) of the object of scientific observation as female, the reading presented here clarifies how women in the play shake up the male, factual knowledge of a court academy, turning it into the procedural knowledge game of courtly love. Thus, they turn themselves from objects into subjects of the knowledge discourse. The play's choreography of discrepant awareness emerges as a specific formal device deployed to involve both the play and its contemporary recipients in the knowledge debates of their time. While awareness implies sovereignty and power, the play stages and finally suspends its inversion of a gendered episteme, postponing it to Shakespeare's The Winter's Tale.
\end{abstract}

\section{Theatre and Knowledge}

Within the realm of literature, knowledge is addressed particularly strongly in drama. This is due to the fact that drama is closely connected to the medium of theatre, ${ }^{1}$ where knowledge is not only described and discussed but staged before an audience and embodied by living actors. Knowledge in drama/theatre is therefore not only a content, but a process the dramatic characters (as well as the audience) are situated in according to their varying degrees of awareness of what is going on. ${ }^{2}$ Theatre brings to mind one of the main differentiations within the semantics of knowledge - that between propositional knowledge (knowledge of 'what') and procedural

1 For theatre as medium and its relation to literature (another medium), cf. Merten, Intermediales Text-Theater.

2 Cf. Daniel Schäbler in this volume. 
knowledge (knowledge of 'how') (cf. Ryle). At the same time, by 'processing' knowledge, i.e. by embedding it in actions that involve individuals, their social relations and hierarchies, theatre also stages, in the sense that it both represents and analyses, the politics of knowledge, i.e. the power relations involved in and expressed by knowledge. ${ }^{3}$ Theatre is one of the prime media of knowledge - both of its joy and its terrors, ${ }^{4}$ both of its human necessity and its painful power politics. Theatre stages these politics, but it also analyses and unravels them. This is the interest of my article.

My focus will be on gender, because within the field of power knowledge, gender is particularly common as a knowledge that will shape, organize, and suppress human individuals and their bodies. At the same time, gender knowledge is in several ways central to the history of Western theatre, because acting entails the representation and negotiation of the (costumed) body on stage as well as its gender performance. The gendered body is particularly strong in comedy, the theatrical genre addressed in this article. Comedy, among other things, engages in human sexuality, for example, by connecting sex with the advantages and the disadvantages of different levels of knowledge about other human beings and their bodies. In satirical comedy, characters will use their knowledge against other characters and for their own (and the audiences') amusement, both by exposing to ridicule the academic ignorance and social incompetence of pretenders and by using their own knowledge to 'know' other characters sexually. On a less aggressive note, in romantic comedy some characters remain funnily but also touchingly unaware of their own love for another human being and his or her body.

My example, William Shakespeare's comedy Love's Labour's Lost $(1594 / 95)$, is in many ways both a satirical and a romantic comedy. The play abundantly features the staging and analysis of knowledge (power), not just because it is, according to Katherine Eggert, "Shakespeare's most explicit portrayal of the scene of knowledge making" (193), but also because it was written in a time of particularly strong historical shifts in

3 Cf. the introduction and Ann Spangenberg's article in this volume on the discursive nature of knowledge as explored by Michel Foucault and other poststructuralists.

4 On the terrors of knowledge in tragic anagnorisis, cf. Bishop (33-36). 
knowledge, as we shall see, and not least about gender. The connection of factual (academic) knowledge and social know-how ('wit') is typical of early modern satirical comedy. What is unique about Love's Labour's Lost, however, is its shift from the initial discursive stability of knowledge to the precariousness of social practice and ultimately the 'death' of knowledge. Love's Labour's Lost shows how seemingly set and stabilized knowledge can at first become socially and performatively 'shaky' before grinding to a halt altogether. This negotiative and epistemic quality of Love's Labour's Lost and particularly its gender dimension has not yet been noticed: women in the play shake up the male, factual knowledge of a court academy, turning it into the procedural knowledge game of courtly love and thus turn themselves from objects into subjects of the knowledge discourse.

\section{Establishing a Male Knowledge Order in Love's Labour's Lost}

Love's Labour's Lost concerns itself with knowledge almost from the beginning. The scene is set at the court of Navarre. Three courtiers enter in conversation with the King who makes the following proposal:

Our court shall be a little academe,

Still and contemplative in living art.

You three, Berowne, Dumaine and Longaville,

Have sworn for three years' term to live with me,

My fellow-scholars [...] (1.1.13-17)

The "statutes" (1.1.17) of this academy are regular fasting, voluntary sleep deprivation, and (hetero)sexual abstinence, all in order to enable study maximization over the period of three years to which the academy is limited. ${ }^{6}$ The last commandment in particular raises comments among the courtiers, and Berowne is especially keen to re-introduce women into the curriculum of the men's knowledge project, saying he will "study where to

5 References are to the Third Arden Edition, ed. H.R. Woudhuysen.

6 The context of early modern court academies (and of courts as the precursors of modern academies) has been extensively studied, with respect to both Shakespeare and to the history of knowledge in a more general sense, cf. Yates (A Study; French Academies) and Moran. However, no systematic reading of 'knowledge' in Love's Labour's Lost has so far been undertaken. 
meet some mistress fine" (1.1.63). What might be seen as a sly reversal of the King's epistemic endeavor through the use of academic language against its expressed purposes (or, for that matter, as a lame joke ${ }^{7}$ ), has actually been convincingly read as an in-depth analysis of the Navarrian knowledge discourse: "[Berowne] suggests that desire for books or desire for 'some mistress fine' are in fact interchangeable objects of desire [...] The original opposition between abstract knowledge and corporeal knowledge has been dissolved" (Breitenberg 438).

And so, as soon as the four men meet the Princess of France and her three attending ladies, the principal female characters of the play, they immediately write love sonnets about them to both document and express their 'knowledge' of women. Far from halting their academy project, these poems implement it in full; in the play, "Petrarchism [is] a representation of woman-as-the-Other that seeks a form of 'knowledge' about her that always already remains elusive" (Breitenberg 435). ${ }^{8}$ Breitenberg subsequently analyses a structure of obsessively and constitutionally deferred male gratification in Love's Labour's Lost, which comprises sexual objects just as much as it does objects of study. For him, this structure is ultimately based on the unattainability of the real outside language and thus represents the basic cultural law of patriarchy. While I agree with the main thrust of this argument, I suggest refocusing the perspective somewhat, taking the history and the politics of knowledge into account. The male academy is not distracted by Berowne's suggestion and the courtiers' subsequent courtly love activities, as many critics have contended. ${ }^{9}$ Instead, following Breitenberg,

7 Cf. "From women's eyes this doctrine I derive: / They sparkle still the right Promethean fire; / They are the books, the arts, the academes, / That show, contain and nourish all the world" (4.3.324-326). To take this parallelism seriously analytically and thus to deliver the play from a shadow that might otherwise have hung over it, its perceived atmosphere of 'old boys off-colour jocularity,' so to speak, was one of the starting points for this article.

8 Cf. Schalkwyk on Petrarchism's construction of silent women and Erickson (69) on Berowne's captivity in the "closed linguistic system" of Petrarchism.

9 Krippendorff contends that the "patriarchalisches Wissen einer Gender-blinden Wissenschaft" ('patriarchal knowledge of a science that is blind to gender') in Love's Labour's Lost is in need of a female principle for completion (98). I do not see this science as gender-blind at all. Quite the opposite: male knowledge already emphatically and constitutively includes the female and therefore does 
the interest in women must be seen as a constitutive element of the academy. By studying and writing about women, it realizes one of its goals; in a sense, the love sonnets are its proceedings. ${ }^{10}$ Seen from another angle, ruling out women and studying women are not opposites, but structural equivalents because both betray a desire to control them by way of objectification. ${ }^{11}$

By looking at the history of knowledge in the early modern period more generally, this reading can be strengthened and connected to other epistemic control projects of the period. Even if gender differences were not as strict as in the $18^{\text {th }}$ and $19^{\text {th }}$ centuries (Outram 801-10; Honegger), women were routinely seen and conceptualized as needing male control, simply because their sexuality was regarded by many men as comparable to their own (male) sexuality (Outram 801; Maclean). A significant body of work, therefore, advocated that they be socially controlled, whereas the discursive control of women had not yet been implemented to the extent it was from the $18^{\text {th }}$ century onward. Science, however, was already strongly gendered in the $17^{\text {th }}$ century, and this gendering began to change at the time. This was due to a shift in the conception of nature, that was no longer seen as a nurturing mother but as "a female to be controlled and dissected through experiment” (Merchant 190) as advocated by Francis Bacon and René Descartes. Concomitant with this scientification of 'mother nature' was a general gendering of scientific practice, "with the [object] gendered as female and [the observer], inevitably, as male" (Outram 810). In this sense, the academy in Love's Labour's Lost, far from excluding women from their curriculum, studies nothing but women.

This scientification of nature also considerably changed the epistemic status of the miracle. Whereas miracles were seen well into the $16^{\text {th }}$ century as

not need to be expanded by a female principle but countered by a new form of knowledge.

10 Cf. Breitenberg: "women and male desire for them become the condition of all knowledge" (442); Cf. Peter Sloterdijk's latest novel (2016) for a contemporary take on this.

11 Cf. Mazzio (204). Turner argues that the compensatory quality of the academy is meant to provide an outlet for violent military competitiveness through a knowledge rivalry (22). 
expressions of God's power creating the world and 'wonder'12 and hence welcomed as adequate responses to the metaphysical and therefore inexplicable origins of nature, from the $17^{\text {th }}$ century onwards, miracles were regarded more and more skeptically. Again, Bacon was at the forefront of the movement, demanding that instead of blissfully proclaiming the miraculous, man needed to discover the "essential but often hidden workings of nature" so that "the properties and qualities of those things, which may be deemed miracles [...] of nature, be reduced to, and comprehended in, some form or certain law" (Bacon qtd. in Daston 111). In the same context, a lack of knowledge, or 'ignorance,' was no longer seen as a pious, modest, and ultimately enabling condition, as, for example, in Nicholas of Cusa's Docta Ignorantia (1440) in the $15^{\text {th }}$ century. Instead, ignorance was now condemned as a lapsarian state which it was the duty of the responsible believer to leave behind (Beyer 27; Meier-Öser). Nature was no longer a nurturing female to be venerated and admired in ignorance, she was to be scientifically found out and exploited fully.

Therefore, when Shakespeare in Love's Labour's Lost has Berowne use all the epistemic buzzwords of the period to describe his 'love,' the men's academic sonnets' project is deliberately marked as 'modern.'

If knowledge be the mark, to know thee shall suffice:

Well learned is that tongue, that well can thee commend,

All ignorant that soul, that sees thee without wonder;

Which is to me some praise, that I thy parts admire. (4.2.111-14; emphasis added)

Again, Berowne suggests that the academy fully realizes itself in the study of women, a knowledge that is represented by the very poem recited at this moment. In accordance with contemporary episteme, the supersession of ignorance is implied in the court's modern knowledge project, not only here but several times in the course of the play. ${ }^{13}$ The discourse of wonder/miracle is duly conjured up - with an interesting twist, however. On the one hand, Berowne's "to know thee shall suffice" typically expresses the epistemic objectification of women as explored, and the

12 Interestingly, the English word 'wonder' both denotes the phenomenon and the human reaction to it.

13 Ignorance is called a "monster" in 4.2.22. As will be shown in the following pages, the women return the academy to the ignorance it struggles to overcome. 
"wonder" claimed to be necessary for this knowledge could be seen as simply incorporating the earlier response to the world into the new culture of epistemic exploitation. On the other hand, there is also a critique of male objectification behind Berowne's call (back) to wonder and admiration, which reminds the men of the limitations that all their new-found knowledge will have, just because these limitations have never been overcome. The questioning and deconstruction of the male academy, however, is undertaken mainly by the female characters, as we will see in the next section of this article.

\section{From the Academy to Wit: The Female Mobilization of Knowledge}

Following the first encounter of the courtiers with the French ladies in 2.1, the atmosphere suddenly changes. Whereas the 'academic' exchanges of the courtiers in Act One, with the exception of Berowne's interjections (which on inspection also prove affirmative rather than subversive), were measured and statutory, the female characters speed up, mobilize, and question knowledge right away:

KING

Hear me, dear lady: I have sworn an oath.

PRINCESS

Our lady help my lord! He'll be forsworn.

KING

Not for the world, fair madam, by my will.

PRINCESS

Why, will shall break it; will and nothing else.

KING

Your ladyship is ignorant what it is.

PRINCESS

Were my lord so, his ignorance were wise,

Where now his knowledge must prove ignorance. (2.1.97-103)

The Princess immediately sets about attacking the male academic project and its celibate rationale, both by twisting the King's words in decontextualizing repetitions ("lady"/“Lady," "will”/“will”) and by using epistemic vocabulary herself ("ignorance," "wise," "knowledge") in order to both counteract the male episteme and to claim her own. The women have set out to disturb the male academic project (which includes their objectification) and they proceed 
to do so by transferring male academic speech into a new, much faster, more dialogic, and stichomythic context. However, at the same time it becomes clear that, far from merely destroying existing knowledge, it is their intention to give it a new, mobile, and performative, shape: the stabilizing and objectifying academic male knowledge about women must be turned, as the Princess puts it, into a "civil war of wits" $(2.1 .225)$ between men and women. ${ }^{14}$

'Wit,' I contend, is a term denoting a procedural alternative to the factual knowledge of the academy. By making 'wit' 15 out of knowledge, the women transform the academic and Petrarchian discourse into a social practice. ${ }^{16}$ This becomes especially clear in Act 5 as the Princess and her ladies receive the sonnets written about - and now also addressed to - them. Complaining about the overwhelming, fixating, and deadening quality of this stabilizing discourse, ${ }^{17}$ they decide to outwit its senders. Again, their project (as yet unspecified) is characterized as a 'witty' female counter-episteme that takes up, mobilizes, and reverses the language of male knowledge:

None are so surely caught, when they are catched,

As wit turned fool. Folly, in wisdom hatched,

Hath wisdom's warrant and the help of school

And wit's own grace to grace a learned fool. (5.2.69-72; emphasis added)

'Wit' will reverse 'wisdom,' turning it into 'folly' and the 'scholastic' "bookmen” (2.1.226) into living paradoxes - 'learned fools' whose "knowledge,"

14 Cf. Turner for the competitiveness of early modern courtly love (games) and the female part therein, both in Love's Labour's Lost and elsewhere (32-36).

15 'Wit' denotes both a mental quality and a particular kind of person. Both meanings are present in "civil war of wits." However, according to Zucker the former meaning is the more basic, particularly in early modern comedy (3-11). What is more, the English 'wit' (a quality) and the German 'Wissen' share the same root.

16 According to standard discourse theory, practice is of course part and parcel of discourse, not an alternative to it. Note, however, Bhabha's witty notion that, in the case of the 'nation' at least, discourse is inevitably undermined by the sheer fact that it needs to be performed, i.e. practiced, to become available at all. What is more, as I will proceed to demonstrate, the undermining of discourse (knowledge) by practice (wit) is brought to a halt by the death of the Father and thus ultimately posits the female subversive mobilization of male discourse as a utopia that is not yet available either in comedy or in 'real life.'

17 "as much love in rhyme/As would be crammed up in a sheet of paper" (5.2.6f.); "This letter is too long by half a mile" (5.2.54). 
as the women agree, "must" indeed "prove ignorance" (2.1.103) when turned from stable text into precarious practice.

Admittedly, however, the men themselves have contributed their bit to this practical turn of knowledge. At the end of Act 4, after they have found each other out as secret authors of Petrarchan sonnets, they decide to send their poems to the lady each one is in love with. A momentous communicative decision - rather than publish the poems, they turn them into letters. By doing so, I suggest, they forfeit themselves the stability of their 'academic' and patriarchal love discourse in favor of personalized, situationally concrete, and ultimately precarious communication by letter. As Jonathan Culler has shown, poems become readable because of their impersonal quality and by virtue of the fact that they construct a fictional communicative situation at a certain distance from real-world speech acts (164-66). This impersonality and lack of concreteness guarantee its stability: by being constitutionally independent, the poem can be read again and again in ever so many different contexts. In heterosexual love poems written by men (as those negotiated in Love's Labour's Lost), I suggest, this provides stability for a subject-object constellation of a loving man/speaker and the beloved woman who is either the $2^{\text {nd }}$-person object (addressee) or the $3^{\text {rd }}$-person object of the text. As I have argued above, it is this very stability that places love poetry at the very center of an epistemic discourse meant to objectify and control women: love poems objectify women over and over again, eternally perhaps, because each time they are read their communicative constellation is reactivated. Time and again, the female reader will read about - and maybe identify with - a female 'object,' whereas the male reader will eternally experience himself as a subject describing and controlling women. Letters, on the other hand (Culler 164f.), are situationally concrete: they only make full sense when they are read by the recipient addressed both on the envelope and in the letter itself. This renders letters communicatively precarious, because they need to reach their one and only addressee in order to be fully readable, ${ }^{18}$ whereas poems may be understood by anybody who 'opens' them. By sending poems as letters,

18 There are several misdirected letters in Love's Labour's Lost: Berowne's letter to his beloved Rosaline reaches another woman and Rosaline instead receives a letter addressed to that woman. 
the men themselves thus contribute to turning their stable, factual, and male-dominated knowledge about women into a procedural and precarious practice which, in Shakespeare's play, is led by women, and which depends on situational - often improvised - know-how.

When the men ultimately fail in this game which they have brought upon themselves, this is not merely another instance of the desire fulfillment deferral and anti-materialism that Breitenberg sees as constitutive of the male control-of-women discourse. There is, I believe, a rupture between the stable discourse of the celibate men and the uncontrollable communication with women (by letter, by gaze). ${ }^{19}$ In the latter, the "discursive control of women" is not just repeated by means of the "specular" (439), as Breitenberg claims, because in Love's Labour's Lost, writing poetry about a woman is a different thing entirely from writing to, and looking at, her. ${ }^{20}$ If the endless conjuration of the unattainable female in stable texts (and visual media) represents a constitutive and ultimately (knowledge-)enabling failure, defeat in the game of wit game is a real - or at least: a different - kind of failure, one that will leave the men with their knowledge literally in tatters should it turn out that the women have torn the letters. Therefore, I tend to agree rather that the "female characters seize the means of representation - the forms and phrases of courtship - and expose them as mere representations that operate without regard to the particular situation or people involved" (Breitenberg 446). ${ }^{21}$ And taking up a point that other readers of Love's Labour's Lost have made - readers who accentuate book and media history rather than the history of gender (and) knowledge - it is also worth stressing that the procedural practice of courtly love instigated and run by the women in the play recapitulates - and reverses - the prominent early modern shift from oral to written culture, especially in the realm of love

19 Therefore, I take issue with Breitenberg's characterization of "love letters and sonnets" as structurally equivalent forms of "writing" (443).

20 Visual media can, of course, create the kind of discursive control over women described by Breitenberg, "specular control" of women is thus fully possible. Such visual media, however, are not addressed in Love's Labour's Lost. The gaze is necessarily part of a social practice that represents a different kind of knowledge from texts.

21 For Breitenberg, this is only a potential position regarding Love's Labour's Lost, one he does not (fully) share and proceeds to (partly) reject (446). 
poetry (Mazzio 200; Schalkwyk), and returns it to a field of communication and skills in which women, upper-class women at least (Turner 26; 32-36), could still assume subject positions.

\section{Knowledge as Discrepant Awareness in Love's Labour's Lost}

When the female knowledge game finally takes place in the fifth act of Love's Labour's Lost, it comes in the guise of a masquerade in which the characters have dramatically different capabilities to see through the disguise(s) of the other(s) and therefore subjectivities with very different powers and stability. The masquerade is further bound up with the third form of knowledge that is explored in Love's Labour's Lost, a knowledge pertaining to the enabling conditions of the theatre itself: discrepant awareness. Discrepant awareness generally also involves the reader of a drama (or the spectator of a play) because different 'knowledges' about dramatic events and dramatic identities among the characters can only ever be perceived by a reader/spectator who knows more than or at least as much as the most 'aware' characters.

The term "discrepant awareness" was coined and the phenomenon first described by Bertrand Evans in a book on Shakespeare's comedies (viii). Meticulously describing the "stair-step structure of awareness" (20) in Love's Labour's Lost and all other comedies by Shakespeare, he is less interested in the political and epistemic functions and contexts of such hierarchizations. Likewise, Manfred Pfister, who refers prominently to discrepant awareness in his theory of drama, uses it only to establish one of the formal criteria for the perspective structure of the drama (49-68). With regard to Love's Labour's Lost, however, I believe there is much to be gained by historicizing (and also politicizing) the different forms and levels of knowledge that are being negotiated. In this play, discrepant awareness emerges not so much as a supra-temporal feature of the dramatic genre than a specific form developed by Shakespeare to involve both his plays and their recipients in the knowledge debates of his time.

Interestingly, discrepant awareness is first played out between the men and only then taken up and perfected by the women. In 4.3, the courtiers enter one after the other, each of them reciting to himself his own love 
sonnet. Complicating things somewhat, each of them notices only the reciter coming after him, (not the one who has gone before) and secretly observes his successor, so that a stair-step of awareness evolves, so to speak, in which each man exposes the man after himself and is in turn exposed by his own predecessor. Berowne is the head of this awareness roundel because he is the first to enter and therefore has no one unmasking him - and he capitalizes on his advantage once everybody else has been found out:

I am betrayed by keeping company

With men like you, men of inconstancy.

When shall you see me write a thing in rhyme?

Or groan for Joan? [...] (4.3.176-79)

He gleefully accuses the others of breaking the academy contract, but immediately afterwards is himself unmasked when his own sonnet is brought onto the stage by the people it has been mistakenly directed to. The awareness discrepancy is now resolved all round: everybody knows everybody else's love poems and knows that they know, too. Importantly, the last one to enjoy a higher degree of awareness is the reader/spectator because s/he is aware that Berowne will be compromised well before the character himself has a clue (Evans 20-22).

This scene does not yet explicitly connect discrepant awareness to contemporary episteme (or a critique thereof) but it does subtly expose the precariousness of the textual subject thrown into social practice. As each man enters the stage to read his love poem - to himself alone, as it seems he is trying to celebrate, and profit from, the stable subject-object order of the poem: through the poem, its reading (and before that, its writing) men can narcissistically experience themselves as in full control of the female object of the poem, seemingly without in any way being themselves observed or controlled from without the text. At the same time, by being the observer of the male writer/reader who succeeds him, each man doubles his sovereignty, as it were. This illusion, however, is destroyed for each of the reading men as soon as the observer who has preceded him steps forth and makes it clear that far from being a subject, he has himself been, so to speak, no more than an object of observation all along. In each case (except ours as readers or viewers) the observing "demi-god [...] in the sky" who "wretched fools' secrets o'er-eye[s]" (4.3.76f.), as Berowne puts it, finally 
finds himself exposed as a narcissistic, self-affirming author/reader of love poetry and turned from a subject into an object.

It is in this situation of general male identity breakdown that the four men decide to give up the academy (text) to regain their subjectivities ("find [them]selves," 4.3.335) by "woo[ing]" and "win[ning]" the women, i.e. by turning them into objects once more. Their ruse is to disguise themselves as "Muscovites" (5.2.121) when they meet the ladies, so as to be unobserved (or rather in this case: unidentified) subjects that observe the women once again. The men presume that their textual regime might be re-established simply by extension to include 'real' women. They do not realize how by turning poems into letters and face-to-face encounters, as analyzed above, they are leaving the stable world of the text behind and tread on the treacherous ground of procedural know-how that the women have cleverly prepared, in a communicative situation co-determined by and open to the 'real' other outside the poetic text.

To be sure, the women are aware of the disguise and, what is more, interchange identities through their own disguises, so that the men, as Evans nicely puts it, are "doubly ignorant." 22 Far from becoming objects to the men's subjects, they (again) turn the courtiers into observed observers who only think that they are aware/sovereign whereas in reality they are being observed being not sovereign (and are not sovereign because they are observed/objectified) (cf. Parker 457). What is more, by disguising each as the other, the women indeed expose the men's attempt to perpetuate "mere representations that operate without regard to the particular situation or people involved," as claimed by Breitenberg (446). In what could be seen as poststructuralist parlance avant la lettre, Berowne, again the courtiers' spokesman, ruefully admits not only that the men have failed to regain their sovereignty, but also that instead they have been shown what it means to "woo[...] but the sign of she" (5.2.469), woman as a mere textual signifier. The real women, on the other hand, having transformed the factual knowledge of the male love discourse into the procedural knowledge of a courtly

22 Evans reminds us that the men's ignorance is double because they do not know the exact identities of the women and they do not know that the woman in turn know theirs (23). 
identity game organized around discrepant awareness, have managed to turn the tables and become subjects in relation to the men. ${ }^{23}$

Wit and dramatic awareness have emerged as meta-knowledges, criticizing the contemporary (gender) episteme and subjecting it to a (possibly utopian) reality test, in which this episteme is shown to suffer from the very "ignorance" that it has set out to overcome, as Berowne finally admits in 5.2.398. Shakespeare uses the pattern of early modern satirical comedy with its play on 'witty' degradation and discrepant awareness, not to make particular forms of knowledge socially exclusive by exposing those who just pretend to know them, ${ }^{24}$ but, on the contrary, in order to attack this kind of ruling knowledge by punishing and exposing its prime representatives. At the same time, he turns the audience into prime knowers as well as knowledge analysts (and thus into 'supporters' of his epistemic critique).

\section{Knowledge's 'End': The Death of the Father and its Supersession in Female 'Wonder'}

Love's Labour's Lost, however, does not end here. In keeping with the title of the play, the women's newly won sovereignty is almost immediately questioned again and the play's critique of gendered episteme arrested. When, after the common amusement of the Nine Worthies, suddenly the death of the Princess's father is announced, not only does all courtly play stop immediately but the Princess confesses that she does not "understand" (5.2.746) this game any longer and thereby loses (or willingly forgoes) her epistemic sovereignty. At this point it becomes clear, in a way that might be compared to Jane Austen's novel Mansfield Park, ${ }^{25}$ that any game can only be played by the father's grace. The women may have disrupted the

23 After their humiliation, the men are allowed to regain some of their subjectivity and (social) grace by ridiculing the incompetent court masque of the 'Nine Worthies' that is presented to them by lower(-class) characters (5.2.520-710).

24 As is the case in other comedies of the day, such as Ben Jonson's Everyman out of his Humour (1599), where a lack of both academic knowledge and social skills is brutally exposed and exploited.

25 As opposed to the novel - where the theatre is simply disrupted by another theatre as Litvak (1-27) has pointed out -, the theatre in Love's Labour's Lost ends abruptly and self-consciously without any final resolution between the characters. 
patriarchal knowledge discourse by turning it into a concrete practice and by coming out on top of it, but they are still dependent on the 'Father' for any knowledge activity whatsoever.

The women's game is up and there will be no happy ending in marriage either. ${ }^{26}$ This fact has traditionally been read as a deferral of the play's denouement to a later play, most likely to the lost comedy Love's Labour's Won. In concluding, however, I would much rather make the case - brief and necessarily sketchy, of course - that the gender (and) knowledge constellation suspended in Love's Labour's Lost is finally unraveled in one of Shakespeare's last plays with comedic elements, namely The Winter's Tale. ${ }^{27}$ As I have shown elsewhere, in The Winter's Tale Shakespeare has the female characters create their own independent and separate "female cultural sphere" (Merten, "Broadside" 56; translation mine) after Queen Hermione has been cast out by her jealous husband. In this sphere, Hermione, who is believed dead, is famously resurrected as her statue seemingly becomes alive at the end of the play. In the context of gendered knowledge, this denouement may be read as a woman becoming a subject by superseding from within the sphere of her own knowledge the patriarchal discourse both of marital violence ${ }^{28}$ and of the female effigy. Thus, The Winter's Tale symbolically overcomes the 'ending of knowledge' in the death of the Father in Love's Labour's Lost by resurrecting a woman who is, similarly to the women in the earlier play, representative of a female counter-episteme. What is more, the statue coming alive re-opens (female) knowledge to "wonder," 29 an epistemic object/stance rigorously rejected in contemporary masculine knowledge projects, such as Francis Bacon's Novum Organum mentioned above. In Love's Labour's Lost, as I have shown, wonder is only briefly glimpsed as a possible alternative to the masculine knowledge fixation of the

26 "Our wooing doth not end like an old play: / Jack hath not Jill" (5.2.862f.). Turner maintains that the "play paradoxically disowns itself, problematizes its own play by frustrating the hopes of a happy ending which it fed" (46).

27 According to the (posthumous) Shakespeare canon, The Winter's Tale is, of course, a romance, not a comedy.

28 To be sure, violence is quintessential discourse-and/as-practice, so that Hermione could be seen as overcoming a re-joining of the two in patriarchal discourse with which Love's Labour's Lost had so sadly ended.

29 In The Winter's Tale 5.3.22, the reaction to the statue is described as "wonder". 
academy, but not explored further nor implemented in the female knowledge and awareness games. In The Winter's Tale, however, by including his audience in the experience of wonder because, quite uniquely in his oeuvre, he does not grant them an awareness superior to that of the characters during the statue's unveiling (cf. Bishop 125-75), Shakespeare seems to suggest that after male knowledge-control of women has been superseded, wonder can (again) become the highest form of knowledge. In Love's Labour's Lost, Shakespeare subjects patriarchal knowledge first to a female mobilization and concretization, thus granting women subjectivity in relation to men, while ultimately patriarchy prevails ex negativo by stopping all knowledge activity after the death of the Father. Only at the far end of his comedic cosmos, in The Winter's Tale, is the objectifying, 'deadening' quality of male patriarchal knowledge finally overcome when an inclusive miracle between both sexes, and one that embraces the audience as well, is made possible perhaps the highest form of knowledge that the theatre can attain.

\section{Works Cited}

Beyer, Manfred. Das Staunen in Shakespeares Dramen: Ursachen, Darstellungsweisen und Wirkungsintentionen. Köln: Böhlau, 1987.

Bhabha, Homi B. "DissemiNation: Time, Narrative and the Margins of the Modern Nation." The Location of Culture. London: Routledge, 2004. 199-244.

Bishop, Tom. Shakespeare and the Theatre of Wonder. New York: Cambridge University Press, 1996.

Breitenberg, Mark. "The Anatomy of Masculine Desire in Love's Labour's Lost." Shakespeare Quarterly 43.4 (1992): 430-49.

Culler, Jonathan. Structuralist Poetics: Structuralism, Linguistics and the Study of Literature. New York: Cambridge University Press, 1975.

Daston, Lorraine. "Marvelous Facts and Miraculous Evidence in Early Modern Europe.” Critical Inquiry 18.1 (1991): 93-124.

Eggert, Katherine. Disknowledge: Literature, Alchemy, and the End of Humanism in Renaissance England. Pennsylvania: University of Pennsylvania Press, 2015.

Erickson, Peter B. “The Failure of Relationships Between Men and Women in Love's Labour's Lost.” Women's Studies 9 (1981): 65-81. 
Evans, Bertram. Shakespeare's Comedies. Oxford: Claredon, 1960.

Honegger, Claudia. Die Ordnung der Geschlechter: Die Wissenschaft vom Menschen und das Weib. Frankfurt a.M.: Suhrkamp, 1991.

Krippendorff, Ekkehart. Shakespeares Komödien: Spiele aus dem Reich der Freiheit. Berlin: Kulturverlag Kadmos, 2007.

Litvak, Joseph. Caught in the Act: Theatricality in the Nineteenth-Century Novel. Berkeley: University of California Press, 1992.

Maclean, Ian. The Renaissance Notion of Women: A Study in the Fortunes of Scholasticism and Medical Science in European Intellectual Life. Cambridge: Cambridge University Press, 1980.

Mazzio, Carla. “The Melancholy of Print: Love's Labour's Lost.” Historicism, Psychoanalysis and Early Modern Culture. Ed. Douglas Trevor. New York: Routledge, 2000. 186-227.

Meier-Öser, Stephan. "Unwissenheit." Historisches Wörterbuch der Philosophie. Vol. 11. Ed. Joachim Ritter, Karlfried Gründer, and Gottfried Gabriel. Basel: Schwabe, 2001. 341-48.

Merchant, Caroline. The Death of Nature: Women, Ecology, and the Scientific Revolution. New York: Harper Collins, 1980.

Merten, Kai. “Broadside Ballads und Old Wives' Tales: Zur Intermedialität des Erzählens in Shakespeares The Winter's Tale." Shakespeare-Jahrbuch 142 (2006): 47-59.

-. Intermediales Text-Theater: Die Bühne des Politischen und des Wissens vom Menschen bei Wordsworth und Scott. Berlin: Walter de Gruyter, 2014.

Moran, Bruce T. "Courts and Academies." Early Modern Science. Vol. 3 of The Cambridge History of Science. Ed. Katherine Park and Lorraine Daston. New York: Cambridge University Press, 2006. 251-71.

Outram, Dorina. "Gender." Early Modern Science. Vol. 3 of The Cambridge History of Science. Ed. Katherine Park and Lorraine Daston. New York: Cambridge University Press, 2006. 797-817.

Parker, Patricia. "Preposterous Reversals: Love Labour's Lost.” Modern Language Quarterly 54.4 (1993): 435-82.

Pfister, Manfred. The Theory and Analysis of Drama. New York: Cambridge University Press, 1988. 
Ryle, Gilbert. The Concept of Mind. Chicago: University of Chicago Press, 1949.

Schalkwyk, David. "She Never Told Her Love: Embodiment, Textuality, and Silence in Shakespeare's Sonnets and Plays." Shakespeare Quarterly 45.4 (1994): 381-407.

Shakespeare, William. Love's Labour's Lost. Ed. H.R. Woudhuysen. London: Arden Shakespeare, 1998.

-. Winter's Tale. Ed. R. Proudfood, A. Thompson, D.S. Kasten, and H.R. Woudhuysen. London: Arden Shakespeare, 2010.

Sloterdijk, Peter. Das Schelling Projekt. Berlin: Suhrkamp, 2016.

Yates, Francis. The French Academies of the Sixteenth Century. London: Warburg Institute, 1947.

-. A Study of Love's Labour's Lost. Cambridge: Cambridge University Press, 1936.

Zucker, Adam. The Places of Wit in Early Modern English Comedy. New York: Cambridge University Press, 2011. 


\title{
Richard Nate \\ “The pleasing visions I had formed": Natural Knowledge and Self-Awareness in Jonathan Swift's Satires
}

\begin{abstract}
Focusing on the relation between not yet entirely secularized scientific inquiry and the human inquirer, between scientific knowledge and self-knowledge, this essay reads Jonathan Swift's satire A Tale of a Tub (1704) and his novel Gulliver's Travels (1726) to explain how Swift's textual experiments chastise those scientific voices that do not only seek to improve the human lot, but do so with what seemed to Swift undue self-confidence and pride. To study the outside world without taking into account human fallibility was - for a writer steeped in the humanist tradition and an adherent of the belief that literature had a moral agenda - an indication that human pride was once again triumphant. For Swift and his friend Pope, critical self-inspection was regarded far more essential in developing a true personality than any attempt at discovering God's secrets through a scientific investigation of nature. Swift's satirical portrayals of modern victims of their own curiosity bespeak this philosophical diagnosis.
\end{abstract}

The preface to Jonathan Swift's The Battle of the Books (1704) begins with a rather unconventional definition of a literary genre. Readers are informed that "Satyr is a sort of Glass, wherein Beholders do generally discover every body's Face but their Own" (Tale 140). The writer does not hesitate to add that it is probably this characteristic which is responsible for the genre's continuing success. If this definition is taken seriously, satire could appear like a welcome tool for hypocrites who always like to put the blame on somebody else. Since it does not occur to recipients that their behavior is targeted in any way, nobody will ever feel offended. In other words, satire is an instrument which stabilizes prejudices rather than inviting readers to think about their own limitations.

It may be asked, of course, why Swift decided to put such a definition before a text which is obviously satirical. For one thing, it is clear that the problem of finding faults in others while paying a blind eye to one's own failures is by no means restricted to the reception of satires. Given 
that Swift was a clergyman, we may safely assume, for instance, that he was familiar with the Sermon on the Mount, which includes the query: "[W]hy beholdest thou the mote that is in thy brother's eye, but considerest not the beam that is in thine own eye?" (St. Matthew 7,3). For Swift, such an attitude obviously represented an anthropological constant to be reckoned with at any time. In this light, it seems feasible to read the remark in the preface not so much as a definition of the function of satire but rather as a provocative statement pointing to a general human deficiency Swift regarded as widespread. Even at an early stage of his writing career, it seems to indicate the program that Swift would express much later, namely "to vex the world rather then divert it" (Correspondence 606).

The observation that humans are seldom willing to admit their own limitations must be viewed against the background of Christian anthropology, of which Swift had an intimate knowledge. According to an orthodox reading of the third chapter of Genesis, human imperfections were the result of "man's first disobedience" as John Milton put it in Paradise Lost (114). Through this act Adam not just forfeited the perfection which God had granted to him, but his 'original sin' affected humanity as a whole. In a postlapsarian universe, human beings might strive to make the best of their state, notably by adhering to Christian virtues, but without the help of God's grace, they would never be able to free themselves from the consequences of the Fall. Not accepting this fundamental insight counted as a sign of superbia or pride, considered as the worst of all imaginable sins.

In $17^{\text {th }}$-century England, however, such a traditional reading of the book of Genesis had already begun to compete with other interpretations which enjoyed considerable popularity especially among the promoters of the new experimental philosophy. ${ }^{1}$ When in 1620, Francis Bacon proclaimed a "Great Instauration" of all arts and sciences, he was not only thinking of overcoming the limits of classical knowledge, but he also had in mind a particular interpretation of providential history, in which scientific progress was linked up with the promise of restoring humanity to its primordial perfect state. Among many $17^{\text {th }}$-century scientists, this view would soon assume the nature of a commonplace. Thus, it is no surprise that Swift

1 For an overview see Harrison. 
would repeatedly portray the advocates of science as victims of their own impious ambitions.

Although Swift dealt with the topic of pride not only in his satires, ${ }^{2}$ it was here that he most drastically exposed it as the result of a lack of selfawareness which was typically modern. In Gulliver's Travels (1726), the protagonist and first-person narrator stumbles through the world driven by his insatiable curiosity and incapable of drawing the right conclusions from what he observes. Since he makes no secret of his fascination for everything modern, he can be seen as representing the contemporary 'scientific sailor.' What distinguishes him from peers such as William Dampier, however, is the fact that his journey of exploration turns out to be highly ambivalent. The more Gulliver learns about the exotic inhabitants of the "remote nations" he visits, the more he finds himself confronted with the question of who he really is. Even if it eventually turns out that he will probably never discover his true self, it is obvious that the problematic relationship between scientific knowledge and self-knowledge forms a central theme of the novel. Before taking a closer look at Gulliver's ill-fated journey, however, it seems worthwhile to reconsider those elements in $17^{\text {th }}$-century philosophy which Swift found most disturbing. That the accusation of a lack of self-awareness among some defenders of the modern cause forms a recurrent theme in Swift's writings can further be demonstrated with respect to his earlier satire, A Tale of a Tub (1704).

\section{Curiosity and the Carcass of Human Nature}

As already indicated, science in the $17^{\text {th }}$ century was not yet defined in purely secular terms. In their attempts to defend the new experimental philosophy against possible accusations of heresy, authors regularly referred to biblical passages which they interpreted according to their own purposes. Thus, in his Instauratio Magna (1620), Bacon offered a very specific reading of the third chapter of Genesis when he stated that "it was not that pure and uncorrupted natural knowledge [...] which gave occasion to the fall. It was the ambitious and proud desire of moral knowledge to judge of good and

2 On the human pride as a central issue in Swift's pulpit rhetoric, see Bullard.

3 On the scientific sailor, see Adams (162 ff.). 
evil" (IV.20). A desire for natural knowledge, Bacon held, could never be transgressive. On the contrary, God had presented the world to Adam as a riddle and had invited him to partake in an innocent and pleasant game of "hide and seek." This was also the reason why natural knowledge could still provide a path to the restoration of human perfection. Convinced that his concept of applied science contributed to the "benefit of mankind," Bacon felt free to equate it with charity as the highest Christian virtue. "[I]t was from lust of power that the angels fell, from lust of knowledge that man fell," he wrote with respect to the sins of Lucifer and Adam, and finished his sentence with the statement that "of charity there can be no excess" (IV.21). In other words, science was ascribed the role of an alternative form of religious practice.

It fits into this context that curiosity, which traditionally had been regarded rather as a sign of man's sinful lust for worldly pleasures, also assumed a positive meaning (Blumenberg $401 \mathrm{ff}$.). ${ }^{4}$ Not only had curiosity inspired the celebrated voyages of discovery, it also formed a necessary requirement for scientific research. It is not by accident that Bacon pointed to the exploration of new worlds when he argued that a new age of knowledge was awaiting humanity. An isolated verse taken from the Book of Daniel - "Many shall go to and fro, and knowledge shall be increased" (IV.92) - provided enough evidence for him that the current changes in geography and science corresponded to a divine plan.

A problem to which Swift would repeatedly point in his satires, however, was that curiosity knew no boundaries. It could relate to the discovery of new territories as well as to those phenomena which traditionally had been considered too mean to create any serious interest. In the preface to his $\mathrm{Mi}$ crographia (1665), Robert Hooke claimed that all these directions were of equal value. While other scientists did "neglect no opportunity to bring all the rare things of Remote Countries within the compaß of their knowledge and practice," he maintained, his own microscopic studies of insects and lifeless objects could open up "a new visible World" of its own ("Preface"). Convinced of the spectacular nature of his findings, Hooke even went so far as to promise his readers "material and sensible pleasure", including a

4 On the changing role of curiosity, see also Benedict. 
"high rapture and delight of the mind" ("Preface"). ${ }^{5}$ How provocative such a statement must have appeared in the eyes of some of his contemporaries, who still adhered to a traditional view of decorum, becomes obvious, if one considers the range of Hooke's objects of investigation. Next to more pleasant things such as snowflakes, his curiosity extended not only to fleas and lice, traditionally regarded as disgusting 'vermin,' but also to the invisible texture of human excreta. ${ }^{6}$ In his Leviathan (1651), Thomas Hobbes had only shortly before stressed the fact that decorum was a context-dependent phenomenon. "An anatomist, or a physician," he had explained in a chapter on intellectual faculties, "may speak, or write his judgment of unclean things; because it is not to please, but profit" (III.59). However, Hobbes had also pointed to the fact that this license had clearly defined limits. On occasions where usefulness was not at stake, the anatomist's or physician's statements might prove utterly inacceptable, making the audience feel "as if a man, from being tumbled in the dirt, should come and present himself before good company" (III.59).

Contemporary satirists knew how to draw profit from tacitly ignoring Hobbes' pragmatically defined distinctions. In their portrayals, the scientific virtuoso appeared as a kind of lunatic (cf. Lynall 31). What played into their hands was the fact that $17^{\text {th }}$-century scientists often did not rest content with soberly reporting their observations but also pointed to the alleged edifying quality of their presentations. If the world was God's creation, the physico-theological argument ran, even 'base' things could serve as suitable instruments of worship and readers would morally profit from this. In a panegyrical poem prefixed to Thomas Sprat's History of the Royal Society (1667), Abraham Cowley went so far as to present Bacon as another Moses who had directed his followers to the promised land of science. Significantly, he praised the microscopists of his age for extending their "curious Sight" into "the privatest recess" of the world's "imperceptible Littleness" (qtd. in Sprat 5).

Swift was to become one of the satirists who tried to turn such arguments against their promoters. What disturbed him was not so much scientific

5 On the spectacular quality of early modern experimental science, see Schramm.

6 Cf. for instance Hooke's chapters on "Gravel in Urine" ( $81 \mathrm{f}$.) and on "Figures Form'd on the Surface of Urine by Freezing” ( $88 \mathrm{ff}$.). 
curiosity as such, but the way in which it was advertised as a way to the salvation of humanity. Indeed, following Bacon, Hooke had declared: "at first, mankind fell by tasting of the forbidden Tree of Knowledge, so we, their Posterity, may be in part restor'd by [...] tasting too those fruits of Natural knowledge, that were never yet forbidden" ("Preface"). Since Swift did not believe that humanity would ever be able to achieve its own salvation, he also rejected the claim implicit in such rhetoric, namely that moral problems would also disappear once scientific and technological progress had reached a certain level.

As a writer steeped in the humanist tradition, Swift shared the belief that literature had a moral agenda. It is to be remembered that in the late $16^{\text {th }}$ century, Philip Sidney had explained that poetical works were composed not only to delight but also to teach. A poet's aim was to "move" an audience to "take [...] goodness in hand" (103), i.e. to act virtuously. Swift would not have objected to such a view, even if it appears that he had less confidence in human educability than his $16^{\text {th }}$-century predecessor. Still, Samuel Holt Monk was probably not far from the point when he stressed Swift's moralism, observing that while "[a]ll of Swift's satire was written in anger, contempt, or disgust," it was at the same time "written to promote self-knowledge in the faith that self-knowledge will lead to right action" (112).

In order to locate Swift's view of poetry within an early modern context, it is helpful to remember that in the second half of the $17^{\text {th }}$ century it had become customary to distinguish between different spheres of knowledge each of which was ascribed its own value and its own logic (cf. Shapiro). In contrast to notable changes in the sphere of natural knowledge, poetic rules were thought to be principally timeless. ${ }^{7}$ When in An Essay on Criticism (1711), Swift's friend Alexander Pope gave poets the advice to "[f]irst follow Nature, and your judgment frame/By her just standard (20, emphasis in the original)," he did not think of any scientific discoveries but of poetic principles that had been established by ancient writers long before. As a true classicist, he did not forget to add: "To copy nature is to copy them" (22). Given that poetic mimesis worked on the premise of tua res agitur, it was

7 For a more thorough discussion, see Nate (Wissenschaft und Literatur 198 f.). 
considered also as an instrument suitable to generate self-knowledge. Pope later expanded his classicist convictions to comprise also the ancient philosophical principle of nosce teipsum. In his Essay on Man (1732), he succinctly stated: "Know then thyself, presume not God to scan; / The proper study of mankind is man" (281). In other words, critical self-inspection was regarded far more essential in developing a true personality than any attempt at discovering God's secrets through a scientific investigation of nature.

Although Swift would not have objected to these principles, his poetical works do not necessarily reflect them at surface level. The fact that critics have warned repeatedly not to mistake the opinions of his satirical personae for the author's views, shows that Swift preferred indirect methods to articulate his anthropological convictions. ${ }^{8}$ His narrators are known to be notoriously unreliable. Rather than acting as the author's mouthpieces, they illustrate the follies of modern civilization. Functioning as tools of literary parody, they often fall prey to exactly those vices Swift criticized: an unreserved curiosity and selfishness.

The narrator of $A$ Tale of a Tub provides a perfect example of this strategy. Although he constantly presents himself as an enlightened philosopher, writing with no smaller ambition than a "Universal Improvement of Mankind," it turns out that he is nothing but a hack writer, incapable of digesting all the information that the early modern book market holds in store for him. What he offers his readers is bits of knowledge hastily assembled from a range of mostly dubious sources he is unable to classify and assess critically. Thus, his claim to explain "human nature" suffers from a confusion between the physiological and the psychological spheres. In the taleteller's universe, where a Cartesian distinction between res extensa and res cogitans matters as little as that between literal and figurative meanings, body and soul are merged into just one lifeless study object. "I have [...] dissected the Carcass of Human Nature, till at last it smelt so strong, I could

8 This point has been made quite early, cf. Williams (116 f.).

9 In this respect, the taleteller could also be characterized as a caricature of the hermetic philosopher, cf. Nate (Wissenschaft und Literatur 282 f.). 
preserve it no longer" $(77),{ }^{10}$ the taleteller reports, in an obvious attempt to imitate the style of contemporary experimental scientists.

That the taleteller is a victim of his curiosity is indicated by his professed determination to "comply with the Modes of the World" (54). Indeed, it seems that he loses himself completely in the attempt of absorbing every intellectual fashion he meets on his way. His lack of identity perfectly illustrates what Barbara Benedict has written with respect to the early modern critique of the cult of curiosity. While those suffering from it superficially appeared "to be seeking their own identity," she writes, they were in fact busy "annihilat[ing] any concrete self" (110). The more knowledge they acquired, the more their personality dissolved. "Their self," Benedict goes on paraphrasing early modern critics, "becomes a vacuum whose sucking implosiveness is intensified by the novelties poured into it" (110). In A Tale of a Tub, this lack of self is linked to a longing for recognition which appears principally insatiable. As the taleteller's dedicatory epistle to "Prince Posterity" and other sections of the work reveal, his true ambition is not to inform readers about the ways of the world but to gain "an everlasting Remembrance, and never-dying Fame" (77). On another occasion, he openly confesses his desire to overcome "the transitory State of all sublunary Things" (40).

Only when they are ready to accept the nonsensical quality of the taleteller's deliberations will readers be able to avoid getting distracted by the confused organization of the text - an obvious consequence of the taleteller's inability to stick to his subject - and detect the rather conventional moral message hidden underneath. Most of the contradictions the taleteller runs into are intended to demonstrate that he suffers from an "over-weening pride" - to use an expression with which the learned Bee in The Battle of the Books accuses its opponent, the self-centered Spider who is reported to produce nothing but "Excrement and Venom" (150). It is no wonder that in the final analysis, all the taleteller's pretensions are revealed as empty and void. "I am now trying an Experiment very frequent among Modern Authors," he declares towards the end of his text, "which is, to write upon Nothing. When the Subject is utterly exhausted, to let the Pen still move on"

10 Cf. Lynall (41 f.) for an explanation of how Swift made use of Robert Boyle's Occasional Reflections in this passage. 
(133, emphasis in the original). In other words, the taleteller reduces the creative process of writing to a dead mechanism in much the same way he has declared the soul to be a mere carcass. Apart from arousing associations of an Epicurean philosophy, which contemporaries would have regarded as genuinely un-Christian, ${ }^{11}$ lines like these were obviously meant to irritate, if not to shock, readers who still expected from literature a moral edification of some kind. "If the Reader fairly considers the Strength of what I have advanced in the foregoing Section," the taleteller proclaims referring to the preceding "Digression Concerning Madness," "I am convinced it will produce a wonderful Revolution in his Notions and Opinions" (117). Given Swift's theological background, it does not seem far-fetched to assume that the taleteller's "wonderful Revolution" implies more than just mental disorder. It is an indication that his intellectual cosmos is a topsy-turvy world also in a religious sense. Seen from the author's perspective, it is a world against the will of God.

\section{Gulliver's Distorted Exploration of the Self}

"I have got Materials Towards a Treatis, proving the falsity of that Definition animal rationale, and to show that it should be only rationis capax," Swift wrote to Alexander Pope in the autumn of 1725, referring to the manuscript of Gulliver's Travels (Correspondence 607). It seems that what disturbed the author was not so much a traditional concept, however, but the problematic conclusions which had lately been drawn from it. To take the definition as a proof that human behavior was rational at any time appeared to be just another indication of the sin of pride. ${ }^{12}$

Like in the Tale, Swift chose a defender of the modern cause as his narrator. When Gulliver declares that his "sole design" is to contribute "to the benefit of public as well as private life" (133), he is merely repeating a stock phrase of the new science. As a true modern, Gulliver is driven by his curiosity. "I stayed but two months with my wife and family, for my insatiable desire of seeing foreign countries would suffer me to continue no

11 Cf. Real ("A Taste” 89) for a thorough discussion of this background.

12 Correspondingly, Panagopoulos observes that "Gulliver's Travels follows traditional ethics in regarding pride as the gravest of sins," since it encourages "the moral error that comes with self-mistaking" (63). 
longer" (117), he confesses after his return from Lilliput, and although his second journey proves to be even more life-threatening than the first one, he reports that afterwards his desire remained "as violent as ever" (195).

Rather than furnishing him with some undisputable facts, Gulliver's first two journeys are more likely to confuse him. Thus, he is forced to accept that nothing seems to be fixed anymore. The whole world, including himself, is becoming dubious. Living for a time as a giant, he finds himself reduced to the size of a dwarf only a bit later. Significantly, pride plays a role in both contexts, and as it turns out it is always the less important creatures who succumb to it, thus illustrating an idea expressed in The Battle of the Books, where pride had already been associated with "Beggary and Want” (Tale 141). In Lilliput, the blame falls on Gulliver's dwarfish hosts. By keeping the reader constantly aware of their small size, Swift manages to make the Lilliputans' high self-esteem seem utterly ridiculous, despite Gulliver's uncritical rendering of the seemingly indisputable "facts." Nowhere does this become more obvious than in the king's official title, which Gulliver renders as "Delight and Terror of the Universe [...], Monarch of all Monarchs, taller than the sons of men; whose feet press down to the centre, and whose head strikes against the sun" (79).

In the land of the giants, it is Gulliver himself who becomes the object of ridicule. The King of Brobdingnag sees in him, above all, a perfect warning against vanity, being reminded of "how contemptible a thing was human grandeur, which could be mimicked by such diminutive insects" as Gulliver (146). Most devastating is the conclusion, which the king draws from Gulliver's account of the current state of his home country. From the giant's perspective, Europeans represent but "the most pernicious race of little odious vermin that Nature ever suffered to crawl upon the surface of the earth" (173).

With respect to Gulliver's scientific leanings, the country of Brobdingnag also holds some sobering lessons in store. Put into the position of a dwarf, the protagonist suddenly finds himself endowed with a microscopic vision. ${ }^{13}$ Other than Robert Hooke and Abraham Cowley had suggested, however, it is only nature's ugliness which is revealed to him. In contrast

13 Cf. Smith for a detailed analysis. 
to the scientist's microscopic specimen, the lice which Gulliver observes are a part of everyday life. Together with their monstrous size, this clearly exempts them from the license that Thomas Hobbes had granted to "unclean things." "What is more, the inhabitants of Brobdingnag appear ugly under Gulliver's microscopic gaze, too. The Queen chewing a slice of bread, for instance, makes a "very nauseous sight" (145). This is the more remarkable since in many respects the giants appear as a people of noble character, well versed in terms of "morality, history, poetry, and mathematics" - a fact that only the naïve Gulliver can characterize as "defective" (176). For all its spectacular qualities, Swift seems to suggest here, a purely scientific gaze may be of little help in determining a person's character.

Book III marks the beginning of Gulliver's disillusionment. The Laputans, a bunch of speculative scientists inhabiting an artificial island, have "one of their eyes turned inward, and the other directly up to the zenith" (200). It would be misleading to take this grotesque description as an indication of their readiness for critical self-inspection and piety, since it soon turns out that the Laputans are a people lacking any sociability or compassion. Significantly, in The Battle of the Books, Swift had furnished the monstrous-like Goddess "Criticism" with similar features, namely eyes "turned inward, as if she lookt only upon herself" (Tale 154). What such a description points to is not a willingness for impartial introspection but a selfish attitude from which a lack of sociability springs almost naturally.

The practical scientists whom Gulliver meets at his next stop, the experimental Academy of Lagado, are hardly any better. The cures they suggest do not heal patients but kill them. A "universal language" they have contrived turns out to be an attempt at abolishing language altogether $(226,230)$. The most drastic example is probably a scientist who is busy with "an operation to reduce human excrement to its original food" (224). In Gulliver's description of the scene, there is nothing which could remind readers of Cowley's enthusiasm for the beauties of creation detected in "the privatest recess" (Cowley qtd. in Sprat 5). The scientist's chamber, we are told, is marked by a "horrible stink" (224).

14 For a more detailed account cf. Nate (Wissenschaft, Rhetorik $112 \mathrm{ff}$.$) .$ 
The fact that Gulliver's depiction of Lagado shows traditional strategies of inversion ${ }^{15}$ should not be taken as evidence that it constitutes a mundus inversus only in aesthetic terms. It seems that the two islands of Laputa and Lagardo represent religious counter-worlds as well. ${ }^{16}$ Not only is the claim of early modern scientists, according to which an intimate knowledge of nature would almost automatically result in a higher morality, radically questioned, ${ }^{17}$ but it is exposed also as an irreligious attitude. This becomes particularly obvious in a scene which depicts Gulliver's ultimate disillusionment after his encounter with the immortal Struldbruggs. These people, he learns, are creatures granted with eternal life. Governed by his vanity, Gulliver spontaneously imagines himself a Struldbrugg and becomes haunted by delusions of grandeur. It is significant that his first desire is to acquire riches while a study of arts and sciences follows only in a second step. And even such a study, Gulliver admits, would be pursued mainly to feed a selfish desire, namely that of becoming "the oracle of the nation" (254). The protagonist is cured from his ambitions only after he has learned that the Struldbruggs are in fact most pitiful creatures, suffering from physiological and intellectual decay beginning at the age of thirty. At this disclosure, he is forced to confess: "I grew heartily ashamed of the pleasing visions I had formed" (259).

The Struldbrugg episode is significant in that it carries to a logical extreme projects of a 'prolongation of life' that had actually been pursued by the Royal Society (cf. Webster 246 ff.). That Swift regarded any wish of overcoming death as a serious delusion is indicated by a remark in “Thoughts on Religion", where he expressed his disbelief that "any thing so natural, so necessary, and so universal as death, should ever have been designed by providence as an evil to mankind" (Irish 263).

It is in the land of the Houyhnhnms, a horse-like species endowed with the faculty of reason, that Gulliver receives his final blow. The Houyhnhnms, who refer to themselves as the "perfection of nature", are sharply

15 For historical references in Gulliver's descriptions of the Lagado experiments, see Nicolson and Mohler.

16 Cf. Todd for a similar view.

17 As Jones (76) explains, humanists had long regarded this claim as a threat to Christian tenets. 
distinguished from another species, the beastlike Yahoos. Although Gulliver spontaneously classifies the Yahoos as brutes, he has to admit that they dispose of "a perfect human figure" (276). The horses, who soon become his role model, maintain that they live in perfect accordance with the principle of reason. Significantly, it is this characteristic which also seems to free them of any need for critical self-inspection. Since fallibility is an experience completely alien to the Houyhnhnms, moral discussions are reported not to play any role in their social life. Obviously, the seemingly perfect society of the horses does not provide any clue for solving the problem of human nature. On the contrary, Gulliver's contact with them results in self-alienation rather than self-inspection. ${ }^{18}$ " $[\mathrm{M}] \mathrm{y}$ master," he reports, "daily convinced me of a thousand faults in myself, whereof I had not the least perception before" (305).

Neither does the species of Yahoos provide any clue. Becoming more and more aware of how much he resembles these creatures, Gulliver's selfalienation only increases. When, in a grotesque inversion of the Narcissus myth, he sees his reflection in a lake, he can only turn away "in horror and detestation of myself" (327). Blinded by the false ideal of animal rationale, Gulliver cannot help but perceive himself as an ugly beast.

Although there have been attempts to view the Houyhnhnms as representing an ideal society, ${ }^{19}$ they betray some highly problematic characteristics. Among these are an unwillingness to tolerate whatever contradicts their convictions, as well as a lack of self-awareness. The former trait is demonstrated by their attitude towards Gulliver, whom they continue to classify as a Yahoo, although they must admit that he is endowed with at least "some small pittance of Reason" (306). Since Gulliver must appear to them not only as a "monstrous hybrid" (Benedict 111) but also as a walking contradiction, their decision is to ostracize him from their community.

The horses' lack of self-awareness becomes obvious in some of the euphemisms with which they denote their behavior. Since they are worshippers of pure reason, Gulliver reports, any form of dialectics or rhetoric must appear

18 For a similar interpretation, see Weiß (219). In an early essay, Taylor has aptly characterized Gulliver's "growing self-delusion" as "the continuous current which runs throughout the whole book" (14).

19 For a summary of these early positions, see Clifford. 
alien to them. "[I]t was with extreme difficulty that I could bring my master to understand the meaning of the word opinion, or how a point could be disputable" (315), he explains. In clear contradiction to this observation, however, they annually engage in an "old debate" (318). The issue which is at stake here appears anything but accidental. The horses discuss nothing less than the question " $[\mathrm{w}]$ hether the Yahoos should be exterminated from the face of the earth" (318-19). Since it is difficult to imagine a 'debate' without any 'disputable points,' it may be concluded that the horses are not always aware of what they are doing or, to put it with A. D. Nuttall: "The truth is that the Houyhnhnms are just not very clever" (278).

There are other examples which reveal a lack of self-awareness among these seemingly ideal creatures. When it turns out that Gulliver's master Houyhnhnm has developed a certain degree of respect for his protégé, the horses see their rational principles in jeopardy. In defending their collective self-image, they even prove to be quite inventive, regardless of how absurd their arguments may appear to an outsider. It is related, for instance, that they are convinced a rational creature cannot be "compelled" to anything, since objecting to a rational decision would contradict the principle of logic (328). Thus, they confine themselves to a friendly "exhortation," when it comes to convincing Gulliver's master to dispense with his Yahoo pet (328). Such a euphemism has no other function than that of covering up an authoritarian policy. At least from a $21^{\text {st }}$-century perspective, it is hard to imagine that the horses are anything else but either completely unenlightened or viciously practicing some kind of Orwellian newspeak.

If Swift's novel depicts a journey into the self rather than to the "remote countries" announced on the original title page, it is also true that his protagonist fails to reach his destination. The complaint he makes at the beginning of book IV - namely that he would have stayed with his wife and children, if he could only "have learned the lesson of knowing when I was well” (267) - does eventually not help him. Deluded by his false role model, Gulliver is not able to cope with his condition of animal rationis capax and ends up in a state which can only be characterized as pathological. In the end, he discloses that he prefers the company of his horses to that of his wife and children whose smell he cannot stand. "My horses understand me tolerably well," he reports, "I converse with them at least four hours every day" (339). Not without a sense of pride does he mention the fact that since 
his visit to the Houyhnhnms he has even acquired a habit of "trot[ting] like a horse" (327). At the end of the novel, readers are confronted with the sobering fact that all the while they have been following the arguments of a narrator who regards them as "stinking Yahoos" anyway. It should be remembered that in a letter to "His Cousin Sympson," which is prefixed to the narrative, Gulliver had already declared: "I should never have attempted so absurd a project as that of reforming the Yahoo race in this kingdom" (41). This remark leaves readers in the dark for quite a while; only towards the end of book IV they are able to grasp its full meaning. While Gulliver is never cured from the ills that his belief in humanity's unlimited capacities has procured, it is now up to the reader to draw an appropriate conclusion from his account. ${ }^{20}$

\section{Conclusion}

Judged against the intellectual debates of his time, Swift's outlook must be characterized as conservative. For all the artistry which his satirical works display the cultural criticism lurking behind the textual façade appears quite traditional. Essentially, it represents a warning against human vanity of the kind that biblical texts had expressed early on. Thus, it is not coincidental that the message which Gulliver receives from the deceased Aristotle in book III - namely that "new systems of nature [are] but new fashions, which [...] vary in every age" (273) - bears a strong likeness to the Preacher's insight that "there is no new thing under the sun" (Ecclesiastes 1, 9-14).

Although the scientific movement had set out to contradict such assumptions, it would be misleading to regard Swift as a radical opponent of science. First, one has to distinguish between the respect that the author still paid to philosophers such as Francis Bacon, and the utterly negative opinion he had of some of Bacon's disciples. ${ }^{21}$ His sharpest criticism he kept for those followers of fashion who would merely adapt the catchphrases of modern science for their own selfish purposes. The well-read, albeit incompetent taleteller and the ever curious but hopelessly naïve Gulliver are fictional counterparts of this type.

20 For a similar view, see Monk (118).

21 This is discussed more thoroughly in Real ("The Dean"). 
Second, what Swift disliked about contemporary scientists, was not so much their intention to improve the human lot, but the self-confidence with which this aim was sometimes proclaimed. In Swift's view, scientific optimism became problematic once it ignored the ambivalence of human nature - or, as Pope would later put it, the fact that "Man [was] created half to rise, and half to fall" (281). To study the outside world without taking into account human fallibility was, in Swift's view, an indication that human pride was once again triumphant.

If Swift was convinced that taking to heart the principle of nosce teipsum was worthier than any desire to 'scan God' (cf. Pope 281), he adhered to a comparatively traditional understanding of what constituted relevant knowledge. On the other hand, the observation that, aesthetically speaking, his satires display so few traditional characteristics is not without some irony. When it came to exposing the shortcomings of the modern age, poetic traditionalism was not what was needed. Mockery suggested itself as a far more effective tool. It is probably for this reason that Swift's satires still appear so astonishingly modern. The experimental spirit which governs them, however, is not scientific but textual. This is most obvious in A Tale of a $T u b$ where principles of coherence are violated throughout and any reader who is not willing to read between the lines must end up entirely frustrated. ${ }^{22}$ It is true that in comparison to the irritating structure of his earlier satire, Gulliver's Travels appears much more straightforward but it betrays an experimental spirit no less. Gulliver is, after all, an embodiment of the modern mind. As he proudly admits, his presentation is not meant to be of any poetic value, but is intended to meet the standards of modern scientific discourse. Paradoxically, the continuing success of Swift's novel may be due to this particular fact. After all, readers are constantly invited to share and enjoy Gulliver's curiosity, ${ }^{23}$ thus indulging in the very sensationalism that Swift would overtly criticize. If it was really the author's aim "to vex the world rather then divert it" (Correspondence 606), the fact that satire was "a sort of glass, wherein Beholders do generally discover every body's Face

22 Not surprisingly, the Tale's incoherence has invited a number of critics to read it within the context of a poststructuralist critique of authorship and representation, cf. Martin for a recent discussion.

23 Cf. also Benedict (110) on this point. 
but their Own" still had to be reckoned with. Indeed, despite the scholarly attention Swift's novel has received among $20^{\text {th }}$-century critics, it remains doubtful whether it is really received in public as that relentless exposure of human ignorance and human vices that Swift probably wanted it to be. To many readers, especially those of the bowdlerized versions which have been published since Victorian times, it may paradoxically appear as just the opposite: another 'pleasing vision.'

\section{Works Cited}

Adams, Percy G. Travelers and Travel Liars: 1660-1800. Berkeley: University of California Press, 1962.

Bacon, Francis. The Works of Francis Bacon. 1858-1874. Ed. James Spedding et al. 14 vols. Stuttgart: Frommann-Holzboog, 1961-1963.

Benedict, Barbara. Curiosity: A Cultural History of Early Modern Inquiry. Chicago: University of Chicago Press, 2001.

Blumenberg, Hans. Die Legitimität der Neuzeit. Frankfurt a. M.: Suhrkamp, 1996.

Bullard, Paddy. "Pride, Pulpit Eloquence, and the Rhetoric of Jonathan Swift." Rhetorica 30 (2012): 252-76.

Clifford, James L. "Gulliver's Fourth Voyage: 'Hard' and 'Soft' Schools of Interpretation." Quick Springs of Sense: Studies in the Eighteenth Century. Ed. Larry S. Champion. Athens: University of Georgia Press, 1974. 32-49.

Harrison, Peter. "Original Sin and the Problem of Knowledge in Early Modern Europe." Journal of the History of Ideas 63 (2002): 239-59.

Hobbes, Thomas. The English Works of Thomas Hobbes. 1839-1845. Ed. W. Molesworth. 13 vols. Aalen: Scientia, 1966.

Hooke, Robert. Micrographia: Or Some Physiological Descriptions of Minute Bodies Made by Magnifying Glasses. London: Martyn and Allestry, 1665.

Jones, Richard F. “The Background of the Attack on Science in the Age of Pope.” Eighteenth Century English Literature. Ed. James L. Clifford. New York: Oxford University Press, 1959. 68-83.

Lynall, Gregory. Swift and Science: The Satire, Politics, and Technology of Natural Knowledge, 1690-1730. London: Palgrave Macmillan, 2012. 
Martin, Kelly. "Swift and Post-Structuralism: The Death of the Author in A Tale of a Tub." Swift Studies 31 (2016): 40-52.

Milton, John. The Works of John Milton. Ware: Wordsworth, 1994.

Monk, Samuel H. "The Pride of Lemuel Gulliver." Eighteenth Century English Literature. Ed. James L. Clifford. New York: Oxford University Press, 1959. 112-29.

Nate, Richard. Wissenschaft und Literatur im England der frühen Neuzeit. Munich: Fink, 2001.

-. Wissenschaft, Rhetorik und Literatur: Historische Perspektiven. Würzburg: Königshausen \& Neumann, 2009.

Nicolson, Marjorie, and Mora M. Mohler. "The Scientific Background to Swift's 'Voyage to Laputa." Fair Liberty Was all His Cry: A Tercentenary Tribute to Jonathan Swift, 1667-1745. Ed. Alexander N. Jeffares. London: Macmillan, 1967. 226-69.

Nuttall, Anthony David. "Gulliver among the Horses." Jonathan Swift: A Collection of Critical Essays. Ed. Claude Rawson. Englewood Cliffs: Prentice Hall, 1995. 264-79.

Panagopoulos, Nic. "Gulliver and the Horse: An Enquiry into Equine Ethics.” Swift Studies 21 (2006): 56-75.

Pope, Alexander. The Major Works. Ed. Pat Rogers. Oxford: Oxford University Press, 2006.

Real, Hermann J. "A Taste of Composition Rare: The Tale's Matter and Void.” Papers from The Third Münster Symposium on Jonathan Swift. Ed. Hermann J. Real and Helgard Stöver-Leidig. Munich: Fink, 1998. 73-90.

-. "The Dean and the Lord Chancellor: or Swift, Saving his Bacon." Britannien und Europa: Studien zur Literatur-, Geistes- und Kulturgeschichte. Festschrift für Jürgen Klein. Ed. Michael Szczekalla. Frankfurt a.M.: Lang, 2010. 95-111.

Schramm, Helmar. "Einleitung: Kunst des Experimentellen, Theater des Wissens." Spektakuläre Experimente: Praktiken der Evidenzproduktion im 17. Jahrbundert. Ed. Helmar Schramm et al. Berlin: de Gruyter, 2006. xi-xxxviii.

Shapiro, Barbara. Probability and Certainty in Seventeenth-Century England: A Study of the Relationships between Natural Science, Religion, History, Law, and Literature. Princeton: Princeton University Press, 1983. 
Sidney, Philip. An Apology for Poetry or The Defence of Poetry. 1595. Ed. Geoffrey Shepherd. Manchester: Manchester University Press, 1973. Smith, Frederick N. "Scientific Discourse: Gulliver's Travels and The Philosophical Transactions." The Genres of Gulliver's Travels. Ed. Frederick N. Smith. Newark: University of Delaware Press, 1990. 139-62.

Sprat, Thomas. The History of the Royal Society. 1667. Ed. Jackson I. Cope and Harold W. Jones. St. Louis: Washington University Press, 1958.

Swift, Jonathan. Irish Tracts 1720-1723 and Sermons. Ed. Herbert Davis and Louis Landa. Oxford: Blackwell, 1968.

-. A Tale of a Tub and Other Satires. Ed. Kathleen Williams. New York: Dutton, 1975.

-. Gulliver's Travels. Ed. Michael Foot. Harmondsworth: Penguin, 1976.

-. The Correspondence of Jonathan Swift, D.D. 4 vols. Vol. 2: Letters 1714-1726. Ed. David Woolley. Frankfurt a. M.: Lang, 2001.

Taylor, Dick. "Gulliver's Pleasing Visions: Self-Deception as Major Theme in Gulliver's Travels.” Tulane Studies in English 12 (1962): 7-61.

Todd, Dennis. "Laputa, the Whore of Babylon, and the Idols of Science." Studies in Philology 75 (1978): 93-120.

Webster, Charles. The Great Instauration: Science, Medicine and Reform 1626-1660. London: Duckworth, 1976.

Weiß, Wolfgang. Swift und die Satire des 18. Jahrhunderts. Munich: Beck, 1992.

Williams, Kathleen. "Conclusion to Swift and the Age of Compromise." Swift: A Collection of Critical Essays. Ed. Ernest Tuveson. Englewood Cliffs: Prentice Hall, 1964. 115-22. 



\section{Albert Meier \\ Access Denied: English Experiences in Karl
Philipp Moritz's Travel Report of 1782}

(Translation by Jasper Verlinden)

Knowledge and improvements are to be got by sailing and posting for that purpose; but whether useful knowledge and real improvements is all a lottery...

Laurence Sterne

Abstract: With an exemplary reading of Moritz's Travel Report, this essay argues that throughout the $17^{\text {th }}$ and into the enlightened $18^{\text {th }}$ century, national character as well as a people's social and cultural mores had to be derived first and foremost from fiction and travel narratives. Both genres work with aesthetically and economically motivated stylizations - rather than naively 'realistic' or pedantically precise depictions - designed to catch and entertain readers' interest. As Moritz's German wanderer's experiences are prefigured by the unreliable, heavily mediated, and consciously crafted guidance of literary writing and thus depend on his choice of literary intake, the authenticity of Moritz's narrative of England proves to be an ultimately literary construction, which - regardless of its basic soundness of detail - makes his generalizing characterization of the country and people factually questionable.

England was not a strange land to the German reading public at the close of the $18^{\text {th }}$ century. Knowledge of the cultural and geographic peculiarities on the other side of the Channel, however, was less due to the already numerous travel descriptions (e.g. travel guides; cf. Moritz, “Kommentar" 256-268) than to contemporary literature in English, which since the mid- $18^{\text {th }}$ century had gained an ever-broader readership. Particularly notable in this regard are, aside from the sentimental epistolary novels in the wake of Samuel Richardson's Pamela, the comically realist novels of Henry Fielding (The History of Tom Jones, a Foundling) and Oliver Goldsmith (The Vicar of Wakefield). In addition, the fashionable pastoral poetry which received attention especially in Alexander Pope's Windsor Forest and James Thomson's The Seasons, also played a decisive role in shaping continental perceptions.

As long as hardly anyone had the opportunity to personally observe the land and the people and to make their own experiences in situ, the social 
and cultural mores of the English population at the time, or what constituted their particular national character, had to be derived first and foremost from fiction. This poetically mediated familiarity with English customs and living conditions became even more significant when during the course of the Enlightenment, the Kingdom of Great Britain replaced France as cultural hegemon and emerged at the forefront of philosophy, literature, science, and political economy (cf. Maurer). This fictional foundation for the knowledge of the British lifeworld and its progressive character is, of course, accompanied by certain exaggerations that are more a reflection of rhetorical utility than of actual circumstances. ${ }^{1}$ After all, novels that were set in the contemporaneous present of the $18^{\text {th }}$ century often practiced a form of "prosaicomi-epic writing" (Fielding 156) which, for the purpose of entertainment, had as its primary aim to "laugh mankind out of their favourite follies and vices" (Fielding LIV). As such, they were all the less inclined to offer a sober portrait of what was considered average or normal, and thus true.

The necessity of interrogating the aesthetically motivated stylizations of realistic depictions is also of concern in the then popular genre of literary travel descriptions. How to narrate concrete experiences in another country in a way that is not only informative but also pleasurable to read was exemplified by Laurence Sterne's A Sentimental Journey Through France and Italy (1768), a book which was foundational to the genre. It overturned all the pedantry of more traditional depictions by means of its unheard of "freedom of wit and humour" (cf. Shaftesbury) in order to foster the individual, necessarily coincidental, and fragmentary nature of perception over precision and wholeness. Without the standard set by Laurence Sterne's A Sentimental Journey, Karl Philipp Moritz's successful Reisen eines Deutschen in England im Jahr 1782, which was quickly published in England as well, would not have been possible. ${ }^{2}$ Indeed, Moritz had already

1 Cf. above all, the comparison between England and Italy, which comes out decidedly in favor of England over the supposedly backward Italy, in Johann Wilhelm von Archenholtz's England und Italien (Leipzig 1785; $2^{\text {nd }}$ ed. 1787).

2 The first English translation appeared in 1795: Travels, Chiefly on Foot, Through Several Parts of England, in 1782. Described in Letters to a Friend, by Charles P. Moritz, a Literary Gentleman of Berlin, translated from the German, by a Lady. London 1795 (from this - largely free and thus imprecise - translation will in the following be cited under the short title Travels). 
read "Yoricks empfindsame Reisen,” Johann Joachim Christoph Bode's German translation of Sterne, "two or three times with great pleasure" in the year of its publication (Moritz, Reiser 172). While he does not adopt the poetic strategy of repeatedly and self-referentially foregrounding the narrative voice, he does, in a sense, describe the manifold genre scenes either in country inns or in parliament "with Sternian humor" (Moritz, Reiser 266) and, in doing so, is not lacking in sentimental irony.

As such, Moritz's Reisen eines Deutschen in England im Jahr 1782 represents an early example of the style of the "individual experiential report" which was still innovative at the time, at least in the German language, and which would find its culmination in the two first volumes of Johann Wolfgang Goethe's Italienische Reise (1816/17). It furthered "the trend of subjective-autotelic-sentimental travel descriptions" that were based on fact and helped in bringing reports that are primarily aimed at providing "culturally and socially critical factual information" by enlightened travelers under the purview of literary history (Jahnke and Wingertszahn 151). Technically, Moritz had been a subject of the English Crown during his school years in Hanover. ${ }^{3}$ Accordingly, he had already received an education in English from a young age and had become familiar with the major works by British authors. What the admittedly philologically questionable Englische Sprachlehre für die Deutschen (1784), which goes back to a seminar [Kollegium] held in the winter of $1781 / 82$, primarily documents is his above-average language competence. It appears, however, that the project of a journey to England had presented itself rather spontaneously in the spring of 1782. The journey, which lasted a total of seven weeks in June and July of 1782, takes Moritz, then a teacher at the Berlin "Gymnasium zum Grauen Kloster”, first from Hamburg to London (arrival on July 2) and then to Richmond, Windsor, and Oxford, mostly on foot through the Peak District. He finally returns by stagecoach via Nottingham and Northhampton to London where Moritz embarks a ship back to Hamburg on July $19 .{ }^{4}$

3 George III William Frederick of Great Britain and Ireland was in Moritz's time also prince-elector of Hanover.

4 Cf. the "Chronological Overview" ["Chronologische Übersicht"] in the commentary on Moritz, Reisen eines Deutschen in England im Jahr 1782, 573. 
Moritz resorted to a number of tourist resources during his travels: he used a city map for London (possibly the 'ground plan' from Johann Jacob Volkmann's Neuesten Reisen), a detailed directory of regional roads (see Paterson), an "accurate map of England" (Travels 106) as well as the highly pragmatically oriented Beyträge zur Kentniß Grosbritanniens vom Jahr 1779 (1780) by Gebhard Friedrich August Wendeborn, who was a preacher at the German church in Ludgate and whom Moritz often personally visited in London. The contemporary London of the $18^{\text {th }}$ century was already known, at least in basic terms, to the German literary public, specifically from Georg Christoph Lichtenberg's letters from his stay there in 1774/75, which had been published in the journal Deutsches Museum in 1779. Still, the Reisen eines Deutschen in England supplement this information about the English capital by providing the first substantive representation of the peculiar mountain landscape of Derbyshire, whose natural wonders had been of interest to geologists since the late $17^{\text {th }}$ century and had subsequently been discussed in numerous English-language reports. First on this list is Daniel Defoe's often-cited "rationalistic demystification" of the cave of Castleton in A Tour thro' the whole Island of Great Britain (1727), which at the close of the $18^{\text {th }}$ century was followed by contrasting reinterpretations in "the Gothic taste" (Jahnke and Wingertszahn 287).

In order to avoid the "smoke of these sea-coal fires" in London and "to breathe a fresher and clearer air" (Travels 67), Moritz decides on the Peak District, "which is famous for its natural curiosities, and also for its romantic situation" (Travels 106f.). Better than the Isle of Wight and Portsmouth, which would have been possibilities as well, Derbyshire fits within his overarching narrative strategy as a counterpoint to the big city. His strategy consists of reflecting the living conditions of the country through which he travels by way of chance experiences and by conveying to the reader impressions that - while not strictly objective - are still sufficiently authentic. To that end, everything that is characteristic is faithfully processed and represented by means of the tourist-oriented secondary literature. The House of Commons, described in joyful detail, belongs just as much to the instructive curiosities of London as the many "academies" which are of professional interest to Moritz the educator and which "notwithstanding their pompous names, $[\ldots]$ are in reality nothing more than small schools set up by private persons, for children and young people" (Travels 80). 
On his journey to the Midlands, however, aside from the peculiar natural phenomena around Castleton, it is the repeated experience of gross "inhospitality" (Travels 161) in country inns that provide a vivid image of the customs of the people in the English province: "To what various, singular, and unaccountable fatalities and adventures are not foottravellers exposed, in this land of carriages and horses!" (Travels 139).

In contrast to the decidedly subjective individual reports from London, which refer to the travel guides on a case-by-case basis at most, the narration of his fortunes as "poor travelling creature" (Travels 238) between Richmond, Castleton, and Northampton, continually develops in relation to fiction. Outside of the big city, our German wanderer finds himself both in the English everyday and at the same time in literature, which does not only steer his conduct through concrete suggestions, but which rather prefigures his perception of the environment through which he travels and which lays the groundwork for its representation in his report. When Moritz lets himself be guided by Oliver Goldsmith's The Vicar of Wakefield, he does wrongly expect that every "inn on the road-side" is, in fact, a "resort of indigence and frugality" that should duly preserve one's wallet (Travels 146). In other cases, the reading does pay off when, for instance, an irritable innkeeper can be appeased with a jug of ale:

This device I had learned of the Vicar of Wakefield, who always made his hosts affable, by inviting them to drink with him. [...] This innkeeper, called me, Sir; and he made his people lay a separate table for himself, and me; for, he said, he could see plainly, I was a gentleman. (Travels 196)

In the village of Nettlebed, northwest of Henley-on-Thames, the expectations he gained from novels even turn into reality entirely when a cold " "why, yes, you may" tells the German wanderer "to sup at the same table with some soldiers and the servants":

They shewed me into the kitchen, and set me down. I now, for the first time, found myself in one of those kitchens which I had so often read of in Fielding's fine novels; and which certainly give one, on the whole, a very accurate idea of English manners. (Travels 149)

Previously, near Windsor, the enthusiastic verses of Alexander Pope's great ode Windsor Forest (1713) transformed a view from a hill into a joyful aesthetic experience: 
Below me lay the most beautiful landscapes in the world; all the rich scenery that nature, in her best attire, can exhibit. Here were the spots, that furnished those delightful themes, of which the muse of Denham and Pope made choice. I seemed to view a whole world at once, rich and beautiful, beyond conception. (Travels 130)

At closer inspection, we are dealing with a third-degree observation of nature: Moritz's aesthetic enjoyment has been doubly mediated since he goes back to a corresponding reference in Wendeborn's Beyträgen. ${ }^{5}$ That such impressions are anything but unmediated and that reality is only capable of confirming previously held poetic knowledge at best, Moritz already indicated when in the area of Richmond at sunset he voiced a desire to be transported "into a most charming valley, that winds all along the banks of the Thames" (Travels 115):

The terrace at Richmond does assuredly afford one of the finest prospects in the world. Whatever is charming in nature, or pleasing in art, is to be seen here. Nothing I had ever seen, or ever can see elsewhere, is to be compared to it. (Travels 115)

The accompanying "chagrin and sorrow for the days and hours I had wasted in London; and [...] thousand bitter reproaches on my irresolution, that I had not long ago quitted that huge dungeon, to come here, and pass my time in paradise" (Travels 115f.), is frankly explained immediately after as conditioned by his reading. After all, Moritz's feeling of happiness only puts into practice that for which reflection had already consciously laid the groundwork:

Yes, my friend, whatever be your ideas of paradise, and how luxuriantly soever it may be depictured to your imagination, I venture to foretell, that here you will be sure to find all those ideas realized. In every point of view, Richmond is assuredly one of the first situations in the world. Here it was that Thompson and Pope gleaned from nature all those beautiful passages with which their inimitable writings abound! (Travels 116)

5 "Pope hat in einem eignen Gedichte die Schönheiten dieser Gegenden besungen, und die Beschreibungen, die er macht, erwecken gewis bei einem Leser das Verlangen, sie zu sehen" [Pope extolled the beauty of these regions in one of his own poems and the descriptions he makes surely arouse within the reader the desire to see them.] (Wendeborn 321). 
In the self-critical manner that is often found in Moritz's work, the artificiality of this second-hand nature observation is immediately ironized for its intentionality:

I now resolved to go to bed early, with a firm purpose of also rising early the next day, to revisit this charming walk. For I thought to myself, I have now seen this Tempe of the modern world imperfectly; I have seen it only by moon-light: how much more charming must it be, when glistening with the morning dew! These fond hopes alas! were all disappointed. (Travels 118)

In the further course of his journey to the Peak District, the English landscape changes dramatically in character:

Instead of green meadows and pleasant hills, I now saw barren mountains and lofty rocks; instead of fine living hedges, the fields, and pasture lands, here, were fenced with a wall of grey stone; and of this very same stone, which is here every where to be found in plenty, all the houses are built, in very uniform and patriarchal manner, inasmuch as the rough stones are almost without any preparation, placed one upon another, and compose four walls. (Travels 201f.)

Moritz responds to these changes by substituting the enlightened pastoral poetry with John Milton's bible epos Paradise Lost. The paradise that he beheld near Richmond is literally lost in the Peak District, and it can hardly be a coincidence when Moritz commentates his first glance of Matlock with the following quotation:

I had got in Milton's Paradise Lost, which I am reading regularly through, just to the part where he describes Paradise, when I arrived here; and the following passage, which I read at the brink of the river, had a most striking and pleasing effect on me. The landscape here described, was as exactly similar to that I saw before me, as if the poet had taken it from hence:

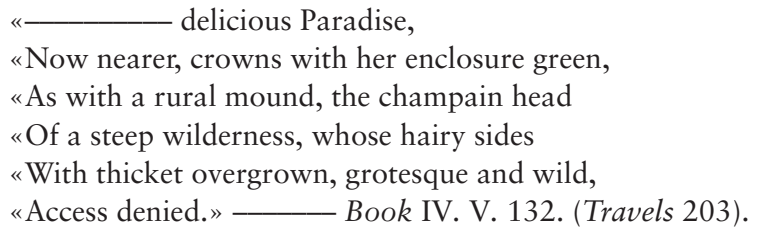

The primacy of Milton's verse is even more explicitly formulated through the empirical observations on his return, when Moritz, once again near Matlock, is supposed to have read

the passage, in Milton, relative to the creation, in which the Angel describes to Adam how the waters subsided and 
'Immediately the mountains huge appear

'Emergent, and their broad bare backs upheave

'Into the clouds, their tops ascent the sky.' Book VII. V. 285.

It seemed to me, while reading this passage, as if every thing around me were in the act of creating, and the mountains themselves appeared to emerge or rise; so animated was the scene. (Travels 236)

Less inspired by Milton than by his Roman role model Virgil is the strikingly evocative, because religiously elevated, sighting of the limestone cave of Castleton, which "goes commonly by a name that is shockingly vulgar: in English it is called The Devil's Arse o' Peake" (Travels 229). Clearly inspired by the katabasis in the sixth book of the Aeneid, Moritz stylizes his extended journey through this long-domesticated attraction as an atmospheric descent into the underworld and thus turns it into the - soon separately reprinted - focal point of meaning in his English travel description. This foreign geological experience centers entirely on ancient mythology, as the guide who Moritz confides in "along with his black stringy hair, and his dirty and tattered cloaths, [had] such a singularly wild and infernal look, that he actually struck me as a real Charon” (215). Fittingly, "a whole subterranean village" appears which was found in "the hollow of the Cavern" and whose "inhabitants, on account of its being Sunday, were resting from their work," in view of the "number of large wheels, on which, on week days, these human moles, the inhabitants of the Cavern, make ropes," 6 exactly as if it were located on the bank of a river in Hades: "I fancied I here saw the wheel of Ixion, and the incessant labour of the Danaides" (216). Afterwards - as with the shadow of one deceased - he continues into the depths in a small boat: "All around us, was one still, solemn, and deadly silence [...] I seemed to myself to be in a coffin, rather than in a boat, as I had no room to stir hand or foot" (218). At the end of the cave, our traveler finds himself "in this land of darkness, and shadow of death" (219) and ultimately in an equivalent of the Elysian Fields, where "all at once something like music at a distance, sounded in mine ears" (220):

6 Johann Jacob Volkmann describes this scene more soberly: “[...] sind in diesem dunklen Auffenthalte zwischen den Felsen einige zerstreute Hütten, darin eine Menge Weiber und Kinder spinnen" [in these dark dwellings in between the crevices are a few scattered huts in which a number of women and children spin] (469). 
I actually saw and felt a violent shower of rain falling from the rock, as from a thick cloud; whose drops, which now fell on our candles, had caused that same melancholy sound, which I had heard at a distance.

This was what is here called a mizzling rain; which fell from the ceiling or roof of the Cavern, through the veins of the rock. (220)

The next cave is instantly perceived, or rather interpreted, in a physicotheological spirit:

This subterranean Temple, in the structure of which no human hand had borne a part, appeared to me at that moment to surpass all the most stupendous buildings in the world, in point of regularity, magnificence and beauty.

Full of admiration and reverence, here even in the inmost recesses of Nature, I saw the Majesty of the Creator displayed; and before I quitted this Temple, here in this solemn silence, and holy gloom, I thought it would be a becoming act of true religion to adore, as I cordially did, the God of Nature. (221)

The actual reward for all the "difficulties" of the path, for his squeezing through the narrowest crevices on hand and feet in the wet sand or going up a steep mound in between two chasms, comes at last when our German visitor's guide initially leaves him behind at a dizzying height: "I lost sight of him for some moments: but at length I perceived not him indeed, but his candle, quite in the bottom, from whence it seemed to shine like a bright and twinkling star" (222). This already "indescribably beautiful sight" (223f.) is nevertheless surpassed by its ensuing reversal, when his guide

let his candle shine again through an opening of the rock, while I covered mine with my hand; and it was now as if on a dark night a bright Star shone down upon me: a sight which, in point of beauty, far surpassed all that I had ever seen. (224)

This experience, reminiscent of Dante's departure from Inferno, ${ }^{7}$ is symbolically charged insofar as it presents as a promise of salvation in the spirit of freemasonry, ${ }^{8}$ for which all beauty is deemed a confirmation of God's benevolence. In such a blend of ancient classical and Christian conceptions

7 "E quindi uscimmo a riveder le stelle" [and thence we came forth to see the stars again] (Dante Alighieri, Inferno XXXIV 139).

8 On Moritz as freemason, cf. in general the commentary to his relevant writings in Moritz, Karl Philipp: Schriften zur Pädagogik und Freimaurerei (especially 715-719). 
of the afterlife, the departure from the limestone cave offers a final look "into Elysium" (224) that soothes all consciousness of one's own mortality.

This experience of bliss is inevitably limited to the moment, as the road back to London brings new troubles along with it. Since Moritz, because of a lack of time, is traveling from Leicester by stagecoach, he is spared the experience of being regarded as a "sort of wild man, or an out-of-the-waybeing" (122), and yet "it seemed to be my fate to be still a scandal, and an eye-sore to all the waiters" (133). Because he feels constantly in danger of his life "on the outside of an English post-coach" (248), he casts the warning of "'O, Sir, Sir, you will be shaken to death!'” to the wind and unsuccessfully seeks out more comfort in the basket, until he, "quite shaken to pieces and sadly bruised" (247), is able to climb back on top of the carriage. This undoubtedly biographically valid experience is of particular significance within the overall scheme of his English travel description because it forms part of a sequence of misfortunes and abasements which Moritz narrates in a similar manner as Goldsmith does the rather more serious yet happily ending fortunes of his Vicar Primrose. In this regard, Moritz's English travel report can be understood as a humoristically oriented adaptation of the Old Testament's Book of Job. The characteristics of this report are not least to be found in the fact that it is largely inspired by literature and that the description of the other country, in spite of all individual credibility, is nevertheless a second-hand description.

Moritz's Reisen eines Deutschen in England was predominantly positively received by the literary public in both Germany and Great Britain. ${ }^{9}$ It has occasionally been asserted that the author is "entertaining [because of] the naiveté of his narration" 10 or that he represents his adventure with a rare "unassuming innocence and unadulterated truth". ${ }^{11}$ These assessments, however, completely miss the literary evidence. The review of the

9 Cf. the collection of contemporary reviews in Jahnke and Wingertszahn, 342372. The harshest critique is found in The Gentleman's Magazine, 65 (Sep 1795): "it is a dull farrago of blunders, misadventures, common-place observation, and low humour" (359).

10 Allgemeine Literatur-Zeitung, 30.5 (Feb 1785; qtd. in Jahnke and Wingertszahn 350).

11 Hallische Neue Gelehrte Zeitungen, 1 and 2 (Jan 5 and 8, 1784; qtd. in Jahnke and Wingertszahn 345). 
English translation published in the European Magazine and London Review (Vol. 28, from July to December 1795), for example, overlooks the multiple mediations in Moritz's travel narrative: "The author writes with an apparent sincerity; he derives no assistance from books; what he records he saw; and when he describes, the original was before him." ${ }^{12}$ More on point, on the other hand, is the skeptical look of the Gothaische gelehrten Zeitungen (Vol. 23, March 20, 1784): “Although England is not an unknown country, each traveler sees things with different eyes, and from such a keen observer as Mr. Moritz, one still learns something new now and again; and because he is a good narrator, one also gladly reads again that which one in essence already knew in a new form and guise." 13

In any case, the detailed tracing of Moritz's sources in the critical edition was able to determine that the ostensible "naiveté" of his Reisen eines Deutschen in England is anything but original and is not only influenced by the travel guides he consulted, but gains its poetic individuality primarily from poetic reference texts by mostly British authors: ${ }^{14}$ "Moritz extended the observation of nature into the romantic and poeticized the landscape through his reading of Milton" (Jahnke and Wingertszahn 276). In this light, the authenticity of Moritz's narrative of England proves to be an ultimately literary construction, which - regardless of its basic soundness of detail - makes his generalizing characterization of the country and people factually questionable. It is precisely because Moritz's highly subjective and individual depictions profit so thoroughly from the humoristic writings of English authors, that their apparent verisimilitude brings the reader under the illusion that they are taking part in a real travel experience. As such, it also makes the corresponding knowledge about the reality of England believable, however much it may be grounded in poetry rather than everyday life. In the wake of Pope, Milton, Fielding, and Goldsmith, the Reisen eines

12 Qtd. in Jahnke and Wingertszahn 360. Cf. the similar assessment in der Allgemeinen Deutschen Bibliothek, 71.1 (1787): „Ob ein Gegenstand sonst schon bekannt ist, das hindert ihn doch nicht, ihn ausführlich zu beschreiben, genug, er sah ihn. - " [Whether something is otherwise already known does not keep him from describing it in detail, enough, he saw it.] (351).

13 Qtd. in Jahnke and Wingertszahn 348.

14 Already in 1904, Albert Leitzmann found correspondences with Johann Wolfgang Goethe's Leiden des jungen Werthers (423). 
Deutschen in England does indeed turn out to be "too literary"15 to remain factually credible. Consequently, in Moritz's "company" one does not get to know "the spirit of the English" 16 in an unfiltered manner, but is compelled to read the poetic tradition at the same time, from whose particular point of view the unfamiliar reality is perceived.

If Moritz's depictions are largely unencumbered by the "conventional national clichees" in Germany (Jahnke and Wingertszahn 265), this is due, first of all, to the fact that in 1782, the author was less traveled in England than in English literature. Thus, Moritz's travel report does not achieve a genuinely autonomous expansion of German knowledge that transcends contingency and is derived from the empirical observation of the other country. Instead, the famous dialectic which Goethe distilled into a formula in 1795 also applies to him: "One only sees, what one knows." If Moritz consequently could only experience what he had already read in both the reference texts as well as in literature, his Reisen eines Deutschen in England, in all its humor, will teach us "little more [...], than how the Thames curves, the streets meander, and how sixty years ago, the houses looked from the outside, whose insides the travelers had not been granted to see". ${ }^{17}$

\section{Works Cited}

Fielding, Henry. The History of Tom Jones, a Foundling. Introd. Claude Rawson. New York: Everyman's Library, 1991.

Jahnke, Jürgen, and Christof Wingertszahn. "Kommentar." Reisebeschreibungen. Teil 1: Reisen eines Deutschen in England im Jahr 1782. Ed. Jürgen Jahnke and Christof Wingertszahn. Berlin: DeGruyter, 2015. 151-574. Vol. 5 of Sämtliche Werke: Kritische und kommentierte Ausgabe. Ed. Anneliese Klingenberg et al.

15 Allgemeine deutsche Bibliothek, 71.1 (1787; qtd. in Jahnke and Wingertszahn 351).

16 Königl. privilegirte Berlinische Staats- und gelehrte Zeitung, 144 (December 2, 1783; qtd. in Jahnke and Wingertszahn 344).

17 Willibald Alexis: Litterarhistorisches Taschenbuch 5 (1847, qtd. in Jahnke and Wingertszahn 399-401, here 400). 
Leitzmann, Albert. Review of Reisen eines Deutschen in England im Jahr 1782 von Karl Philipp Moritz, edited by Otto zur Linde. Berlin 1903. Zeitschrift für deutsche Philologie 36 (1904), 423-427.

Maurer, Michael. Aufklärung und Anglophilie in Deutschland. Göttingen: Vandenhoeck + Ruprecht, 1987.

Moritz, Karl Philipp. Anton Reiser. Ed. Christof Wingertszahn. Tübingen: DeGruyter, 2006. Vol. 1 of Sämtliche Werke: Kritische und kommentierte Ausgabe. Ed. Anneliese Klingenberg et al.

-. Schriften zur Pädagogik und Freimaurerei. Ed. Jürgen Jahnke. Berlin: DeGryuter, 2013. Vol. 6 of Sämtliche Werke. Kritische und kommentierte Ausgabe. Ed. Anneliese Klingenberg et al.

-. Travels, Chiefly on Foot, Through Several Parts of England, in 1782. Described in Letters to a Friend, by Charles P. Moritz, a Literary Gentleman of Berlin, translated from the German, by a Lady. London 1795.

Paterson, Daniel, A New and Accurate Description of All the Direct and the Principal Cross Roads in Great Britain [...]. The Fourth Edition, Corrected and greatly Improved; with Additions. London 1778.

Shaftesbury, Anthony Ashley Cooper, Earl of. Sensus Communis: An Essay on the Freedom of Wit and Humour. In a Letter to a Friend. London 1709.

Volkmann, Johann Jacob. Neueste Reisen durch England [...]. Aus den besten Nachrichten und neuern Schriften zusammengetragen. Vier Theile. Leipzig 1781/82.

Wendeborn, Gebhard Friedrich August. Beyträge zur Kentniß Grosbritanniens vom Jahr 1779. Aus der Handschrift eines Ungenannten herausgegeben von Georg Forster. Lemgo 1780. 



\title{
Marcel Hartwig \\ Fothergill's Web: \\ Transnational Quaker Networks and the Pennsylvania Medical Library
}

\begin{abstract}
This historiographic essay provides an account of the enlightenment scholar and London-based medical practitioner John Fothergill's efforts to negotiate the emergence and solidification of reliable medical knowledge in written exchanges with a host of pen pals. Fothergill's epistolary exchanges are presented in view of the institutional practices of transnational collection and dissemination of the first Medical Library in Philadelphia. The microstudy aims to show the intellectual work and the practices of knowledge production that are involved in institutionalizing a knowledge network of 'professional' medicine that by the end of the $18^{\text {th }}$ century paves the way for the success of rationalized pathological medicine in the Western hemispheres. The letters investigated here frequently borrow from established literary genres underscoring the fact that 'science' as well as the notion of the 'professional' remain anachronisms into the $19^{\text {th }}$ century.
\end{abstract}

In 1765, John Fothergill, Jr., published his Considerations Relative to the North American Colonies. Fothergill never visited any of the thirteen colonies in his lifetime, but his little book surprises with an unexpected agenda and well-informed view on the spatial, political, and economic situation of the North American colonies. It concludes with a proposition that, at least from a contemporary perspective, seems to underline the English physician's awareness of global connectivity and transnational flows. Moreover, it points to the existence of what Hesford and Schell would label as "networks and relations across cultural groups" (465). In thinking about how to build bridges between American and British higher education, Fothergill conceives the following lines:

If we promote scholarships for Americans in our [British] universities; give posts and benefits in America to such Americans who have studied here [in Great Britain], preferably to others; if the government permits such youth as come to Europe, on account of their studies, to come over in the king's ships gratis, we shall still unite them more firmly. The Americans, by mixing with our own youth at the University, will diffuse a spirit of enquiry after America and its affairs; they will 
cement friendships on both sides [of the Atlantic], which will be of more lasting benefit to both countries, than all the armies that Britain can send thither. (416)

The London resident writes these lines while the Stamp Act of 1765 is stirring an ever-increasing number of armed protests against new taxes the British raised in the preceding years. Fothergill's fascination with the colonies was due to the international work of his father, who represented the Society of Friends in the early $18^{\text {th }}$ century on three visits to Maryland, Virginia, and Pennsylvania (Corner 77). It is the latter of these stations that shall be of interest to this paper.

It is worthwhile noting here that Fothergill, an Enlightenment scholar and medical practitioner, subscribed to the age's notion of rationality and what Daston and Galison call "truth-to-nature" representations both in writing and illustrating (18). In this light, he falls in line with enlightenment's educated class whose members work in, write for, and winnow their scholarly networks in search for "working objects": "atlas images, type specimens, or laboratory processes - any manageable, communal representative of the sector of nature under investigation" (Daston and Galison 19). As will be shown here, Fothergill's Quaker network is interested in finding a collectively sharable, identifiable, and usable knowledge - in short, an epistemologically encoded enunciation of knowledge. He and his penpals negotiate ways of generalizing and regularizing their working objects apart from folklore and native medicine. Their common project is thus the negotiation of generic principles that would turn a collectively shared notion of medical truth into medical knowledge. By the same token, however, Fothergill's web is constitutive of institutionalizing and safeguarding mechanisms that would regulate both the access to and the dispersion of knowledge. Their work exists within the discursive constraints of what Hayden White would identify as a "discourse that narrativizes [...and] feigns to make the world speak itself and speak itself as a story" (6-7, emphasis in original). In order to mediate their findings, the nodes in this network come to life via letter writing, authoring manuscripts, or the regulating principles of their archiving institutions. In that sense all intermediaries resort to the production of text, and via writing they produce the codes of their social experience and the symbols of their group's history. In historicizing their experience, these intermediaries necessitate narrative. It is in this wide approach to a concept of literature that this paper studies Fothergill's web. 
As a "Quaker colony" (cf. Barbour and Frost 6), historical Pennsylvania is now thought to be a peculiar hotbed of international knowledge productions and the financing of early institutions that are today regarded as predecessors of modern medicine, such as the Pennsylvania General Hospital and its first Medical Library. This microstudy intends to sketch said library out as a transnational contact zone. From this point of view, the library space can be read as an instance of institutionalized power that aims at categorizing and classifying medical knowledge in that it allows for an authoritative collection area that displays select items to interpellate select individuals through a channeled and supervised deployment of knowledge. By synchronically tracing a small selection of both Fothergill's penpals and their publications, the following pages shall elucidate the nexus between Quaker networks and the appropriation of folk medical knowledge. The aim is to show the intellectual work and the practices of knowledge production that are involved in institutionalizing a knowledge network of 'professional'1 medicine that by the end of the $18^{\text {th }}$ century paves the way for the success of rationalized pathological medicine in the Western hemispheres. The term 'professional' is an anachronism here, can only be applied in retrospect, and would not have been used by the individuals of this study. However, this paper tries to provide an approach to a genealogy of the term and will use it therefore in quotation marks.

To work on this specific subject, I first need to establish the context in which the transit and production of knowledge occurred. Two developments from a time briefly before Fothergill's Considerations - one in medical knowledge and one in the form and organization of the medical market - furthered the tendencies towards new theories of a disease's nature and, accordingly, its treatments. Fothergill's work as physician and

1 The category of 'professional' is put in doubt here as the designation of the terms implies a negotiation between use-knowledge and use-value. It is unclear how value is assessed in this case. The category of usefulness here seems to be strictly bound on the creation of closely-knit, regulated, and utilitarian institutions. Interestingly, these concepts seem to emerge unbound to nations - in this paper these are discussed according to how they spread through private networks - and seem to strive for a sort of universal based on the consensus that they are "useful." The question would be for whom or what, and if this is right and how this is right to whom. 
consultant to the Philadelphia Yearly Meeting of the Society of Friends is framed by the geographical advantage of colonial medicine, in which the learned traditions and scientific investigation methods from the Old World were enhanced by the local bazaars and folklore of the colonies. Surgeons and military physicians such as most of Fothergill's penpals "were part of a new disciplinary regime that aimed to protect their employers' human capital and improve its productivity" (Harrison 5). In the $18^{\text {th }}$ century, it was a common circumstance that British doctors such as John Fothergill, military surgeons, and apothecaries who accompanied British troops soon established their own networks for sharing newly gathered information they thought useful for maintaining the health of the soldiers. In the meantime, the Philosophical Transactions of the Royal Society became an important institution to invite, collect, peer-review, publish, and thus circulate the findings of doctors who worked abroad.

Three factors were of particular importance in this context:

1) Practicing medical workers got acquainted with new diseases and plagues in these colonial environments (one may think, for example, of yellow fever and its long-lasting impacts on the health of people living in the colonies);

2) access to dead bodies for dissection was less constrained in the colonies than in Britain (cf. Harrison 4) plus their supply was at its peak during times of colonial warfare;

3) the geographical specifics sparked a whole new interest on the influence of weather and climate conditions on diseases.

In short, the insights gathered from the colonies triggered a change in the conception of the human body, as no longer only internal factors such as a wrong diet, immoral behavior, or sanitary disregard were considered as reasons for a disease. Owing very much to Newton's classical mechanics, the body was now seen as a more pneumatic or mechanical entity that directly responds to external conditions. In the books that I am going to present shortly, one encounters the contagious and lethal effects of dysentery and tropical fevers and their connections to the existing weather conditions in the colonies. To treat sick soldiers while they are in the field rather than replacing them with new troops highlights a new conception of military health that reflects the utilitarian tendencies of a medical market that relies 
on a fiduciary rather than an authoritative relationship between doctors and patients. Thus, instead of having sick soldiers removed from the military camps, they were now to be treated and restored within the military camp. Such a plan suggests the "centrality of economical considerations to military medical reform" and thus the direct influence of utilitarian thinking with regard to general medical treatment as has been so common in "nearly all the military and naval medical works of the eighteenth century" (Harrison 17).

Resulting from a tradition in which the rise of colonial empires impacted the early modern taxonomy of knowledge, according to which no longer experience and wisdom validate the production of truth, the medical work in Europe and the colonies reshaped the ideological framework of medical staff in the colonies accordingly. The roots of early modern medical sciences lie in the distinction between theorica and practica - the conversation about diseases and the application of truths (cf. Dear 393). Two schools of thought maintained this distinction and accompanied the modernization of medical thought - the non-utilitarian natural philosophical school with its epistemological traditions and the utilitarian natural philosophical school that is "geared toward the production of practical effects" (397). Two theories of the latter school as mediated via the medical literature of that time - the miasma theory of Thomas Sydenham and Herman Boerhaave's theory of diseases as resulting from an imbalance of natural activities - particularly in the early $18^{\text {th }}$ century advanced a mechanical conception of the body that is very much taken for granted in the books of this microstudy. Indeed, colonial practitioners experiencing tropical climates and studying the according fevers grew fonder of these approaches, in particular of the Leiden University professor's hydraulic model of the human body. Added to this interest is the new-found necessity of empirical work that allows for the production of truths about diseases and their cures - particularly based on the new commercial goods found in the colonies. Colonial powers such as Spain and England established institutions - the Casa de la Contratación in Spain and the colonial offices in England - responsible for controlling and developing empirical practices that supported the seizure of the natural goods from the colonies (cf. Barrera 164). In these new knowledge-producing practice regimes, strategies for the collection, systematization, archiving, and channeled dissemination of authoritative knowledge accumulated. Hence, I will focus on the practice of John Fothergill's letter writing and 
publication requests that are formative for the enunciative possibilities of 'professional' medicine in the North American colonies.

John "Fothergill [...] was the linchpin of the medical community in England [...] His great strengths as a physician were practical and empirical: he was restrained in the use of the lancet, and he listened to and watched his patients" (Rousseau 53-54). In 1748, his book An Account of the Sore Throat Attended with Ulcers made the young physician's name well known far beyond the kingdom's borders. It was widely read and saw a plethora of editions. As a consequence, "his advice was sought in writing by practitioners in more distant parts, in the British colonies, and other countries" (Fox 20). An avid reader and writer, Fothergill kept his relations with former study colleagues from his circles at the Edinburgh University and the Royal Medical Society of Edinburgh, among them Dr. Georgius Cleghorn, an appointed surgeon in the $22^{\text {nd }}$ regiment of Foot stationed in Minorca. Both communicated in fluent Latin, the literary code of the time, and, in light of Sydenham's Observationes Medicae, shared an interest in the nexus between meteorological observations and medical therapy. Fothergill passed on books for Cleghorn's library abroad and repeatedly encouraged him to write up his observations of the Minorcan climate and the fever epidemics in the colony. Upon Cleghorn's return to England in 1750, Fothergill invited him home and eventually financed the publication of his Observations on the Epidemical Diseases of Minorca from the Year 1744 to 1749 . The book ran in five editions and was even translated into German (Fox 20).

Cleghorn's study shall be of particular interest, as it illustrates the codified relations between a precisely constructed, working object - the surgeon's experience with a native herbal therapy for dysentery and fevers - and the author's epistemologically encoded enunciation of this knowledge in his role as the bearer of medical truth. On pleurisy, he writes:

To ease the pains in the breast the large leaves of opuntia, toasted in an oven, and split through the middle, were frequently applied: these being thick and succulent, retain the heat a long time, and produce all the good effects that attend anodyne emolient cataplasms and fomentations; as I have frequently experienced in tertian fevers, dysenteries, and other diseases with inflamed bowels, as well as in this disease, since I first learned the virtues of the leaves from the natives of Minorca. (169) 
The opuntia, or Indian fig, is a significant good here. Cleghorn earlier on introduced the fruit in likening it to "fruits common in England" (11) and by stressing the economic availability of the fig tree as one "which not only produces large quantities of excellent fruit (some kinds of it, two crops in a year) but affords a convenient shade" (12), thus making it attractive as a commercial trading good. In the above quote, opuntia is applied as a compress to cure fevers. In order to construct opuntia's value as a credible healing plant, however, Cleghorn stresses his experience through the method of observation and establishes his credibility through his direct access to the natives of Minorca. Folk healers thus are granted authority and knowledge, but at the same time this position is seized by Cleghorn's superior position as observer and interpreter of the native tongue. He produces knowledge about the economic and medical value of a colonial natural good and defines its value in economic terms for the Western medical market. It is through his narrative mediation of his observations that Cleghorn enunciates the rational code of his discipline, hails the representatives of his educated medical group, and reiterates the knowledge producing mechanisms of his discipline. Simultaneously, the superiority and authority of the English surgeon's knowledge is sustained by his repeated condescension of the natives' rampant superstitions: "In the opinion of the natives no diseases are more frequent here than witchcraft, charms, and evil spirits. Those nevertheless, I shall entirely omit, having neither leisure nor inclination to enlarge upon the craft of the clergy, and the credulity of their flocks" ("Introduction" 40). Being encouraged and brought into circulation by Fothergill's financial aid, Cleghorn's study allowed for a priori knowledge by contrast to other Western writers, but more importantly, a representation of the superiority of empirical natural history to folk medicine.

In a similar vein, Fothergill supported the work of William Hillary, a former friend from Bradford. Hillary was probably apprenticed at the same apothecary as Fothergill. The London physician supports the Bradford apprentice in his wishes to serve abroad and as the Society of Friends' 'correspondent' to Barbados (Fox 299) arranges for him a position as appointed surgeon on the island. Again, the epistolary friendship between the two allowed for a vivid flow of information and Fothergill eventually encouraged and sponsored Hillary in putting together his observations of the tropical diseases and the weather conditions. Published in 1759, 
his book Observations on the Changes of the Air and the Concomitant Epidemical Diseases in the Island of Barbados includes a description of tropical sprue and gives advice on fashion choices in the tropical climate of Barbados. Harrison points to Hillary as "one of the first to claim that a study of a particular locality [...] might have relevance for other climates in the Torrid Zone" (56). In his writings, Hillary establishes a distance to the superstitious beliefs of the native population and establishes his observation as more rational and empirical. Interestingly, Hillary seeks a different mode of producing credibility about his observations by referring to colonial explorers and authenticating their encounters with the native population:

We are told by some of the first Voyagers into this Part of the World, that the original Natives of these Islands were then and still are so subject to a cutaneous Disease, $[\ldots]$ which they call in their Language a Cowrap; that they have a Tradition among themselves, that one of the seven first People that were created when the World was first made, (for so many they say were at first created) was a Cowrap. (353)

Here Hillary seizes the privileged position of fellow colonizing authorities as a mediating means for framing an argumentative link with already established travelogues and accounts of those who cartographed Barbados in the first place. His work is thus to be read in line with the truth claims of these authorized accounts.

Both examples of medical literature matter as they will be among the first on the shelves of the Medical Library of the Pennsylvania Hospital (Pennsylvania Hospital 20-21) and therefore enable, constitute, and constrain the constructions of medical knowledge of the physicians and students who seek access to the institution. Again, it is due to Fothergill's epistolary discipline and his privilege earned by kinship (his father) and his accumulated wealth that his funded research projects find their way to Philadelphia. Resulting from his father's travels to the North American colonies, Fothergill represented the Society of Friends as official London correspondent. As such, he was in close correspondence with the acclaimed horticulturist John Bartram, who provided Fothergill with rare seeds for his herbal garden in Surrey. The botanist also was an original member of the American Philosophical Society, the first learned society in the North American colonies. Functioning as patent office, national academy of science, and both national library and museum, the Society holds a pivotal position in governing the 
enunciation of 'professional' knowledge, or in short what is said or unsaid, recorded or unrecorded in the dawning American scientific discourse. Another founding member, Benjamin Franklin, would become another dear penpal to Fothergill. It is in a conversation with Franklin that Fothergill was able to get involved in what is to become "his dearest project" (Corner 78) in writing and designing from afar, the Pennsylvania Hospital.

Dr. Thomas Bond, another study friend of Fothergill, instituted the Pennsylvania Hospital in 1751. This decision was supported by Benjamin Franklin, who was the magistrate of the Pennsylvania Almshouse, the intended location of the Hospital, in 1753. It was eventually commissioned in 1755 . At that time, it was already an established tradition for practicing physicians to give lectures in obstetrics in the almshouse. A close connection to the College of Philadelphia was additionally fostered by the commissioning of both an anatomical theatre and the medical library. As Fothergill during the "transit of culture" (Shryock 18) received medical students from the colonies in his home, he was able to maintain the correspondence with the intelligentsia of the colonies. In 1762, the London physician sent a small parcel to the offices of the Pennsylvania Hospital in Philadelphia: a textbook, some anatomical drawings, as well as three anatomical plaster casts. He proposed this shipment as "a present to the Hospital of some intrinsic value" (qt. in Fox 367), which arrived conveniently on time for the opening of the Medical Library at Pennsylvania Hospital, the first of its kind in the North American colonies. The book sent by Fothergill, the Experimental History of the Materia Medica by William Lewis, was not only the first book to be included in the library collection but would also become a significant resource for Dr. Shippen's students, as would the anatomical plaster casts.

The package was delivered by Shippen upon his return from his studies in England. The enclosed note by John Fothergill proposes him as an apt choice as practicing physician, natural historian, and scholar in Philadelphia. Fothergill also announces "an able assistant” (qt. Fox 367)

2 The term refers to the institutionalized 'professionalization' of American physicians. In large numbers they traveled to Edinburgh or London. Once arrived in either of these 'medical centers' they intended to study medicine and then (most often) returned to the colonies as "first-class medical men" (cf. Shryock 18-19). 
to Shippen, Dr. John Morgan, who in 1765 will found the Pennsylvania School of Medicine. Modeled on the University of Edinburgh, this school advocated bedside training and thus worked in close cooperation with the Pennsylvania Hospital. In this sense, Fothergill supported the introduction and application of European utilitarian medicine in Philadelphia and thus the foundation of the profession:

Whether practical or theoretical, European training translated to vastly increased credibility in Philadelphia. Even in 1762, the young William Shippen lectured on anatomy before an amphitheater packed with auditors whose age and experience far outstripped Shippen's twenty-six years. The famed brothers [William and John] Hunter contributed the content of his lecture. Fothergill contributed the anatomical plates he used to illustrate his arguments. The prestige of Europe gave a young man something to teach his elders. (Finger 39-40)

Elsewhere it has been established that the anatomical studies based on William Harvey's insights on the body's circulatory system that Shippen, Morgan, and Bond represented and further developed in their work already has impacted the perception of systems beyond the medical realm. For example, "theorists like William Paterson likewise imagined the economy as a closed body-system where wealth could be circulated and re-circulated" (Landers and Muñoz 3). ${ }^{3}$ Hence, the opportunities for researching and mastering the physical conditions of the human body goes hand in hand with improving and exploiting the workforce of human capital in the market economy. This ties in well with Fothergill's financial support of the hospital and the medical school. As an official manager of the Hospital, he sent funds, had a say in the human resources of the hospital, and gave advice on the handling of real estate funds and the venture capital trust of the hospital:

Permit me just to mention what has sometimes occurred to my thoughts respecting the disposition of the money. I would by no means be thought to dictate in the least. Would it not be proper to vest $£ 6000$ or $£ 7000$ in proper securities, land or otherwise, towards the constant support of the house and employ the residue according to the present exigencies? (Fothergill to James Pemberton qt. in Fox 374)

In addition to the established literary tradition of discrediting folk medical conventions in the 'professional' literature of colonial surgeons that form

3 Paterson later institutionalized his thinking as a co-founder of the Bank of England. 
the knowledge basis of the first medical library in Philadelphia, the impact of the epistemological traditions of a utilitarian natural philosophical school are palpable in the foundation of the medical tradition of the Northern American colonies. ${ }^{4}$

Lastly, Fothergill also opened his doors to another notable historical character in the American medical tradition during the 1760s. When Benjamin Rush studied in England, Fothergill and his wife saw the young student as a frequent guest over breakfast. It is to no surprise that the English physician in his letters to Thomas Bond recommended Rush as another suitable candidate for the newly established medical school in Philadelphia. Upon his return to North America, Rush was to become the new professor for chemistry - "thus all four of the first faculty of the University of Pennsylvania School of Medicine [Bond, Morgan, Shippen, and Rush] had been encouraged and advised by Dr. Fothergill" (Corner and Booth 15). Today, Rush is remembered as one of the Nation's Founding Fathers and for his pioneer work in smallpox vaccination. However, when looking closely on the shelves of the Medical Library of the Pennsylvania Hospital at the beginning of the $19^{\text {th }}$ century, we find again newer editions of Hillary's and Cleghorn's works. All are edited by Benjamin Rush and feature notes of praise and further annotations. By then, these colonial medical books had become a staple in the medical school's curricula and library. By contrast to the lectures on obstetrics and anatomical studies in Philadelphia, this form of re-publication, annotation, and recirculation proposes a system that relies on serial repetition as a means to manifest credibility and the effectiveness of a utilitarian approach to medicine.

As this microstudy has shown, the British American colonies can be read as a breeding ground for new theories of diseases, their causes, and the corresponding treatments. This development is supported by the circulation and commercialization of medical print media in the first regulated

4 Utilitarianism as a mental concept emerges before its explicit use by intellectual pioneers such as Jeremy Bentham. As this paper proposes, a similar movement can be traced in the medical discourses of the time. Here a thinking about what, how, and why something is valuable emerges. Fothergill's epistolary web shows that his transnational endeavor aims at establishing a universal notion of 'value' in medical concepts. 
medical institutions and their practices of knowledge production. Further, this medical knowledge was spread through semi-institutionalized networks such as Fothergill's epistolary web that propelled media change from folk medical knowledge (oral) to institutionalized ('professional') knowledge in textbook-formats. As the writings by Hillary and Cleghorn have shown, colonial medicine revalued folk medicine and made possible the appropriation of folk traditions in 'professional' medicine. In that sense, colonial medical practice can be argued as being bound to semi-institutionalized spaces that are connected to custodians of knowledge but work like social networks - they are user-based, community-driven, and rely on a semiauthoritarian dispersion of knowledge. This microstudy has further shown how the established medical tradition is countered by colonial medicine's reliance on then new medical theories such as those of Harvey, Boerhaave, and Sydenham. Thus, colonial medicine on the surface is to be seen as being in constant conflict with the established medical profession in Britain. However, colonial medical institutions and their ways of knowledge production penetrate established 'professional' networks in the Old World by re-appropriating their established practices of knowledge production such as archiving, bedside training, and the facilitation and management of medical schools.

As can be seen in the accounts of Cleghorn and Hillary, colonial medical writings also read like travelogues. They report experiences resulting from cross-cultural contact, relate travel routes, and observations about folk medical practice. By the same token, they negotiate authorship, authority, and agency of the reporting observer. Further Fothergill's letters have a legitimizing function: as a patron and official London correspondent to the Society of Friends he has a gatekeeping position that allows him, as a man of letters, to decide on and forward "working objects" that can become objects of knowledge. In his letters, the enclosed documents, and his recommendations regarding staff and finances, Fothergill has a share in enabling, constraining, and constituting medical practices and forms of knowledge. Both the textbooks and Fothergill's letters trace colonial medicine's transformation from a set of practical skills to a systemically shaped and regulated body of knowledge. That these text forms borrow from established literary genres is reminiscent of the missing gap between literature and science of that age. Science as well as the notion of "professional" are still anachronisms here 
and would only become fashionable in the $19^{\text {th }}$ century as terms to tell apart the acquisition of knowledge from reading or studying of letters or books and the very form of knowledge as a personal attribute. Until then, "science was in effect a variety of literature," or as Matthew Arnold has it, literature "could include 'everything written with letters or printed in a book" (Otis xvii-xviii).

\section{Works Cited}

Barbour, Hugh, and J. William Frost. The Quakers. New York: Greenwood, 1988.

Barrera-Osoria, Antonio. "Local Herbs, Global Medicines: Commerce, Knowledge, and Commodities in Spanish America." Merchants and Marvels: Commerce, Science, and Art in Early Modern Europe. Ed. Pamela Smith and Paula Findlen. New York: Routledge, 2002, 163-81.

Cleghorn, Georgius. Observations on the Epidemical Diseases of Minorca from the Year 1744 to 1749: to which is prefixed a short account of the climate, productions, inhabitants, and endemial distempers of Minorca. Philadelphia: Printed for F. Nichols; Silliam Fry, printer, 1812.

Corner, Betsy Cooper. "Dr. John Fothergill and the American Colonies." Quaker History 52.2 (1963): 77-89.

-, and Christopher C. Booth. Chain of Friendship: Selected Letters of Dr. John Fothergill of London, 1735-1780. Cambridge: Belknap, 1971.

Daston, Lorraine, and Peter Galison. Objectivity. New York: Zone, 2010. Finger, Simon. "An Indissoluble Union: How the American War for Independence Transformed Philadelphia's Medical Community and Created a Public Health Establishment." Pennsylvania History: A Journal of Mid-Atlantic Studies 77.1 (Winter 2010): 37-72.

Fothergill, John. The Works of John Fothergill, M.D., Vol. II. Ed. John Coakley Lettsom. London: Printed for Charles Dilly, in the Poultry, 1783.

Fox, R. Hingston. Dr. John Fothergill and His Friends: Chapters in Eighteenth Century Life. 1919. Middletown: Cornell University Library, 2015.

Harrison, Mark. Medicine in an Age of Commerce and Empire: Britain and Its Tropical Colonies 1660-1830. Oxford: Oxford University Press, 2010. 
Hesford, Wendy, and Eileen E. Schell. "Configurations of Transnationality: Locating Feminist Rhetorics." College English 70.5 (2008): 461-70.

Hillary, William. Observations on the Changes of the Air and the Concomitant Epidemical Diseases in the Island of Barbados: to which is added a treatise on the putrid bilious fever commonly called the yellow fever and such other diseases as are indigenous or endemial in the West India islands or in the torrid zone. London: Printed for L. Hawes, W. Clarke and R. Collins, 1766.

Landers, Matthew, and Brian Muñoz. "Introduction". Anatomy and the Organization of Knowledge, 1500-1850. Ed. Matthew Landers and Brian Muñoz. Brookfield: Pickering \& Chatto, 2012.

Otis, Laura. Literature and Science in the Nineteenth Century: An Anthology. Oxford: Oxford University Press, 2009.

Pennsylvania Hospital. A Catalogue of the Books Belonging to the Medical Library in the Pennsylvania Hospital; to which Are Prefixed the Rules to Be Observed in the Use of Them. Philadelphia: Printed by Zachariah Poulson, jr. On the West Side of Fourth Street, between Market-Street and Arch-Street, 1790.

Rousseau, George Sebastian. "Ingenious Pain: Fiction, History, Biography, and the Miraculous Eighteenth Century." Eighteenth Century Life 25.2 (2001): 47-62.

Shryock, Richard H. Medicine and Society in America, 1660-1860. Ithaca: Cornell University Press, 1960.

White, Hayden. "The Value of Narrativity in the Representation of Reality." Critical Inquiry 7.1 (Autumn 1980): 5-27. 


\title{
Anthony John Harding Wordsworth, The Excursion (1814), and the Crisis of Knowledge
}

\begin{abstract}
This essay proposes to read Wordsworth's undervalued poem The Excursion as a response to the late-Enlightenment turn towards philosophical skepticism associated with the thought of John Locke, David Hume, and Immanuel Kant. Their ideas helped to dethrone Cartesian metaphysics and to unsettle Western culture's religiously based conception of what it means to know, while industrialization and profit-driven commercial values brought about profound social changes. In this context, the poem is a response to a crisis of knowledge that is both personal to Wordsworth and part of a much broader $19^{\text {th }}$-century realignment of the relationship between philosophy and poetry. As a basis for a future ethics and politics, The Excursion embraces a limited kind of knowledge rooted not in religious belief (despite its frequent references to the human capacity for faith), but in a secular, anthropological understanding of human experience.
\end{abstract}

\section{The Excursion and the $19^{\text {th }}$-Century Reader}

Despite recent work by Sally Bushell, Kevis Goodman, Paul Hamilton, Stephen Gill, and others, The Excursion is still widely regarded as one of the less approachable works in the Romantic canon, and an artistic failure, even if, for some critics, an interesting one. Kenneth R. Johnston, whose Wordsworth and The Recluse still provides one of the most perceptive commentaries on the poem, astutely remarked that Wordsworth "gave his Victorian epic [The Excursion] to the Romantics; his Romantic one [The Prelude], to the Victorians" (291). Johnston's description of The Excursion (first published in 1814) as a Victorian epic encapsulates the way in which modern readers tend to perceive the poem: its tone of high seriousness appears to today's readers more "Victorian" than "Romantic," and for most of the $19^{\text {th }}$ century it was certainly more highly respected, and considered more influential, than it has been for the past hundred years.

To understand not just why this poem came to be so highly valued by Victorian readers, but also what it reveals about the era in which it was published, it is necessary to redirect attention away from the usual "romantic" 
preoccupation with an individual's experience of crisis (emotional, spiritual, or "existential”), exemplified in Byron's Childe Harold, Keats's Odes, and Wordsworth's own Prelude, and consider the broader epistemological crisis of Wordsworth's time, a crisis of knowledge which was simultaneously a crisis of religious faith and of political stability.

Locke's Essay Concerning Human Understanding had rejected the Cartesian system of metaphysics as too reliant upon philosophical conceptions or "innate principles" that were themselves based on nothing more than ancient, unexamined dogmas, such as the notions of "Substance" and "Cause." Locke took the radical approach of beginning his enquiry by examining the human understanding itself, to "see what objects our understandings were or were not fitted to deal with," as he put it in "Epistle to the Reader." The Essay belongs to the early phase of the Enlightenment: it asked the fundamental, potentially disquieting question "what can we know?" - the same question that Kant was to revisit many decades later.

In Book II, however, Locke did provide an account (one that, for many readers, was persuasive) of how the human mind builds up, or arrives at, its ideas. This is known to philosophers as the Lockean "philosophy of experience.” By the time of Wordsworth's birth, Locke was required reading at the universities, his "philosophy of experience" existing more or less comfortably alongside mainstream Christian belief. But the far more radical skepticism of David Hume - doubting the permanence and coherence of the mental constructs Locke named "ideas" - demonstrated that ideas are all too easily subject to the vagaries of human emotions and imagination, and that our supposed "knowledge," all the way up to the idea of God, is at best mere probability, not certainty. This philosophical challenge threatened to leave a complete void where religious belief had once been. It was this crisis of knowledge that led Kant to arrive at his carefully-crafted distinction between the Pure and the Practical Reason, assigning religious beliefs to the domain of the Practical Reason.

The Excursion was written specifically as a response to this contemporary situation - not only the political upheaval associated with the French Revolution, but the "Copernican Revolution" in thought brought about by Kant's first two Critiques. It was therefore very much a poem both of and for its own time. To balance Johnston's characterization of The Excursion as "Victorian," I would recall David Simpson's equally true assertion: "this 
is a poem that must be central to any coherent understanding of Wordsworth, and to any scrupulous account of what Wordsworth meant to his contemporaries" (185).

This essay, therefore, takes up Simpson's emphasis on the contemporaneity of The Excursion, setting aside its embryonic "Victorian" qualities. The aim of the essay is to demonstrate that the poem is a response to a crisis of knowledge that is both personal to Wordsworth and part of a much broader $19^{\text {th }}$-century realignment of the relationship between philosophy and poetry.

\section{The Recluse project and The Prelude of 1805}

When Wordsworth first conceived of The Recluse, at the time of his close collaboration with Coleridge in the late 1790 s, it was envisioned as a response to the political, moral, and epistemological crisis of the time. It was to be a poet's affirmation of hope, signaling the way forward after the reformers' hopes for social and political change were crushed by the combined effects of the French revolutionists' swerve from democratic republicanism to repression and militarism, and the British government's brutal suppressing of dissent.

The Recluse was to be "addressed," as Coleridge put it in the autumn of 1799, "to those, who, in consequence of the complete failure of the French Revolution, have thrown up all hopes of the amelioration of mankind, and are sinking into an almost epicurean selfishness" (qtd in Moorman 443). The crisis of hope that Wordsworth's contemporaries faced at the start of the new century called for nothing less than a new way of knowing, of which poetry must be the vehicle. As the political philosophers had apparently failed to offer any real grounds for confidence or reasons for optimism, it was time for a poet to attempt a recovery of the hopes for the "amelioration of mankind" that so many had abandoned.

Coleridge himself later remarked that he "looked forward to 'The Recluse' as the first and only true philosophical poem in existence" (qtd in Wordsworth, Poetical Works 5.364). From this perspective, The Excursion did not seem an auspicious start. Yet in many ways, the poem did succeed in defining what one scholar calls the "epistemological and political crisis" that marked the reception of Kant's writings (Swift 2). 
Coleridge's wish that his friend address a blank verse poem "to those, who [...]. have thrown up all hopes of the amelioration of mankind" was not an abandonment of the progressive outlook characteristic of lateEnlightenment writing, but rather a proposal that the two poets - "jointlabourers in the work" 1 - take a longer and more comprehensive view, just as William Godwin had already begun to do in his 1797 publication The Enquirer. In "Essay III" in that work, Godwin remarks on how the "promise of understanding" is commonly seen in young children, even in the children of peasants, but by age fourteen the traces of these gifts are obliterated: "They are brutified by immoderate and unintermitted labour. Their hearts are hardened, and their spirits broken, by all that they see, all that they feel, and all that they look forward to [...] [T] he present order of society [...] is the great slaughter-house of genius and of mind" (89). Part of this striving towards a more comprehensive view, for Coleridge as also for Godwin, entailed a thorough reexamination of the grounds of human knowledge. But by 1799, Coleridge had come to believe that the way forward for such an investigation led not through Godwin's writings, but through those of Immanuel Kant.

Romanticists have tended to associate Coleridge's Kant studies too exclusively with his turn towards more conservative political views, and towards Trinitarianism, during and immediately after his sojourn in Malta, 1804-1805. But as Monika Class has recently shown in her meticulous and crucially important book, this underestimates how well-acquainted Coleridge had already become in the late 1790s with the general principles and purposes of the critical philosophy, and misrepresents the way Kant's thought was received and understood in the dissenting and radical milieux of England between 1796 and 1800. It is quite wrong, Class shows, to assume that Kantianism inevitably led to "escapism and political disenchantment" (38).

In particular, the London-based German scholar and lecturer Friedrich August Nitsch realized that the idea of freedom, both political and religious, "constituted a unique selling point of critical philosophy for his 1790s English audiences" (Class 43). It was thanks to Nitsch's work as an advocate

1 William Wordsworth, The Thirteen-Book Prelude. "Reading Text" (13.349), hereafter cited as Prelude [1805] followed by book and line numbers. 
for Kant's teaching, more than to any other intermediary, that English audiences learned about Kant's concept of the categorical imperative; and, as Class points out, the categorical imperative "served as a means against the unjust limitation of individual freedom; indeed it aimed to protect people's lives from religious and political control” (74). Three of the men with whom Coleridge was in regular contact in the late 1790s - Thomas Beddoes, John Thelwall, and William Godwin - either attended Nitsch's lectures in person or are known to have read the lectures as published his General and Introductory View of Professor Kant's Principles Concerning Man, the World, and the Deity. This introduction to Kant, published in 1796, "offered a possible formulation of the 'true laws' [of freedom] to the friends of freedom" - that is, among others, to Coleridge and his circle, which at this time included representatives of many intersecting groups opposed to the policies of William Pitt's government: Rational Dissenters, liberal Whigs, reformists, radical democrats (Class 82). Nitsch's General and Introductory View was widely reviewed in both radical-reformist and conservative periodicals. Both through this work and through other publications such as J. A. O'Keeffe's 1795 pamphlet On the Progress of Human Understanding (which particularly emphasized how the critical philosophy could support a radical politics), news of Kant's great revolution in philosophy would certainly have reached Coleridge's eyes and ears long before he first set foot in Germany in the autumn of 1798.

The idea that Kant's writings offered a strong philosophical underpinning for a progressive politics contradicts a view of Kantianism that has long been entrenched in Anglo-American scholarship, partly because of Coleridge's own later invention of a conservative, Christianized Kantianism. But it also helps to account for the peculiarly incompatible goals that Coleridge tried to set for Wordsworth, his fellow laborer, when in 1799 he urged him to address a blank-verse poem to those contemporaries who were disillusioned by the failure of the Revolution. Coleridge would have anticipated that in The Recluse Wordsworth would set out grounds for hope based not on pre-Kantian religious dogmatism, but on the critical philosophy's understanding of the limitations of human reason: admitting, as inevitable, doubts and mental sufferings such as those endured by Wordsworth's alter-ego the Solitary (who is often referred to in the poem as "the Sceptic"), but pointing towards a post-Kantian resolution, a new 
structure of knowledge that would be the basis for a new moral/religious belief system.

Yet this task posed a considerable challenge for a poet brought up in the tradition of Spenser and Milton. To be taken seriously, any new moral/ religious belief system would have to take as its starting-point philosophical skepticism, rather than faith. Kant had "saved" human freedom by giving up the possibility of achieving certainty in ultimate knowledge. For the rigorous Kantian, one cannot have knowledge of things-in-themselves at the same time as effective human freedom. This has its theological dimension too, as Kant admitted in the Preface to the 1787 edition of Critique of Pure Reason: "I have therefore found it necessary to deny knowledge, in order to make room for faith" (29). All of Coleridge's later career as a thinker was in a sense aimed at repairing this - to him - scandalous deficiency, positing the individual's conscience as the missing source of assurance, and placing the "Conscience, with its categorical Command" in the position of the authority that "proves it to be my Duty to choose to believe in a God" (Coleridge, Marginalia 4.409-10).

But if this program, a restatement of hopes for the "amelioration of mankind" based on what Coleridge understood as Kantian "practical Reason," were to be carried out in the way Coleridge hoped, the "poet-knowledge" that Wordsworth strove to preserve in the 1805 Prelude - that powerful statement of his poetic coming-of-age - would somehow have to be reconciled with (or absorbed into) a different, carefully-qualified kind of knowledge, grounded on the new philosophical order. It is clear from some of the speeches given to the Pastor in the later books of The Excursion that, though he never immersed himself in Kant's writings as Coleridge did, Wordsworth did have at least an informed layman's understanding of the critical philosophy. Yet, in the dialogues between Solitary, Wanderer, Poet, and Pastor, the Pastor's mild Kantianism ultimately carries rather less poetic force than the Wanderer's expressions of his unquestioning religious faith, and his deep love of nature.

A careful reading of the thirteen-book Prelude indicates that between 1798 and 1805 , Wordsworth was already developing his own sense of the kinds of knowledge that belonged particularly to the poet - the knowledge that sets the poet slightly apart from the rest of humankind, and provides those revelations and insights that only poetry is able to communicate. 
The word "knowledge" itself is used sparingly in the 1805 Prelude; but when it does occur, it is of crucial importance.

There is one passing reference to "knowledge" in the first fifty-four lines of the thirteen-book Prelude. It comes at the very end of the "glad preamble," when the poet enumerates those things he hopes will now occupy his days:

\section{the hope}

Of active days, of dignity and thought,

Of prowess in an honorable field,

Pure passions, virtue, knowledge, and delight,

The holy life of music and of verse. (Prelude [1805], 1.50-54)

As the 1805 Prelude was taking shape, then, it does not seem that the topic of "knowledge" was one the poet wanted to bring immediately to the reader's attention. ${ }^{2}$ The conclusion to the "glad preamble" suggests rather a mood of confidence than any great anxiety about whether the poet possessed the appropriate knowledge for his enterprise. In the climactic concluding line, the emphasis is on a way of life, "The holy life of music and of verse," an idea that seems to encompass and embrace all these other things in perfect harmony: "prowess in an honorable field, / Pure passions, virtue, knowledge, and delight." The "honorable field" can only be that of poetry; and the knowledge referred to is clearly the knowledge that belongs exclusively to a poet. This poet-knowledge is invoked again in the wellknown lines that describe how the River Derwent would "Make ceaseless music through the night and day," and how the sound of the river gave him, "Among the fretful dwellings of mankind, / A knowledge, a dim earnest of the calm / Which Nature breathes among the hills and groves" (Prelude [1805], 1.280, 284-86). But at this early point in the narrative, it is not clear how the poet of these pastoral beginnings can become one whose ambitions

2 Although some lines incorporated in the "glad preamble" are to be found in the earliest drafts of the poem, written at Goslar in the autumn and winter of 1798-1799, the preamble as a whole was probably not composed until after the fair copies of what is now referred to as the Two-Part Prelude had been completed by Mary Hutchinson and Dorothy Wordsworth, in mid-November 1799. By the spring of 1801 , it seems Wordsworth considered the lines as forming a preamble to his autobiographical poem; early in 1804 , they were definitively assigned this place, see Reed (1.5-6). 
are Miltonic in scope - who will eventually write the poem for his age, the poem referred to, from the time of its first conception, as The Recluse.

In Books 12 and 13 of the 1805 Prelude, the poet-knowledge alluded to in the "glad preamble" returns as a topic, but with a more explicit genealogy. Book 12 opens with a thoroughly naturalistic account of creativity: "From nature doth emotion come, and moods / Of calmness equally are nature's gift [...]" (12.1-2). The verse-paragraph that follows constitutes the poet's self-diagnosis or act of contrition, apologizing to nature for the error of having looked for knowledge in the wrong places: "Long time, in search of knowledge desperate, / I was benighted, heart and mind [...]" (12.20-21). The poet's recovery from this state of dark despair and mental paralysis is owed to another gift of nature, by which in early days he learned "To look with feelings of fraternal love / Upon those unassuming things, that hold / A silent station in this beauteous world" (12.50-52).

Such contemplation of "unassuming things" is represented as an erotically-charged experience. Wordsworth explicitly compares it to the "bliss" of "walking daily in Life's prime / Through field or forest with the Maid we love":

Oh! next to such enjoyment of our youth,

In my esteem, next to such dear delight

Was that of wandering on from day to day

Where I could meditate in peace, and find

The knowledge which I lov'd, and teach the sound

Of Poet's music to strange fields and groves (12.135-40)

"The knowledge which I lov'd" is clearly a knowledge derived from the apparently purposeless but actually creative activity of wandering: a connection that takes us back to the "glad preamble" and reaffirms its celebration of wandering "By road or pathway or through open field" (1.30). Such wandering - with no specific aim other than that of "meditat[ing] in peace" and finding, as if by chance, "The knowledge which I lov'd" - once again seems to be the primary, essential poetic activity from which everything else flows. Like the knowledge invoked in the "glad preamble," the knowledge so gathered is more a state of being - receptiveness of feeling, responding sympathetically to the things he sees around him - than a matter of collecting impressions or scientific data; even less, of philosophical enquiry. It is alluded to also in Book 6, when Wordsworth refers to the unprofitable 
time he spent as an undergraduate at Cambridge, and recalls that "My inner knowledge, / (This will I barely note) was oft in depth / And delicacy like another mind / Sequester'd from my outward taste in books [...]" (6.113-16). Yet it is this other mind, and the knowledge it possesses, that renews and energizes Wordsworth's poetic self.

In The Excursion, Wordsworth brings the poet-knowledge he has discovered through reflection on his own formative experiences into dialogue with the disillusionment of the post-revolutionary age, as exemplified in the character of the Solitary.

\section{Wanderer and Solitary: "what avails Imagination high / Or Question deep?”}

The character of the Wanderer has a long and complex history. First introduced as the Pedlar in the earliest manuscript of "The Ruined Cottage" in 1797 , he was developed and given his own history in 1798, then renamed "the Wanderer" some years later, as Wordsworth worked on The Excursion from 1806 until its first publication in 1814 (Gill 49; Butler xii-xiii). Some aspects of the Pedlar's boyhood, as described in the 1798-1799 manuscripts, particularly the intense and transformative experiences he has when alone among the mountains, were transferred with minimal revision into the 1805 Prelude. This suggests to most critics that the Pedlar/Wanderer was, if not a persona of Wordsworth, at least an embodiment of some of his feelings and responses (see Bushell 38; Gill 63, 68-69; Johnston 95, 99; J. Wordsworth, 17).

In 1801, however, Wordsworth gave the Pedlar a Scottish birthplace and upbringing. This stayed with him as "the Wanderer" in the 1814 text, perhaps signaling that the Pedlar was not after all to be identified with Wordsworth himself. But in the notes that Wordsworth dictated to Isabella Fenwick in 1843, he partly modified this act of authorial distancing, remarking, "had I been born in a class which would have deprived me of what is called a liberal education, it is not unlikely that being strong in body, I should have taken to a way of life such as that in which my Pedlar passed the greater part of his days. At all events I am here called upon freely to acknowledge that the character I have represented in his person is chiefly an idea of what I fancied my own character might have become in his 
circumstances" (Excursion 1214-15 [Appendix III]). This is an interesting claim, as if the mature Wordsworth were reluctant to disown the youthful spiritual enthusiasm of the Wanderer, and was even to a degree doubtful whether "what is called a liberal education" was anything more than a suit of clothes that might not fit the wearer.

Whatever part Wordsworth's younger self may have played in creating the Wanderer, the salient point about this figure in the 1814 Excursion is his profound belief in God. As the narrator tells us in his account of the Wanderer's early life, "in the mountains did he feel his faith" (1.247); and this religious conviction remains with him in old age. He has the awesome assurance of a man who has never had religious doubts.

By contrast, Wordsworth says rather less about the individual on whom the Solitary is based; but more than one scholar has suggested that the Solitary is at least as much a version of Wordsworth himself as the Wanderer is (Johnston 264-65; Gravil 207). He shares with Wordsworth some emotionally devastating experiences - notably the loss of his two children, and later his bitter disappointment over the course taken by the Revolution; and his opposition to the new economic theory is identical to Wordsworth's own. In the wider context of Wordsworth's hopes for The Recluse, the skepticism and despondency of the Solitary - his acute awareness of the fragility and thinness of human knowledge - are a dramatic device, a way of dramatizing the need for the supposedly corrective and cheering reassurances of the Wanderer, and later, the Pastor. But the Solitary also poses a challenge of a different kind: the questioning and implied rejection of traditional theodicy. In this drama, the Solitary is a Hamlet figure; that is, one who raises metaphysical questions that the subsequent dialogue and action cannot possibly resolve.

The plan of The Excursion calls for the older men - the Wanderer and the Pastor - to take the role of instructors, imparting the knowledge they have gained over many years of meditative thought and of quiet interaction with those rural dwellers whose "passions" are "incorporated with the beautiful and permanent forms of nature," as it is expressed in the 1802 "Preface" to Lyrical Ballads (21). In Book 4 ("Despondency Corrected”), the Wanderer, often referred to as "the Sage," or "venerable Sage," recommends to the discouraged, doubting Solitary that he learn from his rural neighbors, who live simply, but in a dignified, self-reliant manner: 
"These, with a soothed or elevated heart, May we behold, their knowledge register, Observe their ways; and, free from envy, find

Complacence there" (4.384-87)

The Wanderer's tendency to praise the knowledge of poor rural folk was an offence against the prejudices and assumptions of early $19^{\text {th }}$-century readers. ${ }^{3}$ But the high valuation the Wanderer places on the knowledge of rural people is a move that is written into the very argument of the poem. Though radical in terms of the aesthetic of the time, it does also harmonize with the Wanderer's argument for religious faith, which to modern tastes is a more "conservative" feature of the poem.

In the opening section of Book 4, from which these lines are taken, the Wanderer is attempting to diagnose the moral and spiritual sickness from which the Solitary suffers, a sickness closely related to the general crisis of the time. The Wanderer blames the Solitary's political pessimism, "The loss of confidence in social Man" (4.262), on excessive, utopian hopes, "exalted confidence" (4.267); and, in a remark that now appears even more dogmatic, he recommends to the Solitary - who has lost his wife and two children to sudden, unexplained illnesses - dutiful submission to the will of God, and the law of conscience:

"- The darts of anguish fix not where the seat

Of suffering hath been thoroughly fortified

By acquiescence in the Will Supreme

For Time and for Eternity" (4.18-21)

At such a point, the reader may find something almost inhuman in the Wanderer's rock-solid religious faith.

However, the Wanderer also recommends that the Solitary pursue knowledge of the world around him, provided he does it in a "meek" and "humble" spirit. The description of the Solitary's humble cottage in Book 2 has made it sound like the laboratory of a gentleman scientist, the instruments and paraphernalia of haphazard scientific experiments being strewn around the floor and piled on tables (2.663-69). In Book 4, however, the Wanderer

3 It did not win Coleridge's approval either. In Biographia Literaria, he remarked: "whether this be a character appropriate to a lofty didactick poem, is perhaps questionable" (2.118); Hazlitt made a similar criticism $(4.113,123)$. 
recommends the cultivation of knowledge through a revised and updated version of the "Beatus ille" topos, a familiar one to those $19^{\text {th }}$-century readers who knew Latin, as it originates in Horace's Epodes II.i: “Beatus ille, qui procul negotiis, / Ut prisca gens mortalium, / Paterna rura bubus exercet suis, / Solutus omni faenore." This notion of the happiest man being the one who stays far removed from public affairs, tilling his "paternal acres" with his own oxen, is a familiar one in $18^{\text {th }}$-century poetry, and seems to point in the direction of Vergilian georgic. Here, the Wanderer's version of the "Beatus ille" trope emphasizes that the quest for knowledge is profitable only when it is carried out in a "meek, / Sincere, and humble Spirit":

"Happy is He who lives to understand!

Not human Nature only, but explores

All Natures, - - to the end that he may find

The law that governs each; and where begins

The union, the partition where, that makes

Kind and degree, among all visible Beings;

The constitutions, powers, and faculties,

Which they inherit, - cannot step beyond, -

And cannot fall beneath; that do assign

To every Class its station and its office,

Through all the mighty Commonwealth of things;

Up from the creeping plant to sovereign Man.

Such Converse, if directed by a meek,

Sincere, and humble Spirit, teaches love" (4.335-48)

This way of talking about knowledge as reassurance and delight, the discovery of an ordered "commonwealth of things" in which every thing has its "station," now sounds outdated, and not just because of the allusion to Horace. For some readers (such as Alan Liu), georgic is itself synonymous with a turn away from "history" towards the cultivation of self. In the present context, Kevis Goodman is surely right to argue against Liu that georgic tropes need not equate to a denial of history, and can function as "agents of disclosure" (3). There is a further issue to be considered, however: whether or not this way of talking about knowledge as reassurance and delight would also have sounded outdated, and even complacent, to many of Wordsworth's contemporaries.

There are two kinds of objection that can be raised against the Wanderer's concept of knowledge, and both objections were certainly available 
to Wordsworth's readers in 1814 . The first has to do with the natural sciences, the second with ethics. It was already becoming apparent to the more reflective thinkers and scientists of the time that the orderly hierarchy of species which the Wanderer seems to take for granted (with "sovereign Man" at its apex) derived more from the conditions under which human beings acquired and arranged their observations - from, that is, the limitations of humans' sense-perceptions, and the necessity for the mind to structure them under the categories of time and space - than from any order inherent in the universe itself. Further, though modern readers must be careful not to project a "Darwinian" understanding of the natural world backwards into the early $19^{\text {th }}$ century, in some scientific disciplines (geology, astronomy, life sciences) there were already stirrings of a non-anthropocentric, evolutionary understanding of universal forces.

The more strictly ethical problem with the Wanderer's pronouncement has to do with the revealing phrase, "sovereign Man.” The Wanderer's speech, with its references to "Kind and degree," alludes to the noble speech that Milton gives to the Angel Raphael, as he discourses to the not-yet-fallen Adam in Book 5 of Paradise Lost:

O Adam, one Almighty is, from whom

All things proceed, and up to him return [...]

Each in thir several active Spheres assign'd,

Till body up to spirit work, in bounds

Proportion'd to each kind. (5.469-70, 476-79)

The Wanderer cannot know that such a divinely-appointed hierarchical order exists - or rather, he can know it only as a deduction from his religious faith. By his own admission, it is "by faith" that he holds to this belief, this "support / For the calamities of mortal life" (Excursion 4.21; 10-11). The Solitary, lacking the Wanderer's faith, is guided by a wholly different kind of knowledge and by different assumptions about what knowledge is. Though he is an ordained minister of the Church of Scotland, he has seen the suffering and death of the innocent; he has witnessed the deaths of his two children and then of his beloved wife; and - almost equally devastating, since it robbed him of the hopes for the future of humankind that awoke him out of his intense grief for his own loss - he lived through the intoxicating time of early optimism about the Revolution, then the faltering 
and perversion of republican ideals, and the subjection of France to "iron bonds / Of military sway" (Excursion 3.829-30).

It is not surprising, then, that the Solitary's observations of the world cannot easily be brought into harmony with the Wanderer's pious assurances. Quite simply, what the Solitary "knows" is a knowledge radically different from the Wanderer's. It is the Solitary who in Book 2 (2.755-929) tells the story of the old man, living alone and virtually friendless, who died three weeks after spending the night on an upland fell - a narrative that once again brings into the poem the question: what is the purpose of a human life? And, why is it that some people's lives are destined to end with unmerited and often prolonged suffering? The question is first raised through the story of Margaret, in Book 1 of The Excursion. In its original form as "The Ruined Cottage," that part of the poem offered no reassuring formulations of comfort or recompense. Nor are these the only stories in the poem to raise these troubling questions: the narrative of Joseph Sympson, the "Patriarch of the Vale" (7.262), is similarly pessimistic, and even nihilistic. ${ }^{4}$

The Solitary's challenge to the Wanderer is an urgent restatement of the post-Kantian problem. When the Poet reminds him about his little friend, the "fair-faced Cottage-boy" (3.202), perpetually creating models of life (and in his ceaseless creativity very much like the "six years' darling" in the "Intimations" Ode), the Solitary's astonishing response is that it would be best if the boy never had to grow up at all - a remark that seems to echo a well-known line from Sophocles' Oedipus Coloneus, "Not to be born is best":

"Far happiest," answered the desponding Man,

"If, such as now he is, he might remain!

Ah! what avails Imagination high

Or Question deep? what profits all that Earth,

Or Heaven's blue Vault, is suffered to put forth

Of impulse or allurement ...

if neither in the one

Nor in the other region, nor in aught

4 The narrative of Joseph Sympson was originally written in 1808 and included in a never-published blank verse poem, "The Tuft of Primroses," see Kishel's introduction to The Tuft of Primroses with Other Late Poems for The Recluse (18). 
That Fancy, dreaming o'er the map of things, Hath placed beyond these penetrable bounds, Words of assurance can be heard; if no where

A habitation, for consummate good, Or for progressive virtue, by the search

Can be attained, a better sanctuary

From doubt and sorrow, than the senseless grave?"

(Excursion 3.212-17, 221-29)

From the Solitary's perspective, there is no longer any place on earth or in heaven where the thought of the highest ("consummate") good can reside, since human thought and will, though notionally free, are finite. Our faculties of imagination and reason prove to be incapable of discovering or hearing "Words of assurance," in any universe we can know. The Solitary is expressing, as a poet might, the very same bafflement that a contemporary would have felt, upon reading in the Critique of Practical Reason that

happiness and morality are two specifically distinct elements of the summum bonum, and therefore their combination cannot be analytically cognized ... but must be a synthesis of concepts. Now since this combination is recognized as $\grave{a}$ [sic] priori, and therefore as practically necessary, and consequently not as derived from experience ... it follows that the deduction [legitimation] of this concept [consummate good] must be transcendental. (209)

As our finite will and imperfect cognitive powers cannot of themselves combine virtue and happiness into harmony, it is necessary to refer the question to the "idea" of an infinite moral being. ${ }^{5}$ For the skeptic, the fact that our minds have developed the concept of a being possessing "infinite will, power, and intelligence" is of no help: it cannot prove that such a being exists. The Wanderer's answer to the Solitary's predicament is essentially that the words of assurance he seeks are to be found in the Bible. But the Solitary tells his companions that when he did turn to the Bible for such "guidance," he found none, because "the infallible support / Of faith was

5 This is well explained by Frederick C. Beiser's paraphrase of Critique of Practical Reason, "Dialectic," Section V: "our finite human will cannot be a sufficient cause for happiness to correspond with morality [...] the only such cause would be an infinite moral being, that is, one having an infinite will, power, and intelligence" (605). 
wanting” (3.872-73). In this part of The Recluse, the Solitary's “despondency" is not "corrected," his despair not replaced by faith.

\section{4 "We see, then, as we feel"}

In a poem that so often echoes the language of Milton, and contains many explicit allusions to Paradise Lost, a reader would expect to find some kind of reaffirmation of Christian theodicy. But the Solitary has what for us in the $21^{\text {st }}$ century is a recognizable kind of tragic knowledge: the knowledge of the waste of human potential; futile and apparently arbitrary suffering inflicted on innocent people who just happened to be in the way of forces outside their control, especially of human actions unthinkingly taken (wars, revolutions). His rejection of Christian faith is a rejection of traditional theodicy, according to which human suffering is part of a divine plan that will eventually redeem the fallen world. It is also an ethical stand against the transaction, the 'repayment' of 'debt,' that is implied in the redemption narrative. Even if God does intend to make everything right in the end, the skeptic says, I reject the idea of justifying the sufferings of individuals in this world in order to secure a more blessed future in another world.

In The Excursion, there is no equivalent to the story of redemption told in Paradise Lost. The Wanderer and Pastor instead offer an alternative, secularized kind of self-discipline and psychotherapy, based on love of nature and fulfilling one's obligations to a community - far short of a rigorously Kantian position (since for Kant, only the practical Reason, not "nature," nor the shared values of a community, could be a basis for moral faith). This is what seems to be suggested by how the Wanderer summarizes the Pastor's first speech: “'We see, then, as we feel,' the Wanderer thus / With a complacent animation spake" $(5.559-560)$. And for $19^{\text {th }}$-century intellectuals, as Johnston puts it, "placement of the human person at the center was the new condition of philosophy, not metaphysical elaboration" (118). ${ }^{6}$

For all the Wanderer's and Pastor's attacks on the skeptical trend in $18^{\text {th }}$-century thought, they both accept that humankind's reasoning powers are limited, and that stoic acceptance of one's fate is the wisest course.

6 As Paul Hamilton points out, in the Prospectus to The Recluse Wordsworth had already "secularized the Miltonic theological apparatus" (146). 
The Pastor gives this quasi-Kantian assessment of the constraints under which human reason must operate:

\section{"for ourselves,}

That speculative height we may not reach.

The good and evil are our own; and we

Are that which we would contemplate from far.

Knowledge, for us, is difficult to gain -

Is difficult to gain and hard to keep -

As Virtue's self; like Virtue is beset

With snares; tried, tempted, subject to decay." (483-90)

For the Wanderer, it seems that the key to overcoming despair and the poison of skepticism is to follow the lead of those who live as the Solitary's rural neighbors do. The "Shepherd-lad," as the Wanderer imagines him, sets his own internal moral clock by the regularity of nature's times and seasons. He learns to divide up his "pastoral duties" each day according to the sun's progress across the sky; and, the Wanderer continues,

"Early he perceives,

Within himself, a measure and a rule,

Which to the Sun of Truth he can apply,

That shines for him, and shines for all Mankind.” (4.803-06)

The implication is clear. The Solitary should learn from those who live simpler lives close to nature, those whose knowledge is formed from their daily routines and observations of nature's workings. He will thus discover within himself "a measure and a rule" that will enable him to live the rest of his days virtuously, and in contentment. With a similar intention, the Pastor offers his narratives about the lives of those who belonged to the Vale, exemplifying either in a positive sense or a negative one the values implicit in what the Poet later calls "The old domestic morals of the land" (8.238).

The poem certainly represents these domestic morals as under attack by the rapid social changes forced on communities by the factory system, and the displacement of old agrarian values by profit-driven commercial ones. This attempt to defend the values of traditional rural society has led some critics to conclude that the poem retreats from its original concern with the "amelioration of mankind" to a nostalgic, "Burkean" validation of ancient institutions - chivalry, the squirearchy, the Church of England, and so on (Chandler 25-26). 
However, it is also possible to see The Excursion as giving up the elusive assurance of faith for a limited kind of "knowledge" that takes its cue from the Pastor's words: “we / Are that which we would contemplate." Hamilton's commentary is illuminating:

our anthropological situation, how we fit in the world, is what makes Wordsworth think of advancement. We move forward not in line with a banal Whiggish interpretation of history $[. .$.$] but [\ldots]$ through a more Marxian idea of a natural history of self-transformation. (145)

Such a stance sets aside debates about religious belief as unnecessary and unproductive, treating the transcendent as acting powerfully on subjectivities like that of the Wanderer, but ultimately as something to be left to the individual conscience; and metaphysics as something to be left to philosophers. The poet, living closer to ordinary human beings, seeks a different basis for a future ethics and politics, one rooted in a secular, anthropological understanding of human experience ("how we fit in the world"); and in the accumulated knowledge shared by existing communities.

\section{Works Cited}

Beiser, Frederick C. "Moral faith and the highest good." The Cambridge Companion to Kant and Modern Philosophy. Ed. Paul Guyer. Cambridge: Cambridge University Press, 2006. 588-629.

Bushell, Sally. Re-Reading The Excursion: Narrative, Response and the Wordsworthian Dramatic Voice. Aldershot: Ashgate, 2002.

Butler, James. "Introduction." The Ruined Cottage and The Pedlar. Ed. James Butler. Ithaca: Cornell University Press, 1979. 3-35.

Chandler, James K. Wordsworth's Second Nature: A Study of the Poetry and Politics. Chicago: University of Chicago Press, 1984.

Class, Monika. Coleridge and Kantian Ideas in England, 1796-1817. London: Bloomsbury, 2012.

Coleridge, S. T. Collected Letters. Ed. E. L. Griggs. 6 vols. Oxford: Clarendon, 1956-1971.

-. Biographia Literaria. Ed. James Engell and W. Jackson Bate. 2 vols. Collected Works. London and Princeton: Routledge \& Kegan Paul and Princeton University Press, 1983. Bollingen Series LXXV, Vol. 7. 
-. Marginalia. Ed. H. J. Jackson and George Whalley. Collected Works. Vol. 4. Princeton: Princeton University Press, 1998. Bollingen Series LXXV, Vol. 12.

Gill, Stephen. Wordsworth's Revisitings. Oxford: Oxford University Press, 2011.

Godwin, William. The Enquirer. Ed. Pamela Clemit. London: William Pickering, 1993. Vol. 5 of Political and Philosophical Writings. Mark Philp, gen. ed.

Goodman, Kevis. Georgic Modernity and British Romanticism: Poetry and the Mediation of History. Cambridge: Cambridge University Press, 2004.

Gravil, Richard. Wordsworth's Bardic Vocation, 1787-1842. Basingstoke: Palgrave, 2003.

Hamilton, Paul. "The Excursion and Wordsworth's Special Remainder." Wordsworth's Poetic Theory: Knowledge, Language, Experience. Ed. Alexander Regier and Stefan H. Uhlig. Basingstoke: Palgrave Macmillan, 2010. 139-57.

Hazlitt, William. Complete Works. Ed. P. P. Howe. 21 vols. 1930-1934. New York: AMS, 1967.

Hume, David. A Treatise of Human Nature. Ed. L. A. Selby-Bigge. Oxford: Clarendon, 1888.

Johnston, Kenneth R. Wordsworth and The Recluse. New Haven: Yale University Press, 1984.

Kant, Immanuel. Critique of Pure Reason. Trans. Norman Kemp Smith. London: Macmillan, 1933.

-. Critique of Practical Reason and Other Works on the Theory of Ethics. Trans. Thomas Kingsmill Abbott. $6^{\text {th }}$ ed. London: Longmans, 1909.

Kishel, Joseph F. "Introduction." The Tuft of Primroses with Other Late Poems for The Recluse. Ed. Joseph. F. Kishel. Ithaca: Cornell University Press, 1986. 3-29.

Locke, John. An Essay Concerning Human Understanding. Ed. A. S. PringlePattison. Oxford: Clarendon, 1924.

Milton, John. Complete Poems and Major Prose. Ed. Merritt Y. Hughes. New York: Macmillan, 1957.

Moorman, Mary. William Wordsworth: A Biography. 1: The Early Years 1770-1803. London: Oxford University Press, 1957. 
Reed, Mark. "Introduction." The Thirteen-Book Prelude. Ed. Mark L. Reed. Vol. 1. Ithaca: Cornell University Press, 1991. 3-89.

Simpson, David. Wordsworth's Historical Imagination: The Poetry of Displacement. London: Methuen, 1987.

Swift, Simon. Romanticism, Literature and Philosophy: Expressive Rationality in Rousseau, Kant, Wollstonecraft and Contemporary Theory. London: Continuum, 2006.

Wordsworth, Jonathan. The Music of Humanity: A Critical Study of Wordsworth's Ruined Cottage Incorporating Texts from a Manuscript of 1799-1800. London: Nelson, 1969.

Wordsworth, William. Poetical Works. Ed. Ernest de Selincourt. 5 vols. Oxford: Clarendon, 1959-1972.

-. The Excursion. 1814. Ed. Sally Bushell, James A. Butler, and Michael C. Jaye, with David García. Ithaca: Cornell University Press, 2007.

-. The Ruined Cottage and The Pedlar. Ed. James Butler. Ithaca: Cornell University Press, 1979.

-. The Thirteen-Book Prelude. Ed. Mark L. Reed, 2 vols. Ithaca: Cornell University Press, 1991.

-. “Preface.” Lyrical Ballads 1805. Ed. Derek Roper. $2^{\text {nd }}$ ed. Plymouth: MacDonald and Evans, 1976. 18-48. 


\title{
Justus Conrad Gronau \\ Romanticism and Anoetic Knowledge
}

\begin{abstract}
Based on examples from Keats's and Shelley's poetic work, this essay addresses a paradox frequently encountered in Romantic thought between a turn to subjective, non-propositional, and sense-based ways of encountering the world on the one hand and the need to express these in linguistically based reasoning on the other. Romantic writing absorbs the epistemological uncertainty emerging from the simultaneous and frequently conflicting strengthening of adjacent epistemological fields like the literary, the scientific, and the economic. Poetry transforms this uncertainty into a key component of its own aesthetics. Seeking to articulate the epistemic value of limits of knowledge, the essay works toward a Romantic poetology of a particular form of non-propositional, not cognitively conceivable or 'anoetic' knowledge. A key characteristic of this poetology is a self-reflexive awareness of the paradoxical conditions and limitations of poetic mediality, an awareness nurtured by an explorative hovering between knowing and not knowing.
\end{abstract}

\section{The Limits of Knowledge}

Romantic literature is confronted with an inevitable paradox: while negotiating, producing, and legitimizing forms of knowledge and strategies of experiencing the world beyond linguistically based reasoning, these forms still need to be expressed in language. Especially within the realms of poetry, the Romantics dramatize ways of 'knowing' and approaching the world which are highly subjective, often non-propositional, and grounded on the senses rather than on rationality. At the same time, encountered limits of knowledge appear to be of epistemic value in their own right. The aim of this paper is to work toward a poetology of a particular form of knowledge in Romantic poetry which will be called anoetic knowledge, specifically demonstrated within selected examples from the Romantic poets John Keats and Percy Bysshe Shelley.

The Romantic age can be considered an age of epistemological uncertainties: the Romantics had to experience the second of the "two great discontinuities in the episteme of Western culture" (Foucault xxii) around 1800 which equally influenced the arts and sciences. This epistemological 
break at the turn of the $19^{\text {th }}$ century is deeply informed by the Kantian Copernican revolution and the following transcendental shifts eventually constituting the transcendental subject which increasingly observes and reflects on him- or herself while observing the world. Therefore, the concept of knowledge is under consideration as well:

The Romantic age is an age of seeking and contemplating new forms of knowledge. What distinguishes the period that begins in the 1770s is a sustained reflection on what constitutes knowledge and what its borders are. The nature of knowledge, whether it is in 'art' or a 'science,' whether it should be 'philosophical' or 'historical' or 'empirical,' whether there can be a 'disaggregation of disciplines' or whether the boundaries between disciplines are fluid - these issues were very much under negotiation during the Romantic period. (Fricke, Meifert-Menhard, and Pink 9)

The subject renegotiates the conditions of the possibilities of knowledge, frequently being confronted with its respective limits as already the first sentence of the preface to the first edition of Immanuel Kant's Critique of Pure Reason acknowledges limits of human reason (99 [A vii]). When Kant put the mind at the center of all philosophical investigation, he at the same time valorized "the pure (productive) synthesis of the imagination prior to apperception" (238 [A 118]), an idea that Romantic writers expressed, as M.H. Abrams has famously shown in The Mirror and the Lamp, through changing metaphors of mind, often "picturing the mind in perception as active rather than inertly receptive, and as contributing to the world in the very process of perceiving the world" (58). Exploring the powers of the imagination and what the subject might "half-create [...]/And what perceive" (Wordsworth, "Lines" 51-52, 11. 107-08), however, the Romantics also discovered the unconscious, its "unreason" and were confronted with a corresponding "trauma of not knowing” (Faflak 14). Indeed, already the Gothic tradition, "Romanticism's transgressive doppelganger”, as Rolf Lessenich calls it, "subverted both the earlier Enlightenment's and later Platonic Romanticism's optimism by recalling attention to and exploring man's ever-present dark unconscious and its everlasting enmity to clear reason and progress" (Romantic Disillusionism 14).

Furthermore, the potential of language as means of successful communication and tool to pinpoint the human condition is put to the test. Friedrich Schleiermacher, the 'father' of modern hermeneutics and a later friend of Friedrich Schlegel, affirms in 1809/1810 that the "foundation of all 
hermeneutics is the fact of non-understanding" ("Allgemeine Hermeneutik" 73 , translation mine). Romantic hermeneutics at the turn of the $19^{\text {th }}$ century reflects on the nature of human understanding and forcefully asserts the probability of mis- and non-understanding (Schleiermacher, "Hermeneutik und Kritik" 92). It is "vain”, as Romantic poet Percy Bysshe Shelley declares, "to think that words can penetrate the mystery of our being", if anything, "they make evident our ignorance to ourselves" (“On Life” 506).

In the context of such epistemological uncertainties, "Romantic writers explored epistemologies that questioned rationalist certainty and were similarly more open to categories of knowledge that hovered between knowing and not knowing" (Domsch 331). The Neo-classicist grand narratives of reason and rationality - indeed, the entirety of epistemologies that are derivative of the clare et distincte-principle - are under close scrutiny in the Romantic period. Hence Romantic aesthetics and poetics are informed by strategies dismantling reason and objective propositional knowledge. Among the most influential rank the Kantian aesthetics of genius already glimmering in his third Critique (Critique of Judgement 137 [B 182]), the radical exhaustion of the sublime and beautiful formerly theorized by Edmund Burke in A Philosophical Enquiry into the Origin of Our Ideas of the Sublime and Beautiful and again refined in Kant's Critique of Judgement during his "Analytic of the Sublime" (75-164), as well as a valorization of the (transcendental) imagination, fancy, and dreams as alternate means of accessing the world. In these contexts, Romantic literature, poetry at the front line, becomes a self-reflexive project, and repeatedly negotiates its mode and possibilities of being in a hovering state of uncertainty, which is expressed in German Romantic Friedrich Schlegel's aesthetic theory as the concept of Romantic irony between 1799 and $1801 .{ }^{1}$ Romantic literature absorbs the epistemological uncertainty of its time and transforms it into a key component of its own aesthetics and poetics.

A possible reason for these epistemological insecurities could furthermore be traced back to the broader context in which the discourse of the arts and sciences was situated. As Jon Klancher has shown, the Romantic period was marked by the explosion of several institutions of arts and

1 For a discussion of the transferability of German Romantic thinking to English Romanticism see Mellor. 
sciences, for example, "the Royal Institution (opened in 1800), the British Institution (1805), the London Institution (1806), as well as the Surrey (1808), Russell (1808), and Metropolitan (1823) Institutions among others" (1). These institutions had a deep impact on the discourses of the arts and sciences and their production, circulation, and legitimization of knowledge. However, "fields like the literary, the artistic, the scientific, or the economic emerged from the early nineteenth century with dramatically uneven criteria of what counts as 'knowledge' and which of these fields could most strongly lay claim to it" (4). The instability or even "contingent character" (12) of such institutions, the function of which ideally would have been to stabilize knowledge, is also reflected in unstable concepts of knowledge within Romantic writing.

Richard Holmes has aptly described the age of Romanticism in his eponymous book as an Age of Wonder, and this wonder can, firstly, be related to the manifold discoveries and inventions within the natural sciences in such fields as "astronomy, geology, physics, aeronautics, meteorology, chemistry, and geography” (Fricke, Meifert-Menhard, and Pink 13) which are recurrently discussed in Romantic poems as the "Preromantic and Romantic poets wrote their works in the midst of a lively dialogue with science" (Lessenich, "Erasmus" 167). This cannot only be discerned clearly in the works of male and female British Romantics alike, for example in Mary Shelley's Frankenstein: Or, the Modern Prometheus and Charlotte Smith's late poem "Beachy Head," to name but two female Romantic writers, but also within early German Romanticism when, for example, Novalis aimed at a synthesis of the most recent sciences and poetry - perhaps most powerfully represented in Klingsohr's fairy tale at the end of Novalis's novel Heinrich von Ofterdingen (232-58).

Secondly, the Romantic period can be conceived of as an age of wonder in a different sense. In one of the founding documents of Western epistemology, in Plato's Theaetetus - where Socrates makes very clear that he is ignorant of what knowledge might $b^{2}-$ Plato famously argues that

2 In this Platonic dialogue, Socrates affirms: "I can't get a proper grasp of what on earth knowledge really is" (161 [Theat. 146a]). As Andrew Bennett adds, "he is not joking. It's a principle that Socrates holds and holds to, even unto death" (10). In the Theaetetus, Plato lets Socrates discuss three definitions of 
wondering is precisely "where philosophy begins and nowhere else" (173 [Theat. 155d]). From Blakean innocence to sublime experience, the Romantics are frequently dealing with this wonder in the Platonic sense of thaumazein, "the feeling of astonishment and wonder which triggers off the process of questioning and reflection in the first place" (Richter 155, translation mine). Wonder and not knowing, in other words, are ultimately productive of knowledge and understanding - an idea that is expressed in Plato's "famous Socratic docta ignorantia" as the "knowledge of not knowing” (Gadamer 356).

Uncertainty with regard to the question of what constitutes knowledge, let alone what knowledge really is, is not merely an issue within Romanticism, (re)surfacing particularly in Romantic poetry and poetics: up until now, there is no unified consensus among philosophers and literary scholars of what constitutes knowledge, much less an ultimate definition of the term (Quinton 91-101; Borgards et al. 1). However, there have been several approaches to delineate the concept of knowledge. A distinction by now generally agreed upon is a basic differentiation between a theoretical knowledge and a practical knowledge. Such an analytical approach to the concept of knowledge has been proposed by Gilbert Ryle in The Concept of Mind, where he distinguishes between knowing that and knowing how. While theoretical knowledge (knowing that) is a propositional knowledge based on facts, practical knowledge (knowing how) indicates "an ability composed of skills, capabilities, and expertise that inscrutably defies propositional articulation and analysis," as Günter Abel specifies (246). These two forms of knowledge have found their equivalents, albeit with slight alterations, in concepts of an explicit and an implicit or tacit knowledge developed by Michael Polanyi. Explicit knowledge is "capable of being clearly stated" (The Tacit Dimension 22). The notion of a tacit knowledge, conversely, is based on the "fact that we can know more than we can tell" (4). This knowledge cannot be clearly represented or verbalized in language (Ernst and Paul 13). Both forms of knowledge do not necessarily exclude each other, although this is often the case. Indeed, the theoretical knowledge of

knowledge, namely a) knowledge as perception, b) knowledge as true belief, and c) knowledge as true belief with an account. Socrates ultimately rejects all of these definitions and the Theaetetus thus ends in an aporia. 
an action might even result in its failure, as Abel illustrates with the example of a "ballerina who, in the midst of her refined motions, begins to reflect on how she manages to make these motions successfully instantly loses her grace" (246). This threat of "paralysis through analysis" (246) is similarly mentioned by Polanyi because "the damage done by the specification of particulars may be irremediable" (The Tacit Dimension 19), indeed, a "[d]estructive analysis," as he calls it, "may often result in explaining away quite genuine practices or experiences" (Personal Knowledge 51).

Abel's example also reveals that knowing how to do something is equivalent to Heidegger's concept of understanding, which he in Being and Time delineates as a practical ability (134). In order to use the winding mechanism of a mechanical watch (knowing how to wind the watch), it is not necessary to have the theoretical knowledge that the mainspring, balance wheel, and escapement mechanism work together. The concept of knowledge can thus be understood in a narrow (knowing that) and a broad sense (knowing how). Abel defines knowledge in the narrow sense as "knowledge that is methodically gained, organized, and bound to truth and justification. It is necessary to be able to speak of this knowledge and to be able to express, communicate, intersubjectively verify, and salva veritate substitute it in propositions" (247). The broad concept of knowledge, on the other hand, entails "the ability to grasp and appropriately comprehend what a given something is about" (247). And yet the Romantics not only explore ways of knowing far from being "methodically gained," but also accept approaches to the world in which it is not even necessary to "appropriately comprehend" something (247). These ways of knowing lead to an anoetic knowledge, the contours of which shall be delineated in the following.

How can the adjective 'anoetic,' which means 'beyond' or 'away from' thinking and reason, be related to knowledge in the first place? Is not knowledge particularly characterized as an outcome of thinking? ${ }^{3}$ While

3 Similarly, Dieter Mersch claims in his recent research on the Epistemologies of Aesthetics: "Since antiquity, the concept of 'thought' has been predicated on 'dialectics' or 'exegesis' in the sense of 'speaking out' or 'leading out,' open to interpretation and thus to discussion. From the beginning, language is hence the ruling regime; knowledge and the truth thereof are subject to the sentence or, more precisely, to the apophantic judgment and its interpretation. Only that which can 
the adjective 'anoetic' is used in psychology and the study of consciousness to describe "non-knowing states of consciousness" (Roediger III, Rajaram, and Geraci 254), it is also used by pragmatist philosopher John Dewey in Experience and Nature, when he speaks of "'consciousness' as an anoetic occurrence" which is "consciousness wherever meanings do not exist; that is to say, apart from the existence and employment of signs, or independently of communication" (298). "Sentiency," claims John Dewey, “in itself is anoetic" (259), it precedes philosophical concepts and language. In a discussion of Dewey's pragmatist aesthetics, Jim Garrison emphasizes:

We are living participants in the course of cosmic events, not disembodied spectators. Therefore, we bear many relations with the world around us. Our primary relation to existence is not mediated cognitive knowing; rather, it is one of the immediate presence of anoetic being and having. We sustain many intimate relations to existence, including doubt, joy, melancholy, despair, tragedy, reverence, amusement, fear, confusion, and hope whose qualities we feel long before we ever think them. Experienced situations are anoetically given; all the rest is taken or created. (40)

I argue that anoetic knowledge, which is not reducible to practical or tacit knowledge, is non-propositional, and, at the same time, at a distance to thinking, reason, and language. It might eventually provoke (and continually resist) the regime of language and thought, but it has its mode of being elsewhere: it has deep affinities to the nature of aesthetic experience which can be conceived of, as Hans Ulrich Gumbrecht has shown, "as an oscillation (and sometimes as an interference) between 'presence effects' and 'meaning effects'" (2). Just as the relationship between (hermeneutic) understanding and non-understanding can be understood as a process of oscillation, in which both poles are ideals or extremes - it is improbable to understand everything at once as it is improbable to understand nothing at all - so can the relationship between knowing and not knowing be understood in this sense. "Instead of mere ignorance, there is uncertainty, which is not knowing, but still more than 'not knowing"', as Sebastian Domsch puts it, highlighting the "fluid continuity between the extremes, a gradation of which both scientists and poets throughout and beyond the Romantic

be expressed clare et distincte, as Descartes later put it, is recognized and categorized as coherent, and therefore also discursive, and meaningful” (45). 
age became progressively more aware" (331). Anoetic knowledge is an uncertain knowledge (hence its resistance to discourse): in Romanticism, it transcends the Cartesian clareetdistincte-motif of former Enlightenment epistemology; instead, it leaves the human being in what John Keats calls in a letter to John Taylor a "Luxury of twilight" (128).

The process of gaining this knowledge does not rely on language, but is based on immediate sensual experience or de-rationalized imaginative processes, so that it can be called anoetic, because, as indicated above, 'noetic' means "characterized by or involving intellectual activity [...]; of or relating to knowledge or the intellect, cognitive" ("noetic, adj. and n."). Accordingly, speaking of anoetic knowledge, i.e. a knowledge that is not (a positive) knowledge and not (discursive) thinking, forms a double paradox, and at the same time adequately represents the paradoxical situation mentioned at the beginning of this paper: for though Romantic poets express, and need to express, - by virtue of the conditions of their medium - anoetic approaches to the world in language, it does not follow that the approaches dramatized within the poems themselves are linguistic and based on thinking. It is, in other words, important not to confuse but to distinguish the level of discursive representation with the intratextual level of experience not necessarily depending on discursive thought. To claim that all knowledge production, even the knowledge production of and within the aesthetic, must be based on or be eventually reducible to language ${ }^{4}$ is to dissolve the Romantic paradox, the tension of which is of key importance to Romantic aesthetics. Romantic poets such as Keats explicitly explore the epistemic potential of groping in the dark, of a 'blindness' that would result, in Kantian terms, from "intuitions without concepts" (Critique of Pure Reason 193-94 [B 76]). What is more, a poem's level of representation discloses a poetic, figurative, and tropological dimension of language which, in the wake of Nietzsche and the deconstructive maneuvers of Derrida and de Man, contradicts and always already unsettles attempts of finite meaning attribution. Accordingly, the unsettling effect of Romantic poetry is a particularly suitable resource of representing the instability and uncertainties of knowledge production that have been outlined above, and which are

4 As Mersch has shown, this is the case within the history of aesthetics from Baumgarten via Kant to Hegel and even Heidegger (61-110). 
characteristic of the Romantic age. In the following, I will provide selected examples of the poetry and poetics by John Keats and Percy Bysshe Shelley where anoetic knowledge production takes place.

\section{Keats's Poetics of Half Knowledge}

Throughout his poetry, Keats dramatizes approaches to the world based on aisthetic ${ }^{5}$ experiences. As a "dedicated sensualist" (Motion xii), Keats negotiates in his works epistemologies that rely less on discursive thought but rather on the immediate experience of sensuous phenomena. Poems such as "Lamia" (1820) or "Ode on a Grecian Urn" (1820) can be read as allegories of the nature of aesthetic experience, in which knowledge production is, first and foremost, based on anoetic dispositions of the lyrical I's mind. As I have demonstrated at length elsewhere, the hermeneutic processes of discursive understanding are regularly dismantled in Keats's poetry and yet have productive functions (see Gronau).

Equipped with "Negative Capability," Keats accepts the limits of discursive understanding and discusses approaches to the world marked by a lack of knowledge, by relative anoesis. As he writes in a well-known letter to his brothers:

I mean Negative Capability, that is when man is capable of being in uncertainties, Mysteries, doubts, without any irritable reaching after fact and reason. Coleridge, for instance, would let go by a fine isolated verisimilitude caught from the Penetralium of mystery, from being incapable of remaining content with half knowledge.

("Letter to George and Tom Keats" 109)

But what does it mean to be "content with half knowledge"? What form of knowledge is proposed here? When Keats speaks of the "irritable reaching after fact and reason," he first of all implies a teleological hermeneutic process of understanding. Already this very process of attaining knowledge amounting to "fact and reason" is described as "irritable," and thus connoted negatively. In another of his letters, Keats alternatively illustrates this nervous struggle ("irritable reaching") when he allegorizes the human being

5 Aesthetics is understood in its primordial sense as aisthesis. It relates to the bodily perception through sensibility which "contains the way in which we are affected by objects" (Kant, Critique of Pure Reason 193 [B 75]). 
as a bee thirsting for the nectar of knowledge. Instead of actively seeking knowledge, described as "hurrying about and collecting honey-bee like, buzzing here and there impatiently from a knowledge of what is to be arrived at" ("Letter to J. H. Reynolds" 127), Keats proposes a Hermeneutik unter Vorbehalt (see Gronau 87-115) which includes being "passive and receptive" ("Letter to J. H. Reynolds" 127) - a thought also discussed in his sonnet "O thou whose face hath felt the Winter's wind" (128). The "being in uncertainties, Mysteries, doubts," then, amounts to a negative hermeneutics or a serene acceptance of the limits of understanding allowing for the Romantic idea of an experience of the world unspoiled by cultural reasoning, and thereby elaborating more immediate and sensual strategies in which "a sense of Beauty overcomes every other consideration, or rather obliterates all consideration" (Keats, "Letter to George and Tom Keats" 109). To overcome, and even to obliterate, "every other consideration" in the face of beauty, to accept "being in uncertainties, Mysteries, doubts" is irreducible to clear-cut concepts of knowing that or knowing how. Instead, Keatsian poetics - as the theorem of Negative Capability demonstrates advocates an anoetic knowledge oscillating between passive aesthetic experience (Widerfahrnis) and an ateleological half knowledge ("uncertainties, Mysteries, doubts") in favor of renouncing "fact and reason" as the ultimate goals of knowledge production.

Keats's late poem "Lamia" serves as a case in point, as it experiments with approaches to the world beyond "fact and reason" and negotiates the relationship between beauty and the possible knowledge thereof. The long romance can, as indicated above, be read as allegorizing a critique of a purely theoretical knowledge of the beautiful or aesthetic object. In this poem, the youth Lycius falls in love with the fair Lamia of whom it is unclear whether she is a serpent or a woman. Instead of enabling Lycius to produce a proper representational grasp of her in the order of classificatory discourse, Lamia throughout the poem overpowers Lycius's reason and understanding by nonhermeneutic presence effects so that his love relationship with her is sensuous and imaginative. His knowledge of her is, therefore, aisthetic rather than rational. It is only because of the intrusion of Apollonius who is representative of what the Keatsian unreliable narrator in a metaleptical moment of the poem famously, or perhaps infamously, decries as "cold philosophy" that Lycius's and Lamia's wedding and union ultimately fails: 


\section{[...] Do not all charms fly}

At the mere touch of cold philosophy?

There was an awful rainbow once in heaven:

We know her woof, her texture; she is given

In the dull catalogue of common things.

Philosophy will clip an Angel's wings,

Conquer all mysteries by rule and line,

Empty the haunted air, and gnomed mine-

Unweave a rainbow, as it erewhile made

The tender-person'd Lamia melt into a shade. (11. II.229-37)

The rhetorical question at the beginning of this narrative metalepsis can be read as ideological commentary reflecting the suspicion of successful scientific fields, such as Newtonian physics - which Keats felt had "destroyed all the Poetry of the rainbow, by reducing it to a prism" (Haydon 173) - as well as of other mechanistic and rational philosophies that Wordsworth had already vilified in "The Tables Turned” by proclaiming: “we murder to dissect” $(48,1.28)$. In Romanticism, this dissection metaphor reveals itself in a variety of anatomical shapes, for example in William Hazlitt's "clip[ping] the wings of Poesy" ("On Poetry in General” 18), a metaphor the narrator also adopts in "Lamia" (cf. 1. II.234), and in German literature of this time, for example in Goethe's poem "Die Freuden" (19) or in Novalis's novel fragment Die Lehrlinge zu Sais (101).

The implications of the narrator's commentary go one step further: knowing the "woof" and the "texture" of the rainbow, i.e. performing a taxonomical critique of it in order to list the component parts in a "dull catalogue of common things" (analysis in its etymological root sense) amounts to "Conquer[ing] all mysteries by rule and line." The attack on Newton's experiments with the diffraction of light through a prism is obvious, the "rule and line" simultaneously calling into mind William Blake's paintings Newton (1795/1805) and The Ancient of Days (1794), in which Newton and Urizen (a pun on 'your reason'), respectively, are illustrated with a compass setting out to measure "by rule and line" - if we transfer this to the context of the poem "Lamia" - the nature of an aesthetic object. Lamia herself is portrayed as rainbow-colored within the poem (cf. 11. I.47-56) so that her iridescent dazzling beauty, her "phenomenal indeterminacy" (Seel 53) becoming obvious in several passages of the poem (esp. 11. I.47-56), results for Lycius in an epistemic indeterminacy and eventually proves to be unfit 
for precise propositional expression. The topos of the incomprehension of the beautiful is, of course, at least as old as $18^{\text {th }}$-century aesthetics in the wake of Alexander Gottlieb Baumgarten's Aesthetica and the idea of sensuous knowledge beyond or preceding the workings of reason. But as a rainbow, Lamia is also "awful" in that she appears as a sublime phenomenon overpowering Lycius's reason, evading all finalizing description.

A rainbow is a particularly apt symbol of the theoretical and practical intangibility of an aesthetic phenomenon. As philosophical language needs to distance itself from the beautiful (as Keats's Romantic allegory suggests), so does a viewing subject need to be spatially distanced from a rainbow in order to percieve this phenomenon in the first place. This is why all efforts to find the 'origin' or 'end' of it are as vain as is accounting for the beauty of the rainbow by means of its microscopic inspection and dissection into a wide array of wavelengths. Heidegger states in "The Origin of the Work of Art" more than a hundred years later: "Color shines and wants only to shine. If we try to make it comprehensible by analyzing it into numbers of oscillations it is gone. It shows itself only when it remains undisclosed and unexplained" (25).

Thus, after Lycius's several failed attempts to produce a secure knowledge of the Lamia figure (he inquires, for example, how her identity is constructed, a question which she artfully evades), the final theoretical knowledge brought by Apollonius that she is indeed a serpent, and expressing this clearly and distinctly in language ("A Serpent!" 1. II.305), leads to Lamia's dissolution and Lycius's death. An ultimate theoretical knowledge of the beautiful, the poem asserts in an allegorical reading, will be paid for with one's life.

Through the character of Lycius, the poem experiments with anoetic modes of knowledge, it plays with a constitutive indeterminacy willfully accepted in a mode of Negative Capability. The anoetic approach to the world preceding the destruction of the amorous couple in Keats's "Lamia" can therefore be read as a literary experiment of Keats's poetics of half knowledge.

\section{Shelley and the Question of Unpremeditated Art}

Percy Bysshe Shelley in his 1821 poetic manifesto "A Defence of Poetry" expressively states that poetry is "at once the centre and circumference of knowledge," and that a major function of "the poetical faculty" is to "create 
[...] new materials of knowledge" (531). Yet, the process of creating this knowledge is by no means the result of thought and reasoning. "Poetry," Shelley asserts, "is not like reasoning" (531). In addition, the poet does not know when he is blessed with inspiration, for, as Shelley puts it in his famous metaphor of poetic creation, "the mind in creation is as a fading coal which some invisible influence, like an inconstant wind, awakens to transitory brightness" which "arises from within" but where "the conscious portions of our natures are unprophetic either of its approach or its departure" (531). This idea does not only apply to Shelley but also to Keats and can already be found in the aesthetics of genius described by Kant in the Critique of Judgement (137 [B 182]).

Just as the poet does not know the theoretical nature of the compositional process of poetry, so are the recipients of poetry kept in an anoetic state as they "are as men entranced by the melody of an unseen musician, who feel that they are moved and softened, yet know not whence or why" (Shelley, "Defence" 516). Shelley here revives the performative aspect of poetry which must be heard and read out loud (the Romantics sometimes also sang their poems to each other, see Perkins), as had always been the case in oral poetry. In other words, Shelley implies that poetry is less like a text to be read (and understood) and more like music to be listened to, which demonstrates that "[p]oetry is perhaps the most powerful example of the simultaneity of presence effects and meaning effects" (Gumbrecht 18). The metaphor of the poet as an "unseen musician" who produces a "melody" is thus particularly striking. Indeed, as Annegreth Horatschek has emphasized,

Romantic poetics in England used the non-referential semantics of music as a central metaphor for the epistemological value of subjective feelings to counter the classical opinion that reason provides the sole access to true knowledge. (226)

In his 1820 poem "To a Sky-Lark," Shelley in a similar manner addresses a "Spirit" (1. 1) "unseen" (1. 20) which affects its auditors by its "shrill delight” (1. 20). While it is true that a sky-lark flies at such great heights and thus cannot be seen easily against the sun or the "broad day-light" (1. 19), already the second line of the poem suggests that the lyrical I does not speak of an actual bird but uses it as a symbol, because, as the lyrical I addresses it, "Bird thou never wert" (1. 2). In the same vein, the lyrical I explicitly 
avows his epistemological uncertainty in "What thou art we know not" (1. 31) - another instance of what Timothy Webb would have called Shelley's "extraordinary predilection for the negative" (694) as Shelley's poetry and poetics are full of negations and negative particles.

As Catherine Runcie suggests, "Shelley's skylark is carefully worked up to be referential with nothing material, nothing possible in reality as we know it. The skylark is not actual" (210; see also Ludwig 175). Although it is possible to say that the skylark is, as a symbol and as "Spirit" (1. 1), immaterial, its effects on the listener are not. Several instances within the poem support the assumption that the knowledge of the bird's "presence" (1. 35) is gained by the senses, and thus indeed material. Above all, the bird can be heard loudly: "I hear thy shrill delight" (1. 20), "All the earth and air/With thy voice is loud" (11. 26-27), and "from thy presence showers a rain of melody" (1.35) are all references to the sense of hearing. Like the unseen poet of the "Defence" or the emblematic nightingale in Keats's 1819 "Ode to a Nightingale", the skylark advances to the position of a symbol of poetic creativity, which mysteriously affects the listeners by its "music" ("To a Sky-Lark" 1.60) and at the same time can neither be known theoretically nor expressed clearly and distinctly. This idea is supported by the fact that the lyrical I produces four similes appealing to the five senses in stanzas $8,9,10$, and 11 , only then to add in the $12^{\text {th }}$ stanza that "All that ever was/Joyous, and clear and fresh, thy music doth surpass" (1. 60). With this music surpassing and exceeding even poetic similes, the poem in a deconstructive gesture also confronts the reader with the aporia of trying to express in language what is by all appearances inexpressible and cannot be known theoretically. Before the representational grasp of the bird, before possibly knowing what the bird is, the lyrical I only knows that it eventfully affects the recipient with an aisthetic "shrill delight" (1. 20). Like the sublime, which is "fundamentally a discourse of ignorance" (Bennett 56), its temporal mode is suddenness. It happens now as the evidence of presence which precedes, and subsequently also disrupts, any form of discursive mediation. Having no theoretical knowledge of the bird is also confirmed in "we hardly see - we feel that it is there" (1. 25). The gradual privation of sight can be understood as a privation of knowledge and corresponds to the highly undetermined "it." Reason fails to conceptually grasp the phenomenon the lyrical I is trying to describe. 
It would be stretching a point to say, however, that the bird or spirit is not able to be capable of knowledge production in its own right. In the $13^{\text {th }}$ stanza of "To a Sky-Lark," the lyrical I explicitly implores: "Teach us, Sprite or Bird,/What sweet thoughts are thine" (1l. 61-62). This demonstrates that the lyrical I assumes that the bird or spirit has a knowledge and an epistemology of its own not readily accessible to the lyrical I - "I know not how thy joy we ever should come near" (1. 95, emphasis mine) - and which it is, therefore, eager to learn as a practical ability (knowing how), since being able to acquire as a poet the "skill" (1.100) of the bird would enable one to produce "rapture so divine" (1. 65). For this reason, the lyrical I in the last stanza of the poem again requests: "Teach me half the gladness/That thy brain must know" (11. 101-02). Being taught only "half the gladness" of the bird's "brain" would result, as the lyrical I happily acknowledges, in a poetry full of "harmonious madness" (1. 104) to be uttered from the speaker's mouth. It is here that Shelley unfolds a deep Romantic paradox, in which the self-reflexive project of Romantic poetry mentioned above becomes visible: the "madness" is the result of the attempt to blend two different modes of aesthetic expression. The medium of the bird's song is not language but music, its ways of affecting a recipient are not discursive but primarily aisthetic, its aesthetic mode is not representation but presentation - the bird produces presence effects. The poet, on the other hand, is trapped in the prison-house of language and, as the Keatsian lyrical I in "Ode on a Grecian Urn" already does, becomes aware of the irreducibility of anoetic knowledge production to positive knowledge production (knowing how, knowing that) and vice versa; hence the madness as a result of the tension created between these poles, aiming at the Romantic ideal of the synthesis of such extremes, here indicated by the adjective "harmonious". The poet, in other words, is aware of the fact that his poetry will need to hover or oscillate between these poles, and speaking of "madness" as a substitute for this kind of poetry affirms the self-reflexive status of a poetry that knows about the conditions and limitations of its own mediality - a poetry, in short, conscious of its paradoxical status. On the level of textual representation, this paradox is expressed by the contradictio in adiecto "harmonious madness" itself, for an orderly state of harmony would necessarily exclude or overcome any notion of disorderly madness (on a related note see Vatalaro 179). 
Aware of this paradox, neither does the lyrical I have a theoretical knowledge of the bird's "triumphal chaunt" (1. 67) which could be expressed accurately in a clear propositional statement, nor does he have the practical knowledge of how to produce anything in likeness to these songs, which, in addition, are no real songs because the bird is not a real bird. Subsequently, the similes the speaker conjures up in order to grasp the skylark and its song remain insufficient. "What is most like thee?" (1.32) indicates that the lyrical I struggles to ever find any appropriate expression to capture the skylark and the assumed knowledge it produces. Instead, the lyrical I admits that the skylark's skill is “Better than all measures/Of delightful sound-/Better than all treasures/That in books are found" (11. 96-99) which emphasizes that it can neither be calculated ("measures") nor learnt through any theoretical knowledge available in books. For this reason, the type of knowledge the skylark produces (it is, after all, said to be able to "teach"), must be a knowledge that exceeds the "treasures" of discursive knowledge which by its positive semantics simultaneously implies that discursive knowledge is not to be negated but that the lyrical I rather wants to explore yet another form of knowledge. This is because the skylark entertains an approach to the world explicitly marked by not knowing, for example, by an "ignorance of pain” (1. 75), it "ne'er knew love's sad satiety” (1. 80). Like the famous nightingale, it has "never known," in Keats's words, the "weariness, the fever, and the fret" - it is not confronted with realms "Where but to think is to be full of sorrow" ("Ode to a Nightingale," 458, 11. 22, 23, 27). To be blessed with such ignorance is to be blessed with a knowledge unlike the knowledge about one's own human condition.

In an intertextual continuation of the Miltonic "unpremeditated verse" in Paradise Lost, ${ }^{6}$ Shelley in "To a Sky-Lark" negotiates the question and possibility of "profuse strains of unpremeditated art" (1. 5). This, then, amounts to an art which would be both produced and received anoetically: "profuse strains of unpremeditated art" are forms of art not only unplanned or spontaneously produced but also abundant (lat. profusus) and "liberal to excess" ("profuse, adj."), they are excessive as they are unpremeditated, not noetically meditated on, they exceed (lat. excedere: to go out, to stick

6 In book nine of Paradise Lost, Milton describes how his muse "inspires/Easy [his] unpremeditated verse" (197, IX, 11. 23-24). 
out of) the limits of discursive meditation. Put differently, this art is not only unpremeditated in the sense of invoking the Romantic aesthetics of genius but it is also un-pre-mediated. It is not yet mediated or 'imprisoned' in language; it is not always already mediated, i.e. pre-mediated, by cultural discourses and language.

Confronting the limits of informative and theoretical knowledge of the Enlightenment epistemologies, anoetic approaches to the world, nature, art, and its reception are especially negotiated in Romantic poetry. Its selfreflexive project at the same time forms a paradox or Romantic irony in the Schlegelian sense because any form of anoetic knowledge must inevitably still be expressed in language - to whatever aporias this might lead. Romantic poetry thus draws on the tension and constantly hovers between knowing and not knowing, between knowledge and ignorance and in this process negotiates the epistemic potentials of anoetic knowledge.

\section{Works Cited}

Abel, Günter. "Knowing-How: Indispensable but Inscrutable.” Conceptions of Knowledge. Ed. Stefan Tolksdorf and James Conant. Berlin: Walter de Gruyter, 2012. 245-67.

Abrams, M. H. The Mirror and the Lamp: Romantic Theory and the Critical Tradition. Oxford: Oxford University Press, 1971.

Bennett, Andrew. Ignorance: Literature and Agnoiology. Manchester: Manchester University Press, 2009.

Borgards, Roland, et al., eds. Literatur und Wissen: Ein interdisziplinäres Handbuch. Stuttgart: J. B. Metzler, 2013.

Burke, Edmund. A Philosophical Enquiry into the Origin of our Ideas of the Sublime and Beautiful. Ed. Adam Phillips. Oxford: Oxford University Press, 2008.

Dewey, John. Experience and Nature. London: George Allen and Unwin, 1929.

Domsch, Sebastian. "Romantic Probability." Romanticism and Knowledge: Selected Papers from the Munich Joint Conference of the German Society for English Romanticism and the North American Society for the Study of Romanticism. Ed. Stefanie Fricke, Felicitas Meifert-Menhard, and Katharina Pink. Trier: WVT, 2015. 331-41. 
Ernst, Christoph, and Heike Paul. "Präsenz und implizites Wissen: Zur Interdependenz zweier Schlüsselbegriffe der Kultur- und Sozialwissenschaften." Präsenz und implizites Wissen: Zur Interdependenz zweier Schlüsselbegriffe der Kultur-und Sozialwissenschaften. Ed. Christoph Ernst and Heike Paul. Bielefeld: transcript, 2013. 9-32.

Faflak, Joel. Romantic Psychoanalysis: The Burden of the Mystery. Albany: SUNY Press, 2008.

Foucault, Michel. The Order of Things: An Archaeology of the Human Sciences. London: Routledge, 1992.

Fricke, Stefanie, Felicitas Meifert-Menhard, and Katharina Pink. "Introduction: The Forms and Formations of Romantic Knowledge." Romanticism and Knowledge: Selected Papers from the Munich Joint Conference of the German Society for English Romanticism and the North American Society for the Study of Romanticism. Ed. Stefanie Fricke, Felicitas Meifert-Menhard, and Katharina Pink. Trier: WVT, 2015. 9-21.

Gadamer, Hans-Georg. Truth and Method. Trans. Joel Weinsheimer and Donald G. Marshall. $2^{\text {nd }}$ ed. London: Continuum, 2004.

Garrison, Jim. "Dewey's Aesthetics of Body-Mind Functioning." Aesthetics and the Embodied Mind: Beyond Art Theory and the Cartesian Mind-Body Dichotomy. Ed. Alfonsina Scarinzi. Dordrecht: Springer, 2015. 39-54.

Goethe, Johann Wolfgang von. "Die Freuden.” Goethes Werke: Hamburger Ausgabe in 14 Bänden. Band 1, Gedichte und Epen. Ed. Erich Trunz. Vol. 1. München: Beck, 1981. 19.

Gronau, Justus Conrad. "Where reason fades": Formen und Leistungen des Nichtverstehens bei John Keats. Trier: WVT, 2016.

Gumbrecht, Hans Ulrich. Production of Presence: What Meaning Cannot Convey. Stanford: Stanford University Press, 2004.

Haydon, Benjamin R. The Diary of Benjamin Robert Haydon. Ed. Willard Bissell Pope. Vol. 2. Cambridge: Harvard University Press, 1960-1963.

Hazlitt, William. "On Poetry in General." Lectures on the English Poets: Delivered at the Surrey Institution. London: Taylor, 1818. 1-38.

Heidegger, Martin. Being and Time. Trans. Joan Stambaugh. Albany: SUNY Press, 1996.

-. "The Origin of the Work of Art." Off the Beaten Track. Ed. and trans. Julian Young and Kenneth Haynes. Cambridge: Cambridge University Press, 2002. 1-56. 
Holmes, Richard. The Age of Wonder: How the Romantic Generation Discovered the Beauty and Terror of Science. London: Harper, 2009.

Horatschek, Annegreth. "The Auditory Self: Self-Constitution by Text, Voice, and Music in English Literature." Anglistentag 2004 Aachen. Proceedings. Ed. Lilo Moessner and Christa M. Schmidt. Trier: WVT, 2005. 225-35.

Kant, Immanuel. Critique of Judgement. Trans. James Creed Meredith. Ed. Nicholas Walker. Oxford: Oxford University Press, 2007.

-. Critique of Pure Reason. Trans. and ed. Paul Guyer and Allen W. Wood. Cambridge: Cambridge University Press, 2000.

Keats, John. "Letter to George and Tom Keats, December 21, 27?, 1817." Keats's Poetry and Prose. Ed. Jeffrey N. Cox. New York, London: W. W. Norton, 2009. 107-09.

-. "Letter to J. H. Reynolds, February 19, 1818." Keats's Poetry and Prose. Ed. Jeffrey N. Cox. New York, London: W. W. Norton, 2009. 126-27.

-. “Letter to John Taylor, February 27, 1818." Keats's Poetry and Prose. Ed. Jeffrey N. Cox. New York, London: W. W. Norton, 2009. 128-29.

-. "O thou whose face hath felt the Winter's wind." Keats's Poetry and Prose. Ed. Jeffrey N. Cox. New York, London: W. W. Norton, 2009. 128.

-. "Lamia." Keats's Poetry and Prose. Ed. Jeffrey N. Cox. New York, London: W. W. Norton, 2009. 412-429.

-. "Ode on a Grecian Urn." Keats's Poetry and Prose. Ed. Jeffrey N. Cox. New York, London: W. W. Norton, 2009. 460-62.

-. "Ode to a Nightingale." Keats's Poetry and Prose. Ed. Jeffrey N. Cox. New York, London: W. W. Norton, 2009. 456-60.

Klancher, Jon. Transfiguring the Arts and Sciences: Knowledge and Cultural Institutions in the Romantic Age. Cambridge: Cambridge University Press, 2013.

Lessenich, Rolf. "Erasmus Darwin, New Natural Science, and the Uses of Poetry and Myth." Romanticism and Knowledge: Selected Papers from the Munich Joint Conference of the German Society for English Romanticism and the North American Society for the Study of Romanticism. Ed. Stefanie Fricke, Felicitas Meifert-Menhard, and Katharina Pink. Trier: WVT, 2015. 167-176.

-. Romantic Disillusionism and the Sceptical Tradition. Göttingen: V\&R unipress, 2017. 
Ludwig, Hans-Werner. Im Netz der Texte: Bausteine zu einer Stoff- und Motivgeschichte der englischen Lyrik. Tübingen: Narr, 2014.

Mellor, Anne K. English Romantic Irony. Cambridge: Harvard University Press, 1980.

Mersch, Dieter. Epistemologies of Aesthetics. Trans. Laura Radosh. Zürich: Diaphanes, 2015.

Milton, John. Paradise Lost. Ed. Gordon Teskey. New York: W. W. Norton, 2005.

Motion, Andrew. Keats. Chicago: University of Chicago Press, 1999.

"noetic, adj. and n." OED Online. Oxford University Press, 10 March 2017. Web. 30 May 2017.

Novalis. "Die Lehrlinge zu Sais." Novalis Werke. Ed. Gerhard Schulz. $4^{\text {th }}$ ed. München: Beck, 2001. 95-127.

-. "Heinrich von Ofterdingen." Novalis Werke. Ed. Gerhard Schulz. $4^{\text {th }}$ ed. München: Beck, 2001. 129-290.

Perkins, David. "How the Romantics Recited Poetry." Studies in English Literature, 1500-1900 31.4 (1991): 655-71.

Plato, “Theatetus.” Plato: Complete Works. Ed. John M. Cooper. Indianapolis: Hackett, 1997. 157-234.

Polanyi, Michael. Personal Knowledge: Towards a Post-Critical Philosophy. Chicago: University of Chicago Press, 1974.

-. The Tacit Dimension. Chicago: University of Chicago Press, 2009.

"profuse, adj." OED Online. Oxford University Press, 10 March 2017. Web. 30 May 2017.

Quinton, Anthony. "Knowledge and Belief." The Encyclopedia of Philosophy. Ed. Donald M. Borchert. $2^{\text {nd }}$ ed. Vol. 5. Detroit: Macmillan Reference, 2006. 91-100.

Roediger III, Henry L., Suparna Rajaram, and Lisa Geraci. “Three Forms of Consciousness in Retrieving Memories." The Cambridge Handbook of Consciousness. Ed. Philip David Zelazo, Morris Moscovitch, and Evan Thompson. Cambridge: Cambridge University Press, 2007. 251-87.

Runcie, Catherine. “On Figurative Language: A Reading of Shelley's, Hardy's and Hughe's Skylark Poems." Journal of the Australasian Universities Language and Literature Association 66.1 (1986): 205-17.

Ryle, Gilbert. The Concept of Mind. London: Routledge, 2009. 
Schleiermacher, Friedrich. "Allgemeine Hermeneutik 1809/10 (Abschrift von Schleiermachers verlorenem Manuskript)." Kritische Gesamtausgabe: Band 4 Vorlesungen zur Hermeneutik und Kritik. Ed. Wolfgang Virmond. Vol. 4. Berlin: de Gruyter, 2012. 71-116.

-. "Hermeneutik und Kritik." Hermeneutik und Kritik: Mit einem Anhang sprachphilosophischer Texte Schleiermachers. Ed. Manfred Frank. Frankfurt am Main: Suhrkamp, 1977. 69-306.

Seel, Martin. Aesthetics of Appearing. Trans. John Farrell. Stanford: Stanford University Press, 2005.

Shelley, Mary. Frankenstein: A Norton Critical Edition. Ed. J. Paul Hunter. $2^{\text {nd }}$ ed. New York: W. W. Norton, 2012.

Shelley, Percy Bysshe. "A Defence of Poetry; or, Remarks Suggested by an Essay Entitled 'The Four Ages of Poetry'." Shelley's Poetry and Prose: Authoritative Texts, Criticism. Ed. Donald H. Reiman and Neil Fraistat. $2^{\text {nd }}$ ed. New York: W. W. Norton, 2002. 509-35.

-. "To a Sky-Lark." Shelley's Poetry and Prose: Authoritative Texts, Criticism. Ed. Donald H. Reiman and Neil Fraistat. $2^{\text {nd }}$ ed. New York: W. W. Norton, 2002. 304-07.

-. "On Life." Shelley's Poetry and Prose: Authoritative Texts, Criticism. Ed. Donald H. Reiman and Neil Fraistat. $2^{\text {nd }}$ ed. New York: W. W. Norton, 2002. 505-09.

Smith, Charlotte. "Beachy Head." The Poems of Charlotte Smith. Ed. Stuart Curran. New York: Oxford University Press, 1993. 217-247.

Vatalaro, Paul A. Shelley's Music: Fantasy, Authority, and the Object Voice. Farnham: Ashgate, 2009.

Webb, Timothy. "The Unascended Heaven: Negatives in Prometheus Unbound." Shelley's Poetry and Prose. Ed. Donald H. Reiman and Neil Fraistat. $2^{\text {nd }}$ ed. New York: W. W. Norton, 2002. 694-711.

Wordsworth, William. "Lines Written a Few Miles above Tintern Abbey. On Revisiting the Banks of the Wye During a Tour, July 13, 1789.” William Wordsworth. Ed. Stephen Gill. Oxford: Oxford University Press, 2010. 49-53.

-. “The Tables Turned.” William Wordsworth. Ed. Stephen Gill. Oxford: Oxford University Press, 2010. 47-48. 



\title{
Philipp Erchinger \\ Curious to Know: John Clare's “The Nightingale's Nest” (1832)
}

\begin{abstract}
This essay explores the difference between a modern, strongly scientific notion of objective knowledge as 'justified true belief' and literary modes of knowledge production which deliberately replace systematic detachment from with involvement in the objects under consideration. A contrastive case study of an $18^{\text {th }}$-century dictionary entry on the "Nightingale" and some of John Clare's Romantic bird poems exemplifies the difference between articulate and personal knowledge, between what Gilbert Ryle has distinguished as 'knowing that' and 'knowing how'. In contrast to the by then established textbook approach to natural history, Clare's bird poems and natural history letters engage in poetic, process-based forms of investigation that remain sensuously responsive to, and subject to be affected by, the matter they seek to know. Clare's texts enable readers to read an observer's experience in the making and to entertain ecological modes of thinking that challenge the anthropocentric mind.
\end{abstract}

Epistemologically minded scholars, analytic philosophers in particular, usually insist that a belief or statement qualifies as knowledge only if it is justified in a way that proves, or demonstrates, it to be true to its subject-matter (cf. Williams 13-27). Thus defined, nothing that (explicitly or implicitly) claims to be knowledge has a right to this claim unless it identifies itself as more than 'mere' opinion, speculation, impression, or fanciful thought (cf. Herrnstein Smith 1-17). Whenever an idea or argument carries with it, more or less overtly, the allegation that it represents knowledge, it must therefore be prepared to answer the question of what justifies it to do so. Certainly, notions of knowledge can vary, and have varied, immensely, depending on the historical, cultural, and institutional circumstances in which they are, or were, pursued and applied. As the history of science has taught us, what in one context is likely to be dismissed as ill-founded speculation, might in another context well be acceptable as 
valid and serious knowledge. ${ }^{1}$ Johannes Kepler was profoundly interested in astrology, for instance, and Newton could still draw upon alchemical wisdom without having to fear losing his reputation as a natural philosopher (Morrisson 17). By the same token, ways and means of justification are subject to change too.

However, despite this relativity or context-dependency of what 'knowledge' means, it seems safe to say that, in the course of the $18^{\text {th }}$ century, certified true belief became increasingly associated with a general or objective form that, though originating in first-person experience, is manifestly recognizable as dissociated from, and purified of, the contingent qualities supposed to be characteristic of the subjective mode (Levine 1-43; Daston and Galison 191-252). More precisely, this idea of knowledge as objective and pure arose along with, and is inseparably tied to, the modern concept of science and, based on it, a specifically scientific method that has since come to be entrusted with the social task of capturing and safeguarding what is and is not justified as true belief. In what follows, I shall therefore begin by expounding some implications of this modern concept of science and one of the literary forms concomitant to it, namely the encyclopedia. Subsequently, I turn to an analysis of John Clare's bird poems, specifically “The Nightingale's Nest” (1832). As I argue, Clare's work exemplifies a mode of enquiry that is, in more than one sense, curiously involved with, rather than detached from, whatever it seeks to know.

\section{Science, Encyclopedias, and Modern Knowledge}

One of the most concise definitions of the modern concept of science was proposed by John Herschel in 1830. "Science," Herschel writes in his Preliminary Discourse on the Study of Natural Philosophy, "is the knowledge of many, orderly and methodically digested and arranged, so as to become attainable by one" (18). On this conception, science represents a general mode of knowledge that is abstracted from individual circumstances and points of view. Such knowledge is "about" its subject-matter "in the sense

1 Therefore, scholars of literature and culture often deliberately refuse to define the term 'knowledge' independently of the ways in which it is brought to matter in specific historical contexts, cf. Vogl (256-258). 
in which 'about' is away from," as John Dewey and Arthur Bentley explain (282). For it is knowledge only by virtue of removing its referents from the multiple ways in which they can be perceived, so as to encapsulate them in an ideal, often mathematical shape "attainable by one."

In accordance with this idealizing tendency of modern science, whatever was regarded as objectively known came to be situated, by definition, above or beyond people's immediate perception of it. "Knowledge deports us, evicts us," as Steven Connor puts it. "In knowledge we take leave of our senses" (193). While this extraction of the ideal from the sensual, or of the sensual from the ideal, enabled observers to grasp the matters of their investigations in allegedly self-contained forms, it also, at least in theory, separated people's knowledge about the world from their experience of participating in it. Thus, the rise of scientific objectivity came to suggest that humans can only know the environment they inhabit by reconstructing it in a place outside of their immediate, sensuous engagement with it (cf. Ingold, Making 5). In this way, the modern concept of science, along with what Bruno Latour has called "the modern constitution" more generally (13-48), not only established a division between being and knowing, ontology and epistemology, concrete matter and ideal form, as well as subjective feelings and perceptions on the on the one hand and objective facts or data on the other. More importantly, this modern concept of science also implied that all knowledge is premised upon a translation of the subjective into the objective, or an extraction of the objective from the subjective. It stipulated that knowledge is to be attained by an act of subsuming changeable materials under ideal types, or of representing particular experiences in general terms. This explains, as John Dewey has pointed out, why science is inherently predisposed towards forms of classification and definition (Experience 152). Such forms are 'modern' in Latour's sense because they allow for knowledge to be categorized and contained, assigned to predefined places and stored in robust boxes, which seem to preserve it as if it were stable and complete, resistant to time.

The literary genre that perhaps corresponds most closely to this impetus to classify and define is the encyclopedic dictionary which, with its often alphabetically arrayed subject headings, has become emblematic of the modern attempt to define and inventory what is considered to be generally known about the world (see Yeo). It needs to be said, however, that 
the editors of many Enlightenment dictionaries and encyclopedias, such as Denis Diderot or Ephraim Chambers, understood very well that the alphabetical order preferred by most of them imposed an abstract system upon people's experience of the world, cutting it up, according to an arbitrary logic, into a register of independent parts (Kilcher 203-29). Many encyclopedists knew, in other words, that the alphabetical arrangement ripped things and actions out of their accustomed contexts, placing subject-matters next to each other which, in the world of ordinary experience, are not akin while separating others that would usually be expected to belong together (see Erchinger 174-206). Seeking to compensate for this problem, editors therefore introduced the device of the cross-reference, allowing readers to return the knowledge assembled in the dictionary, to some extent, to a mode of existence that would be closer to their commonplace experience of the world. In the third edition of the Encyclopaedia Britannica (1790-1798), for example, the alphabetical order seems to suggest that the wading bird called "snipe" is closely related to "sniggling, a method of fishing for eels," and "snoring," these being the two entries that frame the fowl in the dictionary. But at the same time, the cross-reference integrates the snipe into an ornithological context of Linnean taxonomy on the one hand and of common hunting activity on the other, sending readers to "scolopax" and "shooting" respectively (Vol. 17, 562).

Thus, by means of the cross-reference, dictionaries not only exposed the contingency of the alphabetical order that characterized them; they also allowed for different types of learning or wisdom to coexist within one and the same framework of universal knowledge. Under "scolopax," the bird reappears as the "gallinago, or common snipe" which, among other things, "weighs four ounces," is "near 12 inches" long and "about 14" broad, its head being "divided lengthwise with two black lines, and three of red, one of the last passing over the middle of the head, and one above each eye" (Vol. 16, 715). And if one looks under "shooting," one will learn, in addition, that "[ $t$ ]he snipe is a bird of passage" that is "scarcely worth shooting till the frost commences. In the month of November they begin to grow fat" (Vol. 17, 443). While the first pieces of information are put forth in the mode of a disinterested description that is supposed to do no more than distinguish the common snipe from other kinds of fowl, the details associated with "shooting" represent the bird specifically as prey. 
In both cases, however, the snipe is made known in a way that situates it away from, or above particular situations, sensations, and points of view. As with all other subjects, the snipe that one looks up in the Encyclopaedia Britannica, whether it is the one that is identified by the natural philosopher or the one that is known to be shot by the hunter, is a general or ideal one.

No doubt, then, the cross-reference inserts a flexible and dynamic element into the body of knowledge represented by the encyclopedia, for it suggests that its component parts are not as objective and self-contained as they may seem, but tend to branch out in different directions, forming a mesh of lines that can be followed in multiple, even serendipitous ways. Still, my point remains that there seems, in practice, no better place to look for knowledge in the modern sense than the subject headings in an encyclopedic dictionary. Take the entry on "nightingale," allegedly a species of motacilla, as one learns right at the beginning (Vol. 13, 66), including various wagtails or warblers which, together, are given a separate record. In this second article, under "motacilla," the nightingale, identified by its Latin name luscinia, is described as follows:

The bill is brown: the irides are hazel: the head and back pale tawny, dashed with olive: the tail is of a deep tawny red; the under parts pale ash-colour, growing white towards the vent: the quills are cinereous brown, with the outer margins reddish brown: the legs cinereous brown. The male and female are very similar. This bird, the most famed of the feathered tribe for the variety, length, and sweetness of its notes is migratory, and supposed to be an inhabitant of the Asiatic regions during such times as it is not to be found in Europe. [...] They are solitary birds, never uniting into even small flocks; and in respect to the nests, it is very seldom that two are found near each other. The female builds in some low bush or quickset hedge well covered with foliage, for such only this bird frequents; and lays four or five eggs of a greenish brown. The nest is composed of dry leaves on the outside, mixed with grass and fibres, lined with hair or down within, though not always alike. The female alone sits on and hatches the eggs, while the male not far off regales her with his delightful song; but as soon as the young are hatched, he commonly leaves off singing and joins with the female in the task of providing for and feeding them. (Vol. 12, 398)

In this account, the nightingale is placed before the reader as a body of information that is, as it were, dissected and decomposed, divided into segments and chunks: bill, irides, head and back, tail, under parts, quills, legs. Taken together, these components are supposed to constitute a whole, a positive, self-sufficient unit of knowledge, "this bird." And the typical 
characteristics and behavior of this creature, both "the female" and "the male," are then specified in a manner that is supposed to make them recognizable in any particular case.

As indicated, such encyclopedia entries constitute a terrain of certainty and familiarity, for their main function is, and has always been, to act as a source of reliable knowledge, a means of looking up facts about a certain subject that are assembled and saved in a relatively endurable frame. ${ }^{2}$ In this way, encyclopedic knowledge is supposed to provide an authoritative ground on the basis of which individual assumptions about various subjectmatters may be checked. Thus, whoever holds a specific belief about the appearance and behavior of, say, nightingales, about how they build their nests or perform their songs, can simply justify this belief by referring to the corresponding record in the dictionary. As a result, the dictionary, with its packaged and labelled subject-matters, suggests that knowledge can be grasped and possessed without, or outside, of any personal experience of that to which it refers. Indeed, one might argue that the practice of classifying and defining matters of fact has itself contributed to the modern division between being and knowing as well as, concomitantly, between two senses of knowledge which have since been described as personal and articulate knowledge, or "knowing how" and "knowing that" (Ryle).

These two senses of knowledge may be distinguished, again, by a look at the nightingale. While the dictionary article certainly informs people what the nightingale looks like, that it builds its nest with "dry leaves on the outside," and that it lays "four or five eggs of a greenish brown," it cannot make sure that they know how to tell this bird's nest from that of a hedge sparrow, or even to identify a nightingale when they see or hear one. Rather, the nightingale conjured up by the book presents readers with no more than a schema that remains unfulfilled, unless it is realized in and through practical experiences of searching for, watching, and listening to, the respective bird (cf. Dewey, "Theory" 297-98). By means of such experiences, the knowledge of the nightingale's ways may, over time, grow into people, and they into it, such that they are, so to speak, "at home" in

2 Nowadays, though, the nightingale seems to be more commonly assigned to the thrush (Turdidae) or flycatcher (Muscicapidae) varieties, rather than to the genus motacilla. 
this subject-matter, knowing it inside out (Dewey, Experience 161). In this practical mode, what is known is no longer enshrined, as the dictionary entry, in a fixed and self-contained form outside of one's life. Rather, what is known in practice has become integrated into a person's existence, changing and developing along with it. Such knowledge is alive because it lives in and with the activities of those who use, maintain, extend, and transform it.

\section{John Clare's 'The Nightingale's Nest'}

John Clare, "the peasant poet" (Bate 143) or "bard of the wild flowers" (Mahood 112), as he has been called, was a keen and passionate observer of animals, flowers, trees, and the rural environment of his native Helpstone (Northamptonshire) more generally. His writing has therefore, in recent years, inspired a growing body of work in the ecology of literature, to which my reading can also be seen to contribute. ${ }^{3}$ One of Clare's favorite subjects were birds, especially their ways of living and dwelling, with which he engaged in countless poems such as "The Moorehens Nest," "The Robins Nest," and "The Yellowhammers Nest" [sic], to name but a few. ${ }^{4}$ Inspired by Elizabeth Kent's Flora Domestica (1823) and, to a lesser extent, Gilbert White's Natural History of Selborne (1789), he even made plans for a prose work on natural history, to be called Biographys of Birds and Flowers, drafting several letters, or fragments of letters, on various aspects of the local fauna and flora (Bate 269-88; Heyes). One of these natural history letters, as scholars have now come to call them, contains a characteristic passage in which Clare takes issue with what he calls "bookish" accounts of a bird, such as "the exact description of its head rump \& wings the length of its tail \& the breadth from the tips of the extended wings," which, as we have seen, is typically found in encyclopedias or other such manuals (History 38). In contrast to this textbook approach to natural history, Clare professes to practice a way of looking "on nature with a poetic feeling," as he puts it. "I love to see the nightingale in its hazel retreat $\&$ the cuckoo hiding in its solitudes of oaken foliage $\&$ not to examine their carcasses in

3 See, for instance, McKusick (Green Writing 77-94), Rigby, and Poetzsch.

4 On Clare's notoriously idiosyncratic use of grammar, spelling, and punctuation, see McKusick. 
glass cases" (38). As this indicates, what Clare had in mind was a mode of knowing that allows investigators to remain sensuously responsive to, and subject to be affected by, the matter they seek to know. This "poetic" approach entails a process-based conception of knowledge that is entirely different from the static or "bookish" one described above. For, to know an organism or thing, by Clare's account, does not mean to grasp it as (if it were) a dead, self-contained object confined to a glass case. Rather, in order to know a subject-matter, Clare suggests, one has to follow its changes and motions, to proceed with it along an open-ended path. "I feel as happy as they can in finding a new species of field flower or butter flye which I have not seen before," as Clare himself explains this in an attempt to distinguish his method from that of other naturalists, "yet I have no desire further to dry the plant or torture the Butterflye by sticking it on a cork board with a pin" (History 38-39). All he wished, Clare goes on to say, was for "the fluttering butterflye to settle till I can come up with it to examine the powderd colours on its wings $\&$ then it may dance off from fancyd dangers and welcome" (39).

The aim of Clare's method, then, is not to arrest the matter of his interest (such as a butterfly) in the form of a definite object so as to enable the investigator to gaze at and dissect it from an equally fixed position or point of view. Instead, Clare, as an observer, sought to remain, in all senses of the word, alive to the organisms he observed, just as he preferred these organisms, conversely, to remain alive to him. What Clare proposes, one might therefore say, is what Tim Ingold has called an "art of inquiry", a mode of knowing that "moves forward in real time, along with the lives of those who are touched by it, and with the world to which both it and they belong” (Making 7). In this mode of enquiry, as Clare's “The Nightingale's Nest" may exemplify, knowledge comes to life through the practices and movements that form, and are informed by, it:

Up this green woodland ride lets softly rove

And list the nightingale - she dwelleth here

Hush let the wood gate softly clap - for fear

The noise may drive her from her home of love (Works 213.1-4)

5 All references to this edition will be given by page and line numbers. 
Here, in one of Clare's best-known poems, the act of speaking seems to take place right inside the dwelling area, "this green woodland ride," of the nightingale that we, the readers, are invited to "list," with "list" here meaning primarily "to listen to" but not entirely without the connotation of "to register," as well as "to identify," and "to locate" (OED). As indicated by the whispered request to move as quietly as possible ("lets softly rove," "Hush let the wood gate softly clap"), the muffled excitement of being so close to the famous singer is palpably mixed with, and tempered by, the "fear" of driving her away from her favorite haunt, her "home of love," which, as the subsequent lines suggest, is as familiar to the bird as it is to the speaker.

For here Ive heard her many a merry year

At morn and eve nay all the live long day

As though she lived on song - this very spot

Just where that old mans beard all wildly trails

Rude arbours oer the road and stops the way [...]

There have I hunted like a very boy

Creeping on hands and knees through matted thorns

To find her nest and see her feed her young

And vainly did I many hours employ

All seemed as hidden as a thought unborn

And where these crimping fern leaves ramp among

The hazels under boughs - Ive nestled down

And watched her while she sung - and her renown

Hath made me marvel that so famed a bird

Should have no better dress than russet brown (213-14.5-21)

Instead of flying directly to the "famed" bird "on the viewless wings of Poesy," like the speaker of Keats's quite different "Ode to a Nightingale" (458.33), Clare's creative practice, as Hugh Haughton has pointed out, remains "firmly on the ground" (65), entangled with the ramping "fernleaves" "among/The hazels under boughs." "Creeping," along with the former self of the speaker, "on hands and knees through matted thorns," Clare's imagination seems to inhabit the same environment as the creature that is its subject, rather than listening to, or looking at, it from a different (and distant) vantage or point of view.

Unlike Keats's nightingale, which remains entirely unseen, the songster "watched" in Clare's text is therefore not an ideal presence, a "Dryad of the trees," imagined to live in some "melodious plot/Of beechen green, and 
shadows numberless," to which the poet aspires too (458.7-9). Rather, Clare's nightingale is visible as an empirical organism whose appearance makes the speaker "marvel" precisely because it is not as fanciful and extraordinary as the bird is commonly said to be. In Keats's poem, the speaker repeatedly flirts, albeit tentatively and unsuccessfully, with the thought of escaping the fugacious, time-bound world of material existence, "[w]here youth grows pale, and spectre-thin, and dies" (458.26), for an ideal being of eternal forgetfulness and delirious joy that he takes to be embodied by the singing nightingale: "Thou wast not born for death, immortal Bird!" (459.61). In Clare's poem, by contrast, the "ecstasy" of the bird - a term used by both him and Keats - remains strictly dependent upon the bodily life and experience of the human observer. Indeed, such an observer is necessary, as the subsequent lines suggest, to bring the animal's rapture into existence in the first place:

Her wings would tremble in her extacy,

And feathers stand on end as twere with joy

And mouth wide open to release her heart

Of its out sobbing songs - the happiest part

Of summers fame she shared - for so to me

Did happy fancies shapen her employ (214.22-27)

While Clare's text pays careful attention to the physical manifestations of the bird's supposed "extacy" - her trembling wings, erect feathers, and "wide open" mouth - it also, by means of the conditional form ("as twere"), highlights the difference between the bird's exertions and the way they are perceived by the lyrical I. The creature's apparent delight is not only the result of its singing endeavors. It is also a product of the speaker's "happy fancies" that shape the nightingale's song "so to" him that it becomes an ingredient, "the happiest part" of the blissful summertime scene evoked by the poem. In short, the happiness intimated here originates neither in the singing of the nightingale nor in the sensation-based imagination of the observer. It emerges from the meeting of both. As the rhyme pattern suggests, the nightingale's "employ" and the "joy" the speaker experiences upon observing it are both separate from and intimately related to each other. 
Bird and boy, singer and listener, then, seem affectively caught up in their mutual presence, responding to and becoming with each other. ${ }^{6}$ In this manner, their co-existence may be sustained for a certain amount of time. "But if I touched a bush or scarcely stirred/All in a moment stopt - I watched in vain/The timid bird had left the hazel bush/And at a distance hid to sing again" (214.28-31). As these lines indicate, Clare's writing makes no attempt to conserve the nightingale, neither as an eternal source of inspiration and aesthetic delight (as which it appears in Keats's poem), nor as an object of scientific curiosity. The text does not, and seems hardly tempted to, turn the nightingale into an ideal bird. Instead, it keeps her alive as a being of the material world, capable of escaping the observer's attempt to know her ways. Thus, in the second part, the poem returns to the present tense and the concomitant mood of immediacy with which it has begun, seeming to pursue the bird almost "in real time," to repeat Ingold's phrase. “- Hark there she is" (214.42), the speaker cries out, apparently interrupting his own lyrical musings about the bird's music as an integral component of “summers life” (214.38).

- Hark there she is as usual lets be hush

For in this black thorn clump if rightly guest

Her curious house is hidden - part aside

These hazle branches in a gentle way

And stoop right cautious neath the rustling boughs

For we will have another search to day

And hunt this fern strown thorn clump round and round

And where this seeded wood grass idly bows

Well wade right through - it is a likely nook

In such like spots and often on the ground

Theyll build where rude boys never think to look (214.42-52)

Again, the poem does not teach us, textbook style, about the nightingale as a predefined object, but invites us to join the speaker in a "search" for what is "curious" about the bird's life and "hidden." As we read, we are asked to pass beneath "rustling boughs," "part aside these hazle branches," and "wade right through" the "seeded wood grass" seeming to obstruct our

6 The idea of being as a mode of becoming with others, including other species, has been adopted from Haraway (3-42). "To be one," Haraway notes, "is always to become with many" (4). 
way. Like an expert field guide, the voice of the poem takes us deep into the animal's habitat, showing us how to identify the kinds of "nook" in which her nest is "likely" to be found. Even the grammar of these lines appears as straggling and uncultivated as the area through which they make us pass.

Finally, the text seems to offer a general piece of knowledge about the behavior of nightingales: "In such like spots and often on the ground/Theyll build." But this, as the next passage clarifies, is not an abstract proposition but an insight that is animated by the speaker's personal life, having been gained through practical exercise and experience. “Aye as I live her secret nest is here/Upon this white thorn stulp - Ive searched about/For hours in vain" (214.53-55). The speaker's ornithological knowledge is not only premised upon repeated, often unsuccessful trial. More importantly, it is embodied and alive, subsisting in the practices through which it is enacted. Therefore, whatever knowledge Clare's poem contains is continuous with the personal feelings and emotions that it expresses, rather than made to terminate in an impersonal object, formula, or proposition.

What the text enables us to read, then, is an experience in the making that, even in an apparently accomplished form, remains open to be affected and corrected by unexpected or recalcitrant events. Having almost reached the bird's nest, for instance, the speaker notices a "plaintive note of danger nigh" followed by a sudden stillness reminiscent of "choaking fear" $(214.58 / 60)$. What is more, this experience seems to move the poetic voice to stop short of going any further, and to "leave the nest as we found it - safetys guard/Of pathless solitude shall keep it still", as the speaker puts it, before inviting us to take another look:

See there shes sitting on the old oak bough

Mute in her fears our presence doth retard

Her joys and doubt turns all her rapture chill

Sing on sweet bird may no worse hap befall

Thy visions then the fear that now decieves

We will not plunder music of its dower

Nor turn this spot of happiness to thrall

For melody seems hid in every flower

That blossoms near thy home

(215.64-72)

"Fears," “joys," "doubt," and "rapture" turned "chill”: Once again, the nightingale's reaction is described as if it were human. And yet, Clare's 
mode of anthropomorphism does not simply appropriate the bird's noises and motions for human purposes, aesthetic or otherwise. Rather, it draws attention to the difference between the nightingale's actual life in its environment, which has now receded into the background, and the human perception that has come to intrude into, and impose itself upon, it. As Clare's syntax intimates, it is "our presence" that is at the heart of "her joys" as well as "her fears." The bird's emotions do not exist without, or independently of, the human thoughts and (speech) acts that bring them about. Thus, while the poem suggests that "we do not live with" animals, to put it in Heidegger's terms, "if living means: being in an animal kind of way," it still insists that "we are with them nonetheless" (210). In this manner, the poem's use of anthropomorphism fosters an ecological mode of thinking and awareness that exposes the anthropocentrism inherent in the proposition that nightingales and other animals are, by definition, other to, and outside of, the human (see Ryan, 22-49).

\section{Being Curious}

In summary, one can say that Clare's text neither separates the nightingale's ways of life from the world of human signification, nor does it fully accommodate them to it. In other words, the poem presents the animal's habits as deeply familiar to the speaker while still letting them be what is repeatedly called "curious":

How curious is the nest no other bird

Uses such loose materials or weaves

Their dwellings in such spots - dead oaken leaves

Are placed without and velvet moss within

And little scraps of grass - and scant and spare

Of what seems scarce materials down and hair

For from mans haunts she seemeth nought to win (215.76-82)

Returning the reader from passionate evocation to relatively dispassionate description, these lines represent the nightingale's dwelling as a matter of facts, composed of "loose" and "scarce materials": "leaves," "scraps of grass," "down and hair." The result is what appears to be a comparatively objective account of the bird's nest (cf. Johanne Clare 182). Yet, the animal's construction, by virtue of the curious quality ascribed to it, also remains, at least partly, strange to human ways of building and life ("from mans haunts 
she seemeth nought to win"). However familiar the nightingale's behavior may be to the speaker, the poem still grants it an element of peculiarity that may, at any moment, turn into a source of wonder and astonishment, as the final lines reassert once more:

The nest is made an hermits mossy cell

Snug lie her curious eggs in number five

Of deadened green or rather olive brown

And the old prickly thorn bush guards them well

And here well leave them still unknown to wrong

As the old woodlands legacy of song (215.88-93)

Being “still unknown to wrong," the nightingale's eggs are ultimately left to exist in their own right, as a mode of existence that remains a "curious" phenomenon, even though it may already be well defined in propositional terms (as above: "the female [...] lays four or five eggs of a greenish brown").

It might in fact not be a coincidence that the adjective "curious" can describe an investigating person as well as the matter it investigates. For, Clare's poetic discourse, despite the evident ornithological expertise of its speaker, seems to stay as curious as the bird that it sets out, and invites us, to "list." The text's mode of presentation, this is to say, corresponds to a kind of knowledge that is not about its subject-matter "in the sense in which 'about' is away from," to return to Dewey's phrase. Instead, the poem enacts a way of "knowing from the inside," if I may use another of Ingold's terms (Making 1), that remains in close contact with the creature it studies, caring about and moving along with it. In this mode of participant observation, as Clare's poem vividly illustrates, curiosity and care have not (yet) been disengaged ("Science" 19). Indeed, one might argue, along the lines of Ingold, that Clare's speaker cares about the nightingale's life and safety because he regards her, to some degree, as curious, being curious about her at the same time. Conversely, the text seems to be curious about the nightingale because it cares about her life. Clare's poem, in short, suggests that "curiosity" is "a way of caring" ("Science" 19). Whatever knowledge it conveys can therefore not be objective in the modern sense because that would presuppose a division between the personal feelings and tastes of the researcher and the condition of the matter to be understood. According to the modern concept of science, what is objectively known, needs no longer to be cared about. It is finished and filed, such that whatever may have been 
curious about it has been transformed into manageable data or spelled out in general, propositional terms (Ingold, "Science" 19-20).

By contrast, what Clare's poetry carries with it is a form of knowledge that is essentially in process, or under construction, having no place outside of the activities through which it is brought to matter and put to use. "Knowledge," as Clare himself puts this in a short but suggestive note, "is not confined to Halls or colledges or forum[s]." Rather "like Socrates," she "accompanys us in our walks in the fields and attends on us at our homes," being "every where with us ready to instruct and assist us in our enquireys" (Works 482). Thus conceived, knowledge does not take people out of their senses but enables them to maintain a close personal relationship with whatever they study. Knowledge, in Clare's sense, is what allows you to be at home with a subject-matter without ceasing to care (and, indeed, wonder) about its curiosity. Many of Clare's bird poems are ways of registering and enacting this kind of knowledge that "is not confined to Halls or colledges" or, one might add, encyclopedias, but that comes to matter in, and emerges from, the experience of being with the things and organisms one explores.?

Take, to conclude with a final example, the remarkable stanzas "To the Snipe" (1832), ${ }^{8}$ a "Lover of swamps," as it is addressed, that inhabits a "quagmire overgrown/With hassock tufts of sedge" (Works 205.1-3), ${ }^{9}$ an "untrodden" area of "marshy flats" and "stagnant floods" almost inaccessible to human beings $(206.31,34)$. Here, "where fear encamps/Around thy home alone", the text continues,

The trembling grass

Quakes from the human foot

Nor bears the weight of man to let him pass

Where he alone and mute

Sitteth at rest

7 Thus Clare's writing might even be seen to perform the kind of "sweet" enquiry that Amanda Jo Goldstein has identified as a specifically Romantic way of conducting scientific investigation through poetic work. Goldstein does not deal with Clare, though.

8 This poem, apparently composed in 1832, was not published during Clare's lifetime. Further details on its place within Clare's oeuvre can be found in Gorji (99-121).

9 All references to this poem are given by page and line numbers. 
In safety neath the clump

Of huge flag-forrest that thy haunts invest

Or some old sallow stump (205.3-12)

Again, Clare's poem evidently cares about the safety of the snipe, placing its "haunts" in close relation to encroaching human hunters, "[f]ree booters [...]/Intent to kill and slay" (207.65-66), who might become a threat to the bird's life. The use of "the human foot," in the manner of pars pro toto, for the human race as well as the description of the hassocks as a "huge flag-forrest," suggests that the poetic speech assumes a perspective close to that of the bird sitting underneath a "clump" of reed grass or "some old sallow stump." At the same time, the speaker presents the snipe's way of existence as a strange and, indeed, most curious one. "Thriving on seams/ That tiney islands swell/Just hilling from the mud and rancid streams," the snipe, unlike the nightingale, appears to be a rather unusual subject-matter for poetry or fine art (205.13-15).

Whereas, in other Romantic poems, notably Percy B. Shelley's “To a SkyLark" (1820), birds sometimes inspire the imagination to soar upwards, towards the loftier regions of the ideal, Clare's snipe, equipped with a "bill [...]/Of rude unseemly length," is shown to "delve and drill/The gelid mass for food" (205.17-20). Unlike the nightingale, he does not even sing, and his "mystic nest," the speaker suspects, is entirely hidden in "The moors rude desolate and spungy lap" (205.23-24). There is not much that is ideal about this snipe. Rather, as in the nightingale poem, the act of speaking about the creature to be known remains deeply entwined with, and alive to, the experience of being, more or less intimately, with it. Epistemology has not (yet) been divorced from ontology (cf. Barad 183-85). Clare's writing, notwithstanding the obvious general knowledge it displays, still allows its subjects to exist for their own sake, in the particular conditions to which they are so curiously well "[s]uited" (205.18), as is the snipe's nest to the watery land; "Mystic indeed" (205.25).

\section{Works Cited}

Barad, Karen. Meeting the Universe Halfway: Quantum Physics and the Entanglement of Matter and Meaning. Durham: Duke University Press 2007. 
Bate, Jonathan. John Clare: A Biography. London: Picador, 2003.

Clare, John. Major Works. Ed. Eric Robinson and David Powell. Oxford: Oxford University Press, 1984.

-. The Natural History Prose Writings. Ed. Margaret Grainger. Oxford: Clarendon, 1983.

Clare, Johanne. John Clare and the Bounds of Circumstance. Kingston: McGill Queen's University Press, 1987.

Connor, Steven. “A Short Stirring to Meekness.” Inside Knowledge: (Un) doing Ways of Knowing in the Humanities. Ed. Carolyn Birdsall et al. Newcastle: Cambridge Scholars, 2009. 193-208.

Daston, Lorraine and Peter Galison. Objectivity. Brooklyn: Zone, 2007.

Dewey, John, and Arthur Bentley. Knowing and the Known. Westport: Greenwood, 1975.

Dewey, John. “The Experimental Theory of Knowledge." Mind 15.59 (1906): 293-307.

-. Experience and Nature. 1925. Rev. ed. London: George Allen \& Unwin, 1929.

Erchinger, Philipp. Kontingenzformen: Realisierungsweisen des fiktionalen Erzählens bei Nashe, Sterne und Byron. Würzburg: Königshausen \& Neumann, 2009.

Encyclopaedia Britannica, or a dictionary of arts, sciences, and miscellaneous literature on a plan entirely new [...]. Vols. 1-20. Dublin 1790-98 (Moore's Dublin edition). Eighteenth Century Collections Online. Gale. ULB Duesseldorf 17 January 2017.

Goldstein, Amanda Jo. Sweet Science: Romantic Materialism and the New Logics of Life. Chicago: University of Chicago Press, 2017.

Gorji, Mina. John Clare and the Place of Poetry. Liverpool: Liverpool University Press, 2008.

Haraway, Donna. When Species Meet. Minneapolis: University of Minnesota Press, 2008.

Haughton, Hugh. "Progress and Rhyme: 'The Nightingale's Nest' and Romantic Poetry." John Clare in Context. Ed. Hugh Haughton, Adam Phillips, and Geoffrey Summerfield. Cambridge: Cambridge University Press, 1994. 51-86. 
Heidegger, Martin. The Fundamental Concepts of Metaphysics: World, Finitude, Solitude. Trans. William McNeal and Nicholas Walker. Bloomington: Indiana University Press, 1995.

Herrnstein Smith, Barbara. Scandalous Knowledge: Science, Truth and the Human. Edinburgh: Edinburgh University Press, 2006.

Herschel, John. Preliminary Discourse on the Study of Natural Philosophy. 1830. New ed. London: Longman, 1851.

Heyes, Robert. "John Clare's Natural History.” New Essays on John Clare: Poetry, Culture, Community. Cambridge: Cambridge University Press, 2015. 169-188.

Ingold, Tim. "From Science to Art and back Again." Anuac 5.1 (2016): 5-23.

-. Making: Anthropology, Archaeology, Art and Architecture. London: Routledge, 2013.

Keats, John. Poetry and Prose. Ed. Jeffrey N. Cox. New York: Norton, 2009.

Kilcher, Andreas B. Mathesis und Poiesis: Die Enzyklopädik der Literatur 1600 bis 2000. München: Fink, 2003.

Latour, Bruno. We Have Never Been Modern. Trans. Catherine Porter. Cambridge: Harvard University Press 1993.

Levine, George. Dying to Know. Scientific Epistemology and Narrative in Victorian England. Chicago: The University of Chicago Press, 2002.

Mahood, M.M. The Poet as Botanist. Cambridge: Cambridge University Press, 2008.

McKusick, James. Green Writing: Romanticism and Ecology. New York: Palgrave Macmillan, 2010.

-. "John Clare and the Tyranny of Grammar." Studies in Romanticism 33.2 (1994): 255-77.

Morrisson, Mark S. "Alchemy." The Routledge Companion to Literature and Science. Ed. Bruce Clarke and Manuela Rossini. London: Routledge, 2011. 17-28.

OED. “list, v.2-v.4.” OED Online. Oxford University Press, March 2017. URL: http://www.oed.com/view/Entry/108998; http://www.oed.com/ view/Entry/108996, 26 May 2017.

Poetzsch, Markus. "The Ornithographies of John Clare and Henry David Thoreau." Transatlantic Literary Ecologies: Nature and Culture in the 
Nineteenth Century Anglophone Atlantic World. Ed. Kevin Hutchings and John Miller. London: Routledge, 2017. 91-104.

Rigby, Kate. "Earth's Poesy: Romantic Poetics, Natural Philosophy, and Biosemiotics." Handbook of Ecocriticism and Cultural Ecology. Ed. Hubert Zapf. Berlin: de Gruyter, 2016. 45-64.

Ryan, Derek. Animal Theory. Edinburgh: Edinburgh University Press, 2015.

Ryle, Gilbert. "Knowing How and Knowing That." Collected Essays 1929_ 1968. Vol. 2 of Collected Papers. London: Hutchinson, 1971. 212-26.

Vogl, Josef. "Robuste und idiosynkratische Theorie.” KulturPoetik 7.2 (2007): 249-58.

Williams, Michael. Problems of Knowledge: A Critical Introduction to Epistemology. Oxford: Oxford University Press, 2001.

Yeo, Richard. Encyclopaedic Visions: Scientific Dictionaries and Enlightenment Culture. Cambridge: Cambridge University Press, 2001. 



\title{
Maria Kaspirek \\ Negotiating Authority: Literary and Medical Configurations of Knowledge in $19^{\text {th }}$-Century America
}

\begin{abstract}
Presenting original evidence primarily from $19^{\text {th }}$-century medical journals, this essay reveals the hitherto neglected but substantial influence of literature on the consolidation of scientific knowledge on human nature. Against the background of a gradual institutionalization of medical science, the essay studies literary engagements with medico-scientific discourse, medical professionals' reliance on literary observations in their diagnostics, the work of physician writers Oliver Wendell Holmes and Silas Weir Mitchell, and the medical case study as a literary genre. The essay also lays out how the medical profession began to pathologize writers and their work to consolidate its own discursive authority in the field. All examples called up here paint the relationship between medicine and literature as a mutually beneficial one; two fields that were engaged in the struggle for epistemological authority, vitalized by the public's interest in health and human nature, sharing common subjects, negotiating a field of tension between democratization and professionalism, and united not only in a quest for knowledge but also for national identity and independence from European paragons. These observations also prove suggestive for the contemporary literature and science debates.
\end{abstract}

The relationship between literature and science has been the subject of an ongoing dispute for centuries (Arnold; Dewey; Snow), which has been given a new impetus through recent explorations by scholars such as Rita Felski, Marjorie Garber, and Ottmar Ette and Vera M. Kutzinski. While making strong claims about both the specificity and interdisciplinarity of literary frameworks for explaining human nature, these scholars decry the impression that, when it comes to conceptualizing the world and human's place in it, literature has been relegated to the sidelines, and science has taken over. The following paper takes a step back to another so-called "age of science" - the $19^{\text {th }}$ century (Knight), during which the alleged split between literature and science gained pace. By looking at antebellum medical discourse, I aim to draw attention to the particularly fertile exchange between literature and science at a time when the boundaries of those 
two fields intersected on various levels. The evidence presented in this paper, taken primarily from $19^{\text {th }}$-century medical journals, reveals the hitherto neglected but substantial influence of literature on the consolidation of scientific knowledge on human nature.

\section{Medicine in Antebellum US America}

The $19^{\text {th }}$ century constitutes a time of profound change in US American society on all levels. Authority that formerly resided primarily within religious institutions shifted to other domains and was increasingly assumed by individuals operating under the designation of "scientist," a term coined by William Whewell in 1834. Cultural and political discourse concentrated on the connection between morality and mental as well as physical health, and the welfare of the individual and the nation. These were key issues of social concern that gave rise to and which were addressed and proliferated by the various reform movements of the $19^{\text {th }}$ century. The aims and claims of movements such as Grahamism, Spiritualism, Phrenology, and Animal Magnetism were supported by the modes of thinking about human nature that "science" afforded. Embedded in the discourses of humanistic and humanitarian philosophies that aimed to reform the bodies, minds, and institutions of the American people, both reform movements and the new social sciences (closely connected to the former) turned their back to concepts of "religious predestination and political and social subjugation" (Caplan 5). Instead, they endorsed a belief in the "alterability of human nature" (Dewey 106) which was expressed in the doctrines of perfectibility and individualism. Given this emphasis on progress, and the role of the healthy individual in attaining it, it is not surprising that medicine was amongst the first and most aggressive fields of "science" trying to claim expertise in the field of human nature. In their quest for professional and public authorization, physicians could draw on the long tradition of their profession while simultaneously pointing out their dedication to the scientific and reformist zeitgeist. Additionally, they could argue that their occupation directly benefitted people's well-being and allowed them direct access and insight into one major field of the investigation into human nature - the human body. 
In $19^{\text {th }}$-century US, however, the medical profession was not unanimously respected. On the contrary, physicians were variously accused of undemocratic and un-American elitism, and denounced as butchers, relying on the heroic treatments handed-down by the famous physician Benjamin Rush, which included purging, leeching, toxic doses of calomel, and the cure-all therapy of blood-letting. The notion of the doctor as a quack who profited from the diseases of the less fortunate was prevalent amongst the antebellum American people since medical practice was largely unregulated. By no means had the medical profession at that point reached what the historian Paul Starr calls "professional sovereignty." According to Starr, it was not until much later, "that the profession of medicine could comfortably confer upon itself the status of a 'science,' connoting theoretical, objective knowledge (as opposed to experiential, intuitive, or subjective comprehension) of Nature" (18). ${ }^{1}$ Confronted with lack of state support (as licensing laws were mostly repealed in the 1830s) and internal division, medical practitioners saw the need for professionalization to gain the trust and veneration of the public they so coveted (Shryock). A turning point in this process was taking a step beyond the many regional medical societies and establishing the nation-wide American Medical Association (AMA) in 1847.

The AMA saw itself as the gate-keeper for education and practice in medicine, excluded irregular or fraudulent practitioners, and reaffirmed and fortified physicians' own claim to expertise and authority in areas seemingly apart from medicine. For them, a "true physician was at the same time a social activist and educator" (Grob 5), and medicine irrevocably linked with social policy. This thought was extended when Nathan S. Davis in his address at the first meeting of the AMA proclaimed that "of all the voluntary social organizations in our country, none are at this time in a position to exert a wider or more permanent influence over the temporal interests of our country than the American Medical Association” (qtd. in Davis 19).

1 Starr's definition of antebellum medical science as relying on "experiential, intuitive, or subjective" knowledge is appropriate. Technological advances in science that enabled "theoretical, objective" knowledge, like microscopy, chemical analysis, and histology did not take root in the US until after the Civil War, and even statistics which was increasingly utilized for establishing medical and social policy was at an early stage and heavily flawed. 
However, medicine was not alone in its endeavor to influence the public. In many ways, the adjacent emerging sciences of phrenology, hydropathy, and animal magnetism commanded more trust by the American people than regular medicine, as they appealed towards the preference for individual agency and domestic applicability of their methods.

But the new -isms and -ologies, so thoroughly attacked in Oliver Wendell Holmes' Homeopathy and its Kindred Delusions (1842) and David Meredith Reese's Humbugs of New-York: Being a Remonstrance against Popular Delusion, whether in Science, Philosophy, or Religion (1838), actually supported the authority of orthodox practitioners in unforeseen ways, as my research has shown. By fortifying the link between mind and matter and consolidating assumptions of the reciprocal relationship between mind and body, they enabled medicine to extend their claim of expertise from the body into "the other" domain of human nature - the mind. This led to the establishment of a specialized medical branch of early psychiatry that founded its very own organization, the Association of Medical Superintendents of American Institutions for the Insane (now the American Psychiatric Association). Both the organization and its organ of dissemination of knowledge, the American Journal of Insanity (now the American Journal of Psychiatry) persists until today. In linking vice, immoral, or unnatural behavior with mental health, they medicalized deviance and thus supplanted the clergy's authority with their own. Apart from addressing social concerns over growing numbers of the insane, which they saw as caused by behavior, politics, climate, environment, and heredity, these early psychiatrists increasingly served as expert witnesses on mental health in legal trials. ${ }^{2}$

\section{The Presence of Science in Literature}

The colorful and highly competitive medical marketplace was reflected not only in political and legal discourse, but also in cultural productions of the time. The presence of science and especially of medicine in $19^{\text {th }}$-century literature - poems, essays, novels, short stories - is striking. The growing

2 Isaac Ray, one of the most eminent psychiatrists of the $19^{\text {th }}$ century paid tribute to this development by publishing his Treatise on the Medical Jurisprudence of Insanity (1838), which is commonly regarded as the founding document of forensic psychiatry. 
interest of the public in scientific matters promised a greater readership for a growing literary market. The expansion of the medical field provided fresh frameworks, vocabulary, and topics for authors such as Edgar Allan Poe. Poe's mesmeric tales, for example, feature a first-hand description of how to mesmerize people and what can be achieved by it. In "Mesmeric Revelations," access to metaphysical knowledge is granted to the person under the influence of animal magnetism, and "The Facts in the Case of M. Valdemar" follows a magnetic procedure aimed at arresting death. Poe's faithful use of emerging scientific narrative techniques as analyzed by Roland Barthes, proved to be so convincing to antebellum readers that they interpreted the story to be a factual account. ${ }^{3}$ Many writers were highly engaged in debates about the truthfulness and validity of current fads - while Poe and John Neal were avid believers in the potential of phrenology and animal magnetism, Melville used his Moby Dick to ridicule phrenology and physiognomy; and in Fanny Fern's novel Ruth Hall, the eponymous heroine rejects her phrenological character reading. Nathaniel Hawthorne must also be counted among the sceptics. Hawthorne, amongst many other writers, made frequent use of the figure of the scientist to express his concerns over the dangers residing within this new dedication to unveiling the secrets of Nature and human nature. Both "The Birth-Mark" and "Rappaccini's Daughter" feature scientists, who each pursue knowledge to an extent where the ones most dear to them die as subjects of their experiments. Hawthorne's fiction boasts no less than eight examples of the "mad scientist," who is often a physician such as Chillingworth in The Scarlet Letter. Chillingworth, with his expertise, knowledge, and prying eyes aims to corrupt the soul of his patient Arthur Dimmesdale while pretending to tend to his body. Such stories sparked debates about what counted as good or bad medical practice and bedside-manner. Literary illustrations of doctors' practice became points of reference by physicians who took them at face value and subjected the literary depictions of doctors to critical

3 In the course of the $19^{\text {th }}$ century, according to Ruth Caplan, "the common language of natural philosophy and humanism" (135) subsided to be shared by medical scientists and laymen, as physicians and psychiatrists increasingly established their own terminology and methodology. 
analysis, as Robert Green did for "Dickens' Doctors" in the Boston Medical and Surgical Journal (926-28).

Literary texts thus engage actively in the construction of the medical profession and show how medico-scientific discourse and its ethical concerns seeped into citizens' everyday lives. Accordingly, literary texts could either support medical 'facts,' complement them (what Robert Scholnick has called conduction), criticize them, or oppose them outright (Scholnick's term here is resistance), thus reinforcing literature's claim to a distinct and legitimate domain of knowledge. In this endeavor, antebellum writers received unexpected help from the professions they often ridiculed or vilified in their writing - namely, $19^{\text {th }}$-century medical practitioners, phrenologists, and early psychiatrists.

\section{Physicians Praising Fiction}

In 1844, the very first edition of the American Journal of Insanity featured an article called "Insanity. Illustrated by Histories of Distinguished Men and by the Writings of Poets and Novelists", which was written by the journal's editor and asylum superintendent Amariah Brigham:

Though both poets and novelists are considered fictitious writers, yet in everything relating to the passions and emotions of mankind, the most celebrated of them, are the most correct of historians. [...] The correctness of the writers, in these respects appears to be the result, for the most part, of a wonderful power of observation, or of a kind of miraculous ability. (9)

Brigham explicitly grants novelists the same "power of observation" in diagnosing the "passions and emotions of mankind" that physicians, especially those who specialized in insanity, claimed for themselves. His understanding of the function of literature is twofold: he confers the authority to diagnose, to support or to critique contemporary "truths" about the human psyche to writers of fiction, and he sees literary texts as sources of knowledge that the medical branch he represents can rely on in its work. In doing so, Brigham follows a strategy aimed at validating his own position as physician, scientist, and asylum superintendent.

The same strategy and attitude towards literature can be observed in the Edinburgh-based Phrenological Journal and Miscellany, which functioned as an influential model for American magazines in the genre. In 1823, 
twenty years before the appearance of Brigham's article, the journal introduced its constitutive edition with the following elaboration of the future structure and content of the magazine:

In another department [of the magazine] we propose to institute a course of critical analysis on phrenological principles, of our best and most popular authors [...] in which we shall endeavor [sic] to shew that the best writers are the most strictly phrenological; and that, like Moliere [sic] [...] without knowing it, these writers owe their popularity to their being phrenological, which is another word for natural. The poets will afford us a noble field, and none more than that "priest of nature" - Shakspeare [sic]. [...] We will use the chief excellencies of his work as an exposition of our science [until] we have adduced him as one of our most powerful witnesses (XII)

Here, again, knowledge is ascribed to literary texts and their authors by a scientist. Whether literary writers were aware of their own knowledge or, as this quote suggests, the knowledge was more of a tacit, intuitive nature, both phrenologists and early psychiatrists drew on literature as a source of knowledge for their own sciences. Furthermore, they used literature as a source of validation of this knowledge; they each proposed to use aspects of literary works as an "exposition" of their science, and they wanted to "adduce" authors as "most powerful witnesses." Thus, with the help of literature - given voluntarily or not - they aimed to legitimize their knowledge, their position, their authority, their very institutions. What is particularly enlightening in these two constitutive articles are the names of the writers who were regarded as being the most fertile and powerful for this endeavor - Molière, Shakespeare, Sir Walter Scott, and Lord Byron. As Marjorie Garber has pointed out, insight into human nature, before shifting to the domain of scientists, had been the task and unique ability of poets and philosophers (17). Men of science frequently made "references to the fiction and poetry of the day and to that of earlier generations. By doing so, they declared an affinity, sometimes of thought, but more often of culture, with respected authors and, indirectly, with their readers" (Otis xix). Alexis Easley notes that " $[\mathrm{m}]$ edical periodicals made reference to literary subject matter in a seemingly self-conscious way, as if to present a high-culture rather than a strictly professional perspective on medical science" (158). In short: physicians asserted being professionals in their medical domain by referencing popular and generally accepted literary figures and works who had already questioned epistemological limits of human nature. 


\section{Physicians Writing Fiction}

Apart from this insistence on cultural capital, medical practitioners resorted to yet another opportunity offered by literature. Since literary writing was not subject to scientific requirements of proof ${ }^{4}$ it provided and functioned as a unique space in which medical developments and theories were tested as hypotheses, imagined, and extended. Oliver Wendell Holmes Sr., for instance, a Boston Brahmin (a term which he himself coined in his articles for the Atlantic Monthly) was respected for his medical treatises on puerperal fever, but also for his literary abilities. His three novels, Elsie Venner (1861), The Guardian Angel (1867), and A Moral Antipathy (1885) were dubbed "medicated" by his reviewers, due to the diagnostic methods they employed.

In Elsie Venner, published serially from 1859 onwards in The Atlantic Monthly, Holmes explores the theme of original sin, and negotiates the binary of hereditary determinism and moral responsibility. Drawing on his own medical background, he imbues the narrator of the story with diagnostic power and superior knowledge, and includes no less than three medical professionals in the story. He proclaims in his preface, that "a grave scientific doctrine may be detected lying beneath some of the delineations of the character" of the eponymous heroine (vii). Literature, for Holmes, who lectured extensively on the subject, was not only a respectable pastime for a man of his profession and position, but - as Carmen Birkle addresses in a recent article on Holmes -, novel-writing enabled him to apply and extend his medical thinking beyond the limitations of the scientific community (87).

The same appeal motivated Silas Weir Mitchell to taking up the pen. Nowadays, Mitchell is well known for his radical, but seemingly successful "cures" of hysterical women in catatonic states - setting their beds on fire, or undressing while announcing to rape them (Szasz 106) -, and even more so, in his role as Charlotte Perkins Gilman's attending physician; but he was also a doctor confronted with the horrors of the Civil War. In charge of Turner's Lane Military Hospital in Philadelphia, he was exposed to what he first called "sensory hallucinations"; gravely wounded soldiers who claimed to feel agonizing pain in limbs that were already amputated. Mitchell was

4 Even though those were comparatively lax at that time. 
fascinated by this seemingly irrational condition and conducted further research on the subject. However, instead of publishing his findings in a medical journal, he first framed them within a short story. "The Case of George Dedlow," published in The Atlantic Monthly in 1866, featured as its main protagonist and narrator a physician who, after being severely injured in the war, ended up a "useless torso, more like some strange larval creature than anything of human shape" (5). While phantom limb pain was not a new phenomenon, having been described by a $16^{\text {th }}$-century French surgeon, Mitchell has been credited with the discovery and exploration of this condition based on his fictional short story. This says much about the verisimilitude literature was accredited with - a contention that was emphasized by Mitchell's narrator asserting that he has "dictated these pages, not to shock my readers, but to possess them with facts in regard to the relation of the mind to the body; and I hasten, therefore, to such portions of my case as best illustrate these views" (5).

In their fictional explorations of medical conditions, however, both Holmes and Mitchell equipped their stories with a caveat in case the theories they proposed in literary form were to be falsified. The "scientific doctrine" Holmes described as possibly underlying the character study of Elsie Venner, is diminished in its claim to truthfulness as one that he employed "as a part of the machinery of the story without pledging his absolute belief in it to the extent to which it is asserted or implied" (vii). Mitchell resorted to publishing "The Case of George Dedlow" anonymously, and gave the story a parodic ending. ${ }^{5}$ Despite these fail-safe strategies, both literary texts were taken seriously by general audiences (who read them as factual accounts) and medical peers (who discussed their medical content) alike. In fact, Mitchell's account of a soldier suffering from neuralgia inspired many people to take up collections for the pitiful George Dedlow, and some even tried to visit him at the hospital. The reception of this story as a truthful account, so similar to that of Poe's mesmeric short story "The Facts in the Case of M. Valdemar," speaks to literature's multiple functions in the $19^{\text {th }}$ century: introducing and fortifying medical knowledge; purveying its own kind of knowledge (as seen by the interest and empathy towards the personal neuralgic experience that was

5 During a mesmeric seance, Dedlow is temporarily reunited with his missing legs. 
generated in the audience through the specificities of literary communication); and notably advancing a physician's career and self-conception. Mitchell's “literary' experience [...] contributed to his scientific breakthrough" (Journet 87), and Holmes' didactic literary essays in the Atlantic Monthly established him as a respected physician and gentleman, while fictional techniques enabled both to "explore a phenomenon that [they] could not fully articulate within the scientific paradigms" of their time (87). ${ }^{6}$

\section{The Medical Case Study - A Literary Genre?}

What is also interesting to note is that Holmes' novels and Mitchell's short story, although decidedly fictional texts, take on the form of medical case studies. While this has been interpreted by some as early attempts to tell the implications of a condition or diagnosis from the patient's perspective (Bourke; Kline), the medical case study as a personalized and affective account was not uncommon in $19^{\text {th }}$-century medical writing. In fact, the framework and structure of the $19^{\text {th }}$-century "medical case study" may in many ways have been derived from its literary predecessor, the character study. ${ }^{7}$ That physicians and early psychiatrists modeled their scientific "case studies" on examples provided by established authors becomes evident when tracing the development of this methodology from Brigham's article through subsequent contributions to the American Journal of Insanity. In almost every edition of the journal, descriptions of interesting real cases of insanity alternated with articles in which various asylum superintendents analyzed fictional cases of insanity and praised the authors

6 Their "clinical fiction" also afforded them a way to negotiate and reconcile the different sides of their profession - for Mitchell, that was the paradox of wardoctors "healing" soldiers in order to enable more death; for Holmes, it was the conflict between a physician's drive to objective knowledge and the humane emotions that a patient in need triggered. While this tension remained partly unresolved in the texts, both physician-novelists set up their respective medical main protagonists as authoritative figures in the possession of knowledge about human nature as far superior to those without a medical education and thus contributed in their own way to the AMA's arguments for professionalism.

7 Reading the medical case study as a literary genre, which has been tacitly proposed by Susan Wells in her analysis of the Freudian case study, provides a fascinating opportunity for further scholarship. 
for their "correctness" in depicting the causes and symptoms of the individual's madness, as can be seen, for example, in Isaac Ray's "Shakespeare's Delineations of Insanity" (1847):

It is a curious fact, that metaphysicians whose special province it is to observe and analyze the mental phenomena, have shown much less knowledge of mind as affected by disease, than writers of poetry and romance whose ideas are supposed to be the offspring of imagination, rather than a sober observation of facts. No one would look into Locke, or Kant, or Stewart, to find any light on the subject of insanity, but in the pages of Shakespeare and Scott, are delineations of this disorder that may be ranked with the highest triumphs of their masterly genius. (289)

In attributing novelists' superior knowledge of the human psyche to their talent of observation and the focus on the mind "in the concrete" (289), Ray's article echoes the beliefs exhibited by his fellow psychiatrist Amariah Brigham.

Physicians and psychiatrists like Ray and Brigham not only openly practiced literary criticism but provided a place for poetry and prose in that they replicated full literary passages that either served to illustrate a point made by the medical professional, or spoke for themselves. Apart from referencing, analyzing, or imitating the depictions by established literary authorities, scientists made abundant use of literary techniques in their treatises, tracts, and articles, employing third-person narrators, and relying on "vivid description, metaphor, and narration" (Cervetti 79). In a time of advanced printing techniques and growing literacy, scientists knew that literature functioned as a point of access for interested lay readers. In order to disseminate their knowledge, advance their reputation, and promote scientific literacy, they did not shy away from publishing their findings in either literary form and/or in the popular press.

\section{Medicine and the Literary Marketplace}

This seeming transgression of disciplinary boundaries (from today's view) did seem out of place for neither for readers nor scientists in the $19^{\text {th }}$ century, owing to both the structure of the literary marketplace and barely consolidated demarcation of science, literature, and popular culture. Knowledge, both literary and scientific, was proliferated by magazines and journals, the dominant publication form of the $19^{\text {th }}$ century. In accordance with the broad interests of the public, most magazines were often a hodge-podge of 
contributions from any given field, in any possible form. Political essays were followed by poems and political announcements, scientific treatises and moral advice alternated with literary criticism, letters, and travel reports (Haveman; Otis). The titles of these periodicals often reflected this diversity of content, such as Lippincott's Magazine of Popular Literature and Science or the short lived American Magazine of Useful and Entertaining Knowledge (1834-1837), edited by Hawthorne. Even seemingly specialized journals in the fields of mesmerism, phrenology, or hydropathy paid tribute to broader interests. An excellent example is the aptly titled The American Phrenological Journal and Life Illustrated: A Repository of Science, Literature, and General Intelligence, simultaneously pointing toward the elevated standing of "science" and "literature" in the pursuit of "general intelligence."

Medical publications proved to be no different. Although by the end of the $19^{\text {th }}$ century, medical periodicals increasingly employed technical jargon, in the earlier decades of the century, even with increased specialization, they took pains to include content and language "as to be accessible to a general educated audience" (Easley 156). The necessity of appealing to the public to further advance both general interest and their authority on matters of the mind and body is reflected in medical periodicals of the time including "book reviews, medical curiosities, sensational narratives, and editorials on hot-button medical issues" (156). As Alexis Easley points out, medical journals thus had much in common with mainstream literary reviews and other magazines of the $19^{\text {th }}$ century (156).

All these examples paint the relationship between medicine and literature as a mutually beneficial one; two fields that were engaged in the struggle for epistemological authority, vitalized by the public's interest in health and human nature, sharing common subjects, negotiating a field of tension between democratization and professionalism, and united not only in a quest for knowledge but also for national identity and independence from European paragons. The reciprocal influence of medical and literary frameworks that have been laid out here indeed seem to fortify Jane Wood's belief that $19^{\text {th }}$-century "medicine and literature looked to each other for elucidation and illustration" of knowledge (2), but also, taking the examples of the Phrenological Journal and Miscellany and the American Journal of Insanity, for mutual legitimization and validation. Since then, literature 
and science have apparently parted ways in the quest for knowledge and the methodology employed in obtaining it. Despite the assertions just made in favor of literature's relevance in knowledge construction and legitimization, the $19^{\text {th }}$ century can also be read as a period in which these trends of relegating literature to the sideline gathered pace.

\section{Pathologizing Literature}

From mid-century onwards, fronts began to harden between medical practitioners and creative writers as processes of professionalization and institutionalization progressed. In her study of the nervous system in $19^{\text {th }}$-century literature, culture, and medicine, Justine Murison argues that, especially after the Civil War, more and more literary writers opposed the path adopted by their medical contemporaries who, through neurological and biological theories, pathologized every aspect of human behavior (4). Thus, physicians and alienists proclaimed the need for professional, medical control over physiological and psychological conditions and assumed the sole power of interpretation (6). However, while casting aside the literary imagination as a participant in scientific knowledge production, in an unfortunate but highly fascinating turn of events they made it the object of their study. Expanding $18^{\text {th }}$-century "debates about the effects of reading on mental health" that "fused moral issues to health concerns" $(5), 19^{\text {th }}$-century medical practitioners began to turn their attention anew towards literary texts - only this time not in search of profound insight attributed to the author's "wonderful power of observation," as Brigham contended in 1844, but as symptomatic products of a diseased mind. Insight into the inner workings of the human mind displayed by these texts were explained as having been generated by a pathological drive of their creators. This development can be traced throughout all kinds of magazines, but is especially manifest in editions of the American Journal of Insanity. Examinations of literature persisted after the 1850 s, but the approach was turned into an entirely diagnostic one. Literary characters were diagnosed and re-diagnosed according to the newest theoretical framework; additionally, articles like Pliny Earle’s “The Poetry of Insanity" and other references throughout the journal remark upon the supposedly insane's remarkable talent for creativity and literary abilities, fortifying the long-standing suspicion that there was only a fine 
line between genius and madness. Medicine's focus on "the mad writer," his or her ailments often being attributed to overly long periods of cramped sitting and overexertion of the mental faculties, was presented as a matter of far-reaching concern, since writers were presumably the "facilitators of national progress” (Easley 169). However, when George Gould, an American medical writer and ophthalmologist, voiced his concern over the mental and physical well-being of domestic writers, he can hardly veil his triumph; in 1903, he declares that "[g]eniuses, the instruments and makers of civilization, depend at last on the medical profession” (760).

\section{Summarizing Scientific Strategies}

After reviewing the development of the relationship between science and literature in the $19^{\text {th }}$ century through the lens of medical discourse, let me return to the introductory remarks of the Phrenological Journal and Miscellany. For the medical field - and all its adjacent $19^{\text {th }}$-century branches such as phrenology and asylum medicine - perusing literature "as an exposition of our science" has worked on many different levels. In a first step, practitioners supported the notion of literature as a powerful and authoritative source of knowledge which they could rely on in their own work. Subsequently, by referencing acknowledged authors and equating medical "facts" with those portrayed in novels and poetry, they validated their own position while validating that of literature. Another way in which literature served to "expose" science can be seen by the examples of Holmes and Mitchell who used it as a medium in which they could freely express, test, and extend their medical theories. Likewise, writers of fiction such as Poe and Hawthorne have contributed to the dissemination of scientific theories while being suggestive of the ethical dangers associated with it. Furthermore, medical writers called on literature as a purveyor of techniques with which to convey scientific knowledge in an accessible manner, fulfilling the duty of their profession not only "to discover those individual and social factors governing health," but also "to disseminate those findings among their fellow countrymen in order that they be put to practical use" (Grob 5). In a final step, through medicalizing literature, pathologizing texts and authors alike, medicine tried to assert its authority as surpassing that of literature when it came to establishing norm and deviance of human behavior, thoughts, and 
emotions. I argue that these five main modes of influence - literature as a source of knowledge and mode of dissemination of scientific theories, literature as a medium in which to express medical theories and as a purveyor of technique, as well as finally the medicalization of literature -stand out in their impact on the $19^{\text {th }}$-century relationship between science, literature, and their negotiation of knowledge and authority. They also constitute a fresh starting point from which one might revisit and contribute to the current debate about the status of literary and scientific knowledge and their possible interaction. Even at a short glance, the modes discussed here seem to be applicable to $20^{\text {th }}$-century and contemporary discussions of literature and science. Literature still functions as a medium in which to test and imagine, to disseminate and popularize (scientific) knowledge and its ramifications, and as a purveyor of the techniques with which to achieve those objectives, a potential long realized by both science-fiction writers and an ever-increasing number of popular science writers.

Even the final, derogatory step of pathologizing literary texts has provided fertile soil for literature and literary studies. While fiction continued to incorporate, and negotiate psychological theories and concepts within its realm, the same theories offered a new lens for literary scholars through which to read classical and contemporary texts, thus assuming the diagnostic, clinical gaze reserved for physicians and psychiatrists (Foucault). Symptomatic reading, as this practice has come to be called, has thankfully fallen out of favor in recent years, and has been partly replaced with the turn to affect and investigations into literature's potential for affective knowledge ("George Dedlow" comes to mind). However, the decades-long preoccupation of literary studies with psychoanalytical theories have secured a place for literature in one of the epicenters of investigation into the human mind: in the last decades, psychiatrists and psychologists have reaffirmed Amariah Brigham's contention that novelists have a unique ability to capture the "passions and emotions of mankind," that "literature can provide a method of consolidating knowledge about psychopathology" and "facilitate selfreflection" which can prove essential not only for practitioners, but also for patients (Tischler 55).

This short overview of the contemporary applicability of $19^{\text {th }}$-century modes of interaction reveals the need for further investigations and their potential, but also, that taking a step back in time, and bearing in mind 
the origins of the epistemological debate between literature and (medical) science sheds new light on the unique contributions that result from the interaction of the two fields.

\section{Works Cited}

Anonymous. "Introductory Statement." The Phrenological Journal and Miscellany 1 (1823-1824): III-XXXI.

Arnold, Matthew. "Literature and Science (1882)." Selected Essays. London: Oxford University Press, 1964. 208-33.

Barthes, Roland. "Textual Analysis of a Tale of Poe." On Signs. Ed. Marshall Blonsky. Oxford: Blackwell, 1985. 84-97. [Originally published as “Analyse Textuelle d'un Conte d'Edgar Poe." Semiotique Narrative et Textuelle. Ed. Claude Chabrol. Paris: Librairie Larousse, 1973, 29-53.]

Birkle, Carmen. "Narrative Praxis und diagnostische Interpretation: Literatur und Medizin in Amerika." Literatur und Medizin - Interdisziplinäre Beiträge zu den Medical Humanities. Ed. Pascal Fischer and Maricarla Gadebusch Bondio. Heidelberg: Winter, 2016. 79-100.

Brigham, Amariah. "Insanity, Illustrated by Histories of Distinguished Men and by the Writings of Poets and Novelists." American Journal of Insanity 1 (1844): 9-46.

Bourke, Joanna. "Silas Weir Mitchell's The Case of George Dedlow." The Lancet 373.9672 (2009): 1332-33.

Caplan, Ruth. Psychiatry and the Community in Nineteenth-Century America. New York: Basic, 1969.

Cervetti, Nancy. S. Weir Mitchell, 1829-1914: Philadelphia's Literary Physician. University Park: Penn State University Press, 2016.

Davis, Cynthia J. Bodily and Narrative Forms: The Influence of Medicine on American Literature, 1845-1915. Stanford: Stanford University Press, 2000.

Dewey, John. Human Nature and Conduct: An Introduction to Social Psychology. New York: Modern Library, 1922.

Easley, Alexis. Literary Celebrity, Gender, and Victorian Authorship, 1850 1914. Newark: University of Delaware Press, 2011.

Ette, Ottmar, and Vera M. Kutzinski. "Literature as Knowledge for Living, Literary Studies as Science for Living.” PMLA 125.4 (2010): 977-93. 
Felski, Rita. The Uses of Literature. New York: Wiley-Blackwell, 2008. Foucault, Michel. The Birth of the Clinic: An Archaeology of Medical Perception. New York: Pantheon, 1973.

Garber, Marjorie. A Manifesto for Literary Studies. Seattle: Walter Chapin Simpson Center for the Humanities, 2003.

Garber, Marjorie. The Use and Abuse of Literature. New York: Pantheon, 2011.

Gould, George. "The Role of Eyestrain in Civilization.” British Medical Journal 2 (Sept 1903): 757-60.

Green, Robert M. “Dickens's Doctors.” Boston Medical Journal 167.25 (1912): 926-28.

Grob, Gerald N. Edward Jarvis and the Medical World of NineteenthCentury America. Knoxville: University of Tennessee Press, 1978.

Haveman, Heather A. Magazines and the Making of America: Modernization, Community, and Print Culture, 1741-1860. Princeton: Princeton University Press, 2015.

Holmes, Oliver Wendell. Elsie Venner; A Romance of Destiny. 1861. Rpt. Boston: Houghton Mifflin, 1892.

Journet, Debra. "Phantom Limbs and 'Body-Ego': S. Weir Mitchell's 'George Dedlow'." Mosaic: An Interdisciplinary Critical Journal 23.1 (Winter 1990): 87-99.

Kline, David G. "Silas Weir Mitchell and 'The Strange Case of George Dedlow'.” Neurosurgical Focus 41.1 (2016): 1-8.

Knight, David. The Age of Science: The Scientific World-View in the Nineteenth Century. Oxford: Blackwell, 1988.

Mitchell, Silas Weir. "The Case of George Dedlow." The Atlantic Monthly. A Magazine of Literature, Science, Art, and Politics XVIII (July 1866): $1-10$.

Murison, Justine S. The Politics of Anxiety in Nineteenth-Century American Literature. Cambridge: Cambridge University Press, 2011.

Otis, Laura. "Introduction." Literature and Science in the Nineteenth Century: An Anthology. Oxford: Oxford University Press, 2009. XVIIXXIX.

Ray, Isaac. "Shakespeare's Delineations of Insanity." American Journal of Insanity 3.4 (1847): 289-332. 
Shryock, Richard H. Medicine and Society in America, 1660-1860. Ithaca: Cornell University Press, 1984.

Snow, Charles Percy. Two Cultures and the Scientific Revolution. The Rede Lecture, 1959. New York: Cambridge University Press, 1961.

Starr, Paul. The Social Transformation of American Medicine. New York: Basic, 1995.

Szasz. Thomas. The Medicalization of Everyday Life: Selected Essays. New York: Syracuse University Press, 2007.

Tischler, Victoria. Mental Health, Psychiatry and the Arts: A Teaching Handbook. Oxford: Radcliffe, 2010.

Wells, Susan. "Freud's Rat Man and the Case Study: Genre in Three Keys." New Literary History 34.2 (2003): 353-66.

Wood, Jane. Passion and Pathology in Victorian Fiction. Oxford: Oxford University Press, 2001. 


\title{
Cord-Christian Casper \\ The Fourth Dimension and Impossible Knowledge in Edwardian Speculative Fiction
}

\begin{abstract}
This essay investigates Early Modernist literary confrontations with the humanly unknowable. In Edwardian novels, short stories, or popular scientific tracts such limits of knowledge are associated with a realm of their own: the Fourth Dimension. Edwin Abbott's Flatland (1917), Charles Hinton's Scientific Romances (1886/1896) as well as Joseph Conrad's and Ford Madox Ford's 1901 novel The Inheritors each stage attempts to represent this space beyond the limits of familiar perceptual and cognitive faculties. These narratives of hyperspace, however, deprive their readers of immediate paths towards dimensional transcendence. The journey towards the Fourth Dimension stalls: in their various pursuits of impossible knowledge, these texts self-referentially mark the breakdown of their representational strategies. As a consequence, analogies falter, the unlearning of conventions stagnates, and, ultimately, literature can only register impossible 4-D knowledge as a perpetual absence. This failure is far from elegiac, however. Their marked impasses propel these speculative fictions towards a constant flight from generic constraint and cliché. The article demonstrates that it is precisely by barring easy access to 'supra-sensible' knowledge that the texts inculcate ever-renewed narrative experiments and readerly speculation alike.
\end{abstract}

\section{Introduction: Towards the Fourth Dimension}

"What is the Fourth Dimension?" This question, the title of an 1880 essay by Charles Hinton, underlies a variegated field of inquiry in the late $19^{\text {th }}$ and early $20^{\text {th }}$ century (3). Well before the popularization of Einstein's theory of general relativity, the fourth dimension is conceived in distinctly spatial terms. While ' $n$ dimensional geometry' (cf. Throesch, "Nonsense" 37 ) originates as a mathematical pursuit, accounts of 4-D space exceed disciplinary bounds from the outset. Theories of higher dimensions just out of reach of conventional perception span high and low culture, seamlessly integrating spiritualism or pseudoscience, and coalescing into veritable "hyperspace philosophy" (Henderson 120). These speculations attach a wide range of functions to the alleged higher reality, sharing the broad 
outlook of a "path which leads us beyond the horizon of actual experience" by "questioning whatever seems arbitrary and irrationally limited in the domain of knowledge" (Hinton, "What is" 4) - and offering the prospect of previously impossible knowledge in the process.

Literary accounts of the fourth dimension from the mid- $19^{\text {th }}$ century onwards display a marked concern with ways in which the readers' 'horizon of experience' may be transcended by encountering a 'hyper-reality effect' adequate to higher space. At the same time, however, these texts set limits for the "exploration of the facts of higher space" (Hinton, "Many Dimensions" 43). For all their rhetoric of expanding the knowable, the habitual epistemological horizon to be superseded is presented as remarkably unyielding. Accordingly, in addition to offering formal complements to higher space, early speculative fiction shows equal concern with the incapacity of textual strategies to encompass the constitutively unrepresentable features of these higher dimensions (cf. Stableford 218). This essay will argue that the failure of representative tactics emerges as a crucial feature of this emerging and heterogeneous genre. Descriptions of the fourth dimension implicitly and explicitly accentuate the degree to which they remain projections, never quite shedding the strictures of the language and the concepts developed under the conditions of 3-D space. Edwin Abbott's Flatland (1884), Charles Hinton's Scientific Romances (1886/1896) as well as Joseph Conrad's and Ford Madox Ford's 1901 novel The Inheritors will be shown to self-referentially mark the breakdown of their textual strategies in the pursuit of dimensional transcendence.

In the three late $19^{\text {th }}$ and early $20^{\text {th }}$-century texts under consideration here, the marked failure of dimension-spanning speculative fiction is presented as the impetus for revised experiments in literature. With each breakdown of the literary "extra suprasensible dimension of space, of which our threedimensional world might be merely a section or a boundary" (Henderson 2), the texts outline the necessity for a renewal of the formal devices bringing into view a literary account of that 'section.' Each collapse of external reference to hyperspace is accompanied by self-referential concern with the media on offer, and a performance of the need for a renewal of literary devices. What is more, each unraveling of a literary account of the "vast realm of possibility" (Hinton, "What is" 4) engenders a critical reassessment of the doctrines passing for unimpeachable truths in lower-dimensional space. Thus, 
rather than representing the spatial fourth dimension, the texts in this loose sub-genre display fundamental doubt regarding the possibility of knowledge of higher space. Each impasse is accompanied by a renewed presentation and evaluation of attempts to overcome the gap between lower and higher realities, as well as between linear language and a hyperspace overview.

\section{Knowledge as Analogy in Flatland}

How can literature speculate about a higher sphere not only defined by but also deriving its interest from the fact that it exceeds perception? In tackling this problem, Edwin Abbott's novel Flatland popularizes the device of cross-dimensional, analogical reasoning. This strategy presumes that the "fourth dimension is to three-dimensional space as the third dimension is to two-dimensional space. 4-D: 3-D:: 3-D: 2-D” (Rucker 8). Analogy scales down the problems of dimensional knowledge: it confronts its readers with two-dimensional beings, living their two-dimensional lives on a horizontal plane. An immutable class system and strict gender hierarchy contingent on the conceptual constraints of 2-D space appears entirely natural to its denizens: "Our women are Straight Lines. Our Soldiers and Lowest Classes of Workmen are Triangles" (Abbott 8). This two-dimensional system of knowledge - geared towards maintaining the "Law of Nature" (9) that the symmetry and number of sides of a Flatlander's body is the primary determinant of worth and status - appears as closed and self-contained. The range of interpretations is curtailed by a set of limitations which, themselves, cannot be perceived.

This changes with the arrival of a visitor: a three-dimensional sphere (conveniently named A Sphere) deigns to inspect lower space. While A Sphere surveys the plane in its entirety, the Flatland protagonist - 'A Square' - perceives him as a circle, varying in size as his circumference intersects the two-dimensional plane. As the visitor from 3-D space explains: "You cannot indeed see more than one of my sections, or Circles, at a time; for you have no power to raise your eye out of the plane of Flatland; but you can at least see that, as I rise in Space, so my section becomes smaller" (Abbott 71). To make his point, the didactically inclined sphere detaches A Square from his plane, opening it to a newfound panoramic gaze. This shift in perspective offers a version of the modernist "skeptical drift-from 
world to self, from object to subject of perception" (Levenson 93) that is peculiar to dimensional literature. A Square experiences the disclosure of an excess of meaning, a perspectival shift that expands the range of the knowable: by making the 2-D world literally transparent and its constraints perceptible, dimensional border-crossing renders the conditions of possibility of knowledge unalterably contingent.

The comparison of the higher-dimensional vantage point with the constraints of the 2-D plane prompts expansive speculation on analogous relationships in spaces lower and higher to the ones considered: "[a]ny space can generate its next higher space by moving in a new direction, that is, a direction not contained within itself," as Bragdon summarizes expandable spatial correspondences (9). Flatland narrativizes such expansive analogical leaps. As a result of higher-dimensional education, A Square is not content to accept three-dimensional space as an ultimate, transcendent reality. Analogy, instead, emboldens him to imagine the three-dimensional environment as subject to its own set of perceptual limitations. By extrapolating from the initial experience, any claim to ultimate knowledge can be exposed as partial and constrained. Once this mode of reasoning has been embarked upon, consideration of any one set of spatial parameters as conclusive resembles the translation fallacy Bergson attributes to philosophical empiricists: such certainty equals "[s]eeking for the original in the translation, where naturally it cannot be," only to subsequently deny "the existence of the original on the ground that it is not found in the translation" (32). A Square unsettles the certainties of his three-dimensional guide by subjecting knowledge of 3-D space to the same dimensional skepticism to which his own plane has been exposed. As he points out to the increasingly perturbed Sphere:

In Three Dimensions, did not a moving Square produce-did not this eye of mine behold it - that blessed Being, a Cube, with eight terminal points? And in Four Dimensions shall not a moving Cube-alas, for Analogy, and alas for the Progress of Truth, if it be not so-shall not, I say, the motion of a divine Cube result in a still more divine Organization with sixteen terminal points? (87, emphasis in the original)

Flatland presents the estrangement from conventional knowledge as uncontainable: 'Analogy' (now with a capital A in A Square's exalted monologue) dispels belief in an 'original' sphere, since a superior one appears just a new direction away. Any elevated dimension only ever offers a 
'translation' of even higher space exceeding its own epistemological constraints, deferring any unconstrained, transcendental original in an infinite regress of dimensional realms.

Following Meillassoux, the imagined dimensional shift enables a way out of 'correlationalism,' his term for any model proceeding from the assumption that "thought cannot get outside itself in order to compare the world as it is 'in itself' to the world as it is 'for us'" (3). However, each thought 'outside itself' is - from successive higher vantage points - open to exposure as just another 'in itself,' making it impossible to "distinguish what is a function of our relation to the world from what belongs to the world alone" (3). It is small wonder, then, that maintenance of a given space as 'original' and the representations of its truth-claims as unquestionable fact is, in Abbot's literary treatment, the main goal of any mode of power exerted on dwellers of the same dimension. Consequently, A Sphere, unable to abide skepticism of the 'original' status of his sphere, casts A Square back down, punishing his analogical formulation of a 4-D view of 3-D space. The end of the novel sees the plane protagonist incarcerated, failing to publicly "indicate the direction which I meant when I used the words 'Upward, not Northward'” (Abbott, 98). Higher-dimensional knowledge is curtailed, with decorum and an institutional apparatus - an entire 2-D model of Victorian society - arrayed against it. The subtraction of familiar conceptual schemes from the world yields knowledge that is not only forbidden, but also becomes impossible: “Upward, not Northward”" (100), its remaining indication, "haunts" the protagonist "like a soul-devouring Sphinx" (100), becoming a mere repetition, distinct from the "substantial realities" glimpsed before (100).

The novel's ending penalizes an inordinate focus on the expansive, utopian concept of hyperspace over and above a corresponding counter-movement that acknowledges the limits of any approach to higher knowledge. A Square turns the extrapolation of ever-higher dimensions into unquestioned dogma. Thus oriented towards transcendence with spiritual abandon, he becomes unable to offer a critique of oppressive ideologies in his misogynist, unequal, and violently eugenicist 2-D society. Most of all, his exclusive concern with 'upward' movement renders him indifferent to the "specious analogy between many-sided regularity and moral and intellectual superiority" (Smith 139). As the escalating dimensional analogies preclude a critique of 
the oppressive analogies drawn in his own, limited realm, the novel presents the need for a concomitant 'downward' trajectory - a skeptical return to the arbitrary limits imposed on knowledge and to social critique - that compliments the 'upward' move towards higher space.

That the search for a higher dimension comes to naught, for all its somber consequences in the narrated world, is a prerequisite for rather than a cancellation of the poetics of higher dimensions presented in Flatland. The inaccessibility of higher space is maintained to turn readers into analogical thinkers in their own right. To this end, the fourth (in our case: second) wall is broken by a final image appended to the novel, offering the viewer an inducement to perform analogy in a manner denied and punished in the lower-dimensional diegesis. The image consists of an arrangement of the words “THE END/OF/FLATLAND” (100) vertically arranged amidst an ink drawing of clouds. These clouds are, in turn, interwoven with fragments of Prospero's speech on the dissolution of "the baseless fabric of this vision” (276) from Shakespeare's The Tempest. In this rearranged version of the quote, " $[\mathrm{t}]$ he baseless fabric of this vision/Melted into air, into thin air/ Such stuff as dreams made of" (200). The status of 'vision' is ambiguous in this fragment, not least because “this' is half-obscured by the lower cloud outline: the partial concealment raises the question whether vision generally lacks a foundation, or whether it is this particular vision (of Flatland) that emerges as 'baseless.' The placement of 'vision' in the montage compounds the ambiguity of the term: either it is 'vision' itself that melts, or else, if "[s]uch stuff" is understood as the object, vision can be taken to perform the melting. Perception and reality are folded into each other as we switch to and fro between both readings, mirroring the development of A Square's 'vision' in the novel proper. A reconfigured gaze (vision in the active sense) dissolves familiar knowledge of the world - only to disintegrate upon rereading, as lower-dimensional constraints are re-established. Once higher vision recedes, familiar 'stuff' is reasserted and the second interpretation of the passage gains precedence: the vision from above 'melts' under the conditions of limited knowledge.

This concurrence of emergence and dissolution is reiterated in the layout of the deceptively simple image-text composite. After all, the drawing of the clouds also obscures the auxiliary verb in the phrase "Such stuff as dreams [are] made of" (Abbott 200). As the image disrupts the sequence of words, 
the viewer's perspective shifts: rather than granting to language the capacity of "anchorage" in order to "fix the floating chain of signifieds" (Barthes 39), the occlusion of the word emphasizes the co-existence of two spatial levels. The text is no longer affixed to the image as explanatory supplement - and the image, in turn, exceeds its bounds, destabilizing the text's linearity and re-introducing the basic spatial dimensions of 'up' and 'down' by overlaying the quote. Thus, the emblem tacitly restores the very coordinates A Square is unable to invoke in his defense: the cloud-scribbles move "Upward, not Northward" (100). The text is spatialized by the emblem, forcing the viewer to replace the distinction between text and image with a lower and a higher level of inscription. Both of these are, additionally, foregrounded in their shared "hand-drawn quality," which serves to "highlight the discursive qualities of the narrative representation, rather than emphasizing a storylevel similarity to the actual world" (Horstkotte 33). The reader can switch back and forth between 'anchorage' and this shared indexical quality of the hand-drawn line. A similar oscillation between two aspects of the same sign is inculcated regarding the entirety of the image representing "THE END OF FLATLAND." It can be understood as a mere indication of the end of the narrative about Flatland or a pictorial representation of the 'literal' end of Flatland. On the latter view, it is the two-dimensional world of A Square that dissolves into clouds in front of us, with the flat page doubling as a material plane iconically reproducing the diegetic plane of 'Flatland' itself. Whether we see the emblem as the end of the novel or the end of the 2-D world: we cannot assume both perspectives at the same time, which makes it all the more amenable to dimensional didactics. The drawing functions in the manner of multistable images, Kippbilder, in which "the same image is seen under different aspects" (Holzhey 8). We can oscillate between two sets of distinctions, alternately focusing on the literal ending of the novel or a final visualization of the world of the novel - yet never quite holding both views at the same time.

In this way, Abbot's narrative, while abandoning A Square in lower-dimensional imprisonment, enacts its hero's wish that his memoirs "may find their way to the minds of humanity in Some Dimension, and may stir up a race of rebels who shall refuse to be confined to limited Dimensionality" (Abbott 100). While the innocuous emblem may appear somewhat bathetic compared to the 2-D protagonist's Promethean rhetoric, its instability 
introduces a specific mode of representation characteristic of $19^{\text {th }}$ - and early $20^{\text {th }}$-century dimensional speculation: it refuses closure. Just as the emblem rebuffs coalescence into a cohesive sign, the approach to higher knowledge, projected by analogy from the third unto the fourth dimension, can only be conceived as an interplay of vision and limitation, sudden heteroreference (diegetic Flatland) and self-reference (to the novel Flatland as well as to the drawn 'flat land' dissolved into ink lines). Any conclusive fusion of the clouds and the quote has to be replaced with a renewed "moment of resistance or counterdesire that occurs when we sense that the difference between the visual and verbal might collapse and the figurative, imaginary desire of ekphrasis might be realized literally and actually" (Mitchell 154). Text and image are either pried apart or, if considered together, reduced to the shared materiality of the hand-drawn line. As Flatland refuses the hierarchies of 'anchorage' and, indeed, complicates its status as text, any foray into the fourth dimension - extrapolating from the analogical reasoning practiced by its hero - has to be conceived as equally tenuous. If we are to read the "unstable dialectic" (Mitchell 38) of the emblem analogically, a conclusion of the negotiation between representation and breakdown is as unlikely as a final, synthesized 'imagetext.' The incommensurability of higher-dimensional 'original' and lower-dimensional 'translation' must be retained to inculcate ever-renewed series of failing attempts to transcend epistemological limitations.

\section{Knowledge as Restriction in Scientific Romances}

Like Abbott's presentation and evaluation of analogical approaches to higher space, Hinton's texts function as experiments in competing modes of "Casting out the Self" (205) in favor of higher-dimensional knowledge. What is to be dismantled in the process is a constriction of knowledge according to which “[o]ne's own particular relation to any object, or group of objects, presents itself to us as qualities affecting those objects-influencing our feeling with regard to them, and making us perceive something in them which is not really there" ("Casting" 210). To go beyond this "correlationalism,' the generic shifts between narratives, allegories, essays, scientific tracts, and self-exegeses that make up Scientific Romances present sections and boundaries of a higher space beyond the reader's "particular relation." 
These intimations of the fourth dimension are, however, only briefly indicated before the constraints of a lower 'self' and its restricted conception of the knowable reasserts themselves. The texts negotiate a back-and-forth movement: taking A Square's cue, even those parts of Hinton's Romances mired in the scientific and mathematical jargon of its time require a precipitating "revolutionary element' in relation to the world picture" enabling a foray beyond lower space (Lotman 238). Whenever the fourth dimension appears to be reached, however, the reader is reminded of its status as a textual construct, casting doubt on its own grandiloquent ambitions. Higher reality is presented as 'not really there' after all.

In the vein of Flatland, Hinton's "What is the Fourth Dimension?" introduces a being "confined to a plane divided by an infinite straight line" (26), which under normal conditions presents an absolute boundary. A specifically dimensional event impinging on this rudimentary differential setup consists not only in a traversal of the line, but also in a subsequent reordering of the diegesis: "if the being moves from the first plane by a motion in the third dimension, it will move into this new plane. [...] Then let it go back to the first plane. It has appeared now on the other side of the line which divides the infinite plane into two parts" (26). By crossing dimensions, the being performs a meta-event, in which, with Titzmann, not only the status of the 2-D entity has changed but also the represented order of the world itself (cf. 3081). This emplotment restates the caveat already introduced in Flatland: dimensional texts, by positing expandable dimensional realms, can only venture so far as to posit a temporary version of the 'Great Outdoors' - they enable a non-correlationist world to be made visible at the moment of dimensional border-crossing. A permanent representation of a plotless vision of higher space, however, would render it unduly mappable. To avoid such re-familiarization of higher spheres, Hinton's 2-D being has to return; the traversability of lines remains an exceptional event rather than a sustained topological possibility. Due to this focus on the successive traversal and restitution of constraints, higher space becomes only briefly presentable in narrative form; emplotment in a meta-event allows for the ephemeral possibility to "express in intelligible terms things of which we can form no image" ("What is" 31) only under the condition that this possibility is subsequently revoked. 
The insistence on a return to the 'intelligible' serves as a self-referential reminder that it is extrapolation "from analogical reasoning rather than reality" (Throesch, "Phenomenology" 29) that marks Hinton's writing of the fourth dimension. Any claim to a triumphant writing of higher space, an inter-dimensional unio mystica, is dispelled in ever-renewed interruptions of stable representation. This is encapsulated by a lengthy allegorical interlude in "An Unfinished Communication," in which personified 'Nature' attempts to cast off ill-fitting categories with which she has been burdened: "I, who all the while have no part in any of these things, whose it is to move the atoms on their ceaseless wheeling" ("Unfinished" 164). The allegorical figure threatens to exceed representative capabilities as "she began to be herself, not clothed in the feigned robes she wore before, in which, because man had woven them, there was of his evil" (165). In the wake of this liberation from conceptual constraints (associated with gendered limitations imposed by men as much as 'man'), Nature threatens to incarnate higher space. To avoid the epiphanic certainty pursuant to the liberation from limited descriptions assigned to her, the 'evil' of lower-dimensional categories must be reasserted. To this end, the looming simulation of external reference to "atoms in their ceaseless wheeling" is interrupted by self-referential insistence that all of this is merely text and intertext. The higher-dimensional revelation is disrupted by a seemingly unrelated vignette from the protagonist's past, in which he is shown to relive a vaguely Faustian plot: "Why, Gretchen, don't you know the kind of love I love you with" (170). She does not know, embroiling the protagonist in a narrative development in which she marries him "because she must get money" (170) - with conventionally narratable, non-allegorical consequences. The variation on Faust and a marriage-plot adduces the necessary self-referential break to the incursion of an unrepresentable higher reality. A complete presentation of 4-D space, after all, would render futile any further efforts of representation. These efforts shifts in style, structure, and genre - are presented and dismissed in order to motivate further attempts to find an unreachable literary equivalent for higher dimensions. Although the narrator, thus, reflects that " $[t]$ here must be a reality somewhere. But all I have ever sought has been fictitious" (134), the path towards this 'reality' is contingent upon detours into the overtly 'fictitious.' Even the scientific speculations Hinton appends to the stories, 
on this view, present just another recoil from narrative encapsulation of the fourth dimension rather than the certainty of a stabilizing meta-language.

Thus, dimensional knowledge cannot simply be imparted but, in Scientific Romances, emerges from the reader's confrontation with the limitations of the media by means of which it is transmitted. In "Many Dimensions," this strategy is taken further by foregrounding the materiality of the printed page itself. The speaker observes "lads and errand boys bend over the scraps of badly printed paper, reading fearful tales" (33). This brings out the dimensional teacher in Hinton's literary persona, who reflects "how much better it would be if they were doing that which I may call 'communing with space.' 'Twould be of infinite delight, romance, and interest” (33). A closer look at the printed papers, however, puts an end to the narrator's vision of higher-dimensional didactics. It is not by inducing intimations of higher space that the fourth dimension comes into view. Instead, as in the case of the lower-dimensional oscillation exemplified by the final emblem in Flatland, it is by reorienting attention to the limitations of the 'low' medium that higher knowledge can be momentarily indicated:

And yet, looking at the same printed papers, being curious, and looking deeper and deeper into them with a microscope, I have seen that in splodgy ink stroke and dull fibrous texture, each part was definite, exact, absolutely so far and no farther, punctiliously correct; and deeper and deeper lying a wealth of form, a rich variety and amplitude of shapes, that in a moment leapt higher than my wildest dreams could conceive. (33)

To "pass beyond the knowledge of the things about us in the world" (34), the observer, once more, cannot move 'upwards' to present the higher sphere in its entirety. Instead, words in familiar media are dislodged from signification by reorienting attention towards the unmarked possibilities furnished by the materiality of the medium. If mass-media emerge as the stand-in for the epistemological restrictions of lower space, what is required is a reorientation of attention in order to decompose the tight coupling of medial substrate and the forms constituted in it (cf. Luhmann 104). This makes available new, possible forms, the "splodgy ink strokes" and "fibrous texture" made visible by an estrangement of their familiar meaning (cf. Wilde 30). These do not offer reproducible 'tight coupling': the new, possible 'forms' are "punctiliously correct," yet we cannot be sure according to which criteria the "variety and amplitude of shapes" is judged. What 
is more, the precise nature of the medial substrate as "the source from which articulate forms emerge and the pool of disarticulation into which they return" (Denson 314) is obscured by the microscopic movement 'deeper and deeper': does each lower dimension furnish a new distinction of medial substrate and form, or does the downward trajectory merely specify the initial distinction between ink and texture? Reconstituting "infinite delight, romance, and interest" emerges as the task of the observer, who is called upon to de-couple the automatic reconstruction of signs and, instead, draw counter-intuitive distinctions. In dimensional terms, the passage presents a medial analogue to the search for conventionally impossible directions, be it A Square's 'Upward, not Northward,' or the directions of ana and kata (Greek: 'along' and 'against') that Hinton invents for the added directions of 4-D space (cf. Rucker 28). Re-materialization as ink and texture and the movement downwards into the text furnish an analogue to impossible directions: the literary incarnation of higher knowledge is once more presented as a generative, yet transitory effort to leave behind the constraints of lower space.

\section{Knowledge as Determination in The Inheritors}

The speaker in "What is the Fourth Dimension" ultimately settles on an ambiguous image of dimensional relations. In this setup, curved threads pass through a plane: "We can imagine these threads as weaving together to form connected shapes, each complete in itself, and these shapes as they pass through the fluid plane give rise to a series of moving points" (Romances 1, 22). The relationship between the three-dimensional form and its two-dimensional expression in this image is uncertain: if consciousness is attributed to the threads, after all, their expression on the intersected plane appears to lack freedom, the points of intersection moving in accordance with the preordained undulations of the strand as it passes through. Hinton's speaker offers the interpretation that "the moving figures share this consciousness, only that in their case it is limited to those parts of the shapes that simultaneously pass through the plane" (23). This view offers a momentary solution, granting epistemological autonomy to lower beings, while offering - as evidenced by "An Unfinished Communication" - the assurance that "we ourselves are larger than the limited life we think is all" 
(176). The same story, however, presents relegation to a lower-dimensional state as fundamentally limiting. The protagonist relives sequences of his life, yet, as he laments, "an oppressive bond is on me, I do exactly the same things I did before; I say the same things, I cannot get out of the chain of events" (174). The confrontation with impossible knowledge veers into dimensional horror: the presentation of lower-space processes as mere epiphenomena yields metaphors of determination as much as liberation.

A similar loss of autonomy in the face of dimensions beyond and outside familiar knowledge also concludes The Inheritors. Conrad and Ford present the fourth dimension as an enforced and disorienting imposition, a gap in its narrator's understanding of the world. A view of higher space is imposed upon this hapless homodiegetic narrator, who becomes involved in the schemes of fourth-dimensional beings. His main interlocutor appears as a young woman who proceeds to inform him that she belongs to a 'race' in the process of taking over the world - inheriting the world, more specifically, in sharp contrast to the narrator's floundering attempts to circumscribe what precisely might constitute his own cultural (and genealogical) inheritance. As far as the plot can be reconstructed from the narrator's limited scope, the takeover from hyperspace involves two steps. Firstly, bankers, financiers, and politicians are lured into participation in a colonial venture in Greenland, couched in the rhetoric of "[p]rogress, improvement, civilisation, a little less evil in the world" yet amounting to a violent "corporate exploitation of unhappy Esquimaux" (60). Secondly, however, the failure of this scheme is to be exposed in the media. The ensuing public outrage over the colonial venture and its "cruelty to the miserable, helpless, and defenceless" (136) is to precipitate a financial crisis and to drive any supporter of the Greenland project to ruin or suicide. The Dimensionists create a redoubled colonial scheme, in which Britain is placed in the position of the colonized by eroding its own self-image, replacing any ideology of superiority with the "sudden perception that all the traditional ideals of honour, glory, conscience, had been committed to the upholding of a gigantic and atrocious fraud" (136). This plot orchestrated by the 4-D beings is barely stated outright, but has to be inferred from halting, elliptical conversations. What becomes certain is the levelling of political antagonisms effected by the higher being: she does not distinguish between those involved in what is grudgingly termed the "Old morality business" 
(41) and those masking exploitative colonial violence behind philanthropic rhetoric. Both positions are "pieces" (41) arranged according to an absent, fourth-dimensional plan.

Against the inter-dimensional takeover, the narrator proceeds to mount a defense of the value of the lower dimension, focusing on a notion of great literature and connoisseurship that resembles the Victorian demand for "the best which has been thought and said in the world" (Arnold 5). Despite this valorization of 'Culture,' however, Granger's own art and language is presented as depleted. His obsolete illustrative images spell out their relationship of similarity: when he remarks that the "rush-bottom of his chair resembled a wind-torn thatch" (107) the tertium comparationis is minuscule, the transfer of characteristics barely maintaining a residual reality effect. Compared to this malaise of vanishing tropes, the incursion of higher space may be catastrophic for the protagonist - yet, the novel is at its most formally experimental once it turns away from barely metaphorical evocations of forgotten traditions and, instead, endeavors to represent the higher plane in the manner of Hinton and Abbott.

The literary evocation of higher-dimensional knowledge is at first a matter of rendering a shift of visual perception. The novel opens with Granger's halting attempts to connect his individual visual impressions with cohesive, shared knowledge: "the associations-the ideas-the historical ideas-" (1). The view of a cathedral is to furnish proof of shared tradition; it "was a vision, the last word of a great art. I looked at her. I was moved, and I knew that the glory of it must have moved her" (8). His inter-dimensional travelling companion, however, swiftly disabuses him of any such notions of a shared response. In an imperative reformulation of Hinton's strategies of 'casting out the self,' she makes the protagonist see the scenery anew:

She was smiling. "Look!" she repeated. I looked.

There was the purple and the red, and the golden tower, the vision, the last word. She said something-uttered some sound.

What had happened? I don't know. It all looked contemptible. One seemed to see something beyond, something vaster-vaster than cathedrals, vaster than the conception of the gods to whom cathedrals were raised. The tower reeled out of the perpendicular. One saw beyond it, not roofs, or smoke, or hills, but an unrealised, an unrealisable infinity of space.

It was merely momentary. The tower filled its place again and I looked at her. (8) 
As the tower 'reels out of the perpendicular,' such that angles disobey rules of three-dimensional space, its function of imparting coherence is equally effaced. The collapse of the 'soaring' structuring principle and the metonymical chain guaranteed by it - "tower," "vision," "last word" - opens up one of the few directly epiphanic renderings of the fourth dimension as an "unrealisable infinity." It is in the wake of this "merely momentary" glimpse of higher space that The Inheritors reiterates Abbott's and Hinton's impasse: knowledge of higher space resists stable representation. Accordingly, the rest of the novel is dedicated to failing attempts to find an appropriate realization for the "unrealisable infinity" of a higher reality, of encoding the view "beyond" the protagonist's perspective in language. Rather than motivating salutary striving for the fourth dimension in the manner of its predecessor texts, however, The Inheritors exhibits a more fundamental skepticism regarding the possibility of going beyond halting, inconsistent approximations. 4-D knowledge is subjected to unremitting skepticism, without the hopes of transcendence sustained even by Abbott's incarcerated Square. If 'dimensional fiction' displays a double strategy - striving for higher knowledge and self-referential indications of its inaccessibility in equal measure - Conrad and Ford veer toward the latter, restrictive mode.

As a result, the novel reads as an inventory of the limitations of knowledge. One such constraint is posed by the relationship between Granger and the Dimensionist, characterized as it is by the insight that there is "no bridge-no bridge at all. We can't meet ...” (192, emphasis in the original). Traversing this impassable gap becomes the narrator's main goal, without, however, ever yielding a commensurate visual epiphany. Although his attempts are unsuccessful - gaps multiply instead of being bridged, leading to a surfeit of typographical ellipses as the plot lurches towards its inevitable anti-climax - they are nonetheless shown to be preferable to minute adjustments of perspective in the lower dimension of receding British culture. The "thatch" and the "rush-bottom," an abortive attempt to write a biography of Cromwell, and mutual appreciation of half-forgotten cultural artefacts alike fail to measure up to the "contemptible" yet compelling vastness of a higher reality out of reach. The tower may re-align in accordance with familiar spatial confines, yet neither the novel nor its protagonist can commit to the series of values it upholds. As in the predecessor texts, hierarchies 
rooted in three dimensions are gone for good, rendered inadequate after a momentary glimpse of "something beyond."

In a text replete with failed authors and hack writers, literature does not offer an alternative to the inexplicable incursion of the Dimensionists. However, The Inheritors does feature attempts at deriving formal correlatives to a fourth-dimensional perspective that align it with its predecessors' literary experiments. First and foremost, similarly to the analogical thought of Flatland, the text induces its readers to occupy experimentally a higher vantage point vis-à-vis the represented world, considering it as words on the page. To this end, the I-narrator, rather than a psychologically complex representation of a unique consciousness, is reduced to a mere quotation. When Granger is invited to a club by his editor, the request to "come and dine with me at the Paragraph round the corner" (57) is followed up by a description of this meeting in what is literally the next paragraph, located in the text in front of the reader. The protagonist may assert his personhood, but, as the higher dimension establishes itself, he is already a mere distribution of information on a page. The inheritors' perspective renders him "only a detail, like all the others, [...] set in place like all the others. [...] It was in your character" as the Dimensionist explains (316), conflating 'character' as personality, his status as a 'character' in the narrative, as well as a printed 'character' in a text he cannot survey: a succession of 'I's' on the page, seen from above. He appears “as if I were the picture of a man. Well, that was it; I was a picture, she a statue" (315). Reduced in dimensional extension, Granger ends up as a set of two-dimensional signs dispersed throughout the text, a 'Flatlander' confronted with a three-dimensional, sculptural analogue of unrepresentable four-dimensional beings.

In a similar vein, the presentation of events in the novel emerges as a means of briefly inducing a higher perspective in the reader, unconstrained from linear reading and narrated time. To this end, what counts as an eventful crossing of a differential border is, from a higher-dimensional point of view, denied its status as revolutionary change. It is the enactment of this dimensional re-evaluation of semantic spaces that renders The Inheritors a "curiously bland nightmare" (Green 19). The novel consistently indicates that nothing of note has taken place, despite the narrator's insistence that the fate of the world depends on his decisions: "It rested 
with me now to stretch out my hand to that button in the wall or to let the whole world — the ... the probity ... that sort of thing,' she had said-fall to pieces" (283). In contrast to such self-aggrandizement, the reader can turn back to an earlier pronouncement by the Dimensionist, tersely laying out the succeeding plot: "There will be friendships-and desertions" (93), she proclaims with a proleptic accuracy that makes the narrator's action a foregone conclusion. In accordance with this preordained progression, Granger is informed that he has not, in fact, been responsible for an eventful change of state at all:

"You have done nothing at all," she said. "Nothing."

"And yet," I said, "I was at the heart of it all."

"Nothing at all," she repeated. "You were at the heart, yes; but at the heart of a machine." (316)

As a part of a fourth-dimensional 'machine,' Granger performs his mandated function, but does not qualify as a hero precipitating an eventful change. The Dimensionists, like the readers once they have completed the novel, are placed out-side of the time of the represented world: the narrator resigns himself to the fact that he had "given up to her my past and my future" (317). In the terms of Hinton's hyperspace metaphor, the four-dimensional beings have rearranged the higher-dimensional 'threads,' generating and animating the 'point' of Granger's consciousness in a predetermined fashion. Readers confronted with this constellation are rendered arbiters of 'spatial time,' reading the work "spatially, in a moment of time, rather than as a sequence" (Frank 46). The liberating replacement of stultifying conventions induced by spatial form, however, is offset by its diegetic representatives, for whom the formal devices recur as amoral arbiters of destruction in the narrated world. To a greater degree than the dimensional poetics of Hinton and Abbott, The Inheritors, thus, features a critical evaluation of the limits of literature and the knowledge it can encode. Instead of reiterating the search for innovative means of representing the fourth dimension, the novel displays "superseder's contempt" (4) of its own means of expression. The fourth dimension, rather than a means to transcend what can be known, is redeployed to mark the limits of literature. 


\section{Conclusion}

In speculative fiction engaging with the fourth dimension of space, the sought-after higher reality is both held up as a repository of knowledge and as a stark reminder that literature cannot offer adequate representations of a reality unconstrained by convention. The texts share a reckoning with the perennial absence of "the immobile angles and curves of the fourth dimension" (Ouspensky 115), with every textual strategy falling short. As a result, analogies falter, unlearning stalls, and, in the case of The Inheritors, literature can only register impossible 4-D knowledge as a perpetual absence. As much as it shares a dimensional theme, the sub-genre gains its coherence from this self-referential exhibition of its medial limitations in confrontation with impossible knowledge outside its scope.

Although they mark and re-mark the limits of their own strategies of representation, these texts, however, are far from elegiac. The presentation of both the possibilities and the restrictions of the transcendence of narrow horizons of knowledge emerges as a productive feature of the speculative literary approach. The process motivates a constant flight from generic constraint and cliché, undercutting any simple path to the 'great outdoors' of higher space. If stable 'suprasensible' knowledge and a representation of hyperspace were reached, after all, there would be no inducement to further speculation. Thus, the more expansive the characteristics these texts ascribe to higher space, the more explicitly do they present the countervailing necessity for a breakdown of representation.

"How can we talk productively about something that is almost impossible to visualize?" (Rucker 8). One cannot, according to Edwardian speculative fiction - yet literature should, according to its implicit poetics, use this impossibility as a spur to self-reflexive consideration of the limits of knowledge. The search for the fourth dimension requires the "supposing away" of "certain limitations of the fundamental conditions of existence as we know it" (Hinton, "What is" 4) - an endeavor that finds its complement in the recursive, faltering attempt to 'suppose away' the limits of literary knowledge. 


\section{Works Cited}

Abbott, Edwin A. Flatland: A Romance of Many Dimensions. London: Seeley, 1884.

Arnold, Matthew. Culture and Anarchy. Ed. Jane Garnett. Oxford: Oxford University Press, 2009.

Barthes, Roland. "The Rhetoric of the Image." Image - Music - Text. Sel. and trans. Stephen Heath. London: Fontana, 1977. 32-52.

Bergson, Henri. An Introduction to Metaphysics. Trans. T.E. Hulme. New York: G. P. Putnam's Sons, 1912.

Bragdon, Claude. A Primer of Higher Space: The Fourth Dimension. Rochester: Mana, 1913.

Conrad, Joseph, and Ford Madox Ford. The Inheritors: An Extravagant Story. New York: McClure, Phillips \& Co, 1901.

Denson, Shane. Postnaturalism: Frankenstein, Film, and the Anthropotechnical Interface. Bielefeld: transcript, 2014.

Frank, Joseph. The Idea of Spatial Form. New Brunswick: Rutgers University Press, 1991.

Green, Robert. Ford Madox Ford: Prose and Politics. New York: Cambridge University Press, 1981.

Hinton, Charles Howard. "What is the Fourth Dimension?" Scientific Romances. Vol. 1. London: Swan Sonnenschein, 1886. 3-31.

-. "Casting Out the Self.” Scientific Romances. Vol. 1. London: Swan Sonnenschein, 1886. 205-28.

-. "Many Dimensions." Scientific Romances. Vol. 2. London: Swan Sonnenschein, 1896. 27-44.

-. “An Unfinished Communication.” Scientific Romances. Vol. 2. London: Swan Sonnenschein, 1896. 109-77.

Henderson, Linda Dalrymple. The Fourth Dimension and Non-Euclidean Geometry in Modern Art. Cambridge: MIT Press, 2013.

Holzhey, Christoph F. E. "Introduction.” Multistable Figures: On the Critical Potentials of Ir/Reversible Aspect-Seeing. Ed. Christoph F.E. Holzhey. Wien: Turia + Kant, 2014. 7-21.

Horstkotte, Silke. "Zooming In and Out: Panels, Frames, Sequences and the Building of Graphic Storyworlds." From Comic Strips to Graphic 
Novels: Contributions to the Theory and History of Graphic Narrative. Ed. Daniel Stein and Jan-Noël Thon. Berlin: De Gruyter, 2013. 27-48. Levenson, Michael. Modernism. New Haven: Yale University Press, 2011. Lotman, Jurij. The Structure of the Artistic Text. Trans. Ronald Vroon. Ann Arbor: University of Michigan Press, 1977.

Luhmann, Niklas. Art as a Social System. Trans. Eva M. Knodt. Stanford: Stanford University Press, 2000.

Meillassoux, Quentin. After Finitude: An Essay on the Necessity of Contingency. London: Continuum, 2009.

Mitchell, W William John Thomas. Picture Theory: Essays on Verbal and Visual Representation. Chicago: University of Chicago Press, 1994.

Ouspensky, Pyotr. Tertium Organum: The Third Canon of Thought. A Key to the Enigmas of the World. Trans. Nicholas Bessaraboff and Claude Bragdon. New York: Alfred A. Knopf, 1922.

Rucker, Rudy. The Fourth Dimension: Toward a Geometry of Higher Reality. Boston: Houghton Mifflin, 1984.

Shakespeare, William. The Tempest. Ed. Virginia Mason Vaughan and Alden T. Vaughan. London: A \& C Black, 1999. Arden Shakespeare.

Smith, Jonathan, Lawrence I. Berkove, and Gerald A. Baker. "A Grammar of Dissent: Flatland, Newman, and the Theology of Probability." Victorian Studies 39 (1996): 129-50.

Throesch, Elizabeth. "Charles Howard Hinton's Fourth Dimension and the Phenomenology of the Scientific Romances (1884-1886)." Foundation 99 (2007): 29-49.

-. "Nonsense in the Fourth Dimension of Literature: Hyperspace Philosophy, the 'New' Mathematics, and the Alice Books." Alice beyond Wonderland: Essays for the Twenty-First Century. Ed. Christopher Hollingsworth. Iowa City: University of Iowa Press, 2009. 37-52.

Titzmann, Michael. "Semiotische Aspekte der Literaturwissenschaft: Literatursemiotik." Semiotik: Ein Handbuch zu den zeichentheoretischen Grundlagen von Natur und Kultur. Vol. 3. Ed. Roland Posner, Klaus Robering, and Thomas A. Sebeok. Berlin: de Gruyter, 2003. 3028-118. Wilde, Lukas. "Was unterscheiden Comic-Medien?” Closure 1 (2014). $25-50$. 


\title{
Aleksandra Boss and Martin Klepper What Nancy Knew, What Carol Knew: Mass Literature and Knowledge
}

\begin{abstract}
Based on the assumption that mass literature matters, this essay analyzes in connection with the then particularly popular culture of self-help - the American middle-class girl detective series Nancy Drew that appeared from the 1930s through the 1960s as well as the African American serial novel "Hell" that appeared in the Chicago Defender in 1929. Reviewing the series' content and formats, white and black literary mass markets of the time, and the tradition of American rituals of self-improvement, the essay suggests that the discourse of self-improvement and mental mobility is so strong in the products of consumer culture and mass circulation because these products were on demand by virtue of this very discourse. Throughout the series, the protagonists' knowledge proves to be ambivalent, riddled by the contradictions and silences of the discourses sustaining it, and fundamentally constrained by the violence and prejudices of its times. The series themselves thus develop a very specific cultural knowledge of self-help in terms of socially permissible behaviors, practices, and aspirations, and have much to say to both their contemporaneous readers as well as readers and critics today.
\end{abstract}

For this volume, we started with the question: what does mass literature know? The question immediately raises a number of follow-up questions. Does mass literature transport any kind of knowledge beyond its own usefulness as a commodity? Or, put differently, does the knowledge hidden in popular newspapers, magazines, pulps, and syndicated serials go beyond the superficial clichés and stereotypes that gratify the escapist and/or selfasserting desires of the reader? And then, is all mass literature the same? Do we have to differentiate, to historicize, to contextualize? Finally, does mass literature matter?

Last things first: for the (re-)production of the social world it seems sufficiently plausible that mass literature matters. We want to introduce two examples - a token from a girl-detective book series and a late sentimental, serialized mysteries-of-the-city narrative -, two examples that, at least in their circulation, carry a certain significance. Circulation and production will then lead us to the question of content: genre, plot, and the question of 
knowledge. However, instead of yielding an immediate answer, the discussion of contents will send us on a detour through the history of mass literature and through the context of its participation in a consumer culture, which, epistemologically, appears to be intimately familiar with a deep-seated discourse of self-improvement and a very modern discourse of therapeutic ethos. Finally, we will have to relate our two narratives to these contexts in order to illuminate what Antje Kley in the introduction to this volume has called "irritating forms of connectivity" (23).

In our case, the connectivity is established not only by specific communities of readers but also by the American (popular) culture of self-help, which, spearheaded by Napoleon Hill and Dale Carnegie, flourished after the turn to the $20^{\text {th }}$ century and especially in the 1920 s and 1930 s. Both of our narratives are from these two decades. And, yet, discussing them together may still be a bit surprising: one is the series of Nancy Drew adventures, which began with The Secret of the Old Clock in 1930; the other is the narrative of calamities befalling Carol Marah in Cora Ball Moten's Hell, serialized in The Chicago Defender commencing on 16 Feb 1929 and running for thirteen weeks. Perhaps we may begin by asking: what do Nancy and Carol know?

\section{Validity}

The Nancy Drew Girl Detective series is one of the longest running and most successful mystery book series for teenagers in the US. Begun in 1930 by Edward Stratemeyer (1862-1930), German-American publisher and writer of juvenile fiction (Stratemeyer set up his first printing press in the basement of his father's tobacco shop), it went through several re-launches and today appears as Nancy Drew Diaries under the aegis of Simon \& Schuster, who bought the Stratemeyer syndicate (founded in 1906) in 1987. Stratemeyer belongs to the most important protagonists in the making of American mass literature (more about this later). He specialized in inexpensive juvenile fiction ("fifty-centers") and organized the production process in assembly-line style. He provided the outlines for his series (he also wrote the skeleton for The Secret of the Old Clock) and then passed them on to professional writers, who wrote the books. For the writing process, there was a detailed guideline; and when the manuscripts came in they were 
professionally revised to guarantee consistency. When Stratemeyer died in 1930, his daughter Harriet carried on the process. During the 1930s and on into the 40s, 50s and 60s Nancy Drew became a cultural icon. Among the public personae who have admitted an addiction to the girl sleuth, are people as different (politically and in temper) as Laura Bush, Hillary Rodham Clinton, Nancy Pelosi (all politicians), Ruth Bader Ginsburg, Sonia Sotomayor (both Supreme Court judges), Gayle King, Diane Sawyer (both TV anchorwomen), and Nancy Grace (journalist) (Hoffman).

The fact that the Nancy Drew mysteries swept through the American middle class like an epidemic, may first and foremost attest to their broad entertainment value. They were accessible (easy to read), afforded a modicum of escape from daily worries (especially during the Depression and the war years), and buttressed a belief in the comprehensibility of the world (mysteries are solved) and the fundamental integrity of society (the good win and the bad lose). In addition, one of her readers, Supreme Court judge Sonia Sotomayor, emphasizes Nancy's boldness and intelligence (Hofmann). One of the first things that Nancy knows is that the world is intelligible, that ethical standards prevail, and that girls can play an active and enlightening role in it.

While these convictions are certainly appropriate early intellectual food for later judges, politicians, and journalists, they have, of course, a prehistory. Both Stratemeyer and Mildred Wirt, ${ }^{1}$ who wrote the first Nancy Drew mysteries under the pseudonym Carolyn Keene (still the name on the current Nancy Drew mysteries), were admirers of Horatio Alger. In fact, Stratemeyer was a ghostwriter for Alger and finished his last books (Kismaric and Heifermann 13). Alger's is indeed a similarly simple world, comprehensible and fundamentally righteous and open to boys (not girls) with energy or "pluck." To a degree, Nancy Drew is a more modern and female version of Alger's heroes, an update for girls and for the Thirties. And again, in terms of knowledge, this is more than a coincidence - but more about this in a moment.

Carol Marah is a quite different case. Her adventures in the Chicago Defender are appropriately titled "Hell." Written by Cora Ball Moten, an

1 Later Mildred Wirt Benson. 
African American writer of serial literature for various newspapers such as The Afro American, "Hell" appeared in the Defender in 1929. At that time, the Defender was America's leading Black newspaper, which played more than a modest role in the Great Migration of African Americans to the North after World War I. Robert S. Abbott (1870-1940), the founder and publisher of the paper, was the offspring of former slaves in Georgia and a family with a history in intermarriage. A suggestive coincidence: Abbott learned Ben Franklin's trade (printing) in Virginia. Afterwards he received a law degree from Kent College in Chicago. In 1905 he founded the Chicago Defender with an investment of 25 cents. ${ }^{2}$ In other words, like Stratemeyer he fits well into the Victorian myth of the self-made man. As a result, the Defender preached the gospel of self-reliance: "Eventually your efforts will bring the reward they deserve" (19 Jan. 1929, 2:2). With the same sense of mission, it also preached against race prejudice, disenfranchisement, discrimination and violence against African Americans.

During the 1930s the Defender enjoyed great popularity among Black Americans. Distributed along the lines of the railroads by Pullman porters, it was read far beyond Chicago. According to Abbott's biographer Roi Ottley, "with the exception of the Bible, no publication was more influential among the Negro Masses" (qtd. in Walker 11). ${ }^{3}$ Many African Americans would not have been able to afford books, even those published by the Stratemeyer Syndicate in the 1920s and 30s. They would have to rely on libraries (and libraries were quite reluctant to carry books from the Stratemeyer lowbrow sweatshop in the beginning). Instead, African Americans would read the Defender, and they would read it aloud in the family circle and among friends. We can trust that Hell reached quite a portion of those African Americans growing up in the 1920s.

On the one hand, the Defender championed highbrow culture very much along the ideas of W.E.B. Du Bois: political citizenship would follow cultural citizenship. Education was very high on its agenda. It featured successful college graduates, fought for government schools, presented educational material in its weekly children's pages (the Defender Junior), and supported

2 Wikipedia has a very good entry on Robert Sengstacke Abbott (last accessed: 6.4.2016).

3 In 1930, The Defender had a circulation of 110000 (Walker 40). 
young African Americans through its Bud Billiken Club and the annual Bud Billiken parade, which afforded scholarships for gifted youngsters. To be sure, Nancy Drew's fictional friends also go to college and Nancy has a superhuman knowledge in all walks of life (from Shakespeare to biology), but in Nancy Drew's world social capital (as we will see) derives much more from other sources than from cultural capital. In the world of the Defender, education is the first step to success. On the other hand, Abbott's newspaper catered to a broad community who had not digested Shakespeare with their daily bread. Much of the Defender's content is very practical (recipes, health tips, advice) and overtly sensational (tabloid style political coverage). Hell belongs more to the sensational side of the business.

\section{Content (Genre, Plot, and Knowledge)}

According to Josef Vogl specific genres correlate with specific types of knowledge: in a "poetics of knowledge" these correlations are one gateway to understanding the production of knowledge through literature. Especially for mass literature, the question of genre obviously plays a key role. ${ }^{4}$ The Nancy Drew series advertises its genre not only through the titles (The secret of..., The Clue to ..., The ... mystery etc.) but also, on the cover, with the help of a dark blue silhouette featuring Nancy Drew with a magnifying glass in her hand. Hell is advertised before the first episode as "thrilling, throbbing," a story that "takes you to the Hell of America and lets you see life in its most glaring, intimate form" (Chicago Defender, 9 Feb 1929). The motto of the story, continuously displayed together with title and author, reads: "Beneath the Shadows of American Hypocrisy." Stratemeyer's series promises straightforward detective fiction, Ball's narrative a thriller in the tradition of the mysteries-of-the-city novels from the $19^{\text {th }}$ century. The detective genre, on the face of it, promotes an epistemological and semiotic kind of knowledge: a knowledge that promises to counter contingency and afford control. The mysteries-of-the-city, to all appearances, correlates with political knowledge: a knowledge that counters corruption, exploitation and creates resistance. However, the case is more complicated. As Hollywood teaches, most popular narratives have two plots: a quest plot

4 Ken Gelder practically defines mass literature as genre-fiction (12, 40-74). 
(detection) and a love plot (romantic or tragic). Usually these two plots are skillfully interwoven and propel each other. Our examples are no exceptions. A closer look at "plot" is warranted.

In Hell the plots materialize around the self-confident heroine's attempts to become a successful actress in Kansas City. Carol Marah's efforts are thwarted by the henchmen of the white supremacist establishment of the city. These henchmen incidentally wallow in illegal alcohol and illegitimate sexual relations with (very) young African American women. Their crimes and conspiracies are revealed piecemeal, while Carol negotiates her romantic relationship with Arthur Somers, a successful young jazz musician who owes his success to compromises with the same supremacist ruling class. The revelations about hypocritical Reverend Tinor-Horgotte and corrupt officer Speed Spelton affirm the readers' suspicions about corruption and exploitation as the result of a structurally racist system. The romance plot illustrates how racism poisons intimate relations and even individual minds: Arthur, whose family allegorizes the Atlanta Compromise, has sacrificed his aspiration to "serious" music to the entertainment of white patrons, and Carol, whose family stands for W.E.B. Du Bois's ideas, is destroyed by the impossibility to nourish her talents in a white world.

To come back to Nancy Drew, in The Secret of the Old Clock the detection plot-very typical of the entire series-revolves around the search for a lost will. Nancy, who knows how "to think for herself and to think logically" (6), demonstrates that difficult situations can be mastered, uncertainty can be controlled, and the invisible can be made transparent. The phenomenon that detection is accompanied by a windfall of money (in virtually every early Nancy Drew book) is significant and we will return to it later. There is no classical romance in Nancy Drew (no touching or kissing was one of Stratemeyer's rules), after all it was teenage literature. However, Nancy's cheerful and insistent manner in solving cases is electrifying, and she builds up a trail of grateful friends and beneficiaries, which might help her in a later adventure (for instance the Horner girls in The Secret of the Old Clock). Nancy's form of detection is active networking. In several adventures, the case is solved in a group, and, just as critics have said about Mr. B. in Samuel Richardson's classic Pamela that he had to convert to Pamelism (Folkenflik 215), friends and readers of the teenage sleuth are converting to Nancyism in Stratemeyer's series. 
But what is Nancyism? Let us conjecture: a belief in rationality and transparency; the conviction that "the truth" will be found; the confidence that it will, quite literally, pay off; the insistence in girl power; and the reliance on a group of similarly looking, similarly thinking, and eventually similarly positioned friends, who are friends exactly because of their similarity. And Carol's knowledge? That the Black community must not be divided; that it must not succumb to cheap compromises that sacrifice education and selfrealization to a superficial promise of a modest prosperity and freedom from harassment; that it must not produce sycophants; and that the weakest, the women and children are the first victims of white supremacy. And yes, in order to understand or explain certain contradictions within Nancyism and Carolism more fully, we will have to historicize and to contextualize.

\section{Historicity and Connectivity I (Mass Literature)}

We have to differentiate between various formations of mass literature within a field subdivided by publication formats and reading communities. However, once the reading community becomes too small or too local we can hardly speak of mass literature. ${ }^{5}$ As a result, it would be difficult to speak of Chicana/o or Latina/o mass literature for this time. It would probably even be difficult to speak of Jewish mass literature in the 1920s and 1930s because publications targeted at Jewish readers seem to have been mostly local in these decades. (To be sure, because of mainstream discrimination against Jews working in newspaper, magazine and book publishing, Jewish artists had a significant role in moving pictures, comics and pulp magazines. Most of these were, however not targeted at a Jewish audience).

In contrast, there was a relatively well-developed African American press that was partly non-profit (such as the NAACP's The Crisis) and partly for profit like Abbott's Defender. Abbott mixed capitalist enterprise and

5 Richard Ohmann defines mass culture as follows: "[M]ass culture in societies like this one includes voluntary experiences, produced by a relatively small number of specialists for millions across the nation to share, in similar or identical form, either simultaneously or nearly so; with dependable frequency; mass culture shapes habitual audiences, around common needs or interests, and it is made for profit" (Selling Culture 14). The foursome of voluntary, for-profit, national, with dependable frequency should also be valid for mass literature. 
political convictions so well that it is difficult to distinguish between his objectives. Children joining the Bud Billiken Club had to promise to read, to honor their parents, to support other Billikens (i.e. black children) and to "interest at least five grown-ups in purchasing the Chicago Defender weekly" (Chicago Defender, 25 Jan 1930, 15). As we shall see later, some of these promises have a legacy in Booker T. Washington. The Billikens did it so well that the Defender (together with other African American newspapers) has to be recognized as a specific formation within mass literature. The Defender's clear political leanings (the newspaper had its own platform of political demands) do not make it a lesser part of mass literature. After all, white newspapers were not less political, neither was Stratemeyer's syndicate. Mass literature is not politically disinterested. In fact, the emergence of mass literature was itself class-bound and entangled in political conflicts.

Many commentators connect this emergence to serial publications such as the penny press, the story papers, and the mysteries in the city novels between the 1840s and 1870s. Penny press writers like George Lippard were immensely political (Lippard had a slightly nostalgic, anti-modern but leftist labor orientation, paired with a good deal of jingoism). So were many of the dime novels of the 1860 s to 1890 s. However, most of these publications were still tied to individual persons and, as Richard Ohmann writes, book publishing in the $19^{\text {th }}$ century "failed to consolidate ... into a stable and controlled enterprise with enduring relations to a mass public" (Selling Culture 23). Adolescent book series such as Alger's from-rags-toriches stories (starting with Ragged Dick in 1867 and finishing with the Stratemeyer-written Young Captain Jack in 1901) celebrated a very specific white, Anglo-Saxon, Protestant ideology that propagated a capitalist mindset carefully blended with Christian morality. Although Alger was popular in the 1870 s and 80 s, he never really earned much money with his books and was all but forgotten in the 1930s and 40s.

As Richard Ohmann asserts, the advent of an organized mass market for print products is owed to newspapers and magazines rather than to books. Since the 1860s newspapers such as the Herald and the Tribune "were reprinted around the country" (Selling Culture 21). From the 1880s on certain features in newspapers were syndicated (comics, in this context, emerged in the 1890s), and spaces in the papers were sold by advertising agencies. With the inclusion of photographs (1890s) and the rise of yellow 
journalism circulation was on the rise: "Americans had, (for the first time), available in the format of a newspaper a homogeneous national experience of the news, of opinion, of household advice, and of entertainment" (Ohmann, Selling Culture 21). In 1905 Robert Sengstacke Abbott founded the Chicago Defender as a weekly newspaper-the newspaper that was co-instrumental in driving the Great Migration between 1910 and 1930.

Apart from newspaper publishing, magazines became mass products in the 1890s. Magazines such as Harpers or the Atlantic had been significant cultural products since the 1850s. However, Frank Munsey (1854-1925) is credited with introducing magazine culture to middle brow and low brow audiences. In 1893 McClure's Magazine was founded - it sold for just 15 cents (as against 25 or 35 cents for the before mentioned magazines). In the same year, Munsey lowered the prize for his Munsey's Magazine to just 10 cents. With this step Munsey actually sold the magazine under prize, making his profit through advertising fueled by the unheard-off circulation numbers (in 1895 it hit 600 000). What Munsey knew was that you can change the publishing business by not selling something to your customers, but, instead, selling your customers to the advertising industry. In 1896, Munsey re-issued his second magazine, Argosy Magazine, as the first pulp magazine.

Argosy had existed before as Golden Argosy, a magazine with boys' adventures. But it was Stratemeyer who, after the turn of the century, re-created the market for adolescent fiction as a gold mine. Stratemeyer's stratagem was seriality: with the Rover Boys (since 1899), he wrote the first serial adventures himself. With the foundation of the Stratemeyer Syndicate in 1906, he concentrated on the story lines and employed writers, editors and proof-readers to complete the books. His series included The Bobbsey Twins, The Hardy Boys, Tom Swift and Baseball Joe. With the help of his assembly line production he was also able to lower the prices for the books-they were called fifty-centers (even though the prices actually varied). His rules for the writers included: twenty-five chapters per book, connected by cliff-hangers, intense action, no touching or kissing, no excessive violence (Kismaric and Heiferman 15). The Nancy Drew series follows these rules.

The creation of an audience takes more than low prices and a snappy formula. Richard Wightman Fox and T. J. Jackson Lears, writing about the rise 
of consumer culture, suggest: "Perhaps the key development was the rapid expansion of the professional-managerial stratum, which included (among others) both the technicians who staffed the new corporate bureaucracies and the corps of reformers who consciously undertook to 'harmonize' the relations between labor and capital" (xi). The argument is that not simply urbanization and the expansion of a professional middle class (together with affordable products for consumption) led to the emergence of a public for middle and lowbrow products, but also a reform orientation, which forever transformed the Victorian ideals of self-denial, self-control, Protestant values, and autonomous selfhood (Lears 4-10). In other words: consumer or mass culture emerged with and through a particular mindset, which the products themselves (including newspapers, magazines, and middle and low brow books) helped to create. It is this mindset, which informs what Nancy knows and what Carol knows, that we have to turn to now.

\section{History and Connectivity II (Therapeutic Ethos and Self-Improvement Discourses)}

Lears describes the new orientation as a "therapeutic ethos," or, with William James, as “The Gospel of Relaxation” (6,10). Victorian virtues such as self-denial, frugality, humbleness, and piety subtly turned into values like "harmony, vitality, and the hope of self-realization" (11). At the same time, the Victorian idea of self-made manhood began to change:

In a society increasingly dominated by bureaucratic corporations, one dealt with people rather than things; 'personal magnetism' began to replace character as a key to advancement. In advice literature after 1900, as Walter Susman has observed, success seemed less often a matter of mastering one's physical environment or plodding diligently at one's trade, more often a matter of displaying one's poise among a crowd. (Lears 8$)^{6}$

While Lears, in his essay, focuses on advertising and especially the ideas of advertisement pioneer Bruce Barton (1886-1967), we want to suggest that mass culture and mass literature (as part of consumer culture) also tap into and transform the resources and knowledge from the tradition of

6 Lears is referring to Walter Susman's seminal essay “'Personality” And the Making of Twentieth Century Culture.” 
advice literature and the time-honored self-improvement discourse within American culture. This idea is not wholly original: Bernd Ostendorf has pointed out in 2000 that one of the long-standing resources of popular culture in the United States has been the tradition of "American rituals of self-improvement" (19). These rituals have always advanced a certain therapeutic or psychological impetus (albeit not always a "gospel of relaxation"), a nascent idea of self-realization, a catalogue of necessary attitudes, and a strong sense of (mental and/or social) mobility.

Benjamin Franklin, whose entrance into Philadelphia symbolizes the American dream of mobility and self-making, stands in almost emblematic relation to an early attitude of white self-improvement, namely the practice of common sense in the form of "industry" (3), "frugality" $(4,5)$, and "prudence" (7), as famously proposed by Father Abraham in The Way to Wealth. A few decades later, Ralph Waldo Emerson highlights the attitude of self-reliance as patent in the various practices of self-culture. His presence in what might be called the canon of self-help literature illustrates the importance of inward and outward mobility to self-help attitudes and practices, indicated not simply by the attainment of money but also by cultural capital. The antebellum Lyceum movement (in itself a mobile sort of education), with which Emerson's persona as America's first “democratic intellectual" has been strongly associated (Field 469), presented a space for working adults to pursue the very practice of self-culture, attending lectures on variegated popular scientific and scholarly topics (the Chautauquas carried on this tradition into the 1920s). Emerson's influence on the literature and culture of self-improvement indicates the difficulty of locating it clearly along the highbrow vs. lowbrow divide before the turn of the century. $\mathrm{He}$ can be credited with introducing the kind of idealism to the American public which was about to be taken to the extreme, or to extreme simplification, by later self-help authors associated with the popular New Thought movement of the latter part of the $19^{\text {th }}$ century (see Allen's early and favorable investigation into New Thought).

Horatio Alger, Stratemeyer's spiritus rector, translated the ideas of popular self-improvement movements into the classical rags-to-riches narrative, in which the idea of autonomous self-making seems already undermined by the superior importance of luck over pluck. It is true that resourcefulness, hard work, and practical optimism characterize Alger's young protagonists. 
Yet coincidence in the form of the protagonists' providential meetings with rich benefactors has often been lamented to mark Alger's plots far too dominantly to render any lesson enforcing Franklin's common sense practices effective (cf. Weiss 53). Reliance on social capital to effectuate personal progress is therefore the most obviously championed self-help attitude in Alger.

The New Thought movement, which gained momentum simultaneously with Alger's self-improvement narratives, proposed a worldview informed by the conviction in an unconditionally benevolent higher power's existence. This higher power vests the individual, and especially the individual imagination, with immediate, material creativity, whether or not translated into action. New Thought pioneers like Phineas Quimby looked back to Transcendentalism, Mesmerism, and Swedenborg and forward to various forms of therapy, but, as Lears study makes clear: also advertising. Here, clear mental focus on desired outcomes is imperative to improvement. New Thought authors such as Ralph Waldo Trine, Wallace D. Wattles, and Mary Baker Eddy (whose Christian Science is a religious codification of the principles underlying New Thought) all emphasize the importance of visualization and affirmation to help the individual attain that very focus (cf. Trine 126; Wattles 46; Baker Eddy 368). These practices of mental focus are deeply informed by an attitude of optimism, derived from the de-facto elevation of the individual to divine status (the ultimate victory of mental mobility).

In the 1930s, self-help champions Napoleon Hill and Dale Carnegie re-formulated these attitudes and blended them with therapeutic practices from popular psychology, first and foremost (auto)suggestion. The authors uphold the importance of, and impart, practical knowledge regarding matters as diverse as persuasive communication techniques, body language, and CV-writing (cf. Hill 128-31), at the same time exhorting readers to assume responsibility for their improvement. Especially Carnegie's How to Win Friends and Influence People reads like a text-book for the acquisition of social capital (How to be as popular as Nancy Drew, or, in Lear's words: how to develop "personal magnetism"), aimed at eliminating the very need for the providential coincidence that Alger's Ragged Dick had to rely on to acquire. Both Carnegie and Hill, continued in New Thought's vein of highlighting the importance of mental focus, advocating the same practices of visualization and affirmation (auto-suggestion, see Hill 69-77) and, in 
the case of Hill, expanding on para-scientific notions of thought vibrations as powerful attractors of the thought's material referents (see Hill 239-46). Hill's Think and Grow Rich and Carnegie's How to Win Friends and Influence People can well be regarded as the most comprehensive codifications of self-improvement knowledge in the days of Nancy and Carol. Although both Hill and Carnegie's books operate on the promise of social mobility, they completely render invisible questions of class, let alone gender or race.

A structural similarity between the literature of self-improvement and mass literature is the reliance on repetitive formulae. Indeed, self-help literature often stylizes its content as a secret formula, ${ }^{7}$ which, if followed exactly, does not fail to bring about the desired goal. Self-help books encourage the reader to adopt this formula in the form of very particular and easy to follow habits of thought and practical rituals, presented as disciplines of mind and body. In fact, this message can be identified as a major item of younger self-help knowledge, the knowledge that success necessitates a formula, one that includes and plays on the abovementioned attitudes. Mass literature as a product incorporates and exemplifies this reliance on formula and indeed constitutes and identifies itself on the basis of the structural feature of the formula (see the titles of the Nancy Drew series or the subtitle of Hell). The "secret" is repeated and slightly varied in a manner as to advertise and, at the same time, disguise its own investment in the discipline of mind (formulaic story) and material body (production process of assembly-line writing).

Appraisals of American cultures of self-improvement coincide in stating that the main difference between a white and an African American self-improvement culture unfolds along the dichotomy of individual vs. community. Booker T. Washington's Character Building, a collection of speeches held to the student body of Tuskegee Institute, is a case in point. Optimism, though understandably not as unbridled as New Thought's, practical skills, and focused discipline of mind and body are first and foremost a means to establish a successful community at the Institute and to present a favorable image of the African American community as a whole. The knowledge patent in this attitude of community-mindedness is more pessimistic, for it states that individuality and, as Gayle McKeen states,

7 Note that Hill in the preface to Think and Grow Rich, immediately speaks of "secret" and "formula" - obviously his unique selling proposition. 
the all-important self-help principle of Lockean “self-possession” (411), is not granted to black people. Washington's often criticized implicit "affirmation" of racist prejudice can be viewed as a means of transporting the knowledge that racist oppression will always figure forcefully in African American self-improvement.

Another point of divergence from other black intellectuals regards what might be termed the knowledge about knowledge, or in other words, what kind of knowledge best to acquire. This refers to the old polemic question of whether an industrial or an academic education would best facilitate "uplift." 8 Again, Washington has been criticized for privileging the former. In his speech "Blessings of Liberty and Education," Frederick Douglass summarizes the reasons for changing his stance on this issue. Stating clearly his appreciation for manual labor, Douglass goes on to say

My philosophy of work is, that a man is worked upon by that upon which he works. Some work requires more muscle than it does mind. That work which requires the most thought, skill and ingenuity, will receive the highest commendation, and will otherwise do most for the worker. Things which can be done simply with the exertion of muscle, and with little or no exertion of the intellect, will develop the muscle, but dwarf the mind.

This passage, which in many regards seems to correspond with the spiritual vocabulary of white self-improvement authors favoring self-culture, is nonetheless just a more cordial formulation for another problem regarding manual labor that Douglass states. Douglass knew that manual labor, "for which but the smallest wages are paid or received," will, in the long run, not succeed in furthering material advance, let alone in freeing black people of the equation with service personnel. For W.E.B. DuBois, self-improvement and especially an intellectual education in culture, as Keene points out, represented a possibility to point the way to "the highest human possibilities" (427), but also implied a responsibility to demand and institute full political equality as the condition under which that full potential can be achieved (425).

As a result, the African American culture of self-improvement seems to suggest less of a clear formula and has not been codified in the form of a specific genre of non-fiction popular literature, meant to inspire and also

8 We are aware that the term "uplift" is highly problematic. The reason we cite it here in quotation marks is because the debate was led under this heading. 
to entertain. Instead, African American self-improvement has always been immensely practical (African Americans have always had to practice selfhelp), part of an actual political struggle of liberation, and a discourse of contesting views on how this struggle could be advanced (Du Bois vs. Washington). Its complexities have therefore reflected the tensions of a restrained optimism in the possibility of achieving material security (of life and limb as well of property), political equality, and self-determination, but also of the awareness of the overwhelming racist hostility aimed at their community.

\section{Privilege, Commodity, and Knowledge (Discussion)}

Carol's predicament may seem much closer to these contexts than Nancy's adventure. With Hell, the Chicago Defender prints a racy story (one is almost tempted to call it blaxploitation literature) to which the audience can relate because their aspirations would often have been greater than their opportunities - and more often than not because of Jim Crow and the color line. The story allegorizes the angry contentions arising from the debates about the Atlanta Compromise. Carol knows (with Du Bois) that in the $20^{\text {th }}$ century a purely material orientation (the analog to Douglass's manual labor) will not do:

'Money!' again she lashed him with the word. ... "I'll prove to you and to this American world that color is no bar sinister to realization of the highest and best in life and in art. One doesn't have to compromise with life where there is real merit. Only mediocrity must needs lower his art, degrade it to the amusement of the ignorant horde." (Chicago Defender 16 Feb 1929, 2:7).

Her suitor, Arthur, knows (with Washington) that money is a more malleable equalizer than cultural capital:

... dad makes 'em pay through the nose for all they get out of him. He play 'monkey,' as you say, for white folks, but he gets the dough, and dough is what counts in this little old world ... you don't think the guy at the head of the biggest dramatic school in the USA is going to risk his living and his success by changing the complexion of his school, do you? (Chicago Defender 16 Feb 1929, 2:7)

The story ends in a cataclysm, which violently eliminates the debauched and corrupt leadership of fictional Kansas City (the reverend, his officer, and his henchman die from their own illegal, poisoned booze). But Carol's energy and happiness have also been destroyed. Her aspiration (to play theater) 
and self-improvement have been thwarted (in the end she is forced to dance for Arthur's Jazz-Company), and she is bound to hate her lover and husband for surrendering their lives to the cheap, racist commodity fetishism of a hateful, white audience. Hell is a cautionary tale about the simultaneous impossibility of following Du Bois's ideas of racial improvement (because of racism and discrimination) and the unfeasibility of following Washington's ideas of improvement (because they end in self-hatred).

As a result, the serial novel leaves the reader with a fundamental sense of ambivalence, expressed in the contradiction of Arthur's success/redemption (he was right, after all) and Arthur's dishonor (he does business with those who destroyed his wife's life). This ambivalence is even heightened if we take into account the newspaper in which it was published: The Chicago Defender relentlessly pushed a discourse of self-improvement. Abbott iterated the ideas of self-reliance and self-culture (usually in framed boxes) in the typical formulaic style of the movement. Here are only a few examples: "The reward for a good deed lies in the performance of that deed," "Waste time today means extra work tomorrow," "Every time you postpone a duty you weaken the habit of decision and make it harder to do the duty" (11 Jan 1930, 14-15); "Eventually your efforts will bring the reward they deserve" (19 Jan 1929, 2:2); "To quit before the finish is to admit defeat," "By conquering our fear we conquer ourselves and thus may advance well armed" (25 Jan 1930, 14); "Curiosity killed a cat - but you are no cat - be curious" (8 Feb 1930, 14).

Abbott militantly endorsed individual curiosity, learning, education, ambition, effort; he also featured high culture (theater, concerts, lectures) in the pages of his newspaper. And, yet, his very product speaks to the futility of any individual effort in the light of race prejudice. Time and again, he summons the forces of solidarity and class action against white privilege and race or class discrimination. It is as if self-improvement, self-culture, harmony is feasible in a future in which racial discrimination has been eliminated. Until then, Carol knows, vitality and self-realization may lead to Hell.

The discourse of self-improvement and mental mobility is so strong in the products of consumer culture and mass circulation because these products were on demand by virtue of this very discourse. Picking up the Defender might improve your life and that of your little Billikens. So might Nancy 
Drew if you are undeterred by what Andrew Levy has called American culture's "admixture of unresolved aristocratic and democratic values" (qtd. in Geyh 546). And because America has partly supplanted race differences for class differences, Stratemeyer's heroine is securely on the white side of life and will have nothing to do with its nemesis. The early series (before its cleansing in the 1960s) ) $^{9}$ is blatantly racist - whenever a black (or other non-white, for that matter) character appears, it directly leads to a crime without further detour. The question is, whether this fact will not tell the reader something about mobility and self-improvement which s/he is not supposed to know.

As a matter of fact, Nancy as a detective perfectly personifies the ethos of the new professional-managerial class - perhaps so perfectly because the new orientation demands certain skills which were formerly thought to be rather feminine: intuition, empathy, communication etc. Here are some of Dale Carnegie's rules for leadership: "smile, be a good listener, encourage others to talk about themselves, make the other person feel important" (112); "let the other person do a great deal of the talking, let the other person feel that the idea is his or hers, try honestly to see things from the other person's point of view, appeal to nobler motives" (200-01); "call attention to people's mistakes indirectly, let the other person save face, use encouragement" (248-49). Nancy's techniques of interrogation in The Secret of the Old Clock work in exactly this way: Nancy would never have learned about the old clock (from Abigail Rowen) or about the whereabouts of the clock (from Mrs. Topham), had she not learned these lessons.

Nancy is extremely strong on soft skills, she "had studied psychology in school and was familiar with the power of suggestion and association" (Keene 88). Her father, a well-known lawyer, "had taught her to think for herself and to think logically" (Keene 6). Mr. Drew has a psychological bent himself: "Of course I don't need to warn you not to appear too eager for information" (Keene 12) The father also knows about the therapeutic value of relaxation: "Give your mind a rest and perhaps you'll have an inspiration,' Mr. Drew encouraged her kindly” (Immediately, Nancy goes

9 Volumes 1-34 of the series were extensively revised between 1959 and 1975. The language was modernized, racism and classism was abetted and, sometimes, the plots were modified. 
shopping! Keene 51-52). And, of course, Nancy has the unquenchable desire and the faith to solve her cases (which are, incidentally, Napoleon Hill's first and second steps to riches): "'Where there's a will, there's a way' she quoted whimsically. 'That old proverb is doubly true in the Crowley case"” (Keene 23).

All of these aspects of self-realization (to find the will and the soft skills to succeed) are programmatic and explicit not only in The Secret of the Old Clock. Even the fact that Nancy's mysteries are always about money, that she usually finds a will, a lost treasure, or stolen jewelry are no big surprises in a period which reflected its own materialism as excessively as the 1920s and 1930s. What makes one think, however, and probably not in the direction Napoleon Hill or Carson Drew intended, is the massive discourse of privilege that continuously runs along the more benign discourse of leadership.

In The Secret of the Old Clock this discourse of privilege mainly unfolds between Nancy Drew and the Topham family (and it has been much alleviated in the revised edition). "Richard Topham," Nancy says, "is an old skinflint who made his money by gambling on the stock exchange. And Cora, his wife, is nothing but a vapid social climber" (Keene 3). The Tophams cannot hide their low origins: the daughter has "acquired an artificial manner of speaking which was both irritating and amusing” (15) and the mother, in order to imitate "society" has "landscaped' [the lawn] with a vengeance. In an effort to 'do it in proper style,' Mrs. Topham had crowded the yard with sundials, benches, bird houses and statues. 'Such lack of taste!' Nancy thought" (95). In contrast, "Carson Drew and his daughter were cordially welcomed in River Heights homes which merely tolerated the Tophams or, in a few cases, barred them" (97).

The worst that can be said about the Tophams is that they are not even able to consume properly. The Topham girls disrupt consumption twice in the local department store $(14-17,52-56)$. Needless to say, these social climbers are sorely punished at the end of the book. One could say that Nancy, in the end, re-distributes their money to people who would never step over the bounds of modesty and talk back at their social betters. It is clear that Nancy, for all her democratic soft skills, is a disguised aristocrat. While one secret formula of her books (the one the reader is meant to find) is about how to win friends and be a leader, the subtext seems to 
remind the reader subliminally that not everybody is born to be a leader or should aspire to be one. In other words, while Nancy transgresses certain boundaries (the proper activities of girls, the boundaries between work and consumption, the limits to unravelling mysteries) she holds up others (race and class). There is a deep ambivalence in the Nancy Drew novels to which extent poverty is self-inflicted, to which extent social capital can really be acquired, and there is a manifest contradiction between the (intended) mass appeal of the series and the residual classism and racism.

Have we solved the secret of mass literature's knowledge, then? Have we glimpsed beneath the shadows of consumer culture's indifference? Only to the degree that we have shown how ambivalent Nancy's and Carol's knowledge is. How riddled it is by the contradictions and silences of the discourses sustaining it. How much it is limited by the violence and prejudices of its times. And how much it can tell us about these limitations - once we look at it with hindsight.

\section{Works Cited}

Abbott, Robert S. The Chicago Defender. Chicago, Ill. Various Issues from 1929 and 1930. Microfilm.

Allen, Abel. The Message of New Thought. New York: Thomas Y. Crowell, 1914.

Baker Eddy, Mary. Science and Health With Key to the Scriptures. 1875. Boston: Christian Science Board of Directors, 2006. URL: https://christiansciencemedia.org/files/2010/03/Science-and-Health-with-Key-to-theScriptures.pdf, 20 Aug. 2015.

Carnegie, Dale. How to Win Friends and Influence People. New York: Pocket Books, 2010.

Douglass, Frederick. "Blessings of Liberty and Education." 1894. Teaching American History. Ashbrook Center, n.d. URL: http://teachingamericanhistory.org/library/document/blessings-of-liberty-and-education/, 8 March 2016.

Field, Peter S. “'The Transformation of Genius into Practical Power': Ralph Waldo Emerson and the Public Lecture." Journal of the Early Republic 21.3 (Autumn 2001): 467-93. 
Folkenflik, Robert. "The Heirs of Ian Watt." Eighteenth-Century Studies 25.2 (1991/92): 203-17.

Fox, Richard Wightman and T.J. Jackson Lears. "Introduction." The Culture of Consumption: Critical Essays in American History, 1880-1980. Ed. Richard Wightman Fox and T.J. Jackson Lears. New York: Pantheon, 1983. ix-xvii.

Franklin, Benjamin. The Way to Wealth. New York: New York Association for Improving the Condition of the Poor, 1848. URL: https://books. google.de/books?id=TWwqAAAAYAAJ \& printsec=frontcover \&hl=de\&s ource $=\mathrm{gbs}$ ge summary $\mathrm{r} \& \mathrm{cad}=0 \# \mathrm{v}=$ onepage\& $\mathrm{q} \& \mathrm{f}=$ false, 4 Apr. 2016.

Gelder, Ken. Popular Fiction: The Logics and Practices of a Literary Field. London: Routledge, 2004.

Geyh, Paula. "Not-so-Distant Relations: Mass Culture and Literary Capital in Twentieth-Century American Literature." Contemporary Literature 36.3 (1995): 545-52.

Hill, Napoleaon. Think and Grow Rich. 1937. New York: Penguin, 2003. Hoffman, Jan. "Nancy Drew's Granddaughters." The New York Times, July 19, 2009, ST1.

Keene, Carolyn. The Secret of the Old Clock. (Nancy Drew Mystery Stories). New York: Grosset \& Dunlap, 1930.

Kismaric, Carole and Marvin Heiferman. The Mysterious Case of Nancy Drew \& The Hardy Boys. New York: Simon \& Schuster, 1998.

Lears, T.J. Jackson. "From Salvation to Self-Realization: Advertising and the Therapeutic Roots of the Consumer Culture, 1880-1930." The Culture of Consumption: Critical Essays in American History, 1880-1980. Ed. Richard Wightman Fox and T.J. Jackson Lears. New York: Pantheon, 1983. 1-38.

McKeen, Gayle. "Whose Rights? Whose Responsibility? Self-Help in African American Thought." Polity 34.4 (Summer 2002): 409-32.

Moten, Cora Ball. Hell. Serialized in The Chicago Defender, 16 Feb. 1929 4 May 1929. Microfilm.

Ohmann, Richard. "History and Literary History: The Case of Mass Culture." Poetics Today 9.2 (1988): 357-75.

-. Selling Culture: Magazines, Markets and Class at the Turn of the Century. New York: Verso, 1996. 
Ostendorf, Bernd. "Why is American Popular Culture so Popular?" American Studies in Scandinavia 34 (2000): 1-46.

Susman, Walter. "'Personality' And the Making of Twentieth Century Culture." New Directions in American Intellectual History. Ed. John Higham and Paul Conkin. Baltimore: Johns Hopkins University Press, 1979. 212-25.

Trine, Ralph Waldo. In Tune With the Infinite. 1897. Rockville: Arc Manor, 2008.

Vogl, Josef. Das Wissen der Literatur. Humboldt Graduate School, n.d. URL: http://www2.hu-berlin.de/wissen-literatur/program.php? setlang=de, 7 March, 2016.

Walker, Juliet E.K. "The Promised Land: The Chicago Defender and the Black Press in Illinois: 1862-1970." The Black Press in the Middle West 1865-1985. Ed. Henry Lewis Suggs. Westport: Greenwood, 1996. 9-50.

Wattles, Wallace. The Science of Getting Rich. 1927. N.p.: Simon Wallenberg, 2007.

Weiss, Richard. The American Myth of Success: From Horatio Alger to Norman Vincent Peale. 1969. Urbana: University of Illinois Press, 1988. 



\title{
Matthias Bauer \\ Scientific Knowledge and the Display Function of Literature: The White Hotel (1981) and Freud's Megalomania (2000)
}

\begin{abstract}
Literature may display, work through, and transfigure bodies of scientific knowledge, ideology, and rhetoric. Sociological accounts which distinguish between raw information and processed knowledge (Burke 1-17) support the claim that only subjective mediation of bits and pieces of information may produce relevant meaning. Modern literature as an instrument of subjective mediation therefore assumes significance in the production of the cultural achievements of subjectivity and responsivity. This essay turns to psychoanalysis as a scientific discourse strongly influenced by literary writing and explores two exemplary literary displays of the psychoanalytic processes to show how explicitly literary writing redresses psychoanalytic theory's main weakness, namely its disregard for self-reference. Selfreferentiality makes literature a fascinating mode of experimental thinking. This experimental thought reveals contradictions in Freud's theory or between his findings and the findings in other disciplines in Rosenfield's novel Freund's Megalomania; and it confronts knowledge and history, academic discourse and real events in D. M. Thomas' novel The White Hotel both to stress the importance of psychoanalysis and to mark its boundaries.
\end{abstract}

Literature has the capacity to store information and to provide knowledge. When reading Moby-Dick (1851) one can learn a lot about sailing and whaling. Nevertheless, it would be quite strange to use this novel as a primal source of information or to reduce its meaning to that of a non-fiction book. Rather, the story adds something to knowledge or even transforms knowledge in a specific way. For example, the 'Etymology' and the 'Extracts' before the first chapter do not only prepare readers for the narration; they also stimulate them in a way that is different from reading a scientific treatise or an encyclopedia. Consequently, the interlacing of fact and fiction differs from the production and compilation of objective information. Readers might learn a lot; however, their attention is drawn to questions that reach far beyond the realm of scientific knowledge. Judging from the 'Epilogue,' the overall impression resembles much more the adventurous 
discovery of a personal truth than a demonstration of erudition or, even worse, a moral lesson. It seems that the transformation of knowledge by reading a novel is about readers' immersion: It is about their immersion into the diegetic world and the metamorphosis during the interaction of information and imagination, objective knowledge and subjectivity. One might infer that the self-reference distinguishes the reading of a novel from the way scientific findings are learned. One might also infer that there is something in the text that encourages readers to relate the story to their personal experience and memory in such a way that a new relevance emerges a relevance that is hard to find in a textbook on sailing or in a historical description of whaling.

\section{The Display Function of Literature}

Mary Louise Pratt has argued convincingly that narratives are equipped with a "display producing relevance" (136). Apparently, this principle involves the double meaning of the verb 'to display': a narration can both show something and run through its implications and consequences. "To show" something often means "to lay out" a structure according to the spatial form of perceiving; and "to run through" implications and consequences often leads to the unfolding of a drama. It is no wonder, then, that the very idea of the Aristotelian 'myth' already promotes this understanding of 'display.' The 'myth' is a course of events that promotes causal knowledge, moral reflection, and pragmatic inferences since one is able to see how the 'things' develop and how contingency is reduced by action. Narrotology is in line with this understanding of stage drama and 'myth.' Both Hayden White's notion of 'emplotment' (cf. 38) and Paul Ricoeur's concept of 'configuration' (cf. 54-135) confirm the Aristotelian idea of 'myth.' White argues that there is no meaningful course of events without plot. Therefore, to tell (hi)story someone must re-arrange data according to a plot:

[...] narrative accounts do not consist only of factual statements (singular existential propositions) and arguments; they consist as well of poetic and rhetorical elements by which what would otherwise be a list of facts is transformed into a story. Among those elements are those generic story patterns we recognize as providing the 'plots'. (38) 
Ricœur, additionally, points at the logic of motivation, intention, action etc. that make up a plot. Instead of 'plot' he speaks of 'configuration.' The main function of such a configuration is to trigger inferences about the meaning of the story told. Every well told story is not only an arrangement of events but also an arrangement of desires and ambitions, character features and actions. It offers insights into psychology and it contributes to a complex view of the world by displaying a more or less sophisticated 'grammar of motives' (cf. Burke).

Another important concept that can enrich the 'display theory' has been defined by Roland Barthes in his seminal Leçon. According to Barthes, literature conveys a considerable amount of knowledge but is not able to reproduce all the dimensions of reality in the one-dimensional world of a written discourse. Therefore, the 'trick' is to suspend the tendency inherent in any language to suppress ambivalence and polysemy. Instead, literature uses the signs that normally restrict meaning and put things in order for a play that transgresses every rule. Thus, the semiotic potential of literature lies in a kind of 'heteronomy' that subverts scientific taxonomy, ideology, and rhetoric (cf. 40-41). Even if one would not subscribe to Barthes' ideas and deem them exaggerations, the main argument is intriguing: playing with signs might result in a transfiguration of knowledge. Literature provides knowledge or changes the reader's attitude which has been established through social construction. There is always a battle of values and convictions, world views and moral judgements, and literature has not only the capacity to reflect this battle - for example in the form of the polyphonic novel, the mock-epic, or the Menippean Satire - it has also the power to break the ruling principles of discursive knowledge and to free up personal imagination from the constraints connected with the demands of social conformity and contemporary mentality. Censorship is a clear proof of literature's subversive power. If fiction were not critical and transgressive, there would be no reason to prevent people from reading literature.

It is important to realize that the display function of literature is not only a means to subvert or to transfigure knowledge. The display function might also change the notion of knowledge itself. Normally it is held that one gains knowledge by sampling information - a view that has become very popular in the age of the World Wide Web and the culture of Wikipedia. However, reduced to bits of information, knowledge is deprived of exactly 
that relevance that depends on self-reference. An apt notion of knowledge therefore must take into account this relation - otherwise the aggregate of information will never become a personal system of beliefs and habits. Such a system develops in a constant process of mediation that goes on during a person's whole life time. School and other institutions of education support this mediation, but the main burden lies on the individual. It is always the subjective mediation of knowledge that produces relevant meaning - a task that no one can delegate to anybody else.

If the significance of literature - besides its public esteem - is grounded in subjective mediation, one could even say that subjectivity is a cultural achievement of art and literature. Indeed, a reflexive novel like Tristram Shandy (1760-1768) displays the structure of subjectivity, its implications, and consequences. Wolfgang Iser has explored this reading in depth. Inspired by Nelson Goodman's Ways of Worldmaking (1978) Iser read Sterne's novel as a playful set-up of subjectivity, and he argues that there is probably no other way to show how information is processed in the human mind. The narrator follows the strange law of association with great humor. His witty display of notorious misunderstandings does not only parody John Locke's epistemology, it also establishes a more realistic view of consciousness. Since this view does not take on the form of a theory, the reader must engage in the novel's specific mode of demonstration to grasp its meaning. Without relating the opinions of the narrator and the flaws of the characters to his/her own experience, he or she would miss the point. (cf. Iser Laurence)

Given the fact that the display function is always in need of subjectivity, there is evidence that the reader's imagination must run through what is laid out in the text - both on the level of story or drama and on the level of narration. Taking up the role of the so-called 'implicit reader' the empirical reader is enabled to explore how the plot works: how the diegetic world is constructed and how the characters exemplify different ways of world making - including all the misconceptions and, consequently, the pitfalls of communication that result from misconceptions. Iser (again with reference to Goodman) therefore suggests that a work of art exemplifies a system of relations in such a way that the process of world making becomes evident. Rather than talking about world making in an abstract manner as, for example, philosophy would do, the narration is a very concrete performance 
of the very process itself (Iser, Das Fiktive 278). Following the traces laid out in the text, the reader participates in this process and, by the same token, reflects on its contingent quality.

Laurence Sterne's novel belongs to a tradition of writing that was strongly influenced by Robert Burton's Anatomy of Melancholy (1621). By imitating scientific discourses and their often-digressive structure, this book already employed the technique of exemplification. The full title of Burton's treatise, An Anatomy of Melancholy, invites a specific reading. Rather than defining the disease in proper terms, Burtons displays its symptoms through the associative, digressive, and elliptic manner in which his book is written. In the same manner, The Life and Opinions of Tristram Shandy, Gentleman provides the reader with the birth of opinions that lead into dead ends instead of the biography announced in the title. The linkage between exemplification and display function, digressive structure and reflection (as to be found in Burton's anatomy and, even more, Sterne's novel) seems to be a common feature of literature that departs from linear storytelling and that arrives at the vast field of phenomenological analysis and psychological sensitivity. Authors like James Joyce in Ulysses (1922), Thomas Mann in Der Zauberberg (1924), Marcel Proust in À la recherche du temps perdu (1913-27), or Virginia Woolf in The Waves (1931), to name only a few, scrutinized the stream of consciousness, the 'interior' sense of time and the structure of subjectivity in a similar way as contemporary psychology and philosophy did, especially William James, Edmund Husserl, and Sigmund Freud. These novels show a great interest in the human mind. On the other hand, a skilled researcher like Freud could not overlook the poetic features in his case studies and even considered the theory of the drive as a myth that should be replaced one day by a more appropriate conception of desire and motivation: “[...] es berührt mich selbst noch eigentümlich, daß die Krankengeschichten, die ich schreibe, wie Novellen zu lesen sind und des ernsten Gepräges der Wissenschaftlichkeit entbehren,” wrote Freud in 1895 (Freud and Breuer, Studien 180). ${ }^{1}$ And in 1933, he admitted: "Die Trieblehre ist sozusagen unsere Mythologie. Die Triebe sind mythische Wesen, großartig

1 Translation by Nicola Luckhurst: "[...] and I myself find it strange that the case histories that I write read like novellas and lack, so to speak, the serious stamp of science" (Freud and Breuer, Studies 164). 
in ihrer Unbestimmtheit. Wir können in unserer Arbeit keinen Augenblick von ihnen absehen und sind dabei nie sicher, sie scharf zu sehen" (Freud, Vorlesung 94). ${ }^{2}$

\section{Freud's Megalomania: An Anatomy of Self-deception}

The myth of the drives, the novelistic style of the case studies, and the frequent fusion of narration and argumentation in Freud's writing have caused harsh comments and debates about the scientific value of psychoanalysis. However, the same features have invited artists to take up Freud's style and to imitate his case studies in novels. Consequently, the specific knowledge provided by psychoanalysis is displayed in works of literature, ranging from books like Nicholas Meyer's The Seven-Per-Cent-Solution (1974) up to Carol de Chellis Hill's Henry James' Midnight Song (1993) and from D. M. Thomas' The White Hotel (1981) up to Israel Rosenfield's Freud's Megalomania (2000). Interestingly, most authors either exploit the narrative formula of the detective story that attracted Freud himself - among them Meyer and Hill -, or follow the traits of the anatomy like D. M. Thomas and Israel Rosenfield. If a detective story imitates the logic of deduction, induction, and abduction, an anatomy is more concerned with the critique of rival interpretations. Even more interesting is the fact that Rosenfield has not only written Freud's Megalomania but has studied medicine and undertaken An Anatomy of Consciousness entitled The Strange, Familiar, and Forgotten (1992). In this book, he presents harsh critique of those theories that compare the human mind to a computer. According to Rosenfield, the weakness of these theories lies in their ignorance of self-reference. The following paragraphs deal with Rosenfield's anatomy and Thomas's novel.

Rosenfield's argument is based on a pragmatic conception of knowledge: knowledge, he argues, is something comprehensible. To communicate knowledge, therefore, means to convey information. But to receive information is different from the feeling that one has a consciousness. This sensation arises from the sequential development of perceptions and from the

2 Translation by James Strachey: "The theory of the instincts is so to say our mythology. Instincts are mythical entities, magnificent in their indefiniteness. In our work we cannot for a moment disregard them, yet we are never sure that we are seeing them clearly" (Freud, New Introductory 118). 
temporal-spatial relationships that converge on the unique viewpoint which sustains every personal experience. Since it cannot be reduced to bits of information, consciousness must be more than just a storehouse of knowledge. It develops constantly and thereby changes. It is dynamic whereas knowledge is static (13-15). In contrast to mere information and unmediated perception, consciousness cannot be separated from the memory of its own development. And memory always involves a self-reference. It is bound to a personal viewpoint. Finally, this viewpoint is connected with a body scheme, a representation that works as a prime frame of reference for every sensation and perception, piece of information and experience (16-17).

Clearly, this prime frame of reference is ignored when the brain is compared to a computer. A computer can store and copy information, but this is not what human memory does. The specific processing of human memory involves the body scheme and the notion of time. Neither the body scheme nor the notion of time is activated in the computer. Consequently, the computer's capacity to store and to copy information is very different both from the way human memory contributes to a stream of consciousness and from the awareness of this stream that is characteristic of human experience. Consciousness is always the consciousness of a dynamic interplay, of a development with reference to the body scheme and a person's actual situation. Since all memory and feeling is embodied (Rosenfield 54), a computer does neither feel itself nor engage in knowledge production. Its indifference to the personal meaning of information makes the computer a perfect machine of manipulation but a very inappropriate model of the brain and of the conscious development of human beings. Since the body scheme is the prime frame of reference, or the central knot in the dynamic web of relationships that make up consciousness, every diagram that represents knowledge without self-reference and without connection to body and time can only be a misconception (81). Of course, such a deficient diagram can convey information in quite an objective way, but it misses the subjective meaning that depends on the personal reaction to every bit of information.

In this respect, subjectivity is "responsitivity." Like Bernhard Waldenfels, who has coined this term, Rosenfield relies on the research of Kurt Goldstein (cf. Rosenfield 37-39; Waldenfels; Goldstein). Responsitivity is important for every realm of consciousness and is not bound to language. 
Instead, any spoken or written response must be grounded in a relation of the self to the instance or experience, situation or person demanding an answer. The specific performance of the human brain lies in the abstraction and generalization of concrete instances and situations and in the continuity of personal experience and memory. (cf. Rosenfield 123, 126) Because of this, human beings are able to understand the present in contrast to the past and to infer what might happen in the future (154), even though the present is not a copy of the past and the future does not replicate the present. The mediation of continuity and contingency rather promotes a dynamic understanding of the world and of the self, of history and society.

With this in mind it comes as no surprise that self-reference is also the crucial point in the critique of self-deception which has been the main concern of Freud's psychoanalysis. People tend to misunderstand themselves, their actions, and their reactions towards others, because they are trapped in a loop of false memories: those that cover traumatic experiences and disturb or even destroy the body scheme that invokes sexual desire. In his novel, Rosenfield tries to deconstruct this theory. However, this deconstruction is not his main ambition. Instead, as in Anatomy of Consciousness, Rosenfield attacks the misconception of the human mind that is provoked by its comparison with artificial intelligence.

Freud's Megalomania starts and ends "With an Introduction and Notes by Professor Albert J. Stewart" who tells the reader at the beginning that he never liked Freud (11) since he was "a man who invented the psychiatric syndromes, the patients and the patients' stories to 'prove' his theories" (12). Funny enough, Stewart presents the reader with exactly such a story to prove another theory ascribed to Freud. "One day a woman of medium height with an uncommonly beautiful face came to my office. She introduced herself to me as Bernadette Schilder and handed me a manuscript that she said was by Sigmund Freud" (14-15). A reader of Rosenfield's Anatomy is immediately alarmed by Bernadette's family name, since it was a certain Paul Schilder from Vienna who was one of the first neurologists and psychiatrists who promoted the concept of the body scheme. In line with Rosenfield's Anatomy, Stewart, despite his skepticism about Freud, rejects the physiological reduction of human consciousness to neuro-chemistry: "[...] knowing that there is more of a particular neurotransmitter when we are depressed does not explain depression any better 
than Freudian theory; nor does an analysis of neurotransmitter levels help us understand our feelings" (16). The gap between the sub-symbolic and the symbolic, between scientific explanation and personal meaning is a crucial point in Rosenfield's novel, and, of course, a point of differentiation between computer simulation and literature.

Another gap separates knowledge from action. Freud's manuscript is concerned with the question how to bridge that gap. "Since the limits of knowledge make it impossible for reason to tell us what to do, our emotions deceive us into believing in the 'rightness' of our actions" (19), Stewart informs the reader. In this respect, self-deception is a prerequisite for action. Stewart contrasts Freud's ideas about the relationship of emotion, self-deception, and action with the so-called 'Loop Theory' that enabled his scientific and personal rival Norman Dicke to construct his Marilyn Machine. "Loops describe the intricate and subtle ways the brain communicates with itself, with other brains, with our surroundings and ultimately with the universe as a whole" (24). The Machine captures the real Marilyn Monroe's thoughts and "thinks of herself as having 'looks'” (27). Stewart is quick to mention the rumor that Dicke was only able to have sex with a flesh-and-blood woman when the Machine was watching him (28). He also arouses the reader's suspicion that his rival is a mean, narcissistic person (28).

Be that as it may, Stewart is eager to point out: "Freud would have had trouble grasping the elementary scientific truths that made Marilyn possible, truths such as the widely accepted view that beliefs and desires are physical symbols in our brains [...]" (29). Obviously, it is exactly in this widely accepted view that Stewart and Rosenfield are opposed since the latter is very skeptical about any naturalistic reduction. If one accepts this view, Freud's failure is evident. As Stewart claims, Freud "failed to understand that it's not the idea that the symbol represents that makes us think and act as we do, but the shape, the form of the symbol that causes thought and action" (30). So, if Dicke stands for the neurological science that grew out of the discovery of the DNA and the invention of the computer (35) and has reduced the grammar of motives to physical parts in the brain, Freud, the founder of psychoanalysis, on the contrary, represents the idea that not the form or shape but the content directs a person's beliefs and the actions he or she performs according to these beliefs. 
Consequently, one can read the inner-textual manuscript as a pre-emptory comment on the theory that is implemented in the Marilyn Machine. In Rosenfield's novel, this reading is discredited by the preface Bernadette Schilder has written. Though Bernadette does not doubt the authenticity of the manuscript she informs the reader that it might have been "doctored, altered or somehow tampered with by the Gestapo" (52). Even more important than this reservation is her confession that the manuscript is more than a new theory, because it is the story of Freud's long affair with her grandmother (49). In a spontaneous reaction to this confession the reader is likely to infer that Bernadette does not judge objectively and probably has doctored or altered the manuscript to make her genealogical claims sound profound and authentic. However, in the context of Rosenfield's Anatomy a different reading gains plausibility: the personal subjective relevance of the manuscript underlines the principle of self-reference. Since this principle marks the difference between the Marilyn Machine and a human being - whether a real one or a fictitious person like Bernadette - the reader is challenged to keep this difference in mind when he or she comes to the manuscript itself.

Rosenfield has cleverly embedded the Megalomania-script in the personal history of its alleged author. The text refers to a major problem Freud was concerned with, as a theorist and as a politician of science who had to claim his authority as founder of the movement of psychoanalysis. His efforts are reflected in the legendary narrative of primitive society and the myth of killing the great-grandfather. The structure of Rosenfield's novel establishes a non-arbitrary relationship between Bernadette's supposed grandfather and Freud's position among the first generation of his followers. Another important relationship exists between the problem of authority and the universal trait of self-deception. Though Stewart notes that "Freud never used the term 'self-deception' before writing the Manuscript" (60), it is Freud himself who admits in the novel that he had never asked himself, "[...] if self-deception does not have the status of a primary characteristic of human psychology, if it is not the bedrock on which all else, including civilization, is founded" (60). He arrives at the conclusion that Stewart already came up with in the Introduction: "If we were completely rational we would never be able to ever decide what to do. We would never know enough. Thus, our emotions create the illusion in us of what we want or 
desire. In deceiving us our emotions make us act." (66) Stewart adds that this conclusion might be a generalization of Freud's conviction that love is a subjective 'overevaluation' that drives parents and lovers to do things that, objectively considered, lack rationality (66).

A large part of the inner-fictional manuscript is devoted to Julius WagnerJauregg. His treatment of traumatized soldiers came near to torture. Wagner assumed his patients were simulating their symptoms. Freud hesitated to doubt Wagner's authority and argued in line with his own theory "that the sons' desires, real or imagined, to kill the father, had given rise to a pervasive sense of guilt from which the sons could not liberate themselves" (89). Freud's hesitation foreshadows the moral reservation of his follower's followers to doubt his own authority. The text exhibits Freud's failure and runs through the implications and consequences of its correction. Accordingly, Rosenfield's Freud confesses: "In my clinic I saw patients who were deeply troubled by authority figures; but I never saw the authorities themselves. This was a failing that I can only now begin to overcome" (99). The reader is requested to process this overcoming in his or her own imagination by following a narration that, in the manner of an anatomy, distinguishes the neurotic victims of a pretended authority from the psychotic authorities themselves. They become psychotic as soon as they claim to understand everything and refuse any criticism so that violence becomes the ultima ratio of their social behavior. Consequently, the authoritarian explanation of the world becomes totalitarian (100-101).

The political implication of this authoritarian view does not need further exemplification. But in the Megalomania-script Rosenfield's Freud is also concerned with the consequences that arise when a moral authority's psychology is different from those subject to its impact (112-113). If, for example, a political leader is in constant fear of manipulation and therefore rejects any advice, he becomes alienated from his people and probably even paranoid: "[...] if the paranoid personality is frightened by foreign voices, Moses, on the contrary, uses those voices to frighten others" (121). And Freud continues:

Of course, no human being can claim to have total knowledge and therefore that knowledge must come from somewhere else, if it exists at all. Hence Moses had to attribute his knowledge to information passed on to him by God. The source of this knowledge is then a hallucination and we should make a distinction between the 
superego postulated by psychoanalytic theory and what I will call this all-knowing superego, or hallucinatory superego. (122)

It is well known that the 'real' Freud was preoccupied with Moses and eager to identify himself with the mythic figure. However, Rosenfield's Freud does not miss the self-referentiality of his critique. He argues that a hallucinatory superego might gain power and maintain authority by creating a theory no one else can fully understand: "And thus it is that psychoanalysis, my creation, is doomed" (126). Crucial to his creation was the act of self-analysis that nobody can repeat in the same manner (128-129). His followers can only distribute the legend, but never claim that their own self-analysis is as authentic, as original, and as relevant in terms of theory and authority as Freud's own self-analysis.

In addition to the manuscript, Stewart publishes another work of Freud, apparently an appendix that illustrates the manuscript's argument by another example. Without going into detail, the relevance of this example can be summed up briefly in one sentence: "If we don't challenge authority, it is because we have nothing to replace it with [...]" (148). So in the end, readers are left with a dilemma: if they are able to see through the bluff of authority, they have to ask themselves how the social function of authority can be fulfilled. But since there is no answer to this question, it seems that at least the illusion of authority is indispensable. Consequently, the selfdeception of those who accept authority (though they know that no one ever has total knowledge) is one of the emotions that enables them to take action. And since it might be better to be deceived than to be paralyzed, authority will, even in the age of enlightenment, remain an imperative of civilization. For those readers who feel unsatisfied with a dilemma like this, it might be helpful to recall the rationality of the display function. To show and to run through problems is something else than to solve them. But if the alternative lies in either presenting false solutions or in exhibiting the implications of the problems and the consequences of the false solutions, a sincere person can only opt for the dilemma.

To complete the display function of his novel, Rosenfield has invented another fake document: Anna Freud's "Notes on a Conversation with Johnny von Neumann" (154-162). Neumann, an ingenious mathematician, has inspired computer science and brain modelling in ways that allowed 
researchers like Dicke to construct machines with artificial intelligence. During his conversation with Freud's daughter, Neumann expresses his conviction that her father's theory of deception and distrust "was critical to our understanding of all forms of human behaviour and how the mind works" (156, emphasis in the original). The words in italics indicate that Neumann claims authority in understanding everything, so that the reader - in the context of Rosenfield's novel - may infer that he bluffs and that, consequently, the claim of people like Dicke, that they can simulate the processing of the human mind with machines, is also a bluff. Anna Freud's comment on Neumann is quite illustrative. She compares him with her father and notes in parenthesis: "If there was a difference between Freud and von Neumann it was that Johnny was more interested in how we bluff and deceive each other, while Freud wanted to know about how we deceive ourselves" (158, emphasis in the original) Stewart links this difference to the difference of human beings and machines: "[...] a man who tells lies without thinking of himself as a liar, 'thinks' like a machine. $\mathrm{He}$ is not aware of himself. Lying requires an ability to think about oneself" (158). Thus, it would be pointless to judge machines with recourse to the moral standards of authenticity. Instead one should suspect their creators to be bluffers or liars if they claim that their machines can simulate human consciousness. They eventually cannot, because their machines lack selfreference or awareness of themselves, respectively.

Now, what can be learned by reading Rosenfield's novel in connection with his Anatomy of Consciousness? Freud's Megalomania is a 'thought experiment.' It sets up a discourse on self-deception and illusion, authority and bluff that runs through the implications and consequences of the psychoanalytic legend and the neurological myth of artificial intelligence. Both 'theories' miss the criteria of science as far as science is always specific and restrictive in its claims of relevance. But whereas people like Dicke fall victim to their own misconceptions, Freud's fictitious script provides the reader both with a better theory of consciousness and with a more realistic view of how scientific explanation works appropriately. Finally, the reader may understand through the novel's display of psychoanalysis and neuroscience how theory and knowledge about the history of science are transformed into a novel that is neither a work of science nor of historiography. Following the discourses in Rosenfield's book one is intrigued 
by the relevance of the self-referentiality which makes literature such a fascinating mode of experimental thinking. By processing the information, the reader's conjecture reveals meaning according to a specific configuration (or emplotment). In the case of Freud's Megalomania this processing has the capacity to dissolve self-deception, especially the deception that fiction can only produce illusionary knowledge.

\section{The White Hotel: A Narrative of Supplements}

To double-check these findings, another fictitious case history might be helpful. D. M. Thomas' novel The White Hotel (1981) is structured in a similar manner, but operates differently. The "Author's Note" is a kind of apology: "Freud becomes one of the dramatis personae, in fact, as discoverer of the great and beautiful modern myth of psychoanalysis. By myth, I mean a poetic, dramatic expression of a hidden truth; and in placing this emphasis, I do not intend to put into question the scientific validity of psychoanalysis" (vii). Whereas Rosenfield tried to deconstruct the Freud legend, Thomas takes the myth of psychoanalysis as a blueprint. His novel displays less the problems inherent in the theory but rather emphasizes the literary practice that one can find in Freud's case studies. The "Prologue" is composed of fictitious letters from Sándor Ferenczi, Hanns Sachs, and Freud that were addressed to the Commission investigating Wagner-Jauregg's ill-treatment of war neurotics (7) and to "Frau Anna G.", "a young woman suffering from a severe hysteria" (8). She undergoes a 'talking cure' during which she "has just 'given birth' to some writings which seem to lend support to my [= Freud's] theory” (8).

The young woman's writings consist of a large poem and a journal. In the poem, the patient accuses herself of having started an affair with one of Freud's sons (15) and immerses herself, as the narrator puts it, in "an extreme of libidinous phantasy combined with an extreme of morbidity" (8). The first paragraph of the journal is devoted to a dream-scene and then recounts in a less fantastic manner a stay at the so-called 'white hotel' that is supposed to be the inspiration of the poem. While a young couple makes love, various people are killed during a boat trip or by a fire. There is smoke on the water, but the spirit of the white hotel, set up on a lake in the mountains, points at a non-realistic understanding of the journal. 
In the next section, the writings are given the status of hallucinations. Imitating Freud's narrative style, Thomas invents an analysis of "Frau Anna G.” (87):

She was the second child and only daughter of moderately wealthy parents. Her father came from a Russian Jewish family of the merchant class, and her mother from a cultivated Polish Catholic family which had settled in the Ukraine. In marrying across racial and religious barriers, Frau Anna's parents proved their own liberated ideals but suffered the consequences of being cut off from their families. The only relative who did not turn against the couple was the patient's aunt (with whom she was now living), her mother's twin sister. (91)

It turns out that Anna's disease is grounded in a disturbing experience during her childhood: she witnessed a couple's sexual intercourse but could not bear the fact that she saw her mother and her aunt's husband. Both died shortly afterwards in a hotel that burned down. Encapsulated in the camouflage story of her father and his sister-in-law she was told, Anna could neither identify with her mother and mourn her death nor detect the truth in her mislead memories. Her symptoms persuade Thomas' Freud that in the 'white hotel' - poem and journal - "the autoerotic paradise, the map of our first country of love" (116), e.g. the aim of Anna's pervasive desire, is laid out. He regards most of the poem's content as "purest wish-fulfilment" (115). Thus, it seems likely that Anna's writings allow for an imaginary regression beyond the painful experience of losing her mother, her parents love, and the ideal of faithful marriage. Nevertheless, some parts of the content remain mysterious until the reading of Thomas's novel is completed. "The flood, and the hotel fire, could be related to her mother's death; the other two hallucinations, of falling from a great height and of mourners being buried by a landslide, were inexplicable to her; the last was the most frequent, and also the most horrifying, because she suffered from claustrophobia" (123). To excuse his inability to solve all riddles, Freud states: "No analysis is ever complete; the hysterias have more roots than a tree" (140).

Despite this statement, Thomas's Freud is far from doubting his interpretation of Anna's dreams and writings. Instead he reveals that his essay Beyond the Pleasure Principle (published in 1920) took shape during his analysis of Anna G. (128). In line with his pre-fabricated theory he suggests that she felt guilty because the sudden death of her mother fulfilled her unconfessed desire to get rid of the person who forbid the love she felt for her 
father (138). Suggestions like these have produced skepticism among many readers of Freud's writing. Since all his case studies are bound up with his interest in proposing a specific theory and method, they should be looked at as narratives that serve rhetorical purposes. Due to these purposes the voices of the patients undergo a transformation that may end up in destruction. Consequently, Freud's narratives are elliptic. Like the authentic Bruchstück einer Hysterie-Analyse (1905) the fictitious case study devoted to Anna G. is a fragment in need of supplements. As Jacques Derrida has shown, a supplement has always the potential to subvert the logic it is supposed to complete. If the silenced voice of a patient suddenly speaks out, it is very likely that a re-configuration of the plot takes place that alters its meaning, sometimes fundamentally.

In Thomas' novel the same is true for the supplements that follow the fictitious case study. First, in 'The Health Resort' the reader is confronted with Elisabeth Erdmann, the 'real' Anna in the year 1929. Elisabeth is invited to substitute the famous singer Vera Serebryakova who is pregnant. Vera's husband Victor becomes her stage-partner. The women like each other, but in a flash of second sight, Lisa, as Elisabeth is called cordially, imagines Vera's naked body through the glass top of a coffin (163). Victor is torn between Lisa and Vera but remains faithful until his wife dies giving birth to a boy named Kolya. "Lisa wept for days" (175). "She wondered if she was partly grieving for herself. She associated Vera with the single day in her life when she had been treated, however absurdly and undeservedly, as important” (176). Shortly after Vera's death Lisa receives a letter in which Freud asks for permission to publish his case study 'Anna G.' Lisa reads the manuscript as if it were "the life story of a young sister who is dead" (182), begs Freud's pardon for some lies and omissions in what she told him during their talks and rejects his notion of a homosexual drive in her behavior. Referring back to the crisis of her marriage that made her consult Freud she reveals a hidden problem: her husband and his family were "horribly anti-Semitic" (190), so that she always felt hated rather than loved. Her supplementary post-script sheds new light on her suspicion that she was not her father's daughter but a misfortune of her mother's affair with her uncle. If that were true, she herself would not be a Jew. That, however, would also mean that the reason of her divorce had nothing to 
do with sexual problems. Freud's analysis has apparently been based on a false hypothesis.

Ironically, Thomas does not tear down Freud's interpretation. When Lisa and Victor meet again, they make love "with little Kolya sleeping near them" (211). Lisa takes up Vera's role as spouse and mother and starts to live like a family with Victor and Kolya. This arrangement supports the theory that Freud had applied to Lisa's childish desire of her father's love and her secret wishing of her own mother's death. Victor is an elderly man and in that resembles Lisa's father. One could add that desire often implies a triangular relationship. The more $\mathrm{A}$ is loved by $\mathrm{B}$, the more attractive is $\mathrm{A}$ to $\mathrm{C}$. It is very likely that a love communion that depends on the elimination of one person arouses the feeling of guilt in the surviving lovers.

However, despite the relevance of Lisa's post-script to her analysis and the importance of Freud's theory - this is a main feature of any deconstruction that is not reduced to destruction -, the novel transgresses psychoanalytic theory and practice. The second supplement, 'The Sleeping Carriage,' is designed to give the fictitious case study a political meaning by following the historical course of events. As Jews, Victor, Lisa, and Kolya cannot escape the holocaust. After being separated from her husband and unable to save Vera's son, Lisa is killed in Babi Yar. Here, the unsolved riddles of her hallucinations gain a sinister, tragic meaning. This meaning is not conveyed directly. Instead of Lisa and Kolya another woman and another boy experience what Freud's patient had dreamt of in the carriage where she met the soldier and imaginatively identified him with Freud's son. The significant shift from Lisa and Kolya to another woman and to another boy stresses the horrifying truth of history and lends empathy to the narration.

The text's strong concern for empathy becomes even more evident in the third supplement, apparently a utopian appendix. Somewhere, in a place called 'The Camp,' Lisa meets her mother. In a symbolic action, they suckle each other's breasts. This image does not really assume a primarily homosexual meaning. Rather, the notions of nursing and motherhood are brought up as a counter-image, or even a counter-plot against the dehumanization of all the men who killed women and children in Babi Yar or in one of the many Concentrations Camps erected during World War II. This reading invokes the myth of Demeter, Kore, and their reunion in the Underworld. 
In terms of 'aesthetic bravery,' The White Hotel is much more daring than Freud's Megalomania. Incorporating lyrics, history, and far-reaching ethical considerations, Thomas's novel takes poetry to its extremes. It is intended as a thought experiment that displays the implications inherent in psychoanalytical theory. Theses implications are linked to contemporary history, especially to the cruel politics of 'othering' that paved the way for the holocaust. This is not to say that Rosenfield's anatomy-like narration lacks political relevance. In fact, megalomania is not only present in the scientific world but also in the arena of politics. Nevertheless, the primary focus of Rosenfield is the weakness of any attempt to conceptualize human behavior without taking into account the self-referentiality of human consciousness. By using fiction to deconstruct the myths of both the Freud legend and computer driven neuroscience, his book is concerned with theory (in the broadest sense of the word).

In contrast, Thomas' novel is concerned with problems that cannot be resolved by theory. Neither Freud's theory of desire nor the mythological concept of a death drive make comprehensible what has happened to people like Lisa Erdmann. The cruelty Jewish people had to experience during Freud's lifetime and the years that followed his death in 1939 exceeds any available explanation. Recalling the Shoa and mourning the deaths of millions of innocent people is a task that demands a different attitude and, of course, a verbal practice that transgresses scientific discourse. Whether The White Hotel is considered to be a convincing example of such a practice or not, this novel evidently marks the limits of modern rationality. However, when comparing Thomas' narrative with Freud's Megalomania, one should not underestimate Rosenfield's display. Of course, there is a connection between the misuse of intelligence and the vulnerability of civilization, between the aggressive drive in man and the political will to overcome cruelty. In this respect, Freud's Discomfort of Culture (1930), still, seems to be a work worth reading.

Though psychoanalysis might be a particular case, the way this method is treated in novels like The White Hotel and Freud's Megalomania shows how literature displays scientific knowledge. If this knowledge is already a configuration of information, the plot of these novels can be seen as a reconfiguration or transformation. Of course, some bits of information are only used to set up a frame of reference. However, the plot's main function 
is to question the scientific ordering of information and to run through its implications. So, by the same token, the structure of a scientific theory becomes transparent and contingent, dubious or problematic. To display knowledge, therefore, transgresses the status of information and triggers far-reaching reflections that either might subvert scientific authorities or add alternative readings to their theories. Whereas Israel Rosenfield, himself a skilled researcher, is mainly concerned with the contradictions in Freud's theory or between his findings and the findings in other disciplines, D. M. Thomas confronts knowledge and history, academic discourse, and real events both to stress the importance of psychoanalysis and to mark its boundaries.

\section{Works Cited}

Barthes, Roland. Leçon/Lektion. Französisch und Deutsch. Antrittsvorlesung im Collège de France. Trans. Helmut Scheffel. Frankfurt a. M.: Suhrkamp, 1980.

Burke, Kenneth. A Grammar of Motives. 1945. Berkeley: University of California Press, 1969.

De Chellis Hill, Carol. Henry James' Midnight Song. New York: Poseidon, 1993.

Derrida, Jacques. Of Grammatology. 1967. Baltimore: Johns Hopkins University Press, 1997.

Freud, Sigmund. Bruchstück einer Hysterie-Analyse. 1905. Afterword Stavros Mentzos. Frankfurt a. M.: Fischer, 1993.

-. Das Unbehagen in der Kultur und andere kulturtheoretische Schriften. Introd. Alfred Lorenzer and Bernard Görlich. Frankfurt a. M.: Fischer, 2001.

-. Neue Folge der Vorlesungen zur Einführung in die Psychoanalyse. 1933. Afterword Peter Gay. Frankfurt a. M.: Fischer, 1998.

-. New Introductory Lectures on Psycho-Analysis. 1933. Ed. and trans. James Strachey. Introd. Peter Gay. New York: Norton, 1990.

-, and Josef Breuer. Studien über Hysterie. 1895. Introd. Stavros Mentzos. Frankfurt a. M.: Fischer, 2000.

-, and Josef Breuer. Studies in Hysteria. Trans. Nicola Luckhurst. Introd. Rachel Bowlby. London: Penguin, 2004. 
Goldstein, Kurt. Der Aufbau des Organismus. Einführung in die Biologie unter besonderer Berücksichtigung der Erfahrungen am kranken Menschen. 1934. Ed. Thomas Hoffmann and Frank W. Stahnisch. München: Wilhelm Fink, 2014.

Goodman, Nelson. Ways of Worldmaking. Indianapolis: Hackett, 1978. Iser, Wolfgang. Laurence Sternes 'Tristram Shandy.' Inszenierte Subjektivität. München: Wilhem Fink, 1987.

-. Das Fiktive und das Imaginäre. Perspektiven literarischer Anthropologie. Frankfurt a. M.: Suhrkamp, 1991.

Melville, Herman. Moby-Dick, or the Whale. 1851. London: Penguin, 1994.

Meyer, Nicholas. The Seven-Per-Cent-Solution. Being a Reprint from the Reminiscences of John H. Watson, M.D. New York: Ballantine, 1974.

Pratt, Mary Louise. Towards a Speech Act Theory of Literary Discourse. Bloomington: Indiana University Press, 1977.

Ricoeur, Paul. Zeit und Erzählung. Band I: Zeit und historische Erzählung. 1983. Trans. Rainer Rochlitz. München: Wilhelm Fink, 2007.

Rosenfield, Israel. Das Fremde, das Vertraute und das Vergessene: Anatomie des Bewußtseins. Trans. Sebastian Vogel. Frankfurt a. M.: Fischer, 1999.

-. Freud's Megalomania. New York: W. W. Norton, 2001.

Thomas, D.M. The White Hotel. London: Penguin, 1981.

Waldenfels, Bernard. Antwortregister. Frankfurt a. M.: Suhrkamp, 1994.

White, Hayden. "Historical Emplotment and the Problem of Truth." Probing the Limits of Representation: Nazism and the "Final Solution." Ed. Saul Friedlander. Cambridge: Harvard University Press, 1992. 37-53. 


\title{
Daniel Schäbler The Art of Deception: Knowledge Distribution in English Literature
}

\begin{abstract}
This essay addresses the formal textual realization of knowledge distribution and processes of deception as a special case of discrepant awareness. Case studies of Shakespeare's play Hamlet and Ian McEwan's novel Sweet Tooth serve to conceptualize deceptive relations as a three-way intrafictional communicative act between the deceiver, the deceived, and the audience, primarily designed to catch and entertain the reader's interest. Hamlet also mobilizes the supposedly stable deceptive triangle, so that the structural positions of deceiver and deceived displace each other, resulting in a politically condemning and poetically just view of courtly tactics of the Elizabethan Age as well as of societal power-play on a larger scale. Sweet Tooth employs modes of deception to show that - contrary to official political discourse during the Cold War era - the relation between the epistemological category of truth and the ontological category of reality is an unstable one, governed by the authority which guides the respective formations of knowledge.
\end{abstract}

\section{Introduction: Deception as a Literary Motif}

Based on the well-proven insight that knowledge is power, the following pages seek to explore the question of knowledge distribution in literary texts, focusing on drama and narrative. The predisposition of an individual character is a crucial aspect of plot-analysis. Which character knows what, who knows more than the others, and how can this surplus knowledge be used to the character's advantage? How is this constellation of knowledge dramatized in literature? In fiction and in real life, characters often resort to the act of deception, which constitutes one of the driving forces in history, culture, and more specifically: literature. A closer look reveals how the perspective structure of a text is closely connected with the distribution of knowledge in that text. This raises additional questions: which narrative techniques are advantageous to represent which kinds of deception? Are there historically specific variations in knowledge distribution throughout literary history? Answers to these questions are crucial for the understanding of a fictional narrative or dramatic text. My analysis therefore aims to 
develop a communicative model with which to adequately conceptualize and describe knowledge relations in literary texts. I will thereby focus on a specific motif and relation between characters commonly referred to as deception. Deception is the driving force behind a series of powerful (meta-)narratives running through the fabric of Western culture, from Ulysses' deception of the Cyclops in the Odyssey in Greek mythology, in which the hero repeatedly outwits his opponents, to the elaborate dream-conspiracy in Christopher Nolan's blockbuster movie Inception (2010).

My analysis of deception connects with the aim of this volume to shed light on the relation between knowledge and its literary representation. The argument proceeds in three steps: first, I offer a dynamic communicative model for deception in literature, based on Stempel's and Wolf's ("Schutzironie") model of ironic communication, which I suggest could be called the deception triangle. Next, I will test and validate my model using examples from two different literary periods and genres, namely Shakespeare's Hamlet and the novel Sweet Tooth (2012) by Ian McEwan. I thus aim to offer a selective overview of the diverse forms and functions that the dramatization of deception can fulfil. The model and analysis can of course only provide a first sketch and exploration of a topic which has so far gone virtually unnoticed in literary and cultural studies. Only a few studies dealing with deception exist, and surprisingly none of these theorize the specific configuration of deception in fictional texts and its wider implications for the understanding of literary communication, but rather take the everyday use of the term for granted (cf. Attridge; Thompson; Lynch).

I thus argue that as an age-old literary motif, deception appears to serve three dominant functions. Firstly, it provides engaging plot-twists: the starcrossed lovers who are duped by fate or scheming antagonists, adultery in all its forms and guises, political intrigue at court or in parliament, battle tactics, tricksters and fraudsters all make for good entertainment and serve as catalysts for reflections about the state of humanity and the world in general. Secondly, apart from being entertained, the audience can also be affectively tied into the plot, either as unwitting victim of deception or unobserved accomplice of the deceiver. This in turn heightens the immersive and aesthetic potential of the literary text. Thirdly, deception of readers can also raise interesting metafictional questions, for example about the deceptive power of fiction as a cultural technique. 
Deception as a phenomenon dependent on the distribution of knowledge between text and reader can be classified as a specific case of what in drama theory has been termed as "discrepant awareness." Evans distinguishes three types of "relative awareness of audience and participants [...] available to the dramatist: he can keep the audience less informed than the participants, equally aware with them, or more aware than they" (vii-viii). ${ }^{1}$ Evans applies this concept to Shakespeare's comedies and shows that most of his comedies derive both their dramatic and comic effect from the fact that the audience knows more than the characters. My model is based on the distinctions made by Evans and transposes these on the dynamic shifts within narrative and drama. I aim to show that, as a literary motif and device, deception as a sub-form of discrepant awareness is not limited to comedy but can also play a pivotal role in other genres, text types, and media.

Deception can take on many different forms in various character constellations. The basic setup is that one figure attempts to convince others of facts or manipulate them into actions by means of persuasion and/or providing false information or withholding true information. But as I aim to show, deception does not only unfold on the diegetic level, i.e. on the plot level between characters. It also plays a pivotal role in the relation between reader or audience, author and text: readers too can be deceived by literary characters or narrators themselves, and the author is of course often consciously and directly responsible for the deception. Texts can mislead readers into believing something which is later revealed to be untrue. In this case, the reader takes on the role of the deceived instead of watching characters deceive others or being deceived. My exemplary analysis of the novel Sweet Tooth by Ian McEwan will demonstrate this second case.

\section{Communicative Model of Deception in Literature}

Knowledge distribution between characters in literary texts shall be defined as a formation of power based on language and on concrete actions derived from this discursive power. The configurations and effects of discursive knowledge about specific situations are precisely what constitutes literature

1 On the issue of varying types of awareness, cf. also Pfister (79-87). 
as a privileged site of observation and reflection, in which exemplary worldmodels are imaginatively constructed and put to the test (cf. Horatschek).

Based on a communicative concept of literary texts featuring a sender (author), message (text), and receiver (reader/audience), I would posit a triangular model for deception in literary writing. ${ }^{2}$ This model is primarily applicable to narrative and drama, but also extendable to the medium of film. The model rests on a concept of knowledge transmission and distribution between characters (and thereby also from narrator to the reader) and the consequences this entails in the diegesis. The core criterion and definition of deception is that of an intentional misleading of characters by another character to reach an advantageous goal, which is possible on both the textual and extratextual levels, and which is signalled to the reader during the course of the text. The intentionality of the deceptive act is the key criterion, as for example an unintentional mistake in passing on information or mishearing information can also lead to a transmission or distribution of faulty information, but this cannot be classified as deception. However, the mistakes can well lead to dramatic irony, such as the fatal miscommunication between the two lovers in Shakespeare's Romeo and Juliet. Dramatic irony and deception are structurally analogous in so far as there are three instances involved: the person who creates the irony/the deceiver, the victim of irony/the deceived, and the accomplices/the audience or witnesses, which can either be the reader him- or herself and/or other characters in the fictional world. ${ }^{3}$ From the perspective of the deceiver, the outcome of the deception can either be successful or unsuccessful, or a mixture of both. Uncovered deceptions can be met by counter-deceptions, such as in the elaborate plot-twists of Restoration comedy. ${ }^{4}$ The proposed model of literary deception is dynamic in so far as it can be used to analyze

2 The proposed model is structurally similar to Karl Bühler's "Organon-Model” of communication, comprising sender, receiver, material manifestation and content of the message, cf. Bühler (24-34).

3 My model is derived from Müller's triangular model for ironic communication (2000). On ironic communication, cf. also Stempel and, in continuation of this model, Wolf ("Schutzironie").

4 To cite only one example from William Wycherley's play The Country Wife (1675): the protagonist and notorious rake Harry Horner pretends to be a eunuch so that the husbands of attractive town ladies will not consider him a 
changing situations step-by-step as the text unfolds. Furthermore, it expands to both the intratextual (deceptive relations between characters) as well as extratextual levels (deceptive relations between the author and the reader/audience, whereby this relation is in turn unidirectional as the audience cannot deceive the author), thereby taking into account the fact that a literary text or film in itself can also be part of an artistic deception which goes beyond the willing suspension of disbelief inherent to all fiction.

Taking the specific communicative situation of literary texts into account, the basic layout of these relations is always triangular. Besides the deceiver and the deceived, there is usually an (intrafictional) audience of other characters who know about the deceptive plan and react according to the degree of their awareness. Finally, and most importantly, there is of course the audience or readers of the drama, novel, or film, who constitute the decisive point of convergence of all the knowledge distribution in the text (see Fig. 1).

Fig. 1: Model of Knowledge Distribution in Literary Communication

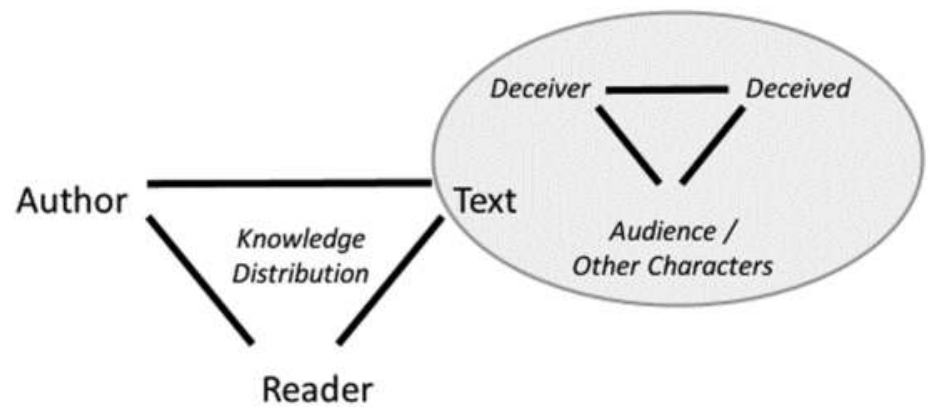

The schematic illustration of the model visualizes the knowledge distribution as black lines and shows how versatile and multidirectional these relations can be. It distinguishes two levels of deceptive communication: in the ellipse on the right, firstly, the intratextual level of deception, which features the deceiver, the deceived, and (optional) other characters, who either witness the deception, somehow know about it, or are in some way affected by

threat and therefore allow him to keep the company of their wives and satisfy his (as well as their) sexual appetite. 
its outcome. Secondly, it features an extratextual level of deception, which extends to the author and the narrator as his or her proxy deceiving the reader by means of withholding crucial information until the very end of the text. On all these levels, the question of knowledge distribution plays a central role so that deception can unfold.

To create an engaging plot, this knowledge distribution in the text is necessarily unbalanced: initially, the deceiver always knows more than the deceived. The audience or readers however always know less at the beginning of a text than at the end, hence the pleasurable curiosity and suspense of engaging with fiction in the first place. During the course of reading the text or watching the film or play, readers tend to acquire more knowledge than all the characters, depending on the perspective structure of the text. For example, in Hamlet the audience is aware of the deceptive plans of the protagonist as well as the counter-deception of his antagonists, Claudius and Polonius, fairly early on. The play facilitates this through the selection and combination of scenes in which the characters reveal crucial information about their plans: Hamlet's planning of the "Mousetrap"-play, with which he hopes to reveal the guilty conscience of his father's murderer, is shown before the actual staging of the play. Likewise, Claudius's plotting of Hamlet's assassination by means of sending him to England is acted out on stage before the audience. Thus, in these examples the knowledge of readers and viewers is at the same level as that of the deceivers, and the pleasure of reception is derived from predicting the outcome and then watching the deception unfold and either succeed or catastrophically fail.

However, in many $20^{\text {th }}$ - and $21^{\text {st }}$-century examples, especially in film but also literature, the audience is not aware of the exact plan of deception, or not even aware that a deception is taking place. For the reader, this induces an element of surprise and affective involvement with the text. Audiences have to decode and interpret subtle clues and surprising plot-twists. One typical example of this second type of deception is the spy narrative, another one the crime story which, together with the intradiegetic deception plot, leaves the audience largely in the dark about how the heist operation will exactly unfold.

I would label the two above mentioned types of knowledge distribution between text and recipients as synchronous and asynchronous knowledge distribution. In the first type, the recipients know as much as all deceivers 
involved, in the second type they only belatedly unravel the deception, either during or after its unfolding. Taking the recipients into the equation and thereby extending the focus beyond the text and plot thus takes into account the dynamic production, transmission, and reception of information in a drama and narrative. In the following, my provisional model will be put to the test by examining the motif of deception in both a dramatic and a narrative text.

\section{Case studies: Deception in Hamlet and Sweet Tooth}

In the long tradition of scholarly debate revolving around Shakespeare's famous play, there is a persistent discussion concerning the true nature of Hamlet's madness. ${ }^{5}$ Some say that he is truly mad, with occasional bouts of sanity, others maintain that he strategically employs simulated madness as a strategy to deceive his opponent Claudius, who assassinated Hamlet's father. ${ }^{6}$ While Claudius's regicide is the ultimate deception - nobody openly suspects him to be responsible for Old Hamlet's death - this act lies temporally before the events of Act I. For this reason, the murder serves as the prehistory, motivation, and context for the unfolding deceptions in Shakespeare's play, but is not an integral part of the action in the play itself.

The unclear ontological status of the father's ghostly appearance at the beginning of the play draws attention to the question of Hamlet's sanity. Although other characters also see the ghost, its words are heard by Hamlet alone. For the purposes of my analysis, I assume that Hamlet is consistently sane and his madness serves the plan to throw his opponents off his trail so that he can exact his revenge on them. Contrary to some other interpretations, my reading expressly excludes the possibility that he is truly mad,

5 The longevity of the debate becomes apparent in an editorial note in an 1864 women's magazine, which announces a new study on "Shakespeare's Characters: Chiefly Those Subordinate." According to the editor, the author of this study asserts that Hamlet is merely acting mad and that "those have read the whole play with very little reflection, who conceive that Shakespeare intended to portray real and not feigned madness in the character of Hamlet" $(1864,247)$.

6 While Qazi and Findlay view Hamlet's madness as a discursive product, Lidz, referring to Sigmund Freud's famous reading, places his madness in the context of psychoanalytical approaches to oedipal neurosis. Bali also assumes a mixture of sanity and madness at work in Hamlet's character. 
because his deliberate actions and logical speeches to his confidantes point to a consistent and rational logic behind them. Apart from the feigned madness there are also other deceptive acts which will be briefly taken into account, namely

1) the "Mousetrap" play Hamlet stages to prove his uncle's guilt

2) the letter Hamlet swapped for his own forged version, thus consigning its bearers, Rosencrantz and Guildenstern, to their deaths

3 ) the poisoned cup and daggers for the final duel, which lead to the deaths of the protagonists.

Each of these intertwined acts of deception rests on deliberately distributed faulty knowledge that induces the victims to unwittingly determine their fate, in all three cases with ultimately catastrophic consequences.

The first case of deception consists of the deceiver, Hamlet, vowing to "put an antic disposition on" (1.5.170) and to thus induce the deceived characters to presume him mad by way of the language and behavior he subsequently displays before them. He swears and insults other characters, especially Ophelia, utters apparently nonsensical phrases, stares wildly about, and neglects his outer appearance (2.1.75-97). Although Hamlet later claims that he is "not in madness but mad in craft" (3.4.185-86), the deception is so convincing that Ophelia exclaims: "O, what a noble mind is here o'erthrown!" (3.1.149). Although not the primarily intended target, Ophelia thus is the main victim of his deception, so much so that after Hamlet's murder of her father Polonius she turns mad herself. In contrast to Hamlet's pun-ridden speeches, Ophelia's madness is conveyed in a semiotic code that is beyond language. She primarily expresses herself through songs and flowers, thus highlighting the difference between deluding and actual madness. ${ }^{7}$ In this context, Lidz maintains that "[w] hereas Shakespeare is ambiguous about the reality of Hamlet's insanity and depicts him as on the border, fluctuating between sanity and madness, he portrays Ophelia as definitely, one might even say classically, insane" (88). But the apparent misogyny of ascribing madness to women is not so

7 On the relation between Ophelia's language and her madness, cf. Findlay's feminist reading (1994). 
clearly cut: rather, Hamlet and Ophelia can be fruitfully read as two ways in which young adults respond to the stifling atmosphere and deadly tactics employed at Elsinore, by cutting loose from traditional communicative systems and establishing a new model of communication, leaving behind the established system of knowledge and power distribution, and thereby claiming and regaining control and autonomy over their own body - in the case of Ophelia - and mind - in the case of Hamlet. Ophelia's madness thus serves as a foil to make Hamlet's madness appear all the more contrived.

Despite or precisely because of his intellect, Hamlet comes dangerously close to the precipice of madness, which he then makes Ophelia topple into. But at the same time, the change of code from sanity to madness also lets Hamlet escape the linguistic rules and established forms of power-play at Elsinore. From his privileged position as an outsider, he is free to take on the role of deceiver in a way that would have been impossible, had he remained within the court's system of linguistic representation.

Meanwhile, the principle targets of the deception remain skeptical: Polonius expresses doubts ("Though this be madness yet there is method in't," 2.2.202-03) and King Claudius is even more clear: "what he spake, though it lacked form a little, was not like madness" (3.1.163-64). Thus, the deception only partially succeeds. While it buys Hamlet some time to first hesitate, then brood and despair, and finally devise and organize further steps against his enemies, the targets of his deception remain unconvinced. This is partly due to several jibes and hints which Hamlet hides in his speeches (to Polonius: “you are a fishmonger. [...] Then I would you were so honest a man” (2.2.171-73). The broken or defective Code which Hamlet uses on his opponents both excludes them from a mutual communication while at the same time sending a message to them on his own terms. As a consequence of the failed deception, Claudius and Polonius plan to send Hamlet away to England because they consider him a threat and hope to thereby calm him down (3.1.168).

In the second instance, the deceiver (Hamlet) inserts information about Claudius's presumed means of murdering Hamlet's father into a play called "The Murder of Gonzago" performed by travelling players: "I'll have these players play something like the murder of my father before mine uncle. I'll observe his looks [...]. The play's the thing wherein I'll catch the conscience 
of the King” (2.2.529-40). ${ }^{8}$ Hamlet here transforms his knowledge about the murder into a new artificial code, the fictional frame and semiotics of a staged play with the aim of disguising his message which has to be decrypted by Claudius, in order to uncover him as the culprit. Hamlet acts as the author of a play-within-a-play, thus meta-dramatically pointing out the parallels between the creation of fiction and the creation of deception.

Because only the culprit could know exactly how Old Hamlet was poisoned, Claudius's abrupt departure from the performance exposes his guilt to Hamlet (3.2.258). The deception here consists of strategically sharing information only the deceiver (Hamlet) and the deceived (Claudius) are privy to, thereby excluding the intrafictional audience, the members of the Court of Elsinore. Claudius is deceived because he as the original deceiver does not expect anyone to share his knowledge and therefore is tricked into giving himself away. The decisive point, however, is that up to the moment of the staging of the play, Claudius is unaware that his regicide has been exposed, and he subsequently becomes suspicious of Hamlet. On the other hand, the deceiver (Hamlet) has also revealed his knowledge of the murder to the murderer, something he clearly intends. The audience of Hamlet however, have synchronously been informed of Hamlet's plan prior to the staging of the play, so it has full knowledge of what happens and why.

While Hamlet's first and second acts of deception involve complex sets of logistics as well as verbal and non-verbal knowledge distribution, the third act of deception works on a purely textual level. Claudius had planned to send Hamlet to England with "letters congruing to that effect the present death of Hamlet. Do it England!” (4.3.62-63). But the supposed victim finds the letter in the purse of one of the two courtiers (5.2.15-24), and turns the deception against the King and his unwitting henchmen: staying behind, Hamlet sends the two alone to England with a new sealed letter which states that "He [the King of England, D.S.] should those bearers [Rosencrantz and Guildenstern, D.S.] put to sudden death" (5.2.46). Claudius's planned murder of Hamlet by means of the letter he would unwittingly deliver into the hands of his killers thus fails due to Hamlet's knowledge of Rosencrantz's and Guildenstern's allegiance to the King. Hamlet subsequently turns the

8 The information about the poison poured into the ear was revealed to him by the ghost of his father in Act I, 1.5.60-70. 
deception around by making the two unsuspecting aides fall prey to exactly the fate intended for him. The play here follows the pattern established in Hamlet's simulated madness: the characters who bear the brunt of his revenge are not his main opponent directly - he is too powerful - but (more or less) innocent bystanders. The Prince's plans thus make the two hapless aides to the King unwittingly "go to't" (5.2.56). The triangular structure of deception devised by the King, whereby Rosencrantz and Guildenstern function as pawns on a chess board, is thus taken up by Hamlet and thrust back at the deceiver, placing a new dyadic relation of counter-deception atop of the earlier one. The knowledge of the reader and audience here are on a par with that of the deceiver and thus superior to that of the deceived.

In Act $\mathrm{V}$, the final plan of deception which unfolds during the supposedly playful duel between Hamlet and Laertes once more follows the established pattern of knowledge distribution, but heightens the complexity of the deception: the setup of poisoned swords and cups of wine is laid out as a premeditated plan for the audience before the fateful event begins (4.7.125-59). Viewers later watch the unravelling of Claudius's and Laertes' plan to kill Hamlet either with Laertes' poisoned sword or by poisoned wine handed to him by the King. First, the Queen unwittingly drinks the wine and then Hamlet, suspecting the plot, swaps swords with Laertes after he himself has been injured by that sword. Subsequently, Laertes is also fatally poisoned.

As far as the distribution of information goes, the audience is again ahead of the deceived and knows more than the various victims and perpetrators of deception. Watching the failure of the murderous deception thus enables the audience, who have become attuned to the deceitful court culture at Elsinore, to try to anticipate and then fully appreciate the both tragic and poetic justice wrought on all of the protagonists at the end of Act V. The retrospective piecing together of the weaknesses of Claudius's plan and how the contingent nature of especially Gertrude's actions initiate its spectacular failure offer a heightened aesthetic and emotional experience for the audience.

The intricate web of deception and counter-deception woven into Hamlet thus reveals the precarious status and power of knowledge: through the introduction of the element of plotting, knowledge can be turned against the powerful and the deceiver can easily become the deceived, as soon as 
new knowledge is created by implementing new codes or elements into the diegesis. Once the "rotten [...] state of Denmark" (1.4.90) comes into the open and the games of deception proliferate, there is no safety for the deceiver anymore: Hamlet falls prey to similar deceptive tactics he has been using all along. The theoretically stable unidirectional thrust of the deceptive triangle - the deceiver wields the power and the deceived is powerless gives way to a dynamic multidirectional movement and creates instability, in which the structural positions of deceiver and deceived are persistently switched. Shakespeare's play thus offers a politically condemning and poetically just view of courtly tactics of the Elizabethan Age as well as of societal power-play on a larger scale.

My analysis now moves on to my contemporary example. After the critical acclaim of Ian McEwan's Atonement (2001), which features a twistending that exposes the whole preceding story as a product of the narrator's imagination, rearranged memories and archive research, the author explores the theme of deception further in his 2012 spy novel Sweet Tooth.

The novel's plot is set in early 1970s England. Up to early adulthood, the homodiegetic narrator Serena Frome - "rhymes with plume" (1), a hint at the invented nature of a nom de plume - shows a talent for mathematics and is admitted to the University of Cambridge, where she soon becomes disenchanted with her subject area. While at Cambridge, she becomes romantically involved with Tony Canning, a middle-aged professor who, before abruptly ending the affair, secures a low-level position for Serena with MI5. A more exciting opportunity appears when Serena is offered a chance to become an agent in a new covert program codenamed "Sweet Tooth." To counter Communist propaganda during the Cold War, the agency wants to offer financial assistance to young writers, academics, and journalists with an anti-Communist agenda. Serena, who is an avid and quick reader of fiction, is given the task of assessing the aspiring writer Tom Haley.

Serena is immediately taken by Haley's published short fiction. She travels to the University of Sussex, where he works, to offer him a stipend from the fictional Freedom International Foundation. Soon the two begin a sexual affair, but things gradually start to unravel. Serena discovers that Professor Canning (who, it turns out, broke off their affair only because he knew he was dying from cancer) was in fact a Soviet spy, and she was recruited because the agency wanted to keep an eye on Canning. Haley's first novel 
is a great critical success, but MI5 is dissatisfied with its dystopian, anticapitalist subtext. Finally, his affair with Serena is exposed by the press, and the whole Sweet Tooth program is publicly disgraced. Serena fears that she has lost Tom's love forever, now he knows she has deceived him all along.

Up to this point, the plot is fairly conventional and combines the spywith the love-plot. As is typical of spy-narratives, the protagonists repeatedly swap the position of deceiver and deceived in the deception triangle throughout the text, with the readers of the novel as the silently observing third party trying to piece together often sketchily asynchronous knowledge offered to them by the narrator. Serena (and the reader) are initially unaware that Tony Canning is a double agent who works for the British Intelligence but was also blackmailed into helping the Russians. This information is only revealed on page 333. Serena thus is both deceiver and deceived: she deceives Tom and is in turn deceived by Tony. For the remainder of this analysis, I want to focus in more detail on how exactly the deception in the closing part of Sweet Tooth is set apart from my previous examples and explain its metafictional implications.

The final plot twist ads a new direction to the well-worn pattern of the spy tale: in a letter to Serena, Tom reveals that he had known about the program for months, and instead of ending the affair, had decided to turn the story into a novel. But his project, in which Haley tells the tale of Serena's deception from his point of view, turns out to be dissatisfying from the beginning. As Tom confesses to Serena: "The problem, I decided, was me. Without thinking, I was presenting myself in the guise of the typical hero of an English comic novel - inept and almost clever, passive, earnest, overexplained, urgently unfunny" (357). The solution, for Tom, is to change his perspective and tell the story from Serena's point of view:

I tried to imagine being you, being in two places at once, loving and ... reporting back. How could I get in there and report back too? And that was it. I saw it. So simple. This story wasn't for me to tell. It was for you. Your job was to report back to me. I had to get out of my skin and into yours. (358)

The reader thus learns that the (intrafictional) author of Sweet Tooth is in fact Tom Haley, despite its being written from Serena's autodiegetic perspective. This is a morally highly ambiguous move - while conducting his relationship with Serena and goading her on, Tom is transforming their lives into fiction: 
I could retreat to the typewriter to describe the moment, from your point of view. Your duplicitous point of view, which would have to include your understanding, your version, of me, lover and Sweet Tooth item. My task was to reconstruct myself through the prism of your consciousness. (359)

In a veritable writing frenzy, Tom completes a preliminary version of the whole Sweet Tooth novel the reader now holds in hand: "I had my material, the wafer of gold, and the motivation to hammer it out. I went at it in a frenzy, more than a hundred thousand words in just over three months" (364). At the close of the letter, Tom asks Serena to marry him. The novel ends before she can respond.

Due to the asynchronous nature of knowledge distribution, readers are left unaware of the true narrator until the very end. ${ }^{9}$ This information was left out at the beginning and throughout the novel. Much like the twistending of Atonement, McEwan's 2012-novel thus too features the narrative device of the missing opening frame. ${ }^{10}$ If the identity of the "true" intrafictional author had been stated right on the first pages of the novel, the narrative situation of a male author telling the tale from the perspective of a female character would have been clear from the start. The whole story would have been placed in a very different context or frame, and thus understood in a different way. As is typical of twist-endings, this results in a surprise effect for the readers. Readers can thus experience as closely as possible what it might feel like to be deceived. Of course, Serena must experience rather more intense emotions after discovering that her lover has turned the tables on her. By means of the narrative device of the missing opening frame, readers are thus affectively drawn into the text and its deception triangle. They no longer only witness intrafictional characters falling prey to various deceptions from a detached audience-perspective, but rather, along with Serena, are revealed to be in the structural position of the deceived. This amounts to a seismic change in the aesthetic experience of

9 As Ksiezopolska argues, there are some hints scattered throughout the novel which point to the fact that the "Serena" who is presented as the narrator is in fact an invention of a male author, such as her style of narration, mathematically precise way of thinking - after all, this novel is set in the early 1970 s - and almost inconceivable all round loveliness.

10 On the structure and implications of this narrative device in McEwan's Atonement, cf. Wolf ("Atonement als Synthese"). 
reading the novel. In the hierarchical position of levels of communication, a logically higher extradiegetic level of deception is added to the deception depicted on the diegetic character level: that of the author deceiving the reader by deliberately withholding information which is belatedly revealed at the very end. The novel demonstrates how reader experience and character experience can be roughly aligned, but can never fully converge. Fiction, it is shown, has the power to seduce and deceive, and the novel not only tells the reader, but rather dramatizes this insight through its narrative structure.

Apart from the metafictional insights as well as the aesthetic and emotional turmoil both the protagonist and the readers may experience at the revelation, the implications of Sweet Tooth also extend into the political realm: as Walker argues, the novel dramatizes a form of "'covert authorship,' a mode of invention reliant on secrecy and deception that, in evoking the conspiratorial sense of plotting, links the manipulations of Cold War politics to narrative manipulation, thus suggesting that the author holds as much potential for control as a spy" (495). Metafictional reflections are thus linked to wider societal issues, raising ethical questions about the relation between trust, authorship, politics, and poetics: in a culture dominated by the Cold War conflict between East and West which was conducted with all means available and on all levels of society, even the seemingly most private realm of emotional and sexual bonds between two individuals proves vulnerable to deception and betrayal. Of course, betrayal in love has been an age-old motif not only in literature, but Sweet Tooth places it in a specific historical context by showing that a politically motivated deception ultimately comes back to haunt the deceiver in an instance of poetic justice. Furthermore, the dramatization of unreliability in the twistending of McEwan's novel points to the intimate bond between author and reader - a relation based on trust and willingness in which the power of knowledge is all too often forgotten until it is brought drastically into the open at the end of the text.

\section{Conclusion}

The two examples scrutinized have shown that deception, as one central outcome of uneven knowledge distribution in drama and fiction, potentially works on three levels: firstly, the diegetic level of character and plot, which 
is the level on which Shakespeare's Hamlet spins its webs of deception. Secondly, the extradiegetic level of narration can also be used to dramatize deception, as seen in McEwan's Sweet Tooth, which metafictionally plays with the reliability of narrators and authors. Thirdly, I have shown that the extradiegetic level on which deception takes place is closely linked to the extratextual level of the reader and author, audience and dramatist. In the case of Sweet Tooth, the two authors - the intrafictional Tom Haley and the extrafictional Ian McEwan - are at the same time hierarchically stratified yet also strangely intertwined and competing for the reader's trust, surprise, and sympathy. ${ }^{11}$ The triple textual voices of Serena, Tom, and ultimately also that of McEwan thus resound together in a metafictional echo chamber, which is made up of the various versions of the "Sweet Tooth" novel: the work in progress authored by Tom, his ventriloquism of Serena's voice, and finally the novel by McEwan the reader holds in his or her hand. Contrary to the official Manichean narrative maintained by political leaders and media during the Cold War with its seemingly clear-cut division between good and evil, Sweet Tooth employs fictional means to show that the relation between the epistemological category of truth and the ontological category of reality is a highly spurious and relative one, and is governed by the perspective or voice who determines these formations of knowledge. While readers think they are viewing the world through Serena's eyes, who is also initially portrayed as the sole deceiver, they are being manipulated into believing this throughout the duration of the novel: the spectator of deception becomes its victim and the deceiver becomes the deceived. In Shakespeare's Hamlet, the audience is made aware of the fact that no character on stage has the moral upper hand, and that even the most carefully devised plan can be foiled by chance or fate. The deceiver can easily become the deceived. Furthermore, the metafictional elements in the texts I have analyzed show how plotting creates additional knowledge, unavailable for the deceived, and thus demonstrate that the authoring of all fiction has a deceptive element to it, as exemplified in Hamlet's staging of the "Mousetrap" play and Tom's writing of the manuscript.

11 Cf. Ksiezopolska (422-426), who draws attention to the striking similarities between McEwan's own early short stories and the ones that Haley writes in Sweet Tooth, which are mostly paraphrased by Serena. 
Although I could here only give a brief and highly selective overview of forms and functions of deception in literary texts, the drama and the novel I have analyzed appear to be indicative of a broader trend in literary history deserving closer scrutiny, namely that most pre-20 $0^{\text {th }}$-century novels (and also plays) represent deception on the diegetic level of plot, whereas late $20^{\text {th }}$ - and $21^{\text {st }}$-century examples, which could easily and very helpfully also be extended to the medium of film, tend to expand their webs of deception onto the extradiegetic level of narration, and thus also take it closer to the realm of the reader/audience. Furthermore, I have demonstrated that conceptualizing deceptive relations in literary texts as a three-way intrafictional communicative act - which takes the form of a triangle of knowledge distribution between the deceiver, the deceived, and the audience - helps to better understand how narrative plots unfold and are driven on, and how they exert their seductive grip on the recipient. The examples have also shown to what - usually dramatic and both positive and negative ends knowledge can be put to use. They demonstrate that the question of knowledge distribution is a central category in literary communication, a phenomenon that has so far been surprisingly neglected in literary studies.

\section{Works Cited}

Anonymous. "Notes and Queries." The Ladies' Repository: A Monthly

Periodical Devoted to Literature, Art, and Religion 24 (1864): 247.

Attridge, John, and Rod Rosenquist, eds. Incredible Modernism: Literature, Trust and Deception. Farnham: Ashgate, 2013.

Bali, Shweta. "Mechanics of Madness in Hamlet, Macbeth and King Lear." Journal of English Studies 9.4 (2014): 81-92.

Bühler, Karl. Sprachtheorie: Die Darstellungsfunktion der Sprache. 1934. Stuttgart: G. Fischer, 1999.

Evans, Bertrand. Shakespeare's Comedies. Oxford: Clarendon, 1960.

Findlay, Alison. "Hamlet: A Document in Madness." New Essays on Hamlet. Ed. Mark Thornton Burnett and John Manning. New York: AMS, 1994. 189-203.

Horatschek, Annegreth. "Die Kartographie der Kultur aus blendender

Nähe." Warum die Geisteswissenschaften Zukunft haben! Ein Beitrag 
zum Wissenschaftsjahr 2007. Ed. Jörg-Dieter Gauger and Günter Rüther. Freiburg: Herder, 2007. 230-41.

Ksiezopolska, Irena. "Turning Tables: Enchantment, Entrapment, and Empowerment in McEwan's Sweet Tooth." Critique: Studies in Contemporary Fiction 56.4 (2015): 415-34.

Lidz, Theodore. Hamlet's Enemy: Madness and Myth in Hamlet. Madison: International University Press, 1975.

Lynch, Jack. Deception and Detection in Eighteenth-Century Britain. Aldershot: Ashgate, 2008.

McEwan, Ian. Atonement. London: Jonathan Cape, 2001.

-. Sweet Tooth. London: Vintage, 2012.

Müller, Harald G. "Ironie." Reallexikon der Deutschen Literaturwissenschaft. Vol. II. Ed. Harald Fricke. Berlin: deGruyter, 2000. 185-89.

Pfister, Manfred. Das Drama: Theorie und Analyse. München: Fink, 1977.

Qazi, Javaid. The Madness of Hamlet. Ann Arbor: UMI, 1978.

Shakespeare, William. Hamlet. Ed. Ann Thompson and Neil Taylor. London: Thomson, 2006. The Arden Shakespeare.

Stempel, Wolf-Dieter. "Ironie als Sprechhandlung." Das Komische. Ed. Wolfgang Preisendanz and Rainer Warning. München: Wilhelm Fink, 1976. 205-35.

Thompson, Peggy. Coyness and Crime in Restoration Comedy: Women's Desire, Deception, and Agency. Lewisburg: Bucknell University Press, 2012.

Walker, Laura Savu. “'A Balance of Power': The Covert Authorship of Ian McEwan's Double Agents in Sweet Tooth." MFS Modern Fiction Studies 61.3 (2015): 493-514.

Wolf, Werner. "Ian McEwans Atonement als Synthese aktueller Trends im englischen Erzählen der Gegenwart.” Sprachkunst 32 (2001): 291-311.

-. “'Schutzironie' als Akzeptanzstrategie für problematische Diskurse: $\mathrm{Zu}$ einer vernachlässigten Nähe erzeugenden Funktion von Ironie.” Irony Revisited: Spurensuche in der englischsprachigen Literatur. Festschrift für Wolfgang G. Müller. Ed. Thomas Honegger, Eva-Maria Orth and Sandra Schwabe. Würzburg: Königshausen \& Neumann, 2007. 27-50. 


\title{
Ann Spangenberg \\ "We are only what we know": Knowledge in David Mitchell's Cloud Atlas (2004)
}

\begin{abstract}
This essay is concerned with a postmodern version of the literary critique of timeless truths. Cloud Atlas's fictional presentation of six different socio-historical settings with different belief and media systems are presented as an exploration of a cross-culturally pervasive human hunger for knowledge and domination. The text attempts to pry apart the perilous conjunction between the desire for power and that for knowledge in order to sound out possibilities for the advancement of scientific and technological knowledge and a higher level of civilization, in the sense of longer, more peaceful and comfortable lives and more justice and equality.
\end{abstract}

\section{Introduction}

Knowledge is one of the central themes in David Mitchell's novel Cloud Atlas. Published in 2004 to largely very positive reviews, the novel is strongly concerned with epistemological questions. As is typical of postmodern novels, Mitchell's text problematizes the notion of universal and timeless truths. Structured into six episodes set in different eras and covering different types of society, the novel shows that what is considered as knowledge and how it is legitimized differs widely. It considers questions of how knowledge and specific cultural and media conditions relate to each other and in which ways/to which extent the discourses individuals are socialized into determine what they know. Connected to this are reflections, typical of historiographic metafiction, concerning the difficulties of reconstructing the past and of transmitting knowledge into the future.

Cloud Atlas specifically traces the relationship of knowledge and power. The text follows a Foucauldian notion of individuals being produced by the structures and rules of the society they live in, in which structures of power and discourses of truth mutually produce and reinforce each other (Foucault, Power/Knowledge 93, 98). Therefore, discourses of truth are also ruled by power, and power needs ideas of what is true, of what counts as knowledge to work: 
There can be no possible exercise of power without a certain economy of discourses of truth which operates through and on the basis of this association. We are subjected to the production of truth through power and we cannot exercise power except through the production of truth. (Foucault, Power/Knowledge 93)

In this context, the question is not that of the freedom of the subject with regard to the power system. Rather, "the subject who knows, the objects to be known and the modalities of knowledge must be regarded as so many effects of these fundamental implications of power-knowledge and their historical transformations" (Foucault, Discipline 27-28). Mitchell's novel emphasizes this by depicting even those figures who are most empowered to gain and control knowledge as products of the power/knowledge system of their specific society.

Yet, the novel also breaks with postmodern notions of the constructedness of the individual by assuming that there is one inbuilt drive which is central to humanity: a "hunger in the hearts o' humans, [...], a hunger for more" (286, see also: 199, 508-09). As Cloud Atlas demonstrates again and again, this hunger especially means a hunger for power and knowledge (e.g. 286,462 ), which is both a means of survival, or, more than that, intellectual as well as material growth, and potential self-destruction. Thus, the text questions the connection of the advancement of scientific and technological knowledge and a higher level of civilization, in the sense of longer, more peaceful and comfortable lives and more justice and equality.

In the text's six episodes, a higher level of scientific and technological knowledge leads to more wide-ranging exclusion and the exploitation of parts of the population which lack power and often knowledge, as well as finally to the collapse of civilization. Only some traditional societies and small, ecologically-minded communities on the margins of modern societies are portrayed as being largely content with their level of power and knowledge and as fairly peaceful. Yet they are constantly in danger of being destroyed and mostly lack the benefits societies focused on reaching higher levels of scientific and technological knowledge offer to parts of the population, such as longer and more comfortable lives. On the whole, Cloud Atlas does not advocate a turn away from quests for knowledge or romanticize the lack or loss of scientific or technological know-how. It rather explores whether there is anything which might counter the dangerous conjunction of the desire for power and that for knowledge. In this 
context, the text asks for the individual's scope for agency and for acting ethically, in contrast to simply following the hunger for more and gathering ever more power and knowledge to exploit others. With regard to society, Cloud Atlas poses the questions of what can replace the model of humanity's advancement through progress and especially of how to harness - to tone down or channel into positive expressions - the equally enabling and destructive "hunger for more."

\section{Knowledge as a Theme in Cloud Atlas}

Knowledge as a theme runs through all of the episodes of Mitchell's novel, revolving around the following set of questions: what determines what is seen as knowledge in specific societies and do different concepts of knowledge enable people to make sense of their world equally well? How does the connection of past, present, and future work, and how accurately are facts transmitted through time? Which effects does the advancement of academic and technological knowledge have? In which forms is knowledge tied to power structures and used in a systematic manner - politically, economically, academically - to exploit others (specific groups of the population, people from other cultures)? This is complemented by the individual use and in the novel very often abuse - of knowledge.

The novel begins in the $19^{\text {th }}$ century and portrays the journey of the American notary Adam Ewing in the Pacific where he encounters the effect of colonization first-hand. With regard to knowledge, this episode deals with the different ways knowledge is constructed by different societies - here Western societies and the traditional societies in which the natives Ewing encounters live. Further themes are the abuse of superior technological and academic knowledge in the form of the exploitation of the natives, the loss of knowledge, here affecting the tribes whose knowledge of their past is destroyed, and the question of using one's specific knowledge and position of power responsibly or not, as Adam Ewing is being poisoned by a greedy doctor who pretends to cure him.

The second episode is set in the 1930s and tells the story of the young English composer Robert Frobisher who breaks off his studies at a Cambridge College, goes to Belgium to become the amanuensis of the famous composer Vyvyan Ayrs and kills himself after having composed what he 
believes to be the great work of his life. Here great achievements of civilized culture - Ayrs' and Frobisher's art - are contrasted with the catastrophe of civilized culture that is the First World War, showing that technological and scientific advancement as well as cultural refinement do not necessarily lead to a more peaceful world. Moreover, the episode focuses on the power games between Frobisher and Ayrs who each try to play off what they see as their knowledge of the situation and their power - e.g. as an established composer vs. an unknown but inspired one - against each other.

A young journalist, Luisa Rey, is the protagonist of the third story set in the 1970s. At great personal risk, she makes public the dangers connected to a new kind of nuclear reactor while the corporation which wants to build this reactor tries very hard to suppress the publication of this knowledge. This story centers on the growing dangers for humanity connected to an advancement of technology, i.e. nuclear power and its risks. These risks are augmented by the political system being undermined by economic interests, a continuation of the tendencies already apparent in episode one. While it is individuals who exploit their knowledge about the Hydra nuclear reactor for their profit, their ability to do so is due to a fault inherent in the political and economic system portrayed.

The fourth story is set in the near future and centers on the vanity publisher Timothy Cavendish who, against his wishes, finds himself in an old people's home and desperately tries to escape from this institution. This episode deals less explicitly with the power structures of society than episodes one and three. It instead concentrates on the workings of power and knowledge on the individual level, as Cavendish is completely cut off from information about the outside world and a powerless prisoner in the old people's home. Though Timothy's case represents an extreme, this abuse of power again seems to be inbuilt in the political and economic system, which removes members who become useless from its midst, while at the same time profiting from them as much as possible (Timothy's relatives pay for his stay at the old people's home). ${ }^{1}$

1 This also serves as a transition to episode five. In episode four, the production of human clones who are at the center of the following episode, is mentioned in passing and one of the themes of the episode is prefigured: the treatment of ageing and less productive people is found in a much more radical form in 
The novel moves on to a more distant future in the fifth episode. Here, the world has mostly become uninhabitable because of environmental destruction, and the remaining inhabitable zones are ruled by powerful corporations that rigidly control all access to knowledge. In the zone at the center of this episode, Nea So Copros, the tendencies apparent especially in episode one and three have culminated in the fusion of politics and economy. Nea So Copros strictly regulates which group of the population is allowed to know what and employs its own version of a 1984-like Newspeak. Again, this episode shows that a higher degree of technology does not lead to a better life for everybody, as parts of the population have comfortable lives but are constantly being misinformed, while other groups - immigrants and clones (called fabricants) - are exploited and have short and uncomfortable lives. The episode focuses on how the fabricant Sonmi 451 is brought into being by knowledge (technological knowledge about cloning) and how all her individual knowledge is socially constructed.

The final episode portrays a future where modern-day states have collapsed and only small communities remain, which have lost most of modern technology. One of these communities, the Valleysmen, live in a fairly peaceful and, in comparison to most other societies in the novel, exploitation-free way, illustrating again that higher technological progress does not necessarily lead to societies characterized by more justice. This episode shows that knowledge can be legitimized differently, as the Valleysmen have a magical worldview as opposed to the empirical and scientific one of the modern societies portrayed in the novel. However, this way of looking at the world seems as true and adequate to its adherents as a scientific one to members of the modern societies portrayed in Cloud Atlas.

The novel undercuts the notion of historical progress, not only by depicting the break-down of civilization but also through its circular form. Except for episode six, all episodes are divided in two. In the first half of the novel, the episodes are arranged chronologically with episode six at the end, while in the second half of the novel the episodes are arranged in reverse chronology, thus ending with the beginning. The form of the novel moreover contributes to the discussion of knowledge, as the ways, in which

episode five, as these clones are killed after twelve years, when they have served their purpose. 
the episodes are narrated, represent different forms of knowledge. They are each narrated through different media, comprising oral narratives as well as written texts, thereby tracing the transformation and transmission of narrative through time in the context of a cultural history of the media (Breidenbach 196-98). The first episode takes the form of a diary (later on published as a book), the second that of letters, the third is a novel, the fourth an autobiography made into a film, the fifth an interview stored in audiovisual form in a futuristic technological device called an orison, and the sixth an oral narrative. All of these intradiegetic texts are found by the protagonists in later episodes, connecting the different episodes and also - by the way they are received and used by the characters who find them - showing different ways of dealing with written relics from the past and also proving how little is transmitted into the future. Questions of knowledge are thus pervasive in Cloud Atlas, as the novel looks at vastly different kinds and forms of knowledge.

\section{Knowledge and Power in Cloud Atlas}

Knowledge and power are omnipresent in Cloud Atlas and connected in different ways. The dictum "knowledge is power" certainly holds true for the novel. One connection consists in the control of knowledge by power and the reinforcement of power through knowledge. The power gained by the control of knowledge is spelled out clearly in "An Orison of Sonmi 451" (episode five) where the hierarchical structure of the state is based on differences in knowledge (e.g. about the world, the past or the state's social practices). As Sonmi 451 realizes in the course of her self-education at university: "What if the differences between social strata stem not from genomics or inherent excellence or even dollars, but differences in knowledge?' [...] '[W]ould this not mean that the whole Pyramid [the social organization of Nea So Copros] is built on shifting sands?'” (231).

The power of controlling knowledge is furthermore exemplified by the corporations in the two episodes "An Orison of Sonmi 451" and "Half Lives - The First Luisa Rey Mystery". In both episodes, the corporations keep vital information secret: Nea So Copros tries to suppress the truth about its treatment of fabricants, e.g. their slaughter after twelve years (360), just as in the "Half Lives"-episode, the corporation "Seaboard" 
attempts to hide the facts about the dangers of the Hydra nuclear reactor, even resorting to assassination (e.g. 113-14). The importance of secrets to hold on to power is not restricted to corporations, as in "An Orison" the different faculties of Nea So Copros' university fight against each other for power by using intrigues, causing a character to state: "Secrets are magic bullets" (242). On an individual level, the power of secrets is elaborated on in "Letters from Zedelghem": the young composer Robert Frobisher retains a sense of power and superiority through gaining the post of amanuensis to the famous composer Vyvyan Ayrs by trickery and secretly becoming the lover of Ayrs' wife. However, in a turn reminiscent of The Draughtsman's Contract, in the end it becomes clear that Ayrs and his family - backed by their powerful social position and experience in manipulating others tricked Frobisher and now threaten to ruin his reputation and his chances of ever becoming a recognized composer (475). As both men create some of the most acclaimed works of art of their time but are presented as being dishonest and exploitative, the novel does not only question technological and scientific progress. It also shows that cultural, in this case artistic, achievement, is not automatically linked to more ethical ways of acting on the individual level and, as their way of acting is not depicted as something out of the ordinary, on the level of society on the whole.

Throughout the novel, secrets are portrayed as part of the human makeup, and, as such, are not always destructive. One example of that is that shortly after her "ascension," Sonmi 451's colleague Yoona 939 discovers a "hidden" room, a broom closet, in the diner where they live and work, which contains forgotten items, such as a book of fairy tales which she takes to represent the outside world. She feels empowered by her secret which helps her towards filling her need to gain a sense of self (196-98).

In addition to the power of keeping knowledge secret, there is a much more straightforward connection of knowledge and power in Mitchell's novel, i.e. in the form of technological knowledge, especially weapons' technology, which e.g. allows a more violent enemy tribe to conquer the Valleysmen (307-08). In the Sonmi 451-episode, the corporations can control their citizens because of their industrial technology, and their surveillance technology, e.g. implanted ID chips (e.g. 335), helps them to keep the population under control. In 'The Pacific Journal of Adam Ewing,' the technological knowledge of the missionaries on Raiatea (weapons, buildings 
techniques, amenities to make life more comfortable) ensures their power over the natives (497-98).

On the whole, power and knowledge work in two different ways in Cloud Atlas, on the one hand in the sense of Foucault's analysis of power and knowledge, in the context of which power is seen as "something which circulates" (Foucault, Power/Knowledge 98) and is never localized anywhere (Wolfreys 197) and on the other hand as the result of a biologically based human drive for more. The connections of power and knowledge which structure society and are beyond the control of the individual are demonstrated in the novel in different ways. For example, the exercise of power over the native populations of the Pacific is justified by what is seen as scientific knowledge, as truth: the superiority of the white race and the various degrees of inferiority of the other races (e.g. 506-08 "The Horrox Ladder of Civilization"). And, as the novel makes clear, those who use power in this way often act according to what they think is true and rightful, like the missionaries on Raiatea $(498,501)$. The same is true for the staff in the old people's home where Timothy Cavendish is kept ("The woman was sincere - bigots mostly are - but no less dangerous for that [...]" [403]). Here, the nurses act in keeping with normalizing discourses (Foucault, Discipline 184). The novel shows how “Aurora House" produces "old people", not only by making their difference (especially a slowness and confusion about the modern world) more visible through medical examination but also by heightening or bringing about their deviation from what is considered as normal. To bring this about they are infantilized by denying them meaningful mental or physical exercise (e.g. 372-73).

In the "Sonmi 451"-episode, the university, a place especially associated with the search for truth, is structured through discourses of power, as it is dominated by the Unanimity Faculty (242), Unanimity being the corporation which rules Nea So Copros. Moreover, the university is characterized by the faculties which are most relevant in Nea So Copros, i.e. those concerned with genetics (e.g. the Faculty of Genome Surgery and the Faculty of Psychogenomics, 214). Here truths are produced which justify the division of the population into humans and fabricants (human and non-human) as well as in different social strata (the superiority of those who are genetically enhanced and therefore have a right to higher positions in society (231, 237). This exemplifies that " $[\mathrm{d}]$ isciplines of knowledge always divide the 
human population into distinct categories that are one of the prime instruments of power" (Mansfield 59).

In contrast to the workings of power described above, Cloud Atlas also posits an apparently transcultural "hunger for more" $(199,286,508-09)$, which enables material, cultural and technological advances and the development of civilization, but, in the form of a ruthless rule of the strongest, is also the means of humanity's self-destruction, leading to the "Fall" which has preceded episode six. The ambivalent result of the human "hunger for more" is summed up by one of the characters in "Letters from Zedelghem": "Our will to power, our science, and those v. [sic] faculties that elevated us from apes, to savages, to modern man, are the same faculties that'll snuff out Homo sapiens before this [the $20^{\text {th }}$ ] century is out!" $(462$, cf. 286).

The novel gives many examples of the destructive aspect of knowledge as a result of the human "hunger for more," as knowledge is depicted as a central means of ascertaining and furthering the power of individuals and as shown above - of ruling elites. Greedy individuals - who often openly adhere to a belief of the right of the strongest to rule - take advantage of power and knowledge offered to them (131-32, 508). In “The Pacific Journal,", many of the people Adam Ewing meets are seeking their own gain, are willing to exploit, lie to or kill others. Examples of this are Dr. Goose who befriends Ewing, only to poison him to steal his money, or the captain of the Prophetess and his mate who are only interested in their gain, consequently mistreat and exploit their crew and lie to the missionaries on Raiatea. In "Half-Lives - The First Luisa Rey Mystery" Alberto Grimaldi, the Chairman of Seaboard, is willing to do anything to keep his power but is in turn killed by an equally ruthless rival (408-10).

However, the "hunger for more" and a drive for knowledge are not always negative, as they might be used for the improvement of society and for a search for truth, even if, in the context of the novel as a whole,

2 The Nietzschean term "will to power" is repeatedly used in the novel, especially in connection with humanity's being in danger of bringing about its selfdestruction (see also 131-32, 462). It can be defined in the following way: "All driving force, for Nietzsche, is to be understood as 'will to power' [...]. On this level, will to power refers to the desire every living thing has to grow, expand, and develop [...]." It does not necessarily involve the need to dominate others but often entails relations of command and obedience (Ansell-Pearson 47-50). 
truth remains elusive and is never ultimately confirmed: what is seen as truth, depends on society, the individual and often on chance. The positive evaluation of a search for truth which is not motivated by a search for power is expressed in the following exchange between Adam and Meronym: "Then the true true is diff'rent from the seemin' true?" said I [Zachry]. "Yay, an' it usually is, I mem'ry Meronym sayin', an' that's why true true is presher'n'rarer'n diamonds" (288) or, in Adam Ewing' musings, which express a modernist belief in a "truer," yet elusive Truth: "As many truths as men. Occasionally, I glimpse a truer Truth, hiding in imperfect simulacrums of itself, but as I approach, it bestirs itself \& moves deeper into the thorny swamp of dissent" (17). Sonmi 451's ascension, her quest for as much knowledge and for gaining access to as much truth as possible is shown as positive as well, even though it is revealed that she was betrayed from the beginning. Yet, the insights she acquires possibly exceed what Unanimity had planned and allow her to envision "a further endgame" (364), a vision which seems to become true as she turns out to have become the goddess of the peaceful Valleysmen.

\section{The Social Construction of Knowledge}

Throughout his novel, Mitchell traces the question of how what can be known and what is considered as knowledge is determined by the society an individual lives in. This is most evident in episode five, the story of Sonmi 451. It is brimming with references to classical dystopian novels like George Orwell's 1984 or - as the name of the protagonist indicates Ray Bradbury's Fahrenheit 451 while sharing many of its concerns with contemporary ones, such as Margaret Atwood's MaddAddam trilogy or Larissa Lai's Salt Fish Girl. As the protagonist Sonmi 451 is a clone who is literally brought into being by her society's technological knowledge and all of what she knows is carefully regulated by the state she lives in, the novel's theme of how the individual is brought into being by society is most pronounced in this episode. It centers on how this process is tied to the kind of knowledge (technologically/academically) a society has, what it sees as knowledge and how access to this knowledge is regulated. That this theme is most prominent in episode five is only fitting, as it is the final episode before civilization collapses: the developments already apparent in 
the first episode, especially capitalist practices and the systematic exclusion and exploitation of specific groups of people (based on ethnicity, class, gender or age), culminate here. ${ }^{3}$

The story is set in the society of Nea So Copros, formerly Korea, which is now ruled by a corporation, Unanimity. Nea So Copros is a strongly hierarchical society which strictly controls and regulates the country's people. Capitalism has reached a stage where it has become a "super-discourse," governing all aspects of society, politics and religion. Thus, the concept of the "citizen" has been replaced by that of the consumer $(189,190)$, and religion has turned into a literal worship of money as the "Soul" has become an implant which serves as ID and credit card and people "genuflect [...] to the dollar" (196). Access to knowledge is tightly controlled and especially the lowest-ranking inhabitants, the enslaved fabricants, are fed only a very rudimentary image of the world. Consumers easily accept this as they are socialized into Nea So Copros' strictly hierarchical conception of society (e.g. 194, 231, 331-32) and profit from the fabricants' cheap labor. Consumers are kept in the dark about many of Nea So Copros' practices, not only concerning the clones. Even the archivist who records the story of Sonmi 451 has hardly any knowledge of the fabricants' slavery and of any form of opposition to Nea So Copros' totalitarian regime (e.g. 360, 364).

How the self and its knowledge of the world are socially shaped is primarily shown through Sonmi 451, a server at a fast-food restaurant called Papa Song's. The fabricants spend their whole life at the diner, are only taught enough words to be able to serve fast-food and to believe that the "Logoman" of their company, Papa Song, is God, whom they have to obey to reach Xultation - paradise - after twelve years (190). They are kept from learning or questioning by their genetic makeup and by eating drugged food (205). Except for Sonmi 451 and one of her colleagues whose "ascension" (191) - their development of a thirst for knowledge and

3 This begins in episode one when $19^{\text {th }}$-century colonialism is shown as being primarily driven by "capitalist interest in financial gain" (Bayer 352) and the natives are inscribed with "Western consumer culture" (Dimovitz 72). In "Halflives - The First Luisa Rey Mystery," corporations have already gained a great degree of power (443), a tendency which becomes even stronger in "An Orison of Sonmi 451," where the world is ruled by corporations. 
learning - is triggered by changing the chemical components of their food, all their colleagues unquestioningly accept the limits of their knowledge. Sonmi 451 believes that the hunger for knowledge is a central proof of her humanity and was only suppressed by the composition of her food (191).

Though she is driven by a ferocious hunger for knowledge - about herself, the society she lives in and the world in general - and the story takes the form of a quest for truth and autonomy, her entire experience turns out to be part of Nea So Copros' careful management of knowledge: in a 1984-like twist, Sonmi 451 reveals to the archivist who records her story her realization that her "ascension" and flight through Nea So Copros were a carefully staged propaganda ploy. She assumes its purpose was to unite the human population against the fabricants and - through involving an opposition to Nea So Copros' regime called Union - to provide "Nea So Copros with the enemy required by any hierarchical state for social cohesion” (364). Thus Sonmi 451 realizes that she never escaped from being shaped by the state and that "[f]ree will plays no part" in her story (364).

The theme of how the society we live in determines what we know and what we consider as knowledge is also shown in the novel by pitting against each other very different kinds of society with different worldviews and different media systems. Here Cloud Atlas primarily contrasts modern Western societies as they emerged since the Renaissance and especially during the Enlightenment and traditional, small-scale societies. The latter appear in the novel mainly in the first episode as the native population subjugated by Western colonizers and as the Valleysmen in episode six. The societies resembling the modern Western model are based on the assumption of an autonomous, rational individual who relies on him- or herself, not on authorities, and whose perceptions and judgments are strongly based on the empirical. Moreover, these societies are cultures of distance determined by the written, audiovisual or digital recording of communications which do not require the bodily presence of communicators (Kley 47-50). They are contrasted to cultures of proximity, predominately oral cultures, made up of small communities, which need bodily presence and mutual acquaintance for communication. Here, shared cultural knowledge is valued over the individual's interpretation of the world. In the novel, these societies have a magic conception of the world and ascribe truth and knowledge to 
metaphysical entities whose intervention serves as an explanation of the world and of natural phenomena.

While the societies which work more or less according to the principles of modern Western societies are dominant in the first five of the novel's six episodes, in the sixth episode, all the modern societies have collapsed and there is a return of traditional communities which coincides with a return to oral narratives. In the novel, it is shown that different approaches to constructing the world and to legitimizing knowledge might work equally well. The prime examples of this are Adam Ewing, the notary of the first episode, and Zachry, a member of the tribe of the Valleysmen in episode six, who relate a similar experience, but make sense of it in very different terms: Ewing by explaining everything rationally, Zachry by taking recourse to supernatural entities.

Ewing has set out on an excursion to scale a hill which will give him a view of Chatham Isle. He feels completely cut off from civilization, even his watch has stopped. ${ }^{4}$ The situation he finds himself in is unfamiliar, sights and sounds are turning uncanny. Instead of ascribing those sights and sounds to ghosts or other supernatural phenomena, however, he immediately rationalizes his experiences and finds natural explanations:

I was circumambulating the crater's lip, seeking a clearer trail back to Ocean Bay, when a startling hoo-roosh! Sent me diving to the ground: - the mind abhors a vacancy $\&$ is wont to people it with phantoms, thus I glimpsed first a trusked hog charging, then a Maori warrior, spear held aloft, his face inscribed with the ancestral hatred of his race. 'Twas but a mollyhawk, wings 'flupping' the air like a wind jammer. (19)

When Ewing hears a strange hum, he traces it back to its source and finds out that it was only flies drawn to excrements (21), and when he thinks he sees a human heart hanging in a tree which seems to pulse as if alive, he immediately discards this as unlikely and investigates what it might really be (21). In a similar manner Ewing immediately discounts a confused dream he has after falling into a hole and being knocked out. Though he takes recourse to a supernatural entity by thanking God for having survived the

4 The importance of clock time for modern society is stressed in the episode "Sloosha's Crossing” (257), where the Valleysmen's last watch is carefully preserved in the school-house. 
fall, this does not affect his approach to the world, as he quickly deduces from the dendroglyphs (tree carvings made by a tribe who had lived in that area) that there has to be a way out of the hole (20).

Ewing's empirical and rationalizing approach to the world is contrasted to Zachry's magical view of the world, which in the context of his narration, however, is as successful for establishing explanations of the events and making meaning of the world as Ewing's: Zachry finds explanations for good or bad occurrences or for natural phenomena by tracing them to supernatural entities. For him nature is animate, e.g. he hears a bird talk to him (251). When Zachry finds himself alone in the woods - as Adam Ewing does in the first episode - he encounters Old Georgie, the Valleysmen's version of the devil. For the implied reader (who presumably has an empirical view of the world) a plausible explanation presents itself by the appearance of a bird, which is again in parallel to the Adam Ewing episode. Later on, in the episode Zachry - similarly to Adam Ewing - climbs a volcano, Mauna Kea on Hawaii, which is very dangerous for the Valleysmen (282-96). In this extraordinary situation, he encounters Old Georgie once more and sees ghosts. Rational explanations as delivered by his travelling companion Meronym, a member of a group called the Prescients who have retained the knowledge of the time before the break-down of the modern world, do not change his perception of the situation (292). Though Zachry realizes that Meronym has greater worldly knowledge, he still thinks that his own approach yields, in the end, more relevant knowledge, as Meronym does not know much about what really matters: "See, [...] Meronym knows a lot 'bout Smart an' life but Valleysmen know more 'bout death" (288).

In contrasting Ewing's and Zachry's perception of the world, Cloud Atlas argues that what is seen as real and true and what counts as knowledge of the world actually depends on cultural context. For the Valleysmen the belief in their Goddess Sonmi and in the devil Old Georgie are true. As Meronym states when Zachry wants to know why she keeps her knowledge about society before the "Fall" (the end of modern civilization) to herself: "Valleysmen'd not want to hear [...] Times are you say a person's b'liefs ain't true, they think you're sayin' their lifes ain't true an' their truths ain't true." (287) Here the novel questions the traditional Western belief in the superiority and self-evidence of a worldview based on rationality, as the Valleysmen do make sense of their world, live successfully in it for 
generations and are not eager to take over Meronym's rationalist, agnostic view of the world.

This ties in with Cloud Atlas' doubting the existence of a continuing civilizing process (Mennell 105-07), i.e. a more or less linear progress towards more rationality, improved technological and scientific knowledge, a higher development of art as well as a more peaceful and non-violent way of life. Instead, the novel creates an ambivalent image of human progress. In contrast to the Valleysmen who have a very positive image of the time before the "Fall" and are "oblivious to the events that precipitated the downfall of the civilized and any negative elements of civilized life" (Sims 187), Meronym has access to a greater store of knowledge about the past and is of the opinion - supported by the preceding episodes - that "Old'uns tripped their own Fall" (286):

[They had] more gear, more food, faster speeds, longer lifes, easier lifes, more power, yay [...] Now the Hole World is big but it weren't big 'nuff for that hunger what made Old'uns rip out the skies an' boil up the seas an' poison soil with crazed atoms an' donkey 'bout with rotted seeds so new plagues was borned an' babbits was freakbirthed. (286)

A further difference between modern and traditional societies is that of their media systems, i.e. the contrast between a primarily oral and a primarily written culture. This ties in with another aspect of the question of what we can know in Cloud Atlas, i.e. the question of the transmission of knowledge through time.

\section{The Instability of Knowledge}

The different media through which the episodes of the novel are narrated draw the readers' attention to questions of how knowledge is transmitted, stored for posterity, and decoded by future recipients. This ties in with the theme of the cultural construction of knowledge, as the effort which is placed in transmitting knowledge into the future and the purposes and ways of reconstructing it hinge on the kind of society which does the reconstruction: how a text is read depends on the recipient and on the act of reading. Cloud Atlas demonstrates this by the fact that the second halves of the first five episodes are only "revealed" after one of the characters engages with a text, film, or recording referring to the episode preceding 
it in time and actively searches for the second half of the story. Something can only be transmitted into the future if there is a recipient who engages with it and the transmitted material is "to be consumed, interpreted, and potentially transformed by (or transformative for) its inheritors" (Shoop and Ryan 100).

This does not only hold true for the readers who are described in the novel, but also for the implied readers. Due to the intense inter- and intratextuality of Cloud Atlas, the richness of the readers' experience depends very much on their cultural and literary knowledge, as well as their ability to notice the many connections between the different episodes (O'Donnell 70-83). Though most of the episodes turn out to be fictional accounts "Half-Lives - The First Luisa Rey Mystery" is a novel, Timothy Cavendish's adventure is viewed by Sonmi 451 in the form of a film - readers are "constantly tempted to forget [this] when entering the narrative world of the text and holding on to the narrative contract that says we will accept the world of the novel as a self-contained unit with its own rules" (Dimovitz 84). Therefore it is difficult to keep apart the levels of the novel which are supposed to represent real events - and therefore convey historical knowledge - and those which are fictional, a tendency which becomes even more marked as it is one of the supposedly fictional accounts, the novel about Luisa Rey's adventures, which mirrors the real case of Karen Silkwood who died in a car accident in the 1970s while trying to make public safety problems at the nuclear facility where she worked, and whose story was later on turned into a film. ${ }^{5}$

Mitchell's novel moreover contains the explicit description of numerous reading experiences. With regard to the effect of narratives on future readers, it quickly becomes clear that they often interpret the transmissions from the past in a completely different context from the original one. Thus Sonmi 451 attributes a much greater cultural weight to the film version of Timothy Cavendish's "ghastly ordeal" than this film presumably merited in the time of its creation. Not only does it enable Sonmi 451 to briefly escape into the world of the imagination and experience a rare moment of happiness (365), for her the film is of high value because it allows a glimpse

5 For further examples of the "blurring and questioning the divisions between literary and historical narratives," see McCulloch (146). 
of the past, as usually "any historical discourse" (243) is outlawed in Nea So Copros. Therefore, the film is also opens up a counter-discourse to Nea So Copros' dominant ideology. It allows a glimpse of lost knowledge, e.g. of how aging people looked, by giving "those lost worlds a brief resurrection" (244).

The after-life of Sonmi 451 depicts how the respective present is transformed by its transmission into the future, as Sonmi and her story survive into the future in two ways. In the episode "Sloosha's Crossin" she is venerated as a goddess by the Valleysmen ${ }^{6}$ Their knowledge of her has probably been passed on orally. Independently of that, an orison with her testimony has survived. The two versions of Sonmi 451 are so disparate that Zachry cannot recognize his goddess in the "ghost-girl" talking in the orison, even though Meronym explains the connection between the two (290-91). One generation further into the future, this historical knowledge is lost completely, as the orison is only turned on because it emits sounds and images. Its new function is to serve as entertainment and as an escape from the present (324-25).

This precarious link of past and future, the difficulty of transmitting knowledge, is stressed by the novel in other ways as well. There are several examples which deal with the loss of knowledge of how to decipher recordings from the past, e.g. the tree carvings Adam Ewing finds cannot be decoded anymore because the tribe who made them is nearly extinguished (20). In the story "Sloosha's Crossin'," the Valleysmen are wiped out or enslaved by a neighboring tribe, the Konas, which causes the recordings they make of their lives and collect in a specific place called the "Icon'ry" (270) lose their intelligibility and meaning. Thus, Mitchell's novel emphasizes that sheer chance is involved in the survival of a recording: only because Meronym wanted to study the religion of the Valleysmen does she upload Sonmi 451's story to her orison, thereby enabling Zachry's son to inherit it after Zachry is dead; and only by chance does Frobisher find the second half of the book made from Adam Ewing's diary when looking under his bed.

6 The Valleysmen's social organization with an abbess as their leader is reminiscent of an anti-capitalist, ecologically-oriented community of people who shelter Sonmi 451 for a night and who are also ruled by an abbess (344-49). 
In addition to exemplifying how unstable the links between past and future are, Cloud Atlas contains explicit reflections typical of historiographic metafiction, especially in the "Half Lives"-episode where one of the characters muses on the fact that there are no objective reconstructions of the past and that often it is power which determines the meaning and view of as well as access to the past (as shown in the "Sonmi 451"-episode analyzed above):

The actual past is brittle, ever-dimming + ever more problematic to access + reconstruct: in contrast, the virtual past is malleable, ever-brightening + ever more difficult to circumvent/expose as fraudulent.

The present presses the virtual past into its own service, to lend credence to its mythologies + legitimacy to the imposition of will. Power seeks + is the right to 'landscape' the virtual past. (He who pays the historian calls the tune). (409)

All of this stresses how difficult it is to retain knowledge of the past: the accounts of bygone times are interpreted in the present's frame of reference and according to the interests which dominate the present.

\section{Conclusion}

Cloud Atlas is an extensive meditation on the different forms knowledge can take, the construction of knowledge in different periods and societies, the connection of knowledge and power; how knowledge shapes people's lives as well as determines the quality of their lives. The novel posits a "hunger for more" - especially more power with the help of more knowledge - as the defining human trait, a trait which has the power of ensuring the survival of humanity (through higher technology and a mastery of the world) but also of destruction (abuse of knowledge in connection to a drive for power). It explores the consequences of this dangerous and potentially destructive conjunction on the level of the individual, featuring many characters who use or rather misuse knowledge to gain power. Yet, the novel also explores power and knowledge and the way they mutually depend on each other in a Foucauldian sense, by showing how individuals are produced by the structures and rules of the society they live in. These rules include what counts as knowledge and who has access to how much/what kind of knowledge. The most extreme example can be seen in episode five where it becomes clear that the fabricant Sonmi 451 is in all respects - in her body, mind and 
even her temporary belief in the autonomy of her inner self - a product of the society she lives in. This is not only the case for Sonmi 451, who is at the bottom of the social scale, but also for those higher up in the hierarchy. Their lives are less narrowly circumscribed, allowing them to doubt and exploit some aspects of the power structure of Nea So Copros and of what is presented as truth or relevant knowledge to those placed below them, but they do not generally question their society and the tenets it is built on.

Cloud Atlas casts doubt on the assumption that a higher level of scientific knowledge is necessarily connected to better lives for more people and a more meaningful construction of the world, as - in the world created by the novel - the societies which are least exploitative and destructive are traditional ones or small, ecologically-minded communities on the margins of modern societies. Moreover, in the novel members of traditional societies do not feel a lack of possibilities to explain the world. Their magical worldview enables them to construct the world in a way which is as satisfactory to them as an empirical one is for members of modern societies. In addition, the novel shows that science and empiricism do not necessarily offer greater truths, e.g. when reminding the reader that some theories which were accepted as scientific knowledge at one time, such as the hierarchy of the different races in the $19^{\text {th }}$ century, served as tools of the West to subjugate the rest of the world and were thoroughly discredited as scientific theories later on. However, despite criticizing the assumption of an automatic link of knowledge and progress and despite showing that knowledge can be legitimized differently, the novel does ascribe some benefits to a scientifically and technologically minded worldview: Meronym can heal people Zachry's tribe cannot heal, she can give Zachry information about the world and the past and she can overpower the tribe's enemies with the help of her weapons (278-82, 284-86, 307-08).

Cloud Atlas poses the question of how the seemingly inevitable move towards the self-destruction of society shown in episodes one to six can be countered, i.e. whether the negative aspects of the human drive for more more knowledge to gain more power - can be kept in check. Part of the answer the novel gives is that the drive for knowledge does have a positive side as well, when, e.g., knowledge is sought as part of a search for (an ever elusive) truth and especially with the aim of contributing to aspects of civilization which improve the life of all people (Luisa Rey's search for 
the truth about the Hydra nuclear reactor or Meronym's medical abilities). The positive aspect and usage of knowledge is coupled with a belief in and a hope for a better society, and linked like this, serves as a counterweight to the drive for power. The belief that a better world is possible is made explicit at a strategic point of the novel, namely at its end. The statement made here is thereby invested with great weight, even though it is qualified by the readers' knowledge that the hope expressed here, at the end of the episode set farthest in the past, will not be fulfilled in the future unfolding throughout the novel: "If we believe that humanity may transcend tooth $\&$ claw, [...] if we believe leaders must be just, violence muzzled, power accountable $\&$ the riches of the Earth $\&$ its Oceans shared equitably, such a world will come to pass” (528).

\section{Works Cited}

Ansell-Pearson, Keith. An Introduction to Nietzsche as Political Thinker: The Perfect Nihilist. Cambridge: Cambridge University Press, 1994.

Bayer, Gerd. "Perpetual Apocalypses: David Mitchell's Cloud Atlas and the Absence of Time." Critique: Studies in Contemporary Fiction 56.4 (2015): 345-54.

Breidenbach, Birgit. "Intermedialität und Prä-/Remediation in Text und Kontext: strukturelle, kognitive und kulturhistorische Medialisierungstendenzen in den Romanen David Mitchells." Medialisierung des Erzählens im englischsprachigen Roman der Gegenwart: Theoretischer Bezugsrahmen, Genres und Modellinterpretationen. Ed. Ansgar Nünning and Jan Rupp. Trier: WVT, 2011. 183-202.

Dimovitz, Scott. "The Sound of Silence: Eschatology and the Limits of the World in David Mitchell's Cloud Atlas.” SubStance 44.1 (2015): 71-91.

Foucault, Michel. Discipline and Punish: The Birth of the Prison. New York: Vintage, 1995.

-. Power/Knowledge. Selected Interviews and Other Writings. New York: Pantheon, 1980.

Kley, Antje. Ethik medialer Repräsentation im britischen und US-amerikanischen Roman, 1741-2000. Heidelberg: Winter, 2009.

Mansfield, Nick. Subjectivity: Theories of the Selffrom Freud to Haraway. St Leonards: Allen Unwin, 2000. 
McCulloch, Fiona. Cosmopolitanism in Contemporary British Fiction: Imagined Identities. London: Palgrave Macmillan, 2012.

Mennell, Stephen. "Civilizing Process." Encyclopedia of Social Theory. Vol 1. Ed. George Ritzer. Thousand Oaks: Sage, 2005. 105-07.

Mitchell, David. Cloud Atlas. London: Hodder and Stoughton, 2004.

O'Donnell, Patrick. A Temporary Future: The Fiction of David Mitchell. New York: Bloomsbury, 2015.

Shoop, Casey and Ryan Dermot. "'Gravid with the Ancient Future': Cloud Atlas and the Politics of Big History." SubStance 44.1 (2015): 92-106.

Sims, Christopher A. Tech Anxiety: Artificial Intelligence and Ontological Awakening in Four Science Fiction Novels. Jefferson: MacFarland, 2013.

Wolfreys, Julian. "Power." Critical Keywords in Literary and Cultural Theory. Ed. Julian Wolfreys. Basingstoke: Palgrave Macmillan, 2004. 197-201. 

Jutta Zimmermann

\title{
Eden Robinson's Monkey Beach (2000) as Multi-Narrative: The Dialogic Relation of Indigenous and Western World Views
}

\begin{abstract}
This essay addresses the need to decolonize regimes of knowledge which claim universal and timeless validity. The multinarrative structure of Monkey Beach interweaves Western trauma narrative and Indigenous survival narrative. As a literary manifestation of an Indigenous worldview, the novel engages in knowledge formation as a dialogic process that puts in relation competing yet at the same time entangled views of the world. The text's structure challenges the predominance of Western knowledge production by presenting Indigenous knowledge as more localized, yet at the same time more encompassing than Western scientific approaches. The novel questions the culturally restrictive force of dominant, normative, medically and psychologically defined notions of individual and collective well-being and thus presents decolonization as a process that ensures not only the survival of indigenous cultures but also that of humankind in general.
\end{abstract}

\section{Introduction: Juxtaposition of Western and Indigenous World Views}

Most critics of Eden Robinson's 2000 novel Monkey Beach ${ }^{1}$ in some way or other comment on the protagonist's in-between position between mainstream Canadian and indigenous Haisla culture. Sonu Purhar, for example, notices an opposition between "the ideologies of [the young protagonist's] modern Canadian upbringing" and "the often discordant beliefs of her First Nations heritage" and considers "the juxtaposition of Lisamarie's proximity to, and alienation from, the Haisla spiritual world" as the central theme of the novel (37). Other critics also focus on juxtaposition as the central thematic or structural principle in the novel (Andrews; Lane; Soper-Jones).

In the text, the competing world views are manifest most prominently in the characters' differing views on ghosts and spirits. The presence of

1 All references to this novel will be given as $M B$. 
ghosts squarely puts the action in the realm of the supernatural and thus foregrounds the dividing line between Western knowledge which is based on empirical evidence and Indigenous knowledge which views the relation between human beings and their natural environment in a holistic manner. The Haisla community in the novel is divided on this issue, which suggests that within the Indigenous community mainstream and Indigenous traditions co-exist in a state of tension. The conflict is manifest in the text through the juxtaposition of passages which present the fictional world from the viewpoint of the young narrator-protagonist, Lisamarie Hill, and sections which present knowledge - for example, on the history of the Haisla, or the human heart - from an authorial, seemingly objective viewpoint. At the opening of the novel, the protagonist finds herself in an emotional crisis after her younger brother has gone missing at sea. Lisamarie decides to go looking for him at Monkey Beach, a place where they went as children to look for the mythical B'gwus, a creature half-human, halfwolf. Stories of this creature hold a special place in the community, and as a child, Lisamarie actually had a face to face encounter with the mythical creature. As far back as she can remember, she has been visited upon by supernatural beings, most often by "a little dark man with bright red hair" (MB 18). With time, Lisamarie comes to realize that the appearance of this spirit means that she can foresee death.

The narrative progresses on two time levels alternating between the present and episodes from the past in which Lisamarie's uncle and grandmother figure prominently as mentors who introduce Lisamarie to Haisla culture. The reconstruction of Lisamarie's past life marks an inner process, which comes to completion at Monkey Beach when the protagonist interacts with spirits and is granted a vision in which her brother's death is revealed to her. The vision indicates that Lisamarie has embraced the spiritual tradition of the Haisla and comes to feel "deeply comforted knowing that magical things were still living in the world” (MB 316).

The presence of ghosts and spirits which are presented as real has led critics to subsume the novel under categories such as the Gothic or magic realism. However, as Jennifer Andrews argues, Monkey Beach completely inverts Gothic conventions: “Robinson's text [...] forcefully critiques the traditional association of Aboriginals with what is monstrous. [...] Monkey Beach provides a rich starting point for rethinking what such a 
juxtaposition of concepts might mean [...]" (21-22). Taking a cue from such scholarly comments on the use of juxtaposition in Monkey Beach, the following analysis will show that this structural device is used to create a 'multinarrative,' a narrative that is double-coded and draws on both the Western Gothic as well as Indigenous story-telling traditions to represent knowledge that is particular to Indigenous cultures. Eden Robinson's novel Monkey Beach, I argue, performs a reconnection with and a creative reinvention of Indigenous knowledge in the medium in which Indigenous knowledge is traditionally transmitted: storytelling. In contemporary Indigenous culture, stories do not only transmit a fixed corpus of traditional Indigenous knowledge but, more importantly, they perform the decolonization of Indigenous cultures and thus attest to the survival of Indigenous cultures: "Stories in Indigenous epistemologies are disruptive, sustaining, knowledge producing, and theory-in-action. Stories are decolonization theory in its most natural form" (Sium and Ritskes II).

\section{The Concept of 'Multinarrative'}

In general terms, 'multinarrative' can be defined as an artifact (textual, visual, auditory, but also multimodal) that consists of more than one narrative. Two basic principles are constitutive of a multinarrative: juxtaposition the arrangement of more than one narrative on a horizontal axis - and superposition - the hierarchical relation that exists between different communicative levels of narratives. Juxtaposition implies the syntagmatic combination of equivalent narratives and is typically marked by gaps between paragraphs, episodes, chapters, parts. These gaps constitute the boundary by which the elements juxtaposed emerge as distinct entities. Superposition refers to the hierarchization of narrative levels and thus implies a struggle for control and dominance. The most typical manifestation of superposition are framing techniques that range from the embedding of characters' discourse in narrator's discourse to the embedding of one narrative within another. Such hierarchical relations between narrative levels are central to Mikhail Bakhtin's concept of "dialogicity" or "the dialogic," which is based on the idea that the novel does not merely reflect but also enact social struggles. "The dialogic" - in contrast to monologue - is thought of as social viewpoints competing with each other (259-75). 
Rupert Wegerif has adapted Bakhtin's concept to pedagogy and refers to a "dialogic space" that "opens up when two or more perspectives are held together in tension" (12). Indigenous scholars of pedagogy and philosophy use similar concepts to characterize the particularity of Indigenous world views and to highlight the cultural difference between Western and Indigenous knowledge formation. Willie Ermine's concept of "ethical space" allows for the dialogue of two distinct forms of knowledge that contradict and compete, yet at the same time are in relation with each other:

The space is initially conceptualized by the unwavering construction of difference and diversity between human communities. These are the differences that highlight uniqueness because each entity is moulded from a distinct history, knowledge tradition, philosophy, and social and political reality. With the calculated disconnection through the contrasting of their identities, and the subsequent creation of two solitudes with each claiming their own distinct and autonomous view of the world, a theoretical space between them is opened. (195)

In their study Indian from the Inside: Native American Philosophy and Cultural Renewal, Dennis H. McPherson and J. Douglas Rabb suggest that Indigenous philosophy is built on "polycentrism":

This perspective, this polycentrism, recognizes that we finite human beings can never obtain a God's-eye view, a non-perspectival view, of reality, of philosophical truth. Every view is a view from somewhere. Hence it follows that no one philosophical perspective can ever provide an entirely adequate metaphysical system. $[\ldots]$ no one perspective can contain the whole truth. (20)

Indigenous concepts such as "ethical space" and "polycentrism" suggest that an awareness for the limitations of any one world view is an integral part of Indigenous culture. The multinarrative structure of Monkey Beach can thus be thought of as the literary manifestation of an Indigenous worldview in which knowledge formation is seen as a dialogic process that puts in relation competing yet at the same time entangled views of the world. By engaging Indigenous and Western knowledge in a critical dialogue, the multinarrative performs a decolonizing move as it challenges the predominance of Western knowledge production by presenting Indigenous knowledge as more localized, yet at the same time more encompassing than Western scientific approaches. 


\section{Juxtaposition and Superposition of Western and Indigenous Knowledge Formations}

In Monkey Beach, the multinarrative takes shape even before the novel proper begins. In the paratext, typographical section breaks (consisting of three waves) separate passages from each other and establish juxtaposition as a structural principle. The dedication "for Laura Robinson and Dean Hunt in dreams I hear you laughing and know that you are near" introduces readers to dreaming as a form of perception that puts the dreamer in touch with the dead or with spirits, something that from a Western rational point of view can only be interpreted as a subjective projection of the dreamer. The ensuing epigraph presents a Haisla proverb and thus draws explicitly on Haisla wisdom and traditional knowledge: "It is possible to retaliate against an enemy, But impossible to retaliate against storms." The proverb's 'message' that nature is beyond human control provides a general frame for the novel. Even before the novel opens, the reference to dreams and the Haisla proverb establish an Indigenous voice, a discourse of Indigeneity (cf. Graham and Penny 4), as a context and meta-discourse for the fictional narrative that follows.

Similarly, the opening of the novel proper relies on juxtaposition to relate Indigenous knowledge and mainstream culture. The first section introduces the protagonist Lisamarie Hill as a first-person narrator who finds herself in a state of transition between sleeping and waking:

Six crows sit in our greengage tree. Half-awake, I hear them speak to me in Haisla.

"La'es, they say. La'es, la'es. [...]

La'es - Go down to the bottom of the ocean. The word means something else, but I can't remember what." ( $M B$ 1)

In the ensuing conversation, the protagonist's mother devalues her daughter's suggestion that the birds speak to her:

"Clearly a sign, Lisa," my mother has come up behind me and grips my shoulders, "that you need Prozac." (MB 3)

In nuce, two different conceptions of what counts as knowledge are manifest here. Lisamarie's suggestion that the birds have spoken to her can be taken as an expression of Native spirituality, the mother's response - even if it is made tongue-in-cheek - reflects the mainstream position that a belief 
in ghosts and spirits does not hold up to the standards of rationalism and thus calls for medical or psychological treatment.

At this point, a section break interrupts the narrative. The second passage is marked by a distinct shift in theme and point of view:

Find a map of British Columbia. Point to the middle of the coast. Beneath Alaska, find the Queen Charlotte Islands. Drag your finger across the map across the Hekate Strait to the coast and you should be able to see a large island hugging the coast. [...]

Early in the nineteenth century, Hudson's Bay traders used Tsimshian guides to show them around which is when the names began to get confusing. "Kitamaat" is a Tsimshian word that means people of the falling snow, and that was their name for the main Haisla village. So when the Hudson's Bay traders asked their guides, "Hey, what's that village called?" and the Tsimshian guides said, "Oh, that's Kitamaat." The name got stuck on the official records and the village has been called Kitamaat ever since, even though it really should be called Haisla. (MB 5)

A narrative voice here directly addresses a reader who is imagined as foreign to the region and the world of the Haisla. Historical knowledge on the colonization process and the foregrounding of the ways in which Western representational strategies such as naming and mapping were imposed on Indigenous cultures suggest an extradiegetic authorial narrator who is more widely knowledgeable than the young first-person narrator of the first segment. Considering, however, that Lisamarie at a later stage in the novel does present knowledge about the history of Kitamaat and information about the Haisla language, the second passage can be attributed to her as the narrating I who presents a carefully crafted and orchestrated narrative composed after the completion of the events told. From the perspective of the narrating I, the narrator's younger self, the experiencing I, is a potentially unreliable narrator/focalizer on account of her alienation from Haisla culture (cf. also Lacombe 263-64; Appleford 92).

The juxtaposition of the two opening passages draws attention to the cultural in-betweenness of Lisamarie and establishes a metadiegetic level by which Lisamarie's discourse is put on display. The second passage is superimposed on the first and provides a commentary on the thematic focus of both passages, namely the colonial relation between the Canadian mainstream and Haisla culture. Considering the colonial history of North America, the mother's response indicates the alienation of the Haisla from 
their cultural traditions. The reference to Lisamarie's inability to understand Haisla supports this reading. It is at this early point in the novel that two competing narratives and two competing knowledge formations begin to take shape. The mother's psychological discourse invokes the mainstream attitude towards supernatural beings: ghosts and spirits exist only in dreams or hallucinations; they are figments of the unconscious. Against the backdrop of the second passage and its thematization of colonialism, however, an alternative narrative suggests itself. Within an Indigenous discourse, dreams and visions such as the ones that tell Lisamarie of the impending death of family members are not so much expressions of unconscious desire than manifestations of a spiritual reality that transcends the material world. When Jo-Ann Archibald in her study Indigenous Story-Work expresses her conviction that "dreams can be a source of Indigenous knowledge and that they can provide guidance for Indigenous research methodology" (3), she indicates that dreams and visions are central to constructing Indigeneity as a counter-discourse to Western rationalism with its inherent claim to cultural superiority.

Juxtaposition in Monkey Beach foregrounds the self-reflexive quality of the multinarrative, i.e. its tendency to foreground its dual affiliation to both Western and Indigenous knowledge formations. In the following, the focus will be shifted to the aspect of heteroreference and intertextuality, i.e. the text's references to discourses beyond the literary. In this manner, the novel can be situated within a social struggle that is directed against the mainstream's systematic attempts to discredit and ultimately extinguish the Indigenous knowledge systems which the First Nations consider the source of their cultural survival.

\section{The Novel in Context: Post-residential School Canada}

The novel's most obvious heteroreference is to the residential school experience. Although on the novel's surface this experience seems to play only a marginal role - the protagonist hears bits and pieces about residential school survivors who have difficulties in coping with their lives and managing their anger - it turns out in the end that the residential school trauma has been the motivating force behind the plot. Lisamarie finds a postcard, which suggests that Josh, a friend of their Uncle Mick, raped her brother's 
fiancé Karaoke. The postcard shows a photograph of Josh as a child next to a Catholic priest. Karaoke has replaced the original faces with her own and Josh's, thus confronting Josh with the uncomfortable truth that he, the former victim, has turned into a perpetrator. In the vision granted to Lisamarie at Monkey Beach, she learns that her brother Jimmy took revenge and killed Josh, an act that led to his own drowning. The revelations about Jimmy's revenge at the end of the novel turn the residential school experience into a point of origin to which many of the events can be traced.

By means of this heteroreference, the novel participates in the public debate over residential schools, which were operated in Canada by both government and Christian churches from 1876 to 1996. The debate was initiated in 1990 by Phil Fontaine, then Chief of the Assembly of Manitoba Chiefs. In an interview with CBC, he spoke of the physical and sexual abuse that he had experienced as a student at a residential school run by the Catholic Church. Although individual cases of abuse had been made public before this event, Phil Fontaine's revelation catalyzed an official investigation, which eventually led to the apology of the Canadian government in 2008. In his response to Prime Minister Harper's apology, Phil Fontaine emphasizes the huge impact that the residential school debate had on Canadian society: "Brave survivors, through telling their stories, have stripped white supremacy of its legitimacy" (Mackey 47). This crisis of legitimacy has empowered Indigenous activists and scholars to challenge the mainstream's authority to decide on matters of concern to Indigenous people for whom the healing of individuals and communities was the most pressing issue. An Aboriginal Healing Foundation was founded to look into the lasting effects of the enforced assimilationist politics. Research into the psychological and social effects of enforced assimilation and psychological and sexual abuse at residential schools has marked an important step in the political struggle for the recognition of Indigenous cultures and the traditional forms of knowledge production and transmission. The claim to decolonize Indigenous knowledge production is closely intertwined with the residential school debate. Dian Million's claim for "Indigenism," for example, is articulated in this context. The function of this discourse

is to define ourselves, rather than be defined. That is an active doing, the imagining and revisioning of an Indigenism that is never, never static. We are constantly eluding frames, and bringing our own knowing with us, carefully parsing our 
experiences. It is paramount that we be awake to the potentia, the knowledge in any moment. ("River in Me" 38)

As Million explains, the need for decolonizing Western knowledge formations also affects the trauma discourse which stigmatizes Indigenous survivors as socially deviant. Statistics are used to document the over-representation of Indigenous people in respect to alcoholism, drug abuse, suicide, and domestic violence. Million counters this public image by shifting the perspective to the survival of Indigenous people and the cultural resources which made this survival possible: "Indigenous peoples reached to the lifeaffirming stories of their enduring experience in these place, these places that are inhabited by our ghosts, our spirits of the potentia, the life force itself" ("River in Me" 40). In this context, Million refers to Indigenous knowledge as "ccoming from the heart,' i.e., [...] felt intuitive knowledge rather than any solely rationalized logic" $(41, \mathrm{fn} .2)$. This 'felt' knowledge is conveyed through stories that counter and challenge the way in which 'academic language' represents the residential school trauma.

However, Million does not simply refute the Western academic discourse on trauma. In her view, it has opened a space which allowed the survivors for the first time to give expression to their experience. In speaking out publicly, the survivors needed to break a taboo that is in place in their own tradition, which does not allow for the public exposure of the violence inflicted upon individuals. By her choice of words - survivors rather than victims - Million makes clear, however, that the focus needs to be shifted to the cultural resources and traditions of Canada's First Nations, in particular the ceremonies and rituals of healing that can help individuals and communities to overcome the trauma. In Million's view, “healing is a counter-narrative to victimization and is seen as a pathway to sovereignty in an emancipation narrative" ("Trauma” 161). In the political struggle for decolonization and emancipation, Indigenous scholars first and foremost resist the individualization of the residential school trauma. "Residential schooling," as Jennifer Henderson points out, cannot be treated as an isolated incident since it is "a project fully continuous with the wider colonial project of dispossession and cultural genocide" (66). Lakota psychologist Maria Yellow Horse Braveheart was among the first to point out that Indigenous people in North America suffer from a historical trauma caused by the effects of colonization 
and enforced assimilation (60-76; cf. Castellano). The intergenerational dimension of the trauma requires a communal or "spiritual" approach towards healing in which people make "a connection to something greater than themselves and their individual griefs" (Castellano 26).

Indigenous research on historical trauma and healing is representative of the manifold attempts by Indigenous scholars and activists to reconnect to traditional cultural practices. George Cajete characterizes the core values that Indigenous cultures across North America share:

In contrast to the relatively one-dimensional reductionist NewtonianCartesian [sic] view of Nature, Indians perceived multiple realities in Nature that experienced by our five senses was only one of many possibilities. In such a perceived "multiverse," knowledge could be received directly from animals, plants, and other living and non-living entities. They perceived that animals and plants have ritual ways of behavior that interact with one another. All life and Nature have a "personhood," a sense of purpose and inherent meaning that is expressed in many ways and at all times. (Look 75)

This notion of a multiverse is based on the assumptions that "the natural environment was the essential reality, the "true place of being" and that "Nature is the ground of spiritual reality" (39). This multiverse takes shape in Monkey Beach's multinarrative in contradistinction to the Western trauma discourse which focuses on the effects of trauma on the individual psyche. In the following, I will show how the novel performs the decolonization of the Western trauma discourse and thereby presents Indigenous knowledge as the more encompassing and holistic system.

\section{Monkey Beach as Trauma Narrative}

The novel's non-linear and fragmented structure and, in particular, its movement towards a surprise revelation at the very end, align Monkey Beach with Western trauma narratives as characterized by Roger Luckhurst:

visual and written stories involving trauma have ostentatiously played around with narrative time, disrupting linearity, suspending logical causation, running out of a temporal sequence, working backwards towards the inaugurating traumatic event, or played with belated revelations that retrospectively rewrite narrative significance. (80)

In particular, the last two features are manifest in Monkey Beach. Read from the end, the residential school experience is the point of origin, which 
provides a connection between many of the events narrated, in particular the numerous manifestations of violence (i.e. the domestic violence to which Lisamarie's aunt is subjected, the sexual abuse of children, the rape of Lisamarie by one of her close friends). Jimmy's disappearance, with which the novel opens, turns out to be the result of the murder he commits in retribution for Josh raping Jimmy's fiancé Karaoke. The act of retribution, however, seems misdirected and tragically futile as Josh's deed can be explained as a result of the abuse that he himself was subjected to as a child at residential school. Josh's behavior illustrates the intergenerational dimension of the residential school experience, which leaves the victims incapable of sustaining relationships. The transmission of the trauma is possible because of the taboo against the public exposure of sexual abuse and violence.

The revelation of the sexual abuse of both Josh and Karaoke in the very end leads to a rewriting of the narrative. Once Josh's history of abuse is revealed, the omnipresence of violence in the community appears in a new light. Against the backdrop of Jimmy's act of retribution, the Haisla proverb at the very beginning "It is possible to retaliate against an enemy, But impossible to retaliate against storms” gains significance. In its effects, the residential school experience is compared to a storm, a force against which individuals are powerless. The plot is constructed in such a way as to underline the wisdom of the Haisla proverb. It draws attention to the tragic entanglements that result from the psychological and sexual abuse to which Indigenous children were subjected. The residential school experience is used as a 'synecdochal representation' (Henderson 66) of the much broader historical trauma caused by colonization and enforced assimilation. The protagonist Lisamarie suffers from the traumatic loss of her grandmother and uncle, the two close relatives who taught her about Haisla traditions. Because she shows symptoms such as emotional numbing, indifference to her surroundings and sleepwalking, her parents take her to see a psychotherapist:

Mom picked me up after school, and we went to the hospital [...]. Ms. Jenkins came out and shook Mom's hand, then introduced herself to me. [...] What I tried not to focus on was the thing that was beside her, whispering in her ear. It had no flesh, just tight, thin skin over bones. Its fingers sank into her arms, its legs wrapped around her waist as it clung to her like a baby. [...] I caught a bit of what it was 
saying to her. "... screws her? Do you think he thinks of you? When he puts his hand on your thigh, does he imagine hers? Is he -" [...] "Please," Ms. Jenkins said, [...] "Call me Doris." [...]. "Do you think," she asked me halfway through our first and last session, "that maybe these ghosts you dream about aren't really ghosts, but are your attempt to deal with death?" "No," I said. [...] "Then you believe ghosts exist?" "Yes," I said. [...] "Are you sure?" The thing unwrapped its arms from Ms. Jenkins and drifted across the room, hovering over me. [...] "Yes," my mouth moving by itself [...]. I couldn't take my eyes from it. "Why?" The thing bent its head, its lips near my ear. "For attention, I guess." "Good, this is good, Lisa." [...] While the thing was feeding, I kept seeing Mick's body as Dad pulled it into the boat, Mick's empty eye sockets in his lipless face, the fishing net embedded in his skin. Words came out of my mouth, ones the thing knew Ms. Jenkins wanted to hear, but I was drowning. I yanked myself away, and the thing fled back to Ms. Jenkins. My heart trip-hammered. [...] "Lisa," Ms. Jenkins said quietly, "I think this was a very good session. I'm sure that with a little work, you'll be back to normal in no time. I'm glad we had this talk." My lips smiled. “Thank you. I feel a hundred times better." (MB 272-74)

This scene poses a challenge to Western readers who are tempted to agree with the therapist's thesis that the ghost - or "the thing" as it is referred to by the narrator - is a figment of Lisamarie's imagination. The assumption that the patient suffers from hallucinations as a result of the traumatic losses of her uncle and grandmother complies with both Freudian theory and more recent trauma research. And yet, the scene resists such a reading as it strangely inverts the relation between therapist and patient. 'The thing' feeds on other human beings and thus seems related to B'gwus, the mythical figure of the Haisla about whom Lisamarie has heard stories from her father and grandmother. In the situation, 'the thing' feeds off the fears of the two women. From a Western viewpoint, the novel stands in the Gothic tradition with its long history of representing the unspeakable as ghosts or supernatural forces (cf. Castricano 801). Freud himself drew on this tradition when he first introduced psychoanalysis. He compared the mind of a neurotic patient to a house invaded by foreign elements and explained these ghosts as projections of the unconscious, and as a result of repression (cf. 141-42). Lisamarie's vision of 'the thing' can easily be explained in such a way. The foreknowledge of her uncle's and grandmother's deaths leave her with feelings of repressed guilt that are acted out, for example, in bouts of sleepwalking in which she puts herself in danger thus displaying an unconscious desire to punish herself and to be reunited with the dead. Up to 
the moment when she is confronted with the therapist, Lisamarie views the visions and dreams of the 'little man' from a Western rational viewpoint that she has internalized. However, once she experiences that 'the thing' puts her in a position of power - she knows more about the therapist than the latter knows about herself and can thus manipulate her -, her attitude towards spirits and monsters begins to change. Following her therapy session, she "want[s] the thing to feed on [her] again" ( $M B$ 275), a change of attitude which can be explained by the effect 'the thing' has on Lisamarie: although it puts her in touch with the feelings of guilt she has repressed and that threaten her sense of self - "I was drowning" - it at the same time gives her satisfaction because it helps her to resist and manipulate the therapist.

\section{Monkey Beach as Survival Narrative: The Resurgence of Indigeneity ${ }^{2}$}

The survival narrative emerges and begins to take shape at this point in the narrative. After the therapy session, for the first time Lisamariesp appreciates her foreknowledge: "Until that moment, I had never appreciated the little man. This is, I thought, what it's like for everybody else. Hell, it's bad news. Bam" ( $M B$ 283). The changed attitude towards spirits and ghosts is anticipated by a scene in which Ma-ma-oo tells her granddaughter that ghosts are nothing to be afraid of: "You don't have to be scared of things you don't understand. They're just ghosts” (MB 265). Lisamarie's transformation culminates in the end when she is granted a vision. Upon arrival at Monkey Beach, she offers the spirits her own blood in exchange for information about her brother's whereabouts. Earlier, after her friend Cheese had raped her, the spirits asked her for meat in exchange for revenge on the perpetrator, an offer that Lisamarie ignores at the time. Now, she is granted a vision in which Jimmy's death is revealed to her, but her wish to join her dead relatives and remain in the spirit world is denied. Her grandmother asks her to return to the world of the living. Among the spirits of the dead, Lisamarie comes to embrace Haisla culture which is expressed through her sudden ability to understand the language: "I can understand the words even though they are in Haisla and it's a farewell song, they are singing

2 I borrow this phrasing from Alfred and Corntassel. 
about leaving and meeting again, and they turn and lift their hands" ( $M B$ 373-74). Lisamarie concludes her narrative with words that suggest that “[c]lose, very close, a b'gwus howls - not quite human, not quite wolf, but something in between. The howl echoes off the mountains. In the distance, I hear the sound of a speedboat" (MB 374).

Although the reference to the sound of a speedboat reiterates earlier scenes in which the speedboat is associated with Uncle Mick's death there is no doubt about Lisamarie's survival. The story itself is proof of that. Her decision to end her narrative with the mythical b'gwus whom she perceives as "not quite human, not quite wolf, but something in-between" indicates that she has reconnected with her traditional culture and uses the mythical story in a way that Ojibwa elder and scholar James Dumont characterizes as follows:

These legends, these myths are [...] no mere childish tales of how a world began, or why human and animal beings have the peculiar features and characteristics they do. Nor are they fanciful explanations for the landscape and the atmosphere being filled with liveliness and strange superhuman beings. Rather, they speak of how meaning and life, that seems of another reality, is brought into the ordinary reality we are born into. 'They make a home out of the world.' (39)

If Monkey Beach is partaking in the Indigenous tradition of "making a home out of the world" through storytelling, it performs this act in a manner that is similar to Ma-ma-oo's teaching of traditional knowledge. While Ma-ma-oo explicitly teaches the narrator about plants, animals, or the land, she also conveys traditional knowledge in an indirect way. Many references to Ma-ma-oo's life style imply that traditional Indigenous nutrition, for example, is healthier than the industrially produced food to be had in supermarkets and restaurants. About Ma-ma-oo's iced tea, the reader gets to know that it "was always bitter because she hated using sugar" (MB 215).

In reviewing her life, Lisamarie comes to re-evaluate the cultural practices and beliefs that her grandmother and uncle performed and believed in. Her change of attitude gives her trauma narrative a distinct shape. In her case, the ghost that seems to haunt her is not primarily a symptom of the traumatic loss of people close to her, but rather an embodiment of the spiritual connection that exists between humans and the natural environment. From the moment when 'the thing' gives Lisamarie the advantage over the psychotherapist, the narrative's concern is with re-connecting Lisamarie to Haisla 
spirituality. The inversion of the Gothic tradition not only foregrounds the difference between Western and Indigenous literary traditions, but opens up a space in which the Indigenous story-telling tradition emerges as the more encompassing - because holistic - knowledge system:

$[\ldots]$ a teaching story $[\ldots]$ illustrates the nature of the way Indigenous people viewed relationships with all things, people, animals, the earth, and the sky. [...] The story is $[\ldots]$ about journeying to the center, to "that place that Indian people talk about." This is a place of spirit within ourselves and in the world as a whole. It is in "that place" that knowledge and gifts of spirit can be obtained. It is a place of vision where one must learn how to seek. (Cajete, Igniting 134)

When read alongside Dennis H. McPherson and Douglas Rabb's study on Indigenous philosophy, the transformative agenda of the text comes into clear focus. The status of ghosts and other supernatural beings in Lisamarie's narrative are representative of a holistic Indigenous worldview. "[T]he intimate relationship between land and person" (McPherson and Rabb 87), on which all Indigenous cultures in North America are founded, is the most important insight that the protagonist/narrator gains once she disentangles her perception of ghosts and spirits from the Western conviction that the belief in supernatural beings indicates a primitive stage of cultural development.

The most important carrier of traditional knowledge is Grandmother Ma-ma-oo who is aware of the precarious state that the Indigenous cultures are in: her TV consumption, for example, illustrates a creative adaptation to mainstream culture. Her acceptance of these new forms of storytelling, however, does not affect the fundamental beliefs of her culture. When telling her granddaughter about the origins of human existence, she refers to a time when there was no distinct boundary between human beings and animals. She tells a version of the b'gwus narrative according to which the latter personifies a man who was murdered by his wife and her lover and turned into a b'gwus to take revenge on his wife and brother. The significance of the story is left open, and Ma-ma-oo suggests that the meaning might have been lost to the Haisla as most of them do no longer speak their language: "to really understand the old stories, she said, you had to speak Haisla" (MB 211). Although this remark self-reflexively comments on the fact that Robinson's novel - written in English - is itself a manifestation of cultural assimilation, it at the same time invokes the ritualistic function of 
Indigenous storytelling. The climactic scene at the end of Monkey Beach represents a vision quest, an Indigenous ritual that puts the individual in touch with the universe:

When you reach out beyond yourself, all of a sudden you have some tremendous strength and your body suddenly becomes one with the earth, air, fire and water. You don't feel any pain - you're sort of above it. You're pushed to a point where you sense you're a spiritual being [...]. (Macpherson and Rabb 70)

Monkey Beach's survival narrative focuses on such a spiritual transformation. The process ultimately results in Lisamarie's changed attitude towards the 'little man' that has appeared to her since childhood:

Now that I think back, the pattern of the little man's visits seems unwelcomely obvious, but at the time, his arrivals and departures had no meaning. As I grew older, he became a variation of the monster under the bed of the thing in the closet, a nightmare that faded with morning. He liked to sit on top of my dresser when he came to visit, and he had a shock of bright red hair, which stood up in messy, tangled puffs that he sometimes hid under a black top hat. (MB 27)

This is the only instance in the novel where Lisamarie directly appears as an authorial narrator who shows herself in control of the narrative and in a position to comment on her younger self. The pattern which she sees indicates her socialization into a mainstream culture in which the presence of ghosts is associated with mental illness. The re-evaluation of the 'little man' in the course of the novel is the result of an Indigenous process of knowledge production. The narrator's presence in the passage indicates that it is the performance of telling her life-story which allows for an alternative pattern to emerge: the seemingly random acts of violence which are reported by Lisamarie turn out to be intertwined with the more comprehensive historical trauma that the Haisla community suffers from as the result of the enforced assimilation in residential schools and the ensuing loss of Indigenous knowledge.

Through the continuous juxtaposition of passages in which Western and Indigenous attitudes towards supernatural phenomena are contrasted, the novel challenges mainstream notions of mental and psychological health. From an Indigenous perspective, "reason, or human cognition, may not be the sole source of knowledge, [...] 'faith and spirit' may also play a significant and alternative role to human reason" (Atleo xii). In the Haisla worldview, the ghosts and spirits that interact with Lisamarie are an integral 
part of the natural environment. The ghosts, for example, relate human beings to animals and trees. Grandmother Ma-ma-oo is instrumental in changing Lisamarie's attitude. At one point, she takes her granddaughter to the woods and introduces her to a plant, Oxasuli, that when put on the windowsill "keeps ghosts away" (MB 151). When she takes some of the plants with her, she performs a ritual:

She broke one of the cigarettes and left the tobacco scattered at the bottom of the cedar trunk. She said some words in Haisla, then she broke off one of the branches. [...]

"You're giving tobacco to a tree?"

"The tobacco is for the tree spirits. You take something, you give something. [...]" (MB 152)

When Lisamarie inquires what spirits look like, her grandmother tells her about the 'little man':

The chief trees - the biggest, strongest, oldest ones - had a spirit, a little man with red hair. Olden days, they'd lead medicine men to the best trees to make canoes with. (MB 152)

For the first time, Lisamarie is told that she has the gift of knowing the future. However, Ma-ma-oo does not answer Lisamarie's question about the meaning of the spirit's appearances and cautions her granddaughter not to rely too much on the 'little man': "He's a guide, but not a reliable one. Never trust the spirit world too much. They think different from the living" (MB 153). The role that Lisamarie's grandmother fulfills closely resembles the teaching of Indigenous elders as characterized by McPherson and Rabb:

Native elders $[\ldots]$ have the reputation of never giving a straight answer. [...] You are given the autonomy, the complex freedom, to discover the relevance of the reply, and hence to work the problem out for yourself. (154)

Knowledge in the novel is transmitted through the performance of Indigenous rituals:

We hung the cedar in her house first and put oxasuli on the windowsills. When we put the cedar up in my room, Dad came up and raised an eyebrow when he saw what we were doing, but he didn't say anything. (MB 154)

These rituals help Lisamarie to come to terms with experiences that from a Western point of view are considered as either superstition or hallucination and thus as an expression of psychological disorder. 
However, the novel does not simply oppose two knowledge systems. The most obvious break in terms of narrative coherence and point of view occurs with passages that are difficult to place in time or to attribute to a narrative agency. Several times during the novel (MB 164, 192, 275), a heterodiegetic narrative voice provides physiological information about the human heart. The following passage is representative:

Behold, your heart. Touch it. Run your fingers across this strong, pulsating organ. Your brain does not completely control your heart. In the embryo, the heart starts beating even before it is supplied by nerves. The electrical currents that ripple across your heart causing it to contract are created by a small bundle of specialized muscle tissue on the upper right-hand corner of your heart. (MB 164)

The relation of these passages to the surrounding ones is not at all clear. Considering that Lisamarie's grandmother suffers from a heart attack, there seems to be a contrast between the objective scientific knowledge related in these passages and the metaphorical meaning of the heart as the center of emotions. The scientific knowledge about the heart is completely removed from the characters' lives and cannot explain anything. Rather, the isolated look at the mechanics of the heart draw attention to the vast gap that exists between the abstract discourse of Western medicine and Lisamarie's harrowing story of violence, abuse, addiction, suicide, and rape.

The juxtaposition of passages that are related by a seemingly objective voice and the subjective perceptions of Lisamarie once again create the 'dialogic space' in which competing views are held in tension. While the Western scientific knowledge system is neither dismissed nor devalued as such, it is shown to be "separating the knowledge from all of the context (the relationships, the world views, values, ethics, cultures, processes, spirituality) that gives it meaning” (Simpson 139). In Leanne Simpson's plea for a recognition of the "spiritual foundations" of Indigenous scholarship and her self-characterization as a scholar, the metaphor of the heart plays an important role: "It is only when I sit quietly, patiently, and listen with my heart, that Indigenous paradigms and processes emerge and begin to assume control" (142). A similarly significant overlap between scholarly and literary discourse can be observed between Jo-Ann Archibald's scholarly book on Indigenous Story-Work and Robinson's novel. Before Archibald starts explaining the role of storytelling in Indigenous cultures, she relates a 
dream, which she interprets as a call "to use the cultural knowledge [of the Stó:lō tribe] and to share it with others, thereby ensuring its continuation":

I was alone in a canoe and approaching land. [...] As the canoe reached shore, many of the Old People came out to greet me. The Old Ones were those who had 'passed on,' or as we say, travelled to the Spirit World. [...] I told them that I wanted to leave that cold place and stay with them. [...] they brought me back outside and put me back in the canoe. They said I had to go back, and that I wouldn't be lonely anymore, and that I had important work to do yet. (3)

Archibald's dream very much resembles the ending of Monkey Beach. Tempted to give in to the desire to let go and drown at Monkey Beach, the narrator has a vision in which she enters "The Land of the Dead" where she meets the relatives whose death she foresaw but could not prevent. Her grandmother tells her to return to the world of the living, her uncle and brother lead her back. At this point, Lisamarie is the person who has survived historical trauma and has been successful in "making a connection to something greater than themselves and their individual griefs" (Castellano 26).

\section{Conclusion}

The Western trauma narrative and the Indigenous survival narrative are the two narratives which constitute Monkey Beach's multinarrative. Through juxtaposition and superposition the novel creates an 'ethical space' (Ermine), a 'polycentric perspective' (McPherson and Rabb), a 'multiverse' (Cajete) which allows for a critical dialogue between Western and Indigenous knowledge traditions. Through heteroreference to the residential school experience and the intertextual relation to the discourse on Indigeneity, the novel moreover partakes in the social struggle that Canada's First Nations have fought to gain autonomy and control over the economic, political, and cultural matters that affect their lives. By foregrounding the telling of the story as an act of spiritual transformation, the novel plays the role that "Indigenous storytelling traditionally plays as resurgence and insurgence, as Indigenous knowledge production, and as disruptive of Eurocentric, colonial norms of 'objectivity' and knowledge" (Sium and Ritskes I). The decolonization of Indigenous knowledge is seen as the means by which the survival of Indigenous cultures - and by extension of humankind - can be secured. 


\section{Works Cited}

Alfred, Taiaiake, and Jeff Corntassel. "Being Indigenous: Resurgences against Contemporary Colonialism." Government and Opposition 40.4 (2005): 597-614.

Andrews, Jennifer. "Native Canadian Gothic Refigured: Reading Eden Robinson's Monkey Beach.” Essays on Canadian Writing 73 (2001): $1-24$.

Appleford, Rob. “'Close, very close, a b'gwus howls': The Contingency of Execution in Eden Robinson's Monkey Beach." Canadian Literature 184 (2005): 85-101.

Archibald, Jo-Ann. Indigenous Story-Work: Educating the Heart, Mind, Body, and Spirit. Vancouver: University of British Columbia Press, 2008.

Atleo, E. Richard. Tsawalk: A Nuu-chah-nulth Worldview. Toronto: University of Toronto Press, 2004.

Bakhtin, Michail. "Discourse in the Novel.” The Dialogic Imagination. Ed. Michael Holquist. Transl. Caryl Emerson and Michael Holquist. Austin: University of Texas Press, 1981. 259-422.

Braveheart, Maria Yellow Horse, and Lemyra M. DeBruyn. "The American Indian Holocaust: Healing Historical Unresolved Grief." American Indian and Alaska Native Mental Health Research 8.2 (1998): 60-82.

Cajete, Gregory. Igniting the Sparkle: An Indigenous Science Education Model. Skyland: Kivaki, 1999.

-. Look to the Mountain: An Ecology of Indigenous Education. Durango: Kivakí, 1994.

Castellano, Marlene Brant. "Healing Residential School Trauma: The Case for Evidence-Based Policy and Community-Led Programs." Native Social Work Journal 7 (2010): 11-31.

Castricano, Jodey. "Learning to Talk with Ghosts: Canadian Gothic and the Poetics of Haunting in Eden Robinson's Monkey Beach." University of Toronto Quarterly 75.2 (2006): 801-13.

Dumont, James. “Journey to Daylight-land: Through Ojibwa Eyes.” Laurentian University Review 8.2 (1979): 31-43.

Ermine, Willie. “The Ethical Space of Engagement.” Indigenous Law Journal 6:1 (2007) 193-203. 
Freud, Sigmund. "A Difficulty in the Path of Psychoanalysis" (1917). An Infantile Neurosis and Other Works. Ed. James Strachey. New York: Vintage, 2001. 135-44.

Graham, Laura, and H. Glen Penny. Performing Indigeneity: Global Histories and Contemporary Experiences. Lincoln: University of Nebraska Press, 2014.

Henderson, Jennifer. "The Camp, the School, and the Child: Discursive Exchanges and (Neo)liberal Axioms in the Culture of Redress." Reconciling Canada: Critical Perspectives on the Culture of Redress. Ed. Jennifer Henderson and Pauline Wakeham. Toronto: University of Toronto Press, 2013. 63-83.

Lacombe, Michèle. "On Critical Frameworks for Analyzing Indigenous Literature: The Case of Monkey Beach." International Journal of Canadian Studies 41 (2010): 253-76.

Lane, Richard J. "Reclaiming Maps and Metaphors: Canadian First Nations and Narratives of Place." Beyond the Borders: American Literature and Post-Colonial Theory. Ed. Deborah L. Madsen. London: Pluto, 2003. 184-194.

Luckhurst, Roger. The Trauma Question. London: Routledge, 2008.

Mackey, Eva. “The Apologizers' Apology.” Reconciling Canada: Critical Perspectives on the Culture of Redress. Ed. Jennifer Henderson and Pauline Wakeham. Toronto: University of Toronto Press, 2013. 47-62.

McPherson, Dennis H., and J. Douglas Rabb. Indian From the Inside: Native American Philosophy and Cultural Renewal. $2^{\text {nd }}$ ed. Jefferson: McFarland, 2011.

Million, Dian. "There is a River in Me: Theories from Life." Theorizing Native Studies. Ed. Audra Simpson and Andrea Smith. Durham: Duke University Press, 2014. 31-42.

-. "Trauma, Power, and the Therapeutic: Speaking Psychotherapeutic Narratives in an Era of Indigenous Human Rights." Reconciling Canada: Critical Perspectives on the Culture of Redress. Ed. Jennifer Henderson and Pauline Wakeham. Toronto: University of Toronto Press, 2013. 159-77.

Purhar, Sonu. "Ephemeral Identity in Eden Robinson's Monkey Beach." Illumine: Journal of the Centre for Studies in Religion and Society Graduate Students' Association 10.1 (2011): 36-52. 
Robinson, Eden. Monkey Beach. Toronto: Knopf, 2000.

Simpson, Leanne. "Aboriginal Peoples and Knowledge: Decolonizing Our Processes.” The Canadian Journal of Native Studies 21.1 (2001): 137-48. Sium, Aman and Eric Ritskes. "Speaking truth to power: Indigenous Storytelling as an Act of Living Resistance." Decolonization: Indigeneity, Education \& Society 2.1 (2013): I-X.

Soper-Jones, Ella. "The Fate of the Oolichan: Prospects of Eco-Cultural Restoration in Eden Robinson's Monkey Beach." Journal of Commonwealth Literature 44.2 (2009): 15-33.

Wegerif, Rupert. Dialogic, Education and Technology: Expanding the Space of Learning. New York: Springer, 2007. 


\title{
André Schwarck \\ "Useless, off-beat information!": Knowledge and Successiveness in Brian Friel's Molly Sweeney (1994)
}

\begin{abstract}
This article provides a close reading of Brian Friel's Molly Sweeney. It shows that the play stages how discursive ramifications of knowledge become embedded in narrative and temporal schemes in order to establish self-fulfilling frames of meaning in the lives of the play's male characters, all of whom are bound to a fundamental and inherently hostile form of succession. The blind Molly is objectified by three male characters, all exerting power by fatally imposing their own narrative schemes on her. However, Molly overcomes successiveness and achieves meaning and understanding of her blind world by generating a placid form of sequentiality.
\end{abstract}

\section{Knowledge, Vision, and Successiveness}

Brian Friel's play Molly Sweeney (1994) tells the story of a woman who has been blind since early childhood and whose vision is then temporarily restored by two succeeding, clinically successful removals of the cataracts on both of her eyes. Although this brief summary captures the gist of the play quite accurately, it does not express the often-perceived tragic dimension of the play nor the profoundly eventful quality of the operative restoration of Molly's sight. The fate of the blind woman Molly Sweeney is a salient story of loss with the operative surgery amounting to an intrusion into her life, manifesting a transformational event, and dividing her life irreversibly into a 'before' and an 'after.' This predominant conception of eventfulness can be traced back to Brian Friel's main source for his play, Oliver Sacks' “To See or Not to See," a neurological and psychological account which delineates the consequences a blind male patient of Sacks, dubbed Virgil, faces when undergoing the same surgery and similar treatment as his fictive (female) counterpart in Friel's play. Here, one can surmise that Sacks considers a large part of the tellability of his 'case study' to lie in the idea that the surgery and its successful restoration of Virgil's sight is a life-changing 
event. This finds its illustrative dramatic peak when, in the aftermath of Virgil's surgery, the bandages on his eyes are removed:

$[T]$ hen the eye was finally exposed, without cover, to the world. The moment of truth had finally come. Or had it? The truth of the matter (as I pieced it together later), if less 'miraculous' than [his wife's] journal suggested, was infinitely stranger. The dramatic moment stayed vacant, grew longer, sagged. No cry ('I can see!') burst from Virgil's lips. He seemed to be staring blankly, bewildered, without focussing, at the surgeon, who stood before him, still holding the bandages. Only when the surgeon spoke - saying 'Well?' - did a look of recognition cross Virgil's face. (Sacks 107)

In Sacks' narration, the dramatic and eventful moment of exposure coincides with the epistemological category of truth. Yet with his hindsight assessment of the "truth of the matter," he discerns a surprising, "infinitely stranger" impact on the dramatic moment; it simply lacks eventfulness. In other words, the underlying notion that the event of removing the bandages amounts to being a transformative moment of dividing time irreversibly into a 'before' and an 'after' is simply not realized, as it "stayed vacant, grew longer and sagged." As this paper attempts to show, it is exactly this startling and unexpected denial of eventfulness in close connection to the conflation of events with notions of 'truth' and 'knowledge' that forms the core aesthetic interest in Brian Friel's Molly Sweeney.

In recent scholarly readings of Molly Sweeney, knowledge is usually seen as closely linked to the capability of sight, and its centrality as a theme in the play is without dispute. Exemplarily, Moloney identifies issues "such as seeing versus understanding, ways of knowing, and the nature of reality" as the play's chief concerns (295). DeVinney goes as far as to say that sight "becomes a metaphor [...] for knowledge," yet she makes sure to stress that "the easy equation of sight and insight is troubled by the unreliability of perception and memory" (111). Indeed, the nexus of knowing and seeing is anything but simple, and yet always in danger of becoming a truism. Therefore, Upton is right when she warns us that the play does

1 "To See or Not to See" is one among seven tales published in Sacks' bestseller $A n$ Anthropologist on Mars, each of which describing "a person who is transformed by a singular neurological 'occurrence"” (Temple 141). Hence, all of them seem to mediate their scientific 'cases' relying on 'histories' that follow this simple, yet, significant pattern. 
not give "credence in its ultimate discourse to casual assimilations between seeing and understanding," and further emphasizes that "an unsentimental refutation of long-established metaphors of light and darkness, ignorance and knowledge, lies at the heart of" the work (347). Kerrigan proposes to regard the play as a whole along these lines, as its "form dramatically approximates the condition of blindness" (154). He suggests that "as the play's narrative advances and Molly becomes more (and then less) able to see, the drama accommodates and entertains new metaphors of seeing and knowing" (154). Friel imports medical and physiological concepts directly from Sacks' case history ${ }^{2}$ and, according to Kerrigan, renders them as discernible extended metaphors incorporated into the overall structure of the play. Hence, the concepts provided Friel "with a vehicle for deepening his treatment of sight and knowledge in the play" (Kerrigan 155). Although Kerrigan's basic analogies between the blindness among the play's characters and the formal 'blindness' the drama as a whole challenges the audience to overcome are consistent, his basic scope remains limited to questions and statements about the diegetic dimension of the play. ${ }^{3}$ Hence, Kerrigan praises Molly Sweeney as "original and particularly compelling” because of the "particular form of narrative drama Friel chooses in order to give rise to the inner worlds of his characters" (153). And yet, what Kerrigan highlights as the "particular form of narrative drama," its generally monologic form realized in its three protagonists' isolated soliloquies, has recently been taken as a point of departure to account for the complexity of the nexus of knowledge and vision. DeVinney, for example, does not find fault with the

2 The three concepts are "agnosic," defined by Frank Sweeney in the play as "seeing but not knowing, not recognizing, what it is [you] see" (Friel 464); "'blindsight,' a physiological condition in which a person receives visual signals and responds to them subconsciously" (Kerrigan 156, see also Friel 498) and "gnosis," a medical term "for the ability to recognize and interpret what is perceived" (Kerrigan 157, see also Friel 496).

3 With "statements about the diegetic dimension" I refer to statements that imply an equation of the fictive character with a living human being. My twofold aim here is, first, to delineate specific inherent narrative phenomena and configurations of Friel's play that find their expression, inevitably, through the diegetic dimension of the play and, second, to show how they contribute to the aesthetic treatment of the work's central themes (knowledge, seeing, loss etc.). With regard to the use of the term "diegetic" in this context, see Souriau (151 and 156). 
play's replacement "of action with narration.” Instead, she suggests: “[It's] lack of conventional stage action is, through a sort of logical hairpin curve, exactly what makes [it] so dramatic" (111). In a similar fashion, Silverstein defends the monologic form of the play against Krause's invective account in which he disapproves of Friel's "crucial decision to narrate rather than dramatize his premise and its unfolding" (Krause 361), and suggests that instead of faulting "the play for being insufficiently dramatic, it would be more accurate" to talk of "the play's insufficient theatricality" (Silverstein 37). In a compelling way Silverstein shows that, in spite of reducing its own theatrical architecture to a sequence of dramatic monologues, the play elaborately investigates the infinitely subtle implications that lie in the "very act of looking" (38). Silverstein demonstrates convincingly that Friel's drama investigates "assumptions about the relationship between desire, subjectivity, knowledge and vision” (38). When Dr. Rice, the ophthalmologist, for example, begins to sense "a feeling of mastery" (Friel 490), Silverstein relates this touch of supremacy to the "'mastery' of self-certainty based on [the spectators'] conviction that [they] know what [they] see, that seeing and knowledge not only mutually reinforce each other, but amount to the same thing" (38).

The present article aims to contribute an explanation for the intricate relationship between knowledge and vision in Friel's Molly Sweeney. However, instead of directly approaching their correlations on a conceptual level, I intend to expose how both of these themes collide due to a more fundamental principle at work in Friel's play. Complementarily to Silverstein's examination of the theatrical and visual reflections implied in Friel's drama, I deliberately put emphasis on its narrative dimension as well as on temporal implications as they become manifest in the story of the play. Taking up the above-mentioned conflation of eventfulness and, as Sacks puts it, "moment[s] of truth" (107), I argue that knowledge, predominantly associated with the male characters in the play, becomes a prevailing source for them to establish and maintain individual narrative patterns. Whether these patterns are episodic or express any of the organizing aspects of a singular event, they are bound to a primary temporal force that manifests itself throughout the play in various ways: the notion of successiveness, i.e. a basic, ever ongoing rhythm of one thing following another. Successiveness is conceived as fundamentally affecting all characters in their temporal and 
narrative disposition. It is thus ignorant of the gender gap and, as such, ineluctable. However, successive units are indistinct and hence devoid of an inherent meaning. Therefore, the characters are compelled to find narrative means in order to impose meaning on their ineluctable successive condition. The latter may be temporarily superimposed, but successiveness remains a latent and to a degree even hostile threat against any endeavors to create meaningful and lasting structures. To the characters this inimical nature may only become manifest on rare occasions (as will be shown in a few 'offbeat'-moments) or become a default mode of existence. The latter is the fate of Molly Sweeney; grown up as a blind person, she had come to terms with her own successive nature, accommodating to it by transforming the ever ongoing successive rhythm into a stable and integral mode of perceptive and narrative sequentiality. When she is persuaded by the male characters to be operated on her eyes, she is deprived of this integrity. Friel's play explores and stages these acts of imposition. The imagery of the play clarifies - in contrast to the fundamental successiveness - the resulting narrative patterns are of a secondary and thus negotiable nature. When Molly is confronted with, and eventually, afflicted by the male characters' struggles and their unrelenting efforts to establish their patterns, this level of imposition does become a site for gender and power struggles. It is knowledge and its specific discursive ramifications which constitute a specific 'blindness' that may prompt members of the audience to misperceive Molly's fate as just another simple story turning upon a life-changing event.

\section{Paternal Testing: Molly's Father}

Molly's opening sentence can be read as pointing at the connection of time, coercive force, and knowledge underlying the whole play: "By the time I was five years of age, my father had taught me the names of dozens of flowers and herbs and shrubs and trees" (455). Her earliest recollections as a child present her with a younger self that has already learned and already knows the names of the plants that grew in her father's garden. Molly's knowledge seems as innocent as her affection towards her father. Molly's first monologue, however, reveals how the acquisition of her botanical knowledge is a result of her father's attempt to establish a frame of meaning for his own bleak life. He is a judge and his marriage to Molly's mother is 
the story of a slow and painful disintegration. Every day when he comes home from work he has a few drinks and takes his young daughter to his "walled garden" (455). There, Molly is allowed to spend precious and exclusive time with her father, but he coerces his daughter to partake in relentless quizzes. Molly is forced to seek her father's love by repetitively naming the names of flowers and trees: forms, numbers, length measures, and color form the criteria of his array of queries: "Now, Molly. Tell me what you saw" (456), he prompts her to speak, and although he lets her smell and feel in the process, his address remains bound to the world of sight. The flowers, for example, are arranged in geometrically perfect "circle[s]" (456) and he demands that she names the correct colors. Under his paternal supervision, Molly is compelled to seek knowledge as if she could see. What is more, the father's daily tests are not only oppressive in an epistemological sense. The repetitive nature of his interrogations is augmented by them being also formally endless (hence successive), inasmuch her father compares their daily tours with hearings in an ongoing trial: "Excellent testimony! We'll adjourn until tomorrow"” (457).

Nonetheless, the young Molly loves and trusts her father and delivers loyally what she can in this paternal frame of inculcations: she wants to "get it right for him," because "to hear the delight in his voice" gives her "such pleasure" (456). The interrogative format is both a means to channel Molly's love towards her father and a desperate attempt on his part to establish a medium that allows him to convey his feelings toward her. Although he remains ignorant of the fact that he imposes an oppressive scheme upon his daughter, it is not necessarily directed against her. The discrepancy between his sight and her blindness and the dual 'true' or 'false' code of his testing not only enable him to either correct her false answers or to praise her for identifying the correct botanical names; the series of pressing queries and repetitive instances of verification also become a compulsory, but the only possible, pattern to express his paternal love to his daughter.

The breakdown of Molly's parents' marriage is the main cause for her father's walled garden trials, and their repetitive nature suggestively calls up the succession of prescribed treatments Molly's mother has to undergo: "in and out of institutions all her days with nervous trouble” (458). Frequently, Molly's mother is absent. Remarkably enough, the only passage which speaks of the mother's presence is itself framed as an iterative situation: 
"if she were at home she'd appear at the front door - always in her headscarf and wellingtons - and she'd shout, 'Molly! Daddy! Dinner!'” (457). Appearing at the front door and interrupting her husband's garden tour with her call seems to be her only impact on his life. Yet as soon as the young Molly is taken to bed, the domestic co-presence becomes unbearable to both marital partners. In their "huge, echoing house" (457) their resounding fights and quarrels form an irresolvable overlay of sequential, repetitive, and endless patterns.

In this regard, Molly's portrayal of her father's garden trials forms the overture of her own story, in which she is to face the fatal consequences of two men imposing specific narrative structures upon her life in order to escape or avoid the effects of a distorting successive temporality. Before she meets the two men, Molly copes with these impositions despite, or even because of, her blindness. She lives her life in a placid and steady mode of sequentiality only to lose this ability with the operation on her eyes to come.

\section{Sciolistic Enthusiasm: Frank Sweeney}

Frank Sweeney, Molly's (future) husband, cherishes knowledge and learning. However, as a self-taught and often jobless sciolist, he lacks the professional and academically trained attitude toward knowledge of Mr. Rice. The spread of his interests is wide and his choices to become passionately absorbed in a new project seem to be made rather randomly. In his digressive monologues, he is repeatedly eager to share with the audience what he deems - to use his favorite expression - "fascinating." Iranian goats, the blueback salmon, bees, whales, the efficient recycling of tea-leaves, speed-reading, Rudolph Valentino, Ethiopia, or the well-being of badgers - whenever he conceives a new project he feels fully committed to it. His frequent impulse to passionately pursue new plans not only affects the diegetic conception of the character, it can also be read as the manifestation of a certain narrative pattern: a pattern or model of episodic new beginnings. Whenever Frank can initiate a new beginning in his life, he is ravished with an inchoate delight as each beginning promises being part of a whole, a holos. Gratification does not depend upon the ending of each respective project; indeed, he remains untroubled by most of his projects ending in failure. As Kerrigan observes, “once Frank has forced the moment 
to its crisis, he is paralyzed" (159). Thus, instead of completing his projects, Frank abandons them prematurely. The dynamic of Frank's mode of existence lies in the ever repeating motion of turning his attention to something new. Therefore, the maintenance of a certain frequency of new episodes becomes compulsory and dictates his life. In fact, the character himself exhibits some awareness of this pattern; its intricacies, however, remain unknown to him. Once he says of himself: "God knows why I've spent my life at dozens of mad schemes" (464). According to his friend Billy, he is "haunted for God's sake, always looking for...whatever..." (464). This dynamic of ever-to-be-realized episodes can be seen as the formula that structures the narrative pattern of his life.

When Frank meets Molly, she is "a happy, competent inhabitant of her blind world, a woman who takes genuine pleasure in her work as a massage therapist, in cycling, in dancing, in socializing with her friends and neighbors [...]" (Moloney 288). At once, Frank's affection towards Molly is evinced: her blindness becomes stock material for a new episode of his enthusiasm. Jobless at the time, he spends a whole week in the library studying this "fascinating” new concept called 'blindness.' He then applies his newly acquired knowledge to successfully woo Molly by exploiting a crucial insight. As he explains with remarkable precision, Molly lives comfortably in a world of sequentiality:

She composes a world from a sequence of impressions; one after the other, in time. For example, she knows that this is a carving knife because first she can feel the handle; then she can feel this long blade; then this sharp edge. In sequence. In time. What is this object? These are ears. This is a furry body. Those are paws. That is a long tail. Ah, a cat! In sequence. Sequentially. (477)

Hence, his 'Molly plan' involves a subtle and seductive undermining of her sequential state. He decides to take her dancing, excitedly praising his charming, and yet, fatal idea:

Dancing. Take her dancing [...] forget about time. This is one continuous, delightful event. Nothing leads to nothing else. There is only now. There is nothing subsequent. I am yours, your eyes, your location, your sense of space. Trust me. (478)

The here-and-now of dancing enables mutual attraction between the otherwise different mindsets of Molly and Frank. With the ongoing continuity of the dancing present, Frank bridges the passing of distinct time sequences 
and establishes a disarming co-presence. On the one hand, Molly is lured into cherishing an ongoing presence that frames all impressions into one singular experience. At the same time, she is not deprived of her sequentiality; in fact, her composite, sequential experience is synchronized with Frank's disposition to holistic and singular eventful information processing. In short, Molly is seduced by continuity. Frank: "She had the time of her life. Knew she would" (479).

Yet there is something else about her that inevitably appeals to Frank; in connection with her blindness, Molly asserts at one point: "He couldn't resist the different, the strange. I think he believed that some elusive offbeat truth resided in the quirky, the off-beat" (480). This rather cryptic remark is a first reference to what becomes the main subject in the aftermath of Molly's surgery; the question of how one can cope with the notion of a somewhat hostile but fundamental successiveness that underlies the lives of all characters in the play. Thus, Frank is not only attracted to Molly because she is content with and confident in her blind world. What makes Molly so irresistible to Frank is the fact that, while calmly converting successive moments into meaningful sequences, she does not attempt to deprive herself of what he conceives of as resistant "off-beat" successiveness. The male characters in the play, in contrast, exhibit exactly this tendency toward erasing their own successive nature by establishing successful, reliant, and meaningful layers of secondary narrative patterns. Along these lines, it is Frank, who, for the sake of maintaining his episodic template, undermines Molly's sequentiality by diminishing her to be just another episode in his life. Molly's best friend Rita, on the evening of their first date, puts it poignantly when she refers to his yet to be made proposal of marriage as "inevitable": "All part of the same pattern, sweetie: bees whales - Iranian goats - "Molly Sweeney" (480). Molly, on the other hand, is deeply impressed by Frank's “energy," "enthusiasm," and "passion," all products of his endless drive to turn sciolist knowledge into meaningful narrative episodes (see 477). And yet it is not necessarily Molly's decision to marry Frank that determines her fate. Frank's successful pursuit resulting in marriage is just the onset of another to-be-aborted amplitude of his episodic pendulum. Thus, early into their marriage, Frank already seeks a new adventure. Molly's profound loss depicted in the play hinges on the 
execution of Frank's spousal obsession of turning knowledge into a lifechanging event: the operation on Molly's eyes.

\section{Ignorant Expertise: Mr. Rice}

Frank initiates the surgery by calling on the expertise of the eye surgeon Mr. Rice. With him, in contrast to the dilettante Frank Sweeney, knowledge obtains a voice through the discourse of medical expertise, academic life, and professionalism. In Rice's monologues, the blind Molly becomes recurrently "a case" he can lecture upon. Accordingly, his first meeting with his patient to be is referred to as a "first cursory examination" which "result[s]" in bringing her "into the clinic for tests" (467). Rice's key word is "theoretical" in all its variations. To Molly, his professional manner and way of speaking generates a certain "assurance," which Frank, on the other hand, finds repellent. Rice also represents the life and discourse of academia. The formerly brilliant and successful ophthalmologist worked "in the top eye hospitals all over the world" (465). In a brief sequence of juxtapositions, he sketches this "luminous, resplendent life":

Insatiable years. Work. Airports. Dinners. Laughter. Operating theatre. Conferences. Gossip. Publications. The professional jealousies and the necessary vigilance. The relentless, devouring excitement. But above all, above all the hunger to accomplish, the greed for achievement. (474)

Rice portrays a life in which professional expertise is consistently transferred into social prestige and male bravado. He is part of a small group of male colleagues who travel the world, meet at the same conferences, and dub each other with boastful names: "The meteors. The young turks [sic]. The four horsemen" (474). In the glorious world of these agents, the operating theatres literally become theatrical stages, where the men become “artists" (488) or "magician[s]" (489), and explicitly "perform" (488) their craft in the operation room. Rice's "hunger to accomplish" mirrors Frank's haunting formula of "always looking for...whatever." Both strategies expose knowledge as an instrument of male desire to establish narratives of success. Rice's former world ("Insatiable years. Work. Airports" etc.) hardly differs from Frank's dabbler universe; both follow an ultimately episodic structure. What is more, both patterns become legible as, at best, provisional attempts to create lasting narratives in order to substantiate their 
male identity. Both men fuel their desire by investing in the same narrative foundation, that is, both are haunted by the idea of succumbing to a hostile and inalterable successiveness.

When Molly meets Rice in Ballybeg, he suffers precisely from such a condition. He lives a bleak life which harks back to a single event in his past (his wife betrays and leaves him). Befittingly conveyed with the play's basic format of the monologue, the event is recounted (see 475) as a phone call Rice receives, at the peak of his career, from his former friend and colleague:

It was Roger Bloomstein. Brilliant Roger. Treacherous Icarus. To tell me that Maria and he were at the airport and about to step on a plane for New York. They were deeply in love. They would be in touch in a few days. He was very sorry to have to tell me this. He hoped that in time I would see the situation from their point of view and come to understand it. And he hung up. The mind was instantly paralysed. All I could think was: He's confusing seeing with understanding. Come on, Bloomstein. What's the matter with you? Seeing isn't understanding. (475)

In the light of the scheme the two central male characters devise for Molly Sweeney, it is notable that at the very moment of realizing the event's profound impact on his life, Rice voices his firm conviction that 'seeing' is not to be confused with 'understanding.' And yet, what he claims in his darkest hour he is ready to ignore in the case of Molly, in which he will deliberately fuse vision with knowledge. This is due to Rice's readiness to apply simple narrative designs to life, especially during the upheaval after his wife's betrayal. The diegetic transformation of the character is profound. Rice not only loses his married life and family, he also withdraws from medicine, renounces his title "doctor," and resorts to a solitary life on the "outskirts" of a remote town drowning his sorrows in drinking. Thus, he views his life through the narrow scope of a simple narrative scheme, one he admits to "sound[ing] like a fairy tale" (489) and one composed of two plain periods, one prior and one after the anchoring event of losing his wife. Due to the logic of this self-imposed script, his former "greed for achievement" and (episodic) craving for professional accomplishments are suspended and become embedded in the period prior to the event. Rice's temporal condition afterwards is marked by his impressions that he has "subsided into terrible darkness" and that his life "no longer...cohered" (489). What Frank tries to keep at bay with his maintenance of his episodic cycles, Mr. Rice faces directly after his personal story of loss. His life in 
Ballybeg is not only constrained by solitude and non-engagement, the period of non-activity is also thoroughly corrupted by successiveness, insofar as it is informed by an endless and pointless series of routines (drinking, sleepless nights, fly-fishing etc.).

However, when Frank Sweeney appears and entreats him to consider operating on Molly's eyes, he is severely tempted to review his simplifying model of life and to instantly transform his current narrative situation. During his first "cursory examination" of Molly (467), he suddenly has a tantalizing idea:

[A] a phantom desire, a fantasy in my head; absurd, bizarre thought that perhaps, perhaps - up here in Donegal - not in Paris or Dallas or Vienna or Milan - but perhaps up here in remote Ballybeg was I about to be given - [...] the chance of a lifetime, the one-in-a-thousand opportunity that can rescue a career - no, no, transform a career - dare I say it, restore a reputation? And if that opportunity were being offered to me and if after all these years I could pull myself together and measure up to it, and if, oh my God, if by some miracle pull it off perhaps... (460, emphasis added)

It is the sheer possibility of operating on Molly that stirs Rice to conceive that he may overcome his painfully repetitive inertia after all. Tentatively he entertains the idea that a successful surgery would establish a frame of meaning that will compensate for his loss, and thus qualify for the epithet "the chance of a lifetime." According to this idea of 'restoration,' the quantum event and its consequence of loss would be miraculously overwritten. And yet, the play makes sure to indicate that this is highly improbable and too tenuous an idea. Rice's delight is tied to a frame of modality. Neither the operation nor its implied performance of his expert knowledge and competence as such are important in this respect. However, they become a means to facilitate a narrative renewal. What Rice finds so intriguing is revealed in the language of the passage quoted above ("perhaps," "if," "chance," "opportunity" etc.). That the event is contingent and has not occurred yet promises the possibility of a narrative reframing and thus relief to Mr. Rice's strained condition of successive drinking and painful memories. Rice's relief first makes itself felt with his assessment that the clinical state of Molly's eyes may allow for a successful operation and culminates in the night before the operation, in which he imagines phoning his former colleagues to tell them "what [he] was about to do," that "Paddy Rice is on the trembling 
verge, Professor" (470). In short, the grief-stricken Rice is delighted at the idea of the operation as an approaching event, not because of its actual execution. For a limited span of time, he is allowed to daydream of a 'possible restoration' of his career. That is why it makes sense that he is hesitant at first about accepting the request made by Frank Sweeney; his hesitation simply prolongs this period. As long as he has not operated on Molly's eyes, he can continue to apply this otherwise impossible 'model of restoration' (he himself asserts that he will "never [be] fully restored" [490]). For the time being, he can harbor his "phantom desire" (460).

The two male characters are not particularly fond of each other, but they both share a compulsion to impose certain patterns and models of eventfulness on their own lives as well as on others'; in Molly's case, they are cruelly complicit because they are both ignorant about the outcome of the operation. Frank is not compelled to wait for the operation to be successful. His episodic energy gains momentum when he implores Mr. Rice to consider an operation and treatment of Molly; and because for him it is all about the pleasure of this inchoative initiative, the execution of the surgery as such even becomes a problem for him, as it signifies the ultimate realization of his pre-set 'Molly episode.' This can be illustrated with a close reading of how Frank experiences Molly's first examination by Mr. Rice. When Mr. Rice is at first reluctant to perform the operation, Frank Sweeney surely conveys how much he despises this hesitancy. In contrast to Rice's restoration model, his episodic model does not rely upon a period of continuity that is eventually interrupted by a single life-changing event. He simply seeks to complete the implementation of Molly into his ever ongoing sequence of episodic adventures (the beginning of which was realized by marrying Molly). Thus, from his point of view, Mr. Rice's “first cursory examination" is unbearable (467), and he actually mocks Rice's preoccupation with 'the possible':

Well of course the moment Rice said in that uppity voice of his, 'In theory - in theory - in theory - perhaps in theory - perhaps - perhaps' - the first time Molly met him - after a few general questions, a very quick examination - ten o'clock in the morning in his house - I'll never forget it - the front room in the rented bungalow - no fire - the remains of last night's supper on a tray in the fireplace teapot, crusts, cracked mug - well of course, goddamit, of course the head exploded! Just exploded! 
Molly was going to see! I knew it! For all his perhapses! Absolutely no doubt about it! A new world - a new life! A new life for both of us! (467)

What to Rice is a slow building up to the event, is to Frank Sweeney a meaningless and even precarious gap of time. All he needs is Mr. Rice to comply with his project and to undertake the operation. Thus, his mocking parody of Mr. Rice's formula is followed by a digressive and fragmentary recounting of that situation. In Frank's rendition (Molly is not mentioned at all), the whole scene is a sheer succession of his impressions of the place that is suddenly interrupted by a strange mental explosion. The non-sequitur "well of course, goddamit, of course the head exploded" culminates in the reductive and loose phrase "Just exploded!" It is as if Frank is already experiencing the eventfulness of the operation in this scene; as if, remotely for himself, he experiences the whole event, including the knowledge of its future outcome. Finally, he praises what by default mode fascinates him the most, the idea of a new beginning. And although he aims at including Molly in his ever-new vision of a 'new life,' it becomes obvious that his narrative pattern has already come to another full circle. The adventurous episode of Molly is finalized or, more precisely, abandoned. Consequently, Frank is already beginning to sense its aftermath, which is why, as he puts it, "immediately after that moment of certainty, that explosion in the head - my mind went numb; fused" (468).

Ultimately, Molly faces the operation with the two initiators being entirely ignorant of its eventful impact. In fact, their own patterns are only temporarily connected to the event that is so fatal to Molly. Whereas Mr. Rice is preoccupied with the time 'before' the event as a tenuous period on which he can project his fantasy of restoring his life and career, Frank is already experiencing an imaginary aftermath of the surgery and begins seeking a new episode in his life even before the operation on Molly's eyes is executed. Completely detached from Molly, both men initiate the event in order to establish their respective narrative patterns and meaningful periods connected to it, and both use forms of knowledge ('professional expertise' and 'sciolism') as building material. What is more, the play exposes what would happen if the two men were not able to effectively impose such patterns on life. Mr. Rice, who is tied to a painful solitary train of successive routines, repeatedly faces the memories of his former life and finds himself 
time and again "drifting in and out of sleep" in his drunkenness. Frank, by contrast, is staged to suffer from the consequences of successiveness: after the surgery he points out that, although he was "happy" (487), all he can think of "was some - some - some absurd scrap of information a Norwegian fisherman told [him] about the eyes of whales. Whales for God's sake! Stupid information. Useless, off-beat information. Stupid, useless, quirky mind..." (487-88). Frank's mind is afflicted by this "off-beat information." For the time being, he cannot establish an episodic cycle, he is stuck with Molly's "new life"; ideas or memories like the fact about the eyes of whales will inevitably be meaningless to him. Frank's episodic motor is idling, and he suffers from successive, "useless” scraps of knowledge.

\section{Gradually Increasing Successive Effects: Molly Sweeney}

What the two men can moderately keep at bay by exploiting Molly's 'case,' the play exhibits with all ruinous consequences with regard to her story. The operation on Molly's first eye is successful only from a clinical point of view. From the start, her sight presents her only with blurry and thus meaningless objects. The first thing she perceives is "a body of mist; a confusion of light, colour, movement" (483). From the very moment her bandages are taken off, Molly's new world of sight is aligned to knowledge. Assessing her new seeing capabilities amounts to her being relentlessly asked 'what she can see,' forcing upon her the task to correctly identify and name the respective object she is visually confronted with. The early stages at the hospital, in the aftermath of the operation, trigger a relapse to her former position as the little girl being tested in her father's walled garden. Here, it is Mr. Rice who serves as a proxy father and voices the paternal "Splendid!" whenever his "Miracle Molly" produces the correct name of a challenged object (490). Hence, Molly finds only meagre delight in a few correct and fatherly applauded replies. She is trapped in a world between sight and sightlessness and forced to adhere to the epistemological trajectory of her 'successful operation.' The second operation yields identical clinical results and brings about no change. Molly is guided to "learn to see" (464, emphasis in the original). She is clinically examined by Mr. Rice, receives treatment from a psychotherapist and a behavioral psychologist, who also write a booklength case study on her, and every night she has to undergo the relentless 
testing by her husband, who presents her any item from quotidian life in order to "build up a repertory of visual engrams to connect with" her already established "tactical engrams" (491). In short, Molly becomes an object of knowledge herself. The more the male initiators of the surgery become reluctant about its eventful impact on Molly, the more they force the idea of seeing upon the notion of knowledge.

Consequently, the play's bitter irony puts Molly more and more in distress. The more the (predominantly) male characters scrutinize and study her new, yet only clinically defined sighted state, the less she is able to translate knowledge into a coherent and meaningful narrative pattern herself. Accordingly, this change is highlighted in the play with an increased use of images evoking the idea of sheer successiveness. What can be gradually discerned as the play's sine qua non, the idea of tying its characters to the fundamental and irreducible cadence of one thing following another, in Molly's case becomes the staging of a character completely abandoned to her own (narrative) fate. Molly is left to her own devices in a new world that consists of successive and strange pieces of information she is forced to process:

Every shape an apparition, a spectre that appeared suddenly from nowhere and challenged you. And all that movement - nothing ever still - everything in motion all the time; and every movement unexpected, somehow threatening. Even the sudden sparrows in the garden, they seemed aggressive, dangerous. (492)

Soon her resilient model of sequentiality of her former blind world, once so cleverly detected and undermined by Frank Sweeney in his pursuit of her, is irrevocably lost. She faces a "very foreign world" (492), which by its cruel nature, demands Molly to answer on the narrative plane. However, the more she is forced to do so, the less she feels capable of it. As with the sparrows in the garden, suddenness becomes a threatening, "even alarming" alternative to the monotonous succession of unintelligible apparitions. Eventually her mind and body fail to respond at all: "Just one more colour light - movement - ghostly shape - and suddenly the head imploded and the hands shook and the heart melted with panic" (492). Molly escapes by becoming motionless herself. She retreats to her room, closes her eyes, and sits on her bed until she finds the "courage to face it all once more" (492). New beginnings amount to a painful effort. 
Molly's physical and mental collapse produces only more queries and theories on the part of the male interrogators. Mr. Rice, for example, discerns and lectures upon "symptoms of a condition known as blindsight" (498), a physiological condition in which, due to a "malfunction in part of the cerebral cortex," Molly "was indeed receiving visual signals and she was indeed responding to them [but] none of this perception reached her consciousness" (498, emphasis in the original). With similar assurance and inspired by the psychological explanations of Molly's "behaviour" from the psychotherapist Jane Wallace (494), Frank declares his wife simply as undergoing a "withdrawal" (497). But the explanatory knowledge Frank is provided with by the medical and therapeutical experts not only entitles him to dismiss Molly, the play also demonstrates its ultimately makeshift and limited nature. When there is "a new development" implying sudden "spells of dizziness" on the part of Molly, even Mr. Rice has no "explanation" (495). Instead, in one of his "skirmishes" (496) with Frank he makes a quip by telling him that it is called "gnosis" (495). In lack of a repartee, Frank has Rice spell the word for him (“'G-n-o-s-i-s””, [496]) and thus not only parses the linguistic constituents of the word but symbolically dismantles its etymological Greek meaning, i.e. "knowledge." Impelled to seek this 'knowledge,' Frank performs his default move, goes instantly to the library, and traces its encyclopedic meaning only to revel in the thought that Molly is now "full of mystical knowledge!" (496). As soon as the male characters lose their valid hold on Molly's case, the reciprocal potency they gained through knowledge is adrift, and the application of knowledge becomes an absurd, self-referential token gesture.

Except for the scientific counselling he receives from Rice and the other scientists, Frank remains utterly clueless about Molly's, as he puts it, “very difficult behaviour" (494). From a narrative point of view, he can make no sense of Molly's increasingly long periods of silence and inertia. What is more, as if conveying her (adrift narrative) experience of her sudden shocks to him, she abruptly interrupts her apathy and requests his immediate support in bursts of strange activities, like diving into the Atlantic Ocean from a steep local cliff:

Then after about half-a-dozen attempts she stood up and came to the door - it was then I could see she was crying - and she switched off the light. Then she went 
back to the dressing-table and sat down again; in the dark; for maybe an hour; sat there and gazed listlessly at the black mirror.

Yes, she did dive into the Atlantic from the top of Napoleon Rock; first time in her life. Difficult times. Oh, I can't tell you. Difficult times for all of us. (495)

Aptly juxtaposed in Frank's rendition, it becomes clear that he cannot understand Molly's extreme changes from inactivity to sudden activity. Neither state provides him (nor Molly) with a coherent narrative structure. Although the (sudden) interruption of any continuous state is fundamental in narrative - the perception of continuity profoundly depending on the idea of interruption and vice versa -, in Molly's case, these transitions don't form any meaningful patterns. 'Continuity,' 'interruption,' 'eventfulness,' the logic of 'before-and-after states,' and other fundamentally narrative aspects do not apply in Molly's alienated world. Instead, successiveness takes over, each period parsable into distinct successive units, all of which being indistinct from one another. Thus, neither knowledge nor narrative is at Molly's disposal to compensate for her loss of meaning from her former days. Her husband, for his part, is similarly confounded by her behavior; the more he tries to apply his resources of episodic knowledge seeking to Molly's 'case,' the more he drifts off, and the disintegration of their marriage comes full circle when the hiatus between knowledge of the sighted men counselling and testing her and Molly's anarrative apathy can no longer be bridged.

The male project to save Molly's viability by imposing male knowledge schemes of narrative progress and success on her is ultimately reduced to a futile successive treatment: “Tests - tests - tests - tests!" (496) - Molly laments, accordingly, in one of her late monologues; and when Frank comes figuratively to "the end of [his] tether" (498), he has no more narrative resources nor willingness to further engage with Molly's disturbed and offbeat narrative state. Frank eventually succumbs to the frequent offers of new adventurous episodes pitched to him by one of his drinking buddies and scheming allies. He leaves Molly in order to supervise a food convoy to Ethiopia, from where she receives a letter in which he praises his new fascination: "Never in his life has he felt so committed, so passionate, so fulfilled" (508). To realize this new 'commitment,' he commits Molly to a psychiatric hospital. Here, she takes on the maternal trauma in her family, 
and her alienation receives a first extension by transgressing the boundary between reality and fiction:

In those last few months I was seeing less and less. I was living in the hospital then, Mother's old hospital. And what was strange was that there were times when I didn't know if the things I did see were real or was I imagining them. I seemed to be living on a borderline between fantasy and reality. (500)

What has been only isolatedly traceable in the men's lives as Frank's “offbeat information" or Rice's drunken "drifting in and out of sleep" (508) manifests itself in Molly's life now as a default mode. Spatially restricted to her ward, Molly's final state is "depicted as a form of matrilineal experience" (Ojrzyńska 263). It is in the psychiatric hospital when Molly recalls her first meeting with Mr. Rice and points out, very accurately, what had been at stake when she was first faced with the possibility of an operation on her eyes:

Oh my God, he's asking you profound questions about good and evil and about the source of knowledge and about big mystical issues! Careful! Don't make a fool of yourself! And of course all the poor man wanted to know was how much vision I had. (506)

What Molly realizes here is an allegedly banal wisdom - already voiced earlier in the play by Rice, who in the light of his painful realization that he had been betrayed by his wife, dismally affirms that one is not to confuse "seeing with understanding" (475). Nevertheless, the play's consistent and bitter irony comes to the fore when it has him utter it at the very moment he realizes this betrayal's full narrative impact on his life, as exactly this would be the very seed for the tempting "phantom desire" to restore his life and reputation with operating on Molly's eye. Thus, Rice finds his knowledge obscured by narrative. In contrast, when Molly finds herself hospitalized, she is finally able to leave coercive testing behind by disconnecting seeing from knowing in a permanent, yet tragic, way. What began with the intimidating feeling of having to reply to profound questions "about the source of knowledge" in her first interview with Rice, ends with him paying her a final visit at her bed, where he observes that "she was trying to compose another life that was neither sighted nor unsighted, somewhere she hoped was beyond disappointment; somewhere, she hoped, without expectation" (501). What Rice inevitably channels through the forms of 
expertise knowledge, Molly pays for on the narrative plane. Yet one 'insight' of hers remains in her "borderline country" (509): she has aborted the idea of addressing any (knowledge seeking) questions with regard to her condition of sight(lessness):

I think I see nothing at all now. But I'm not absolutely sure of that. Anyhow my borderline country is where I live now. I'm at home there. Well...at ease there. It certainly doesn't worry me any more that what I think I see may be fantasy or indeed what I take to be imagined may very well be real - what's Frank's term? external reality. Real - imagined - fact - fiction - reality - there it seems to be. And it seems to be all right. (509)

Molly has many visitors, imaginary ones, real ones; they come and go and mix with memories of her childhood. In short, she has been completely deprived of any conceivable narrative pattern; successiveness has taken over to an absolute degree, and it not only seeks its way in endless, indiscriminate arrays of fictional and real visions, it also undermines the fundamental principle of all narrative: the idea of irreversibility. In this light, Brian Friel's Molly Sweeney dramatizes the story of a woman (who happens to be blind) who, at the end of her days, remains irreversibly bound to an endless realm of reversible successions. In this realm there is no longer any need for any further inquiry nor for knowledge, which is why, with final consequence, her last line in the play is: "And why should I question any of it any more?" (509).

\section{Works Cited}

DeVinney, Karen. “Monologue as Dramatic Action in Brian Friel's Faith Healer and Molly Sweeney." Twentieth Century Literature 45.1 (1999): 110-19.

Friel, Brian. Molly Sweeney. Brian Friel: Plays. Vol. 2. London: Faber and Faber, 1999. 447-509.

Kerrigan, John C. "Swimming in Words: Molly Sweeney's Dramatic Form." A Companion to Brian Friel. Ed. Richard Harp and Robert C. Evans. West Cornwall: Locust Hill, 2002. 151-61.

Krause, David. "The Failed Words of Brian Friel." Modern Drama 40.3 (1997): 359-73. 
Moloney, Karen M. “Molly Astray: Revisioning Ireland in Brian Friel's Molly Sweeney.” TCL 46.3 (2000): 285-308.

Ojrzyńska, Katarzyna. "One, Mad Hornpipe: Dance as a Tool of Subversion in Brian Friel's 'Molly Sweeney." Text Matters: A Journal of Literature, Theory and Culture 1.1 (2011): 252-67.

Sacks, Oliver. “To See and Not See.” An Anthropologist on Mars. London: Picador, 1995. 102-44.

Silverstein, Marc. “'With Greedy, Ravenous Eyes': Viewpoint as Vanishing Point in Molly Sweeney." Essays in Theatre/Etudes Théâtrales 18.1 (1999): 37-52.

Souriau, Etienne. "Die Struktur des filmischen Universums und das Vokabular der Filmologie.” Trans. Frank Kessler. Montage/AV: Zeitschrift für Theorie und Geschichte audiovisueller Kommunikation 6.2 (1997): 140-57.

Temple, Julia. "The Gift of Sight in Molly Sweeney." A Companion to Brian Friel. Ed. Richard Harp and Robert C. Evans. West Cornwall: Locust Hill, 2002. 133-49.

Upton, Carole-Anne. "Visions of the Sightless in Friel's 'Molly Sweeney' and Synge's 'The Well of the Saints." Modern Drama 40.3 (1997): 347-58. 



\title{
Anja Pistor-Hatam \\ Historiography and the Production of
Knowledge: The Mongol Period
}

\begin{abstract}
This essay participates in the postcolonial critique of hegemonic knowledge formations, focusing on the textuality and the narrative quality of historical accounts on the Mongol period in Iran (1216-1335). Modern historical narratives by well-known but non-professional Iranian historians, all of which are regarded as state of the art in Iranian school and university education, are selected for investigation. Large parts of these texts' content can only be accepted as plausible if one reads them as adopting not only Mongol history, but modern Iranian national(ist) historiography: As constructions of historical meaning they retrospectively employ fictions of coherence to forge a usable past that fits and supports an overall nationalist political paradigm.
\end{abstract}

\section{Introduction}

Whenever historical knowledge is conveyed through written narratives, textuality plays an important part in its diffusion. Historical knowledge, then, must be regarded as a specific linguistic entity (Rüsen, "Geschichtsschreibung als Theorieproblem" 31) since the "presentation of a "usable past' [...] is first and foremost a construct of language" (Scott Meisami 12). Moreover, a historical event appears as one of many elements in a narrative, whose author - the historian - has chosen which events to integrate into his or her text. Therefore, his or her writing does not treat immediate reality but "its interpreter's relation to it" (Stock 80):

Narrative requires narration; and this activity is not just a recounting of events but a recounting informed by a certain kind of superior knowledge. [...] The narrator $[\ldots]$ picks out the most important events, traces the casual and motivational connections among them, and gives us an organized, coherent account. (Carr 59)

Although these attitudes and theories regarding historical texts have been part of the academic paradigm in historiography for some decades, many students of history still use historical narratives to retrieve 'facts.' Thus, however, they did and do not sufficiently take into account that historians of the past did not simply put events they themselves experienced or were told 
about by others in a chronological order to enlighten their contemporaries and generations to come. Instead, these authors of historical narratives carefully as well as specifically chose the events they wanted to become part of their accounts and fit them into their tale. Iranian scholars establishing a 'national historiography' under Reza Shah Pahlavi (gov. 1925-1941) in the 1930s as well as their students and successors up to the present, for example, did not and still do not consider historiographical writings of the past a literary genre, but regard it as a source from which historical 'facts' can be deduced.

In this article, I will show how Iranian scholars writing about the Mongol era (1216-1335) employed historiographies from the Mongol period to produce historical knowledge. They specifically gave meaning to a part of Iran's 'national history' that is still considered by Iranians at home and abroad to have been largely disastrous and traumatic. To let the selected exemplary texts speak for themselves, I will refrain from commenting upon the authors' presentations of a 'usable past.' Subsequently, the narrative strands demonstrating the way Iranian scholars give meaning to the Mongol period in Iran will be analyzed in regard to the theoretical frame established.

For the conquered peoples, the Mongol invasions in Central and Western Asia of 1219-1224 and 1256-1258, proved to be experiences of contingency that left contemporary observers, later historians, and even present-day commentators stunned. Since it is a basic principle that human experience of temporal change provokes confusion, such experiences must be integrated into a concept of temporal order and established meaning. The confusion brought about by the breach or rupture of such a conquest must be mended by historiography, which fills historical contingency with significance and meaning (Rüsen, "Einleitung” 51-52). Undoubtedly, the Mongolian conquests brought about war, destruction, starvation, disease, and displacement, and they temporarily ended the rule of Islam in the Eastern part of the then Muslim World. It was under Mongol rule that we witness an "impressive creative outburst of historical writing" (Daniel), if not the actual beginning of historical narrative in the Persian language. Imperial Mongol rule thus served as a stimulus to historiographical production in Persian on a large scale (Melville).

This essay pursues the question whether it is at all plausible that the contemporary as well as the more modern ,trauma', both Muslim and Western 
sources talk about, was actually experienced as a reaction to these violent incidents, or whether this alleged 'trauma' might be part of a metanarrative of modern historiography that has been employed as an interpretive instrument for decidedly ideological reasons. According to Jeffrey Alexander, a cultural trauma only occurs, when members of a collectivity are convinced that they have been subjected to "a horrendous event that leaves indelible marks on their group consciousness, marking their memories forever and changing their future identity in fundamental and irrevocable ways" (1). Thus, a cultural trauma is constructed as such by a society's carrier groups, whose members allege a fundamental threat to their self-image, claiming "emotional, institutional, and symbolic reparation and reconstitution" (Alexander 11). To convince a wider audience of their collective trauma, the carrier group has to "engage in successful meaning work" (11). In the case of Iran, modern authors of historical narratives, whom we may call a carrier group, consider the Mongol invasions a trauma or a genocide and call for recognition of the pain suffered by their ancestors and - due to the Iranian collective memory - themselves.

To give meaning to an event of temporal change that might also be considered 'traumatic,' historians often provide metanarratives that reinterpret historical incidents. They might, for example, resort to the "triumphover-alien-forces" schematic narrative template, according to which an unsuspecting people is conquered by a brutal alien force that the culturally superior former victims finally triumph over (see Wertsch 51, 57-58). More often than not, such metanarratives, developed by nations that establish their identity on victimization, are characterized by self-auratization and mythmaking. Hence, an experience of (repeated) defeat, loss, and humiliation is at the basis of an arsenal of phantasmal reinterpretations, i.e. counterproposals and the transformation of defeat into spiritual or moral elevation (A. Assmann 70).

In the texts on the Mongol period in Iran under review, such reinterpretations, including fictions of coherence, are manifold. Fictions of coherence that are incorporated in these historical narratives serve as constructions of identity and self-assurance. Therefore, they cannot be simply exposed as 'fabrications,' but have to be recognized as constructs that instill often contingent historical events with meaning (J. Assmann 7-8). As the texts presented in the ensuing section of this essay show, modern Iranian historical 
narratives about the Mongol period - regardless of whether they were written during the Pahlavi era or in the Islamic Republic - are assigned the task of giving meaning to this epoch of Iranian 'national' history. They must integrate this era into the "linear time of the nation" (Özkırımlı 208-09) and comply with the needs of society regarding the construction of meaning. This article presents and analyzes modern historical narratives on the Mongol period written by well-known Iranian authors. Significantly, their academic training often lacks history as a field of study. We must therefore regard them as enthusiasts or pastime historians. Yet, the majority of their historical narratives were written and published as textbooks to be taught at schools and universities where they have a large impact on public historical consciousness. They are regarded as state of the art as far as scholarly texts on the Mongol era are concerned. Yet, as will be shown, large parts of their content can only be accepted as plausible if one reads them as a contribution to the history of meaning that leaves room for fictions of coherence.

\section{Modern Iranian Historical Narratives: Mongol History and its Meaning}

In what follows, parts of the historical narratives on the Mongol period in Iran will be presented in relation to the theoretical framework established above. The subjects selected represent some of the major narrative strands like the repercussions of the first Mongolian invasions for 'Iran,' and the Islamization and Iranization of the Mongol dynasty of the Ilkhanids (1256-1335). Both repercussions are closely connected to the way in which the Mongol era in 'Iran' is made to fit into a historical narrative which supports 'national history and Iranian identity.' Remarkably, although the political and social circumstances underwent enormous changes from the Pahlavi monarchy to the Islamic Republic, these premises have not altered.

1 As a political entity, Iran had not existed since the defeat of the Sasanians (224-651 AC) by the conquering Arabs. Only through Mongol rule was a political unity called 'Iran' established again. 


\subsection{The First Mongolian Invasions in Iran (1219-1224) and its Consequences}

In the historical narratives written in Iran between 1933 and 2011, the consequences of the Mongolian invasions in Iran are usually described as disastrous. Overall, according to Eqbal, the Mongol conquests were carried out so rapidly and relentlessly that they resembled a celestial rather than a historical event (Tarikh-e moghul vol. 1, 100). He compares the invasions with a natural catastrophe like a tempest, torrent, or flood (Tarikh-e mofassal-e vol. $2,445,569)$. In their wake, so the dominant narrative configuration goes, the mass killings, lootings, and complete destruction of the lands were catastrophic. Even more devastating was the damage these invasions did to the Islamic civilization and the degradation they imposed upon the Arabic and Persian sciences (Eqbal, Tarikh-e moghul vol. 1, 100, see also 106-08). The victory of a wild nomadic people, who did not have the morality of the sedentary nation at its command, shook the foundations of the conquered society to the core and led to its decline, Safa explains (77). Still, the same author continues, the intellectual deterioration in Iran must be regarded as the most fatal and dangerous result of the Mongol conquest: mostly poor and weak individuals survived, whereas most of the rulers were slain, families of grandees vanished, and the centers of knowledge and morality were ruined. The thread connecting Mongolian Iran with its past was torn, and Iranian civilization, including its literature, wholly decayed (Safa 78, 83, 302-03). Caused by the ferocity of the Mongol attack, Iranians lost most of their national skills as well as their racial thought. Therefore, they proclaimed religious war against the Mongols rather than fighting a national or racial combat (Safa 83-84). Although those one hundred years of Mongol invasions and rule did indeed constitute a historical rupture, Djafariyan argues, there still existed a strong connection with the pre-Mongol past. This was due to the cultural and religious steadfastness of the Islamic world at that time, which was a lot stronger than its political persistence (15).

According to Panahi, it was the Mongols' custom to order massacres and complete destruction of each village or town whose inhabitants had put up resistance. These crimes were used as an effective means of propaganda to strengthen the Mongols and demoralize their victims (39). According to 
Dastgheib, the invasion was a coordinated felony. Because Genghis Khan had promised his troops that they would conquer the world, there existed an interrelation between the foundation of the Mongol empire and a divine and mystical power, including human sacrifice, he states. This, Dastgheib concludes, could be seen as an analogy to the ideology and politics of Hitler's Germany. At the end of the day, Genghis Khan's machinery of war and his sacred imperial routine served the purpose of "conquer[ing] the world at the expense of its annihilation" (14-15). Rather than withdrawing after their attack, the Mongols spread out their belongings on the burnt land and held a lavish banquet on the hill of corpses. They bled the people white and corrupted Iranian culture and society (Dastgheib 49, 141-42, see also 34).

Yet, according to some, Mongol rule also had its positive effects: The Mongols united the lands they had conquered under central rule, established security on the routes, stimulated and promoted trade relations, and set up political relationships between Asia and Europe. They took care of the exchange between scholars of different provenance, disseminated the Persian language and Islam in East Asia, and appointed Iranian viziers and advisers in non-Islamic lands as well as to the administration of China (Eqbal, Tarikh-e moghul vol. 1, 109; Djafariyan 37). Consequently, it was during the Mongol era that political and economic connections of Iran were revived for the first time after the Arab invasions and the fall of the Iranian Sasanians (224-651) (Djafariyan 124). As stated by Mortazavi, even if the Mongol conquests were characterized by bloodshed, destruction, and subsequent stagnancy, later historians had clouded the positive effects of Mongol rule with a curtain of fanaticism, prejudice, and animosity (xv). The state of affairs in Iran after the capture of the Abbasid capital of Baghdad in 1258, he continues, consequently raised the question whether historical tradition had not given us a one-sided account of events. Clearly, the historians' averseness and bias were not founded on their witnessing of the events. Rather, their interpretation of occurrences has to be ascribed to the shock felt by the Sunnite community evoked by the fall of Baghdad and the slaughter of the last Abbasid caliph. In fact, Mortazavi claims, the Ilkhanids supported freedom of thought, prohibited national and religious fanaticism, and established some of the most significant centers of learning (xv-xxiii). 
As a metanarrative, the 'triumph-over-alien-forces' template is widely referred to in the texts under consideration: According to Eqbal, whenever two peoples collide, a time of massive conflict arises between their natural talents and lifestyles. Eventually, the people prevailed whose administrative skills and political experience were more advanced and whose civilization and customs were more entrenched, particularly, if this people possessed literature, legends, and myths as powerful means of connecting them with their forebears (Tarikh-e moghul vol. 1, 81-82). Therefore, he continues, the ancient civilizations of Iran and China soon took revenge against the conquerors and encumbered the Mongol rulers with their own languages, religions, and the basic principles of administration and government (Tarikh-e moghul vol. 2, 449). In fact, Bayani contends, the combat between the Mongolian conquerors and the Iranian conquered was a battle between two dissimilar belief systems and cultures. Whereas the victorious Mongols tried to impose their rule onto Iran, the defeated Iranians carefully and cleverly planned to liberate their "historical identity and their beliefs" (Din vol. 1, vii-viii). Gradually and cautiously, they took authority into their own hands to purge their own customs, their culture, and civilization of an alien influence (Bayani, Hasht 223). Capable Iranian men slowly tamed the 'Mongolian dragon' and put him on the path of scientific progress and scholarship, as schools were founded, trade and economy were encouraged, and fanaticism and heresy were prohibited (Mortazavi xvi). According to Dadfar, the Iranians thus were the eventual victors. It did not take long before the 'wild' Mongols and their leaders were affected by Irano-Islamic culture and succumbed to its appeal. Eagerly, Iranians tried to safeguard their identity and to subjugate their aggressor. In this way, he says, they penetrated the centers of Mongolian power and distributed their language and script in the Mongol realm. Owing to its superior culture and civilization, a people that seemed to be conquered, ultimately transformed its defeat into triumph (81-82).

\subsection{Defeating the Enemy: The Islamization and Iranization of the Ilkhanids (1256-1335)}

Another massive Mongol invasion took place in 1256. One of its aims was to make the Abbasid caliph in Baghdad submit to the Mongols. After the 
caliph refused to subdue, Baghdad was conquered and the caliph slain by the Mongols and their allies in 1258. The Mongolian victors then consolidated their reign as 'Ilkhanids' (i.e. subordinate khans in regard to the great khan) permanently on the Iranian plateau, the Caucasus and Mesopotamia.

According to Bayani, Iranians in the service of the Mongols pursued a common aim: They sought to revive their nation and culture by reigning in the foreign element and defeating its government (Din vol. 2, xi). In the clash of cultures, that is the combat between conquered and conquerors, Mongol and Iranian principles, she states, these Iranian government officials, viziers, and advisors played a vital role. Whereas the Ilkhanids sought to strengthen their power and to be accepted by their subjects, the Iranian people tried to restore their national and cultural existence. Since the Mongols did not themselves administrate the state, their Iranian government officials eagerly worked toward the people's goal and began their clandestine war against the foreign element (Bayani, Din vol. 2, xi; see also Mortazavi 85). The weapons they used were administration and religion. Since Islam was tightly connected to Iran's national culture, the people turned to religion as their sheet anchor to defend their national existence when in the wake of the Mongol invasions they witnessed the annihilation of their nationality and culture (Bayani, Din vol. 1, vii):

There began a merciless and clandestine war at whose end tradition and culture shone again under its banner. The Iranians triumphed, they finally governed themselves. [...] Amongst our legends we hold the myth of a bird called phoenix, which, although it is burned by old age and weakness, rises anew from the ashes and never dies. (Bayani, Din vol. 1, 356-57)

The crucial turning point in the history of Ilkhanid rule, as the authors quoted here agree, came with Ghazan Khan's (gov. 1295-1304) conversion to Islam. He was convinced by one of his emirs that by embracing Islam he would become the permanent ruler of Iran. Muslims would be liberated from the ignominy of having to live under the reign of unbelievers, and God would grant him assistance and victory in his wars. Finally, the Muslim and Iranian principles had prevailed in the contest between Iranians and Mongols, Eqbal concludes. The Ilkhanids not only converted to Islam but also embraced its Shiite creed, the predominant religion amongst Iranians, under Ghazan's rule (Tarikh-e moghul vol. 1, 257). Due to his reforms, his legislative acts and his building activities, Ghazan Khan, according to Eqbal, 
has to be considered one of the greatest sovereigns of the Orient. Even if he could not be compared with the Achemenid (558-330 BC) rulers Cyrus the Great (gov. 558-530 BC) or Dareios I. (gov. 522-486 BC), and the elevated rulers of the Sasanians, due to his governance and administration, Ghazan Khan had to be regarded as one of the most eminent sovereigns of Iran and the greatest ruler of the Ilkhanids (Eqbal, Tarikh-e mofassal-ev vol. 2 512). Together with his Muslim emirs, Safa observes, Ghazan Khan breathed new life into Iranian Islam, rescued it from doom, and saved it from the predominance of other religions that were spreading in Iran. He regards this ruler's conversion to Islam as the starting point of a great change in the history of the Ilkhanids, and considers the khan himself to be an Islamic, or rather an Iranian ruler (Safa 130). According to Mortazavi, the accession of this khan, and especially his conversion, are a turning point in Iranian history. From then on, the Ilkhanid reign allegedly took over an entirely Iranian and Islamic manner. Regarding its importance and the intensity of its human and social aims, this epoch was unique and admirable (Mortazavi 86). Similarly, Mortazavi goes on, Ghazan Khan ensured Iran's social autonomy and initiated its religious freedom - both initiatives counting among the most prestigious deeds in the life of the Iranian people during the Islamic era. After seven hundred years, it was under Ghazan Khan's rule that the basic requirements for the creation of "a large geographic and religious unity, a united and independent Iran” were met (Mortazavi 87). His reign took over Iranian principles and his political style and strategies were shaped by conformity, not force. Thus, as Mortazavi determines, the coincidental agreement of Ghazan Khan's policy with the historical nature of the Iranian people brought together those social and political foundations that encouraged national unity and the naissance of a great state (172-73). Ghazan Khan, he says, cleared away humiliation's dark cloud that foreign rulers had spread over the Iranians' way of thinking, without ever considering their wellbeing. Accordingly, the significant changes brought about during the Ilkhanid period were no coincidence. On the contrary, these changes were considered a stage in the natural and inevitable development of Iranian history. During the reigns of Ghazan Khan and his successor Öljeitü (gov. 1304-1316), the foundations for the historical and socio-political advance were laid down. In this context, the Ilkhanid rulers' true motives for embracing Islam were completely irrelevant (Mortazavi 173-74). 
Bayani argues that, when the Iranian element succeeded in leading the sixth Ilkhan to Islam, the struggle between the Iranian and the foreign elements ended. In this line of argument, the Iranian element subsequently brought down its adversary forever and, using religion as its weapon, resurrected Iranian nationality and culture (Din vol. 2, 435). This was the moment, Bayani goes on to explain, when conquerors and conquered changed places (436). Since Ghazan Khan strengthened his rule and instructed successful reforms, he could end relations with the center of the Mongol empire in Beijing (465). His most important achievement, however, was that he was able to protect Iran's unity from Herat to the Euphrates (471). Öljeitü for his part visited the Taq-e Kesra, that is the ruins of the ancient palace of the Sasanians near Baghdad, thereby proving that Iranian culture had again reached its zenith while Ilkhanid rule had also hit its peak (480-81).

\section{Analysis}

Most of the historical narratives presented above describe the Mongol invasions and rule in Iran as a dramatic event and a traumatic rupture. Congruently, they agree on the main components for the construction of cultural trauma: the pain of the Iranian victims, the liability of the Mongol aggressors, and the ideational consequences their conquests had for the further advance of Iranian civilization. Yet, how profound this rupture had really been, is a matter of discussion. While one author claims that the "thread of the bond" between pre-Mongolian and Mongolian Iran had been torn (Safa 303), others disagree. They maintain that despite increasing moral corruption under the Mongols, the idea of Iran nonetheless persisted. Accordingly, the link between the people of both epochs is claimed to have been maintained and no detachment of their cultural relations occurred because the cultural and religious steadfastness of the Islamic world is seen as stronger than its political constancy (Eqbal, Tarikh-e moghul vol. 1, 81-82; Djafariyan 15).

Although the Mongol invasions are described as exceedingly vicious, not least to explain their victory, it still seems to be more plausible to the mentioned authors to depict the Mongol era in terms of resurrecting Iranianness. This narrative of the Iranian phoenix rising from the ashes is another version of the "triumph-over-alien-forces" narrative. It succeeds mainly in 
consequence of another form of construction of meaning or reinterpretation of history: helped by their superior (Islamic-)Iranian culture and civilization, Iranians had overcome the Mongols; they had tamed the Mongolian dragon and transformed their defeat into victory. Thus, a military defeat is reinterpreted as a mental victory ascribed to the supposed religious and cultural superiority of the original victims. In view of the definition of historiography as a "science of self-understanding" (Lorenz 410), modern Iranian historiography's task is to integrate the Mongol era into a national historical narrative coming into existence about 800 years later and to give meaning to this era in the context of this particular history that is to be told 'from its beginnings to the present day.' For that reason, the historical narrative does not concentrate on the immediate coming to terms with contingent events and the possibly resulting traumas. Instead, historical narrative gives meaning to these events retrospectively by using fictions of coherence. Despite the changing social and political circumstances, the accounts under review advance the concept of an eternal, indestructible Iranianness. The reinterpretation of events confirms this fiction of coherence to declare Iranianness as the true victor that defeated the Mongols and all other invaders. Accordingly, these narratives corroborate the selfawareness of the present day's Iranian nation, offer it security, and open a future perspective. In this context, their comparison of the consequences of the Mongol invasions in the $13^{\text {th }}$ century to the extinction of European Jewry in $20^{\text {th }}$-century Europe fits well into the narrative: Using this analogy, an explanation is offered for the Mongol conquest of Iran - their brutality, their military equipment, and psychological warfare made resistance pointless. According to this fiction of coherence, the 'Iranian people' at that time became victims like the European Jews in the $20^{\text {th }}$ century who had no possibility to defend themselves in the face of an unprecedented onslaught.

Ghazan Khan, it is said, was one of the greatest rulers of the Orient; apart from being a Muslim, he also was an Iranian ruler. In this way Ilkhanid rule was transformed into an Iranian reign. This fiction of coherence on the Islamization and Iranization of the Ilkhanid ruler, who supposedly ended a period of humiliation and initiated a new era in Iranian history, is supported by contemporary narrative sources describing the rule of the Ilkhanids as "another cycle of Iranian kingship, brought to a peak with the reign of the philosopher king and just ruler, Ghazan Khan" (Melville 140, 142). There is 
obviously a great proximity of myth and history in these narratives. In the context of the construction of meaning as it is discussed here, this new era is identified with the victory of the 'Iranian element,' and the reestablishment of an Iranian nation state - which, in fact, was only instituted under Reza Shah Pahlavi in the early $20^{\text {th }}$ century.

"Consistency in the use of reason" is essential for the plausibility of narratives and requires the "principle of mutual recognition of dissimilarities” (Rüsen, "Einleitung” 29). As indicated above, modern historical narratives of the Mongol period are largely affected by reinterpretations and fictions of coherence, which have to be ascribed to socio-political conditions and associated nationalist and religious ideologies, respectively. On closer examination, therefore, they often lack plausibility and do not comply with standards of scholarly analysis such as confirmability, rationality, and the reflection of the individual scholar's own viewpoint. Only on the assumption that these narratives should be understood in the context of a relativistic history of meaning that, instead of deconstructing these fictions of coherence, recognizes them as plausible, it is at all possible to appreciate large portions of their content. In doing so, the consequences of this construction of the past need to be closely linked to the Iranian authors and their surrounding society. At the same time, it is necessary to generate awareness for the fact that historical realities are always constructs established by the historical creation of meaning and that they thereby produce a coherence of continuity (Straub 85-87, 128). That is to say, history itself is the product of a culture or society with its own semantic paradigms (J. Assmann vii, 13). The relativist approach of the history of meaning becomes necessary because of the diversity of historical thought in an inter- as well as intracultural perspective that the historical narratives point to. The polyphony and contingency of historical actions thus cannot be suppressed by a monophonic narrative.

Modern Iranian authors studying Mongol history are assigned the task of giving meaning to history. They need to integrate this era into the "linear time of the nation" (Özkırıml 208-09) and to comply with the requirements of their society regarding the construction of meaning. Similarly, their historical narratives have to be regarded as a culturally embedded form of knowledge production. In the view of those producing this kind of knowledge as well as for teachers and students both at the university level and 
at school, this is methodically established, reliable, and truthful scholarly knowledge. It fits well into the overall nationalist paradigm pursued since the late $19^{\text {th }}$ and established in the early $20^{\text {th }}$ century. In the Islamic Republic of Iran, a strong Shiite narrative strand has been added to the metanarrative while other narrative strands like the emphasis on Persian literature as part of 'Iranian identity,' for example, were allowed to remain.

\section{Works Cited}

Alexander, Jeffrey C. "Toward a Theory of Cultural Trauma." Cultural Trauma and Collective Identity. Ed. J. Jeffrey C. Alexander, Ron Eyerman, Bernard Giesen, Neil J. Smelser, and Piotr Sztompka. Berkeley: University of California Press, 2004. 1-30.

Assmann, Aleida. Der lange Schatten der Vergangenheit. Erinnerungskultur und Geschichtspolitik. München: Beck, 2006.

Assmann, Jan. The Mind of Egypt. History and Meaning in the Time of the Pharaohs. New York: Harvard University Press, 2002.

Bayani, Shirin. Din va doulat dar Iran-e 'ahd-e moghul. 3 vols. Tehran: Markaz-e nashr-e daneshgahi, 1988-1996.

-. Hasht maqale dar zamine-ye tarikh. Tehran: Daneshgah-e Tehran, 1973.

Carr, David. Time, Narrative and History. $2^{\text {nd }}$ ed. Bloomington: Indiana University Press, 1991.

Dadfar, Sajjad. Hamle-ye moghul be-Iran. $2^{\text {nd }}$ ed. Tehran: Mo'assase-ye farhangi-ye madrase-ye Borhan, 2011.

Daniel, Elton L. "Historiography iii: Early Islamic Period.” Encyclopcedia Iranica Online. Center for Iranian Studies, Columbia University. December 15, 2003. URL: http://www.iranicaonline.org/articles/historiography-iii.

Dastgheib, Abd ol-Ali. Hodjum-e ordu-ye moghul be-Iran. Tehran: Entesharat-e 'elm, 1988.

Djafariyan, Rasul. Az yoresh-e moghulan ta zaval-e torkmanan (qarn-e haftom ta nohom-e hedjri). $6^{\text {th }} \mathrm{ed}$. Tehran: Entesharat-e kanun-e andisheye djavan, 2008.

Eqbal, Abbas. Tarikh-e moghul va avayel-e ayyam-e teimuri, 2 vols. Tehran: Nashr-e Namak, 1997. 
Eqbal, Abbas. Tarikh-e mofassal-e Iran az estila-ye moghul ta e'lan-e mashrutiyyat, 2 vols. Tehran: Ketabkhane-ye Khayyam, 1933.

Lorenz, Chris. Konstruktion der Vergangenheit. Eine Einführung in die Geschichtstheorie. Köln: Böhlau, 1997.

Melville, Charles. "History and Myth: the Persianisation of Ghazan Khan." Irano-Turkic Cultural Contacts in the $11^{\text {th }}-17^{\text {th }}$ Centuries. Ed. Éva Jeremiás. Piliscsaba: The Avicenna Institute of Middle Eastern Studies, 2003. 133-60.

Mortazavi, Manuchehr. Masa'el-e 'asr-e ilkhanan. Tehran: Bonyad-e mouqufat-e Dr. M. Afshar, 2006.

Özkırıml, Umut. Theories of Nationalism: A Critical Introduction. $2^{\text {nd }}$ ed. Basingstoke: Palgrave Macmillan, 2010.

Panahi, Mohammad Ahmad. Djengiz Khan, chehre-ye khunriz-e tarikh. Tehran: Entesharat-e Hafez-e Novin, 1994.

Pistor-Hatam, Anja. Geschichtsschreibung und Sinngeschichte in Iran: Historische Erzählungen von mongolischer Eroberung und Herrschaft, 1933-2011. Leiden: Brill, 2014.

Rüsen, Jörn. "Einleitung: Für eine interkulturelle Kommunikation in der Geschichte." Die Vielfalt der Kulturen. Erinnerung, Geschichte, Identität 4. Ed. J. Rüsen. Frankfurt a. M.: Suhrkamp, 1998. 12-36.

-. "Geschichtsschreibung als Theorieproblem der Geschichtswissenschaft. Skizze zum historischen Hintergrund der gegenwärtigen Diskussion." Formen der Geschichtsschreibung. Ed. Reinhart Koselleck et al. München: dtv, 1982. 14-36.

-. Zerbrechende Zeit: Über den Sinn der Geschichte. Köln: Böhlau, 2001. Safa, Zabihollah. Tarikh-e adabiyat dar Iran. Az avayel-e qarn-e haftom ta payan-e qarn-e hashtom-e hedjri. Vol. 3, part 1. Tehran: Entesharat-e Ferdousi, 1989.

Scott Meisami, Julie. Persian Historiography to the End of the Twelfth Century. Edinburgh: Edinburgh University Press, 1999.

Stock, Brian. Listening for the Text: On the Usage of the Past. Baltimore: University of Pennsylvania Press, 1990.

Straub, Jürgen. "Geschichten erzählen, Geschichten bilden. Grundzüge einer narrativen Psychologie historischer Sinnbildung." Erzählung, Identität und historisches Bewußtsein: Die psychologische Konstruktion von 
Zeit und Geschichte. Erinnerung, Geschichte, Identität 1. Ed. Jürgen Straub. Frankfurt a. M.: Suhrkamp, 1998. 81-169.

Wertsch, James V. "Specific Narratives and Schematic Narrative Templates." Theorizing Historical Consciousness. Ed. Peter Seixas. Toronto: University of Toronto Press, 2004. 49-62. 



\section{List of Contributors}

Matthias Bauer is professor of German Literary Studies at Europe University Flensburg. His research interests focus on narratives in different media (especially literature, film) and different times, ranging from the $17^{\text {th }}$ to the $20^{\text {th }}$ century. He is also interested in diagrams and the history of science. See also: www.uni-flensburg.de/germanistik/arbeitsbereiche/literatur-medi$\underline{\text { enwissenschaft-und-didaktik/personen/bauer-matthias-prof-dr }}$

Aleksandra Boss is a research assistant at the Department of English and American Studies at Humboldt-Universität zu Berlin. Among her fields of interest are the literatures of the Early Republic and the Antebellum, the literatures and cultures of self-improvement, as well as spiritual and religious traditions in America such as Deism, Unitarianism, Transcendentalism, New Thought, and Christian Science. More currently, her research has focused on the representations and constructions of democracy in Thomas Paine and Ralph Waldo Emerson.

Cord-Christian Casper has recently completed his $\mathrm{PhD}$ on Political Alterity in Early Modernism at Christian-Albrechts-Universität zu Kiel. His research explores the intersection of literary and political theory, with a focus on the poetics of anarchism and radicalism. Further research areas include modernist language theory, image-text relations, and graphic storytelling, as well as new materialisms of all stripes. See also www.closure.uni-kiel.de/team

Philipp Erchinger is senior lecturer in Modern English Literature at Heinrich-Heine-University Düsseldorf. His research interests include poetry and prose of the long $19^{\text {th }}$ century, literature among the arts and sciences and, increasingly, the ecology of literary work. He has written extensively on contingency and narrative form as well as on ways of knowing in Victorian literature and science. See also: www.anglistik.hhu.de/sections/anglistik-iv$\underline{\text { modern-english-literature/team/detailseite-erchinger.html }}$

Justus Conrad Gronau is an assistant professor and postdoctoral researcher in English Literature at Christian-Albrechts-Universität zu Kiel. His main 
research interests include the relationship between aesthetics, poetics, and epistemology within literature from the $17^{\text {th }}$ century up to the present (with a special interest in the poetry and philosophy of Romanticism), and literary theories such as hermeneutics, deconstruction, posthermeneutics, phenomenology and the aesthetics of presence. In this context, his current postdoctoral project deals with the representations of indigenous epistemes, alternative forms of knowledge production, and non-Western world approaches within Indian English literature.

Anthony John Harding is emeritus professor of English, University of Saskatchewan. He co-edited volume 5 of The Notebooks of Samuel Taylor Coleridge with the late Kathleen Coburn, and is the author of The Reception of Myth in English Romanticism (1995). His more recent publications include "Religion and Myth," in John Keats in Context, ed. Michael O’Neill (2017); “Signs of Change: Percy Shelley's language of mutability as precursor to Darwin's theory of evolution," Literature Compass 13.10 (2016); "The 'I' in The Prelude," in The Oxford Handbook of William Wordsworth, ed. Richard Gravil and Daniel Robinson (2015); and "Shelley, Mythology, and the Classical Tradition," in The Oxford Handbook of Percy Bysshe Shelley, ed. Michael O'Neill and Tony Howe (2012). He has also published in Keats-Shelley Journal, English Studies in Canada, and Proceedings of the German Association of University Teachers of English.

Marcel Hartwig is an assistant professor for English and American Studies at the University of Siegen. At Chemnitz University of Technology, he handed in his $\mathrm{PhD}$ thesis on cultural representations of both September 11, 2001 and the attacks on Pearl Harbor as national traumata. He has contributed research papers in academic readers and international journals in the field of media studies, television studies, literary criticism, gender studies, and popular culture. Currently he is working on his postdoctoral project in the field of transatlantic studies entitled "Transit Cultures: $18^{\text {th }}$-Century Medical Discourses and Knowledge Media in the North American Colonies."

Maria Kaspirek is a Ph.D. candidate in American Studies at FAU ErlangenNürnberg and a fellow of the DFG-funded research program "Presence and Tacit Knowledge." Focusing on the American antebellum era, her dissertation 
project examines the construction and consolidation of medical and literary knowledge on mental hygiene. Her broader research and teaching interests include the reciprocal relationship between literature and medicine, pseudoscience, print culture and book history.

Martin Klepper is professor for American Literature and Culture at Humboldt-Universität zu Berlin. His areas of research and publication are narrative identities; visuality and perspective in the $19^{\text {th }}$ century; the American postmodern and utopian novel; the history of American cinema. He is currently working on a project involving Self-Help and Mass Culture from the Progressive Era to the Depression. His latest publications are: Rethinking Narrative Identity: Persona and Perspective (2013; with Claudia Holler) and Approaches to American Cultural Studies (2017; with Antje Dallmann and Eva Boesenberg). See also: www.angl.hu-berlin.de/department/stafffaculty/professors/klepper

Antje Kley is professor of American Literary Studies at FAU ErlangenNürnberg. Her research interests focus on aesthetic forms and cultural functions of narrative, both autobiographical and fictional, in changing media environments between the $18^{\text {th }}$ century and the present. She is currently working on literature and in particular scientific but also administrative knowledge formation. Further interests include literary articulations of recognition, community, and possible futures. See also: https://www. anglistik.phil.fau.de/fields/amst/literature/staff/antje-kley/

Albert Meier is professor of Modern German Literature at ChristianAlbrechts-Universität zu Kiel. His research interests focus on the history of aesthetic/poetic theory as well as on the particular problems of prose writing and the cultural interrelationship between Italy and Germany. $\mathrm{He}$ is currently working on postmodern and post-postmodern literature. See also: www.ndl-medien.uni-kiel.de/de/personenverzeichnis/emeriti-pensprofessorinnen/prof-dr-phil-albert-meier-m-a

Kai Merten is professor of British Literature at the University of Erfurt. He has taught on British literature, British cultural and media Studies as well as on New English literatures and media. He has written books on 
the role of classical culture in contemporary poetries in English, among them Irish and Caribbean (2004), as well as on British Romanticism as a textual theatre (2014). He has also co-edited collections of essays on the construction of ethnical, national and civilizational differences in $18^{\text {th }}$ - and $19^{\text {th }}$-century Europe (2006) and on the rapprochement of Postcolonial Studies and Media Studies (2016). He is the founder of the Erfurt Network on New Materialism. In general, he is interested in looking at British literature from the perspectives of medial, material and global contexts. See also: www.uni-erfurt.de/anglistik/britischeliteratur/merten/

Richard Nate is professor of English Literature and coordinator of European Studies at the Catholic University of Eichstätt-Ingolstadt. In his research, he has focused on the history of utopian and dystopian literature as well as the relationship between literature and science. His book-length studies include: Wissenschaft und Literatur im England der frühen Neuzeit (2001), Amerikanische Träume: Die Kultur der Vereinigten Staaten in der Zeit des New Deal (2003), Wissenschaft, Rhetorik und Literatur: Historische Perspektiven (2009), and Biologismus und Kulturkritik: Eugenische Diskurse der Moderne (2014). He has also co-edited volumes on various subjects, most recently Cultural Identities in Europe: Nations and Regions, Migration and Minorities (2014, with Verena Gutsche), and Krieg und Frieden im Lied (2017, with Misia Sophia Doms and Bea Klüsener).

Anja Pistor-Hatam is professor of Islamic Studies at Christian-AlbrechtsUniversität zu Kiel. Her research interests focus on history, mainly intellectual history of Iran. Further interests include Twelver Shi'ite Islam, especially the pilgrimage to the Shiite holy places in Iraq, $19^{\text {th }}$-to early $20^{\text {th }}$-century reform movements in Iran and the Ottoman Empire, modern Iranian historiography, and "religious minorities" in Iran. She is currently working on the official discourse on human rights and human dignity in the Islamic Republic of Iran. See also: www.islam.uni-kiel.de/de/mitarbeiter/ prof-dr.-phil-ania-pistor-hatam

Daniel Schäbler was awarded a PhD for a cultural-narratological study on framing strategies in English fiction. He has taught at the universities of Kiel, Graz, and Wuppertal. He is currently teaching at Hildesheim University, 
working on a postdoctoral project about historically specific forms and function of knowledge distribution in English drama in the context of an economy of knowledge. His research interests include cultural and cognitive narratology, game theory and literature, intermediality, Black British literature, theories of alterity, psychoanalysis and Victorian Gothic. He has published on Kazuo Ishiguro, Ian McEwan, computer game aesthetics, historiographic metafiction, and Asian-British coming of age narratives. Currently, he is editing an interdisciplinary volume with case studies on the relation between factuality and fictionality.

André Schwarck, English Department of Christian-Albrechts-Universität zu Kiel, received his PhD with a dissertation on Laurence Sterne's Tristram Shandy (Kontingenz und Zeitlichkeit in Laurence Sternes Tristram Shandy, Würzburg, 2012) which analyzes the novel's interplay of temporal, modal and generic qualities. His current research interest lies on the narratological interface of eventfulness, repetition, and seriality. Further research areas include fictionality, multinarrativity, performance studies, and tragedy.

Ann Spangenberg is a lecturer at the English Department of ChristianAlbrechts-Universität zu Kiel, teaching a variety of courses from introductory classes to master courses with a broad range of subjects, centering e.g. on intermediality or identity/alterity. Her research interest focusses on constructions of identity in the contemporary English novel. She has published her dissertation Kommunikative Identität im Roman der Angelsächsischen Postmoderne: John Fowles, Peter Ackroyd, A.S. Byatt with Königshausen \& Neumann.

Jutta Zimmermann is professor of North American Studies and director of the Center of North American Studies at Christian-Albrechts-University, Kiel. She has published studies on Canadian metafiction and on the gender issue in American realist fiction. She is the co-editor of essay collections on morality and ethics in literature and on Atlantic Islands in the Americas: Site of Cultural Contact and Identity as well as an anthology on postcolonial Canadian literatures. Her current research interests focus on the literature of the Indian diaspora in North America, on intersectionality as a concept of literary studies and on the multinarrative as a narratological phenomenon. 



\section{CONTRIBUTIONS TO ENGLISH AND AMERICAN LITERARY STUDIES}

Edited by Ingo Berensmeyer, Christoph Ehland,

Julika Griem, Andrew S. Gross and Antje Kley

Band 1 Ottilie P. Klein: Lethal Performances. Women Who Kill in Modern American Drama. 2017.

Band 2 Antje Kley / Kai Merten (eds.): What Literature Knows. Forays into Literary Knowledge Production. 2018.

www.peterlang.com 
